University of South Florida

DIGITAL COMMONS

Digital Commons @ University of

@ UNIVERSITY OF SOUTH FLORIDA

South Florida

USF Tampa Graduate Theses and Dissertations

USF Graduate Theses and Dissertations

November 2017

\title{
Episodic Work-Family Conflict and Strain: A Dynamic Perspective
}

Kimberly A. French

University of South Florida, KFrench0429@gmail.com

Follow this and additional works at: https://digitalcommons.usf.edu/etd

Part of the Psychology Commons

\section{Scholar Commons Citation}

French, Kimberly A., "Episodic Work-Family Conflict and Strain: A Dynamic Perspective" (2017). USF Tampa Graduate Theses and Dissertations.

https://digitalcommons.usf.edu/etd/7399

This Dissertation is brought to you for free and open access by the USF Graduate Theses and Dissertations at Digital Commons @ University of South Florida. It has been accepted for inclusion in USF Tampa Graduate Theses and Dissertations by an authorized administrator of Digital Commons @ University of South Florida. For more information, please contact digitalcommons@usf.edu. 
Episodic Work-Family Conflict and Strain: A Dynamic Perspective

by

Kimberly A. French

A dissertation submitted in partial fulfillment

Of the requirement for the degree of

Doctor of Philosophy

Department of Psychology

College of Arts and Sciences

University of South Florida

Major Professor: Tammy D. Allen, Ph.D.

Michael T. Braun, Ph.D.

Judith B. Bryant, Ph.D.

Kristen Salomon, Ph.D.

Paul E. Spector, Ph.D.

Date of Approval:

November 3, 2017

Keywords: work-family conflict, transition, strain, time, allostatic load 


\section{ACKNOWLEDGMENTS}

Many people helped to make this dissertation possible. I would first like to thank the funders who invested in this work: The SIOP Foundation's Lee Hakel Scholarship, The American Psychological Foundation's Dissertation Research Award, the USF Psychology Department's Walvoord Verizon Wireless Work-Family Research Endowment in Honor of Dr. Tammy D. Allen, and the NIOSH/CDC Sunshine Education and Research Center's Pilot Project Grant. I would also like to thank my Work, Family, and Health Research Team members: Andrea Bevill, Alexandra Blume, Allegra Campbell, Sujie Chen, Molly Darby, Wednesday Radke, and Hyeyoung Yoon. Their dependability, positive attitudes, and dedication throughout the study was invaluable. Thank you to my committee members, Mike Braun, Judy Bryant, Kristen Salomon, and Paul Spector whose thoughtful ideas, questions, and suggestions pushed this work to be better at each step. A special thanks to my advisor and mentor Tammy Allen for her help with this work and beyond. Tammy's dedication to science, impact, and mentorship has changed my life, and I am forever grateful for her wise guidance and friendship. Thank you to Soner Dumani and Steph Andel for all the happy dancing, listening, advice giving, shoulder

crying, fro-yo eating, and cat meme-ing. My dissertation (and grad school) would not have been the same without each of them by my side every step of the way. Finally, thank you to Keaton Fletcher, my darling beautiful baby fiancé life partner and king, for his support, encouragement, empathy, and insight. Thank you for being my rock, my number one fan, and a never-ending source of love and joy. 


\section{TABLE OF CONTENTS}

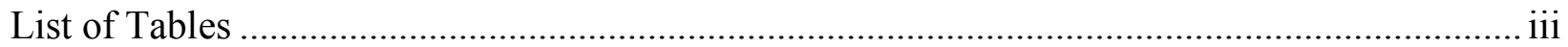

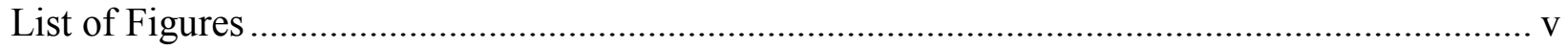

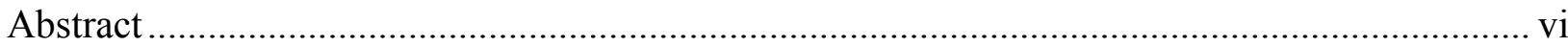

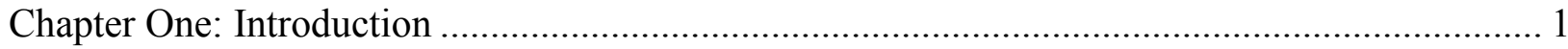

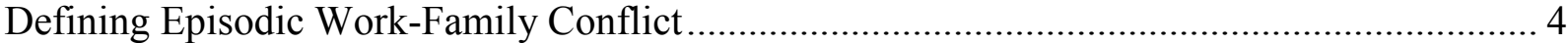

Timing of Episodic Work-Family Conflict ............................................................................ 7

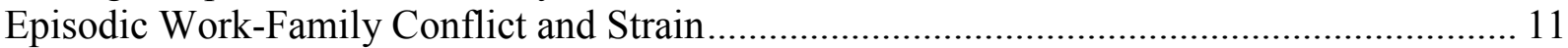

Episodic Work-Family Conflict and Acute Strain Reactivity ....................................... 13

Episodic Work-Family Conflict and Strain Recovery Trajectory .................................... 18

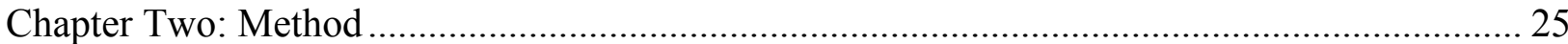

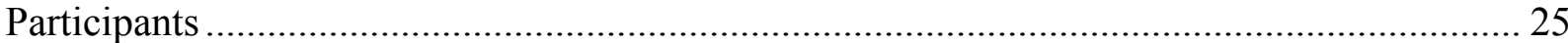

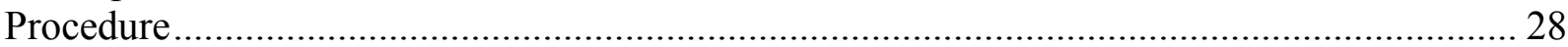

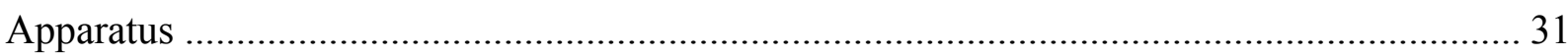

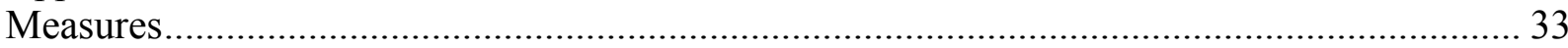

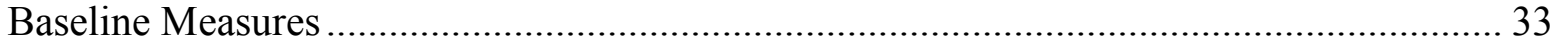

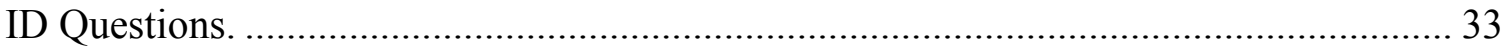

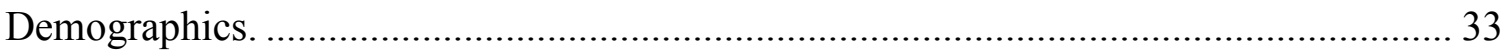

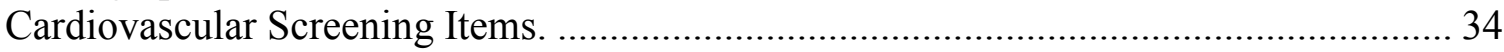

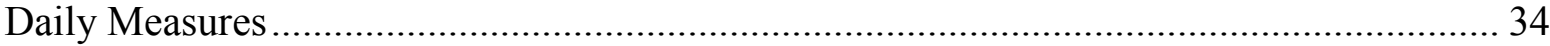

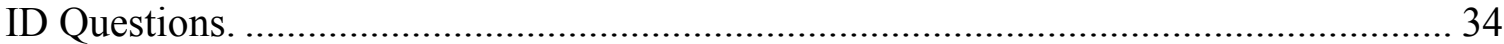

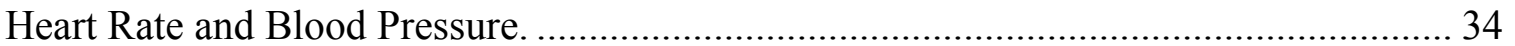

Daily Temporal and Spatial Role Transitions............................................................. 34

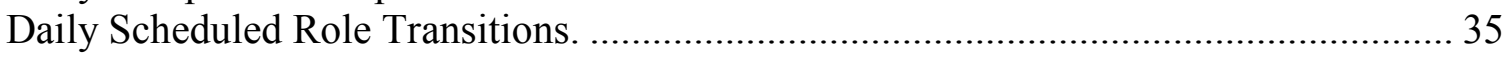

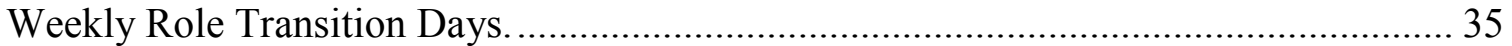

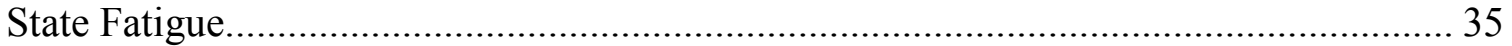

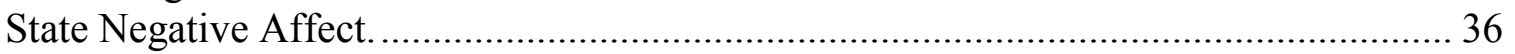

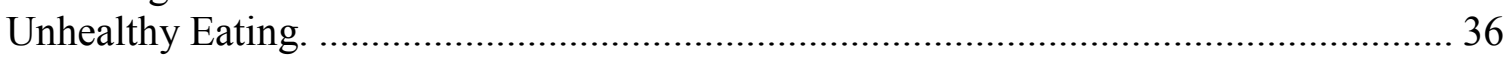

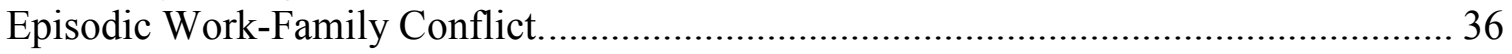

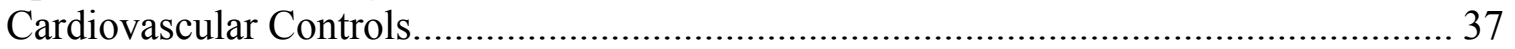

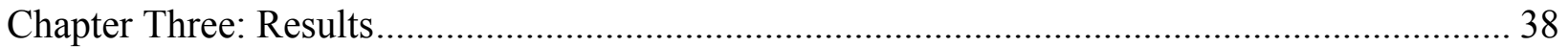

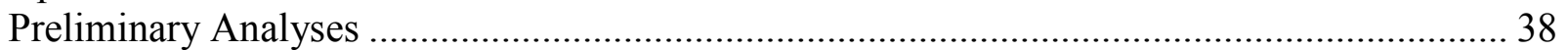

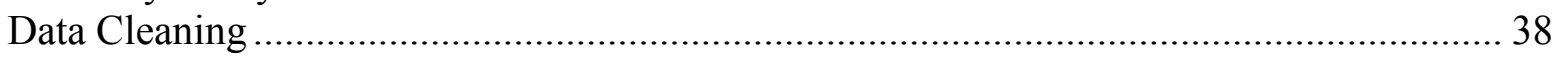

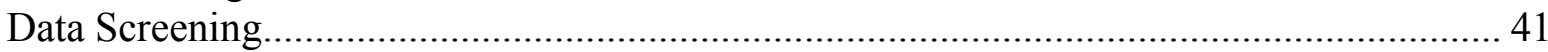

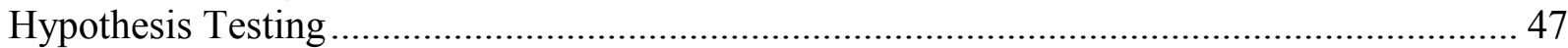

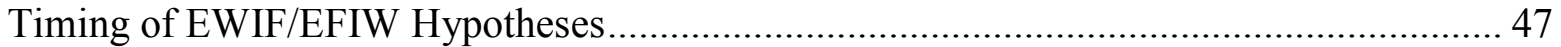

EWIF/EFIW and Strain Hypotheses ......................................................................... 49

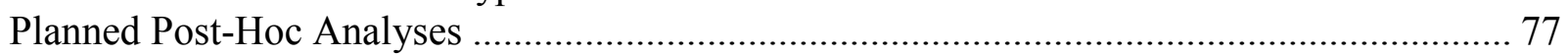




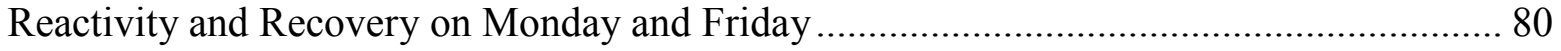

Two Hour Accumulation of EWIF/EFIWs ...................................................................... 81

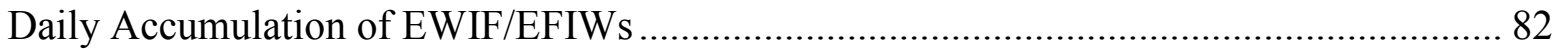

Multi-Day Accumulation of EWIF/EFIWs ............................................................. 84

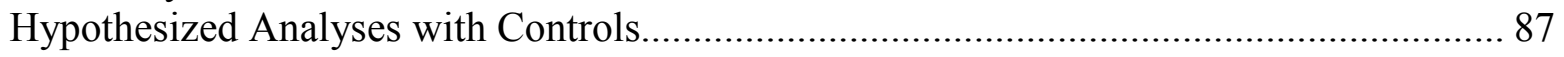

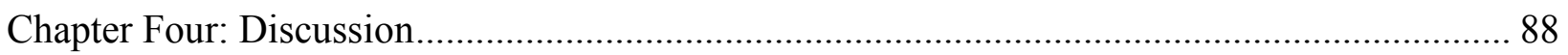

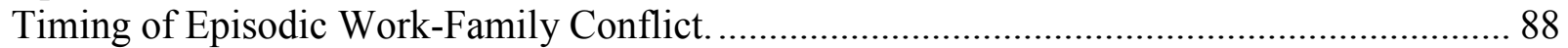

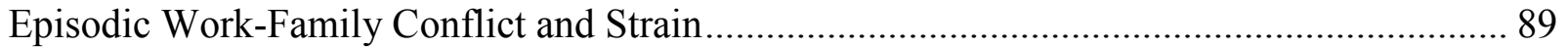

Theoretical Implications........................................................................................... 93

Timing of Episodic Work-Family Conflict ........................................................... 93

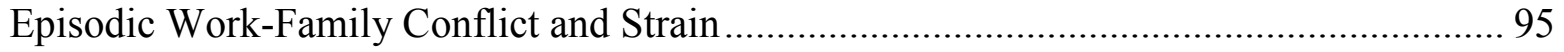

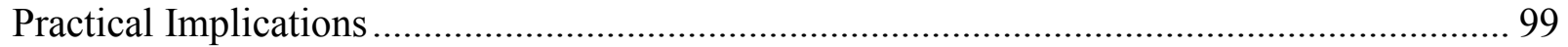

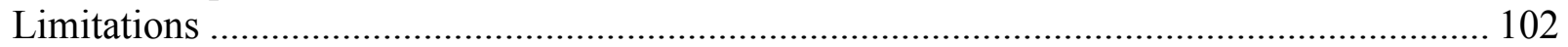

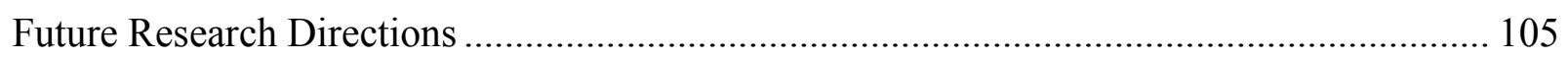

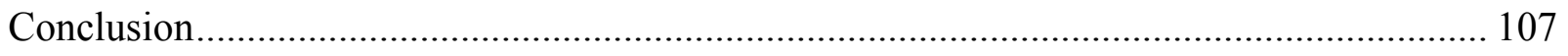

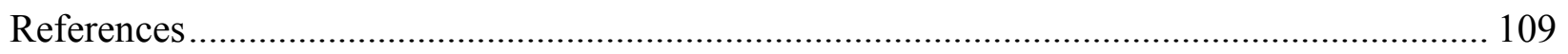

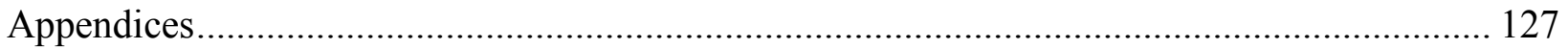

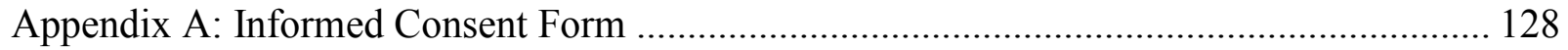

Appendix B: Lab Training Slides................................................................................... 133

Appendix C: Reminder Handout ...................................................................................... 139

Appendix D: Monitor Return Agreement ................................................................... 142

Appendix E: Email and Text Scripts........................................................................... 143

Appendix F: Participant Health Report......................................................................... 150

Appendix G: Baseline Measures. ......................................................................................... 166

Appendix H. Daily Measures for Monday-Wednesday .................................................. 168

Appendix I. Daily Measures for Thursday-Sunday ...................................................... 172

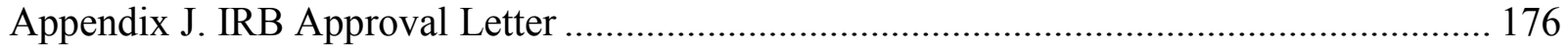




\section{LIST OF TABLES}

Table 1. Comparison of allostatic load and stressor-strain reactivity and recovery patterns...... 21

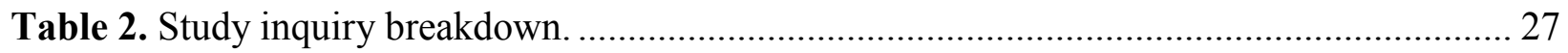

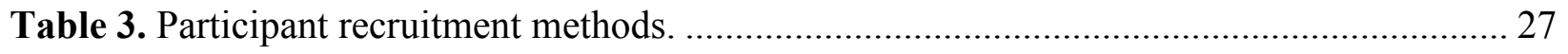

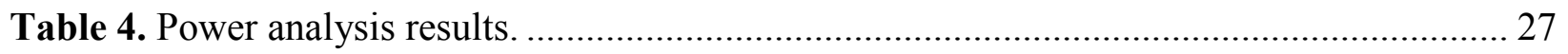

Table 5. Descriptive statistics and missingness for EWIF/EFIW..................................... 41

Table 6. Frequencies of EWIF/EFIW Total reported in a single response. ........................... 41

Table 7. Descriptive statistics and missingness for dependent and control variables................ 42

Table 8. Frequencies for number of valid responses per participant $(\mathrm{N}=100) \ldots \ldots \ldots \ldots \ldots \ldots \ldots \ldots . . . . . . . . . . .44$

Table 9. Frequencies for number of valid responses per time point (possible total $N=2800) \ldots 45$

Table 10. Correlations between number of valid responses, dependent variables, baseline workfamily conflict, job demands, and family demands, and ESM start day of the week $(\mathrm{N}=100) \ldots 45$

Table 11. Unconditional model parameters, ICCs, $-2 \log$ likelihood difference for each

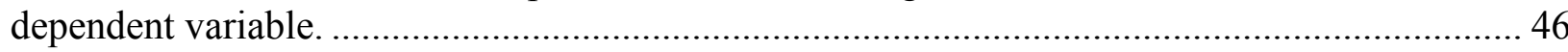

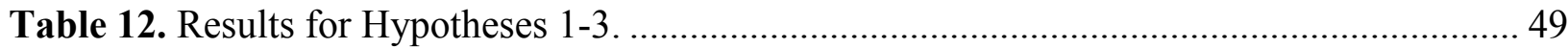

Table 13. Sample coding for discontinuous growth modeling. ............................................. 52

Table 14. Frequencies of EWIF/EFIW by signal time and day. ........................................ 53

Table 15. Frequencies for number of EWIF/EFIW per day and length of recovery................. 53

Table 16. Frequencies of time between EWIF/EFIW and response. ................................... 53

Table 17. State fatigue discontinuous growth modeling fixed effects results........................ 62

Table 18. State negative affect discontinuous growth modeling fixed effects results.............. 63

Table 19. Heart rate discontinuous growth modeling fixed effects results............................. 64

Table 20. Systolic blood pressure discontinuous growth modeling fixed effects results. .......... 65

Table 21. Diastolic blood pressure discontinuous growth modeling fixed effects results.......... 66 
Table 22. Unhealthy eating discontinuous growth modeling fixed effects results.

Table 23. State fatigue discontinuous growth modeling random effects results....................... 72

Table 24. State negative affect discontinuous growth modeling random effects results........... 73

Table 25. Heart rate discontinuous growth modeling random effects results......................... 74

Table 26. Systolic blood pressure discontinuous growth modeling random effects results. ....... 75

Table 27. Diastolic blood pressure discontinuous growth modeling random effects results...... 76

Table 28. Unhealthy eating discontinuous growth modeling random effects results. .............. 77

Table 29. Summary of growth modeling hypothesized and post-hoc results. ........................ 79 


\section{LIST OF FIGURES}

Figure 1. Illustration of strain recovery patterns (Frese and Zapf, 1988, p. 389)................... 20

Figure 2. Illustration of the four allostatic load patterns (McEwen \& Seeman, 1999, p. 36)..... 20

Figure 3. Graphic representation of study procedure for a participant with a Monday start day. 31

Figure 4. Flow chart displaying the cleaning process and samples used for each analysis........ 39

Figure 5. State fatigue over the first three days by participant ID .................................... 55

Figure 6. State negative affect over the first three days by participant ID. ........................... 56

Figure 7. Heart rate over the first three days by participant ID........................................ 57

Figure 8. Systolic blood pressure over the first three days by participant ID.......................... 58

Figure 9. Diastolic blood pressure over the first three days by participant ID........................ 59

Figure 10. Unhealthy eating over the first three days by participant ID............................... 60

Figure 11. Graphic representation of state fatigue change when an EWIF occurs................... 69

Figure 12. Graphic representation of state fatigue change when an EFIW occurs.................... 69

Figure 13. Graphic representation of heart rate change when an EWIF occurs. ...................... 70

Figure 14. Graphic representation of unhealthy eating change when an EWIF occurs............. 70

Figure 15. Graphic representation of state fatigue change as EFIW accumulates.................... 84

Figure 16. Graphic representation of state negative affect change as EFIW accumulates......... 86

Figure 17. Graphic representation of diastolic blood pressure change as EFIW accumulates. ... 86 


\begin{abstract}
Given rising work and family demands in our society for both men and women, the experience of work-family conflict is commonplace. Work-family conflict occurs when the demands of work or family make it difficult to meet the demands of the alternate domain. A sizeable body of research has established work-family conflict and its nomological network. Despite decades of research, we have yet to form a precise understanding of when work-family conflicts occur and "what happens" when a conflict arises. The current research addresses these questions using an experience sampling, episodic approach. Two primary research questions are addressed. First, I used border and boundary theory to identify when work-family conflict episodes are likely to occur. Second, I used stressor-strain and allostatic load theories to examine "what happens" with regard to psychological, physiological, and behavioral strain following an episodic work-family conflict over time. The results suggest work-family conflict occurs when individuals transition in between work and family domains. Further, family-to-work conflict tends to occur in the morning, while work-to-family conflict tends to occur in the afternoon. Fatigue showed significant reactivity at the time of an EWIF and recovered in the following time point. Unhealthy eating also showed a sleeper pattern, such that unhealthy eating increased at the end of the day, following an EWIF. Unexpectedly, fatigue decreased at the time of an EFIW, indicating EFIW may be a restorative, rather than taxing. Post-hoc analyses showed some evidence that EWIF accumulation is associated with increased strain over the course of three days. Again, results suggest EFIW accumulation may reduce, rather than increase, strain. Implications for the theoretical relationship between work-family conflict and strain, as well as
\end{abstract}


border/boundary theory are discussed. In addition, practical implications for flexible work initiatives and episodic research design are considered. 


\section{CHAPTER ONE: INTRODUCTION}

Work and family represent two of the most fundamental life domains in our society. Men and women are increasingly involved in a full-time career, while dedicating time to their family at home (Craig \& Mullan, 2010). Moreover, work and family roles are central components of individuals' identities (Aryee \& Luk, 1996) that have key implications for satisfaction and wellbeing (e.g., Amstad, Meier, Fasel, Elfering, \& Semmer, 2011; Ford, Heinen, \& Langkamer, 2007). This combination of involvement and importance creates the potential for conflicting work and family demands, a concept termed work-family conflict (Greenhaus \& Beutell, 1985).

Over the past thirty years, hundreds of articles have been dedicated to understanding work-family conflict (Allen, 2012). This research shows work-family conflict has important implications for a variety of health-related outcomes, such as anxiety, physical symptoms, life satisfaction, sleep, eating behavior, and cardiovascular functioning (Allen \& Armstrong, 2006; Amstad et al., 2011; Crain, Hammer, Bodner, Kossek, Moen, Lilenthal, \& Buxton, 2014; Frone, Russell, \& Cooper, 1997; Shockley \& Allen, 2013). The majority of this research captures snapshots of work-family conflict "levels" using cross-sectional, self-report methodology (Lapierre \& McMullan, 2016; Maertz \& Boyar, 2011). Although informative, this approach limits our understanding of work-family conflict as a dynamic human experience that unfolds

across time. Consequently, we have yet to fully understand "what happens" when a work-family conflict is experienced (Roe, 2008; Weiss, 2012). 
The purpose of the current research is to examine the dynamic nature of episodic workfamily conflict. This research has two specific, interrelated goals that improve understanding of episodic work-family conflict as it occurs across time. The first goal is to identify if there is an identifiable patter as to when episodic work-family conflict s occur. Boundary/border theory (Ashforth, Kreiner, \& Fugate, 2000; Clark, 2000) is used to propose timeframes during which episodic work-family conflicts are likely to occur within a given day and week. The second goal is to examine the relationship between episodic work-family conflict and short-term psychological, behavioral, and physiological strains, including magnitude of strain increase when experiencing episodic work-family conflict (i.e., reactivity) and subsequent rate of change in strain over time (i.e., recovery trajectory). Using psychological and physiological stressor-strain theories as a grounding framework (Frese \& Zapf, 1988; McEwen, 1998), I propose using discontinuous growth modeling to test dynamic relationships between episodic work-family conflict and strain using daily diary data collected every two hours over three working days.

The proposed study contributes to the work-family and occupational health literature in several ways. First, I test dynamic stressor-strain relationships, allowing me to examine several models of stressor-strain relationships over time (e.g., stress-reaction model, accumulation model, Frese \& Zapf, 1988). Typically, only one or two models are tested within a single study (Sonnentag, Pundt, \& Albrecht, 2014) and most studies use long time lags of months or years (Ford et al., 2014; Garst, Frese, \& Molenaar, 2000). However, dynamic stressor-strain relationships are discussed as events, or as episodic phenomena in theory (McGrath \& Beehr, 1990; Hobfoll, 1989). By examining several dynamic models within a single study the results help to identify which model best explains dynamic work-family conflict and strain relationships. Further, I focus on short-term time lags to more closely link episodic work-family 
conflict with acute strain and to provide a more direct test of theoretical stressor-strain relationships.

Second, I add to the sparse literature on episodic work-family conflict and strain. Few researchers have taken an episodic approach to studying work-family conflict, and only one study has examined episodic work-family conflict and strain-related outcomes (i.e., heart rate, blood pressure; Shockley \& Allen, 2013). I extend this study by examining psychological, behavioral, and physiological strains. Testing diverse outcomes is important for establishing the generalizability of episodic work-family conflict -strain relationships.

Third, this study identifies when episodic work-family conflict is likely to occur within a given day or week. The question of when work-family conflict occurs is currently unknown, due to the dominant approach of examining work-family conflict as a between-person phenomenon. Even for recent within-person designs, researchers typically assess daily levels, rather than discrete episodes (e.g., Wagner, Barnes, \& Scott 2014; Liu, Wang, Chang, Shi, Zhou, \& Shao, 2015). Knowing when episodic work-family conflict occurs has implications for border/boundary theory (Ashforth et al., 2000; Clark, 2000), which proposes role transitions are key points of contention between work and family. The when of episodic work-family conflict also has implications for recovery research (e.g., Sonnentag, Binnewies, \& Mojza, 2008), which assumes post-work periods are times of recovery. The timing of episodic work-family conflict also has practical implications for methodological experience sampling designs, such as when and how often individuals should be sampled in order to capture a desired number of workfamily conflicts. In addition, timing has implications for policies such as paid leave, flextime, and flexplace. For example, if timing of conflicts tends to occur on the edges of the work day, this suggests flextime would be helpful in the form of flexible start/end time arrangements. 
Fourth, the current study extends health psychology research by examining strain reactivity and recovery patterns across multiple types of strain and using field-based methodology. Acute reactivity and recovery research primarily focuses on physiological strain (e.g., blood pressure, heart rate; Bosschoff, Pieper, \& Thayer, 2005; Schwartz et al., 2003) and is conducted in laboratory settings (Schwartz et al., 2003). Psychological and behavioral strain are theoretically important for stress and health, and may feasibly exhibit diverse reactivity and recovery patterns (e.g., Bosschoff et al., 2005; McEwen, 1998). In addition, there is a call for replication of reactivity and response patterns using real-life stressor events, due to the derived nature of many laboratory tasks (e.g., mathematic tasks) (e.g., Schwartz et al., 2003). The current study therefore provides theoretically pertinent information on the generalizability of recovery and reactivity patterns beyond physiological strain and lab settings.

Finally, this study uses objective methods, namely ambulatory blood pressure/heart rate. The work-family conflict literature is replete with single-source self-reports (Lapierre \& McMullan, 2016). By using objective measures, our study triangulates self-report findings and circumvents methodological issues associated with self-report (e.g., memory error, social desirability). Objective measures also create a strong link between work-family conflict and disease endpoints.

\section{Defining Episodic Work-Family Conflict}

Work-family conflict occurs when the demands of work and family are incompatible, making it difficult to meet demands or complete desired activities in both roles (Greenhaus \& Beutell, 1985). It is well-established that work-family conflict can occur in two distinct directions: work demands may interfere with family demands (WIF) or family demands may 
interfere with work demands (FIW). An example of WIF might be preoccupation with an impending work meeting when one is trying to spend time and relax with family members at home. An example FIW is a family emergency that arises during work time, as time and attention allotted to the family would detract from time and energy that would have otherwise been allotted to work. WIF and FIW are both conceptually and empirically distinct, such that WIF tends to be more strongly associated with work antecedents (e.g., work involvement, work demands) than FIW, whereas FIW tends to be more strongly associated with family antecedents (e.g., family involvement, family demands) than WIF (Byron, 2005; Frone et al., 1997; Michel, Kotrba, Mitchelson, Clark, \& Baltes, 2011). Both WIF and FIW are associated with health outcomes such as psychological strain, life satisfaction, and physical symptoms (Amstad et al., 2011).

Work-family conflict can be operationally defined using a levels approach or using an episodic approach (Maertz \& Boyar, 2011). The levels approach assesses general perceptions, or "levels," of work-family conflict, typically in combination with a between persons design. The levels approach has largely dominated the work-family field and generated most of our knowledge about work-family conflict (Lapierre \& McMullan, 2016). Even within person studies of daily work-family conflict have been primarily based on a levels approach that captures average work-family conflict for the day (e.g., Judge, Ilies, \& Scott, 2006; Wagner et al., 2014). There are several advantages to using the levels approach, including relatively easy data collection and analysis, as well as the ability to efficiently test a wide variety of direct, indirect, and moderating relationships (Maertz \& Boyar, 2011). It is therefore not surprising that this research has built the foundation of work-family conflict knowledge to-date. 
Despite these advantages, the levels approach is ill-equipped for studying phenomena that occur in discrete episodes, like work-family conflict (Maertz \& Boyar, 2011). Typical levelsbased work-family conflict measures use agreement or frequency scales to assess "how much" work-family conflict an individual experiences over an often ambiguous or long period of time (Bellavia \& Frone, 2005). These scales are criticized as ambiguous in meaning and cognitively burdensome for participants (González-Morales, Tetrick, \& Ginter, 2012; MacDermid, 2005). Conceptual consolidation of episodes is prone to recall biases, as individuals may have trouble recalling exactly "how much" work-family conflict occurred across a given period of time. Further, items are often broad in scope (e.g., "how often does your job or career interfere with your home life?"), muddying qualitative differences in what happened during or after any one conflict episode (González-Morales et al., 2012). Finally, levels-based work-family conflict measures often confound the conflict episode and strain (e.g., "Tension and anxiety from my family life often weakens my ability to do my job.”) (Bellavia \& Frone, 2005).

The episodic approach is unique in that it assesses discrete events, or "episodes," of work-family conflict. The episodic approach fosters understanding of work-family conflict in a way that is true to the nature of the construct and is unconfounded by potential biases that influence levels-based work-family conflict such as self-serving attributions, memory error, and confounding of the event and its outcomes (Bellavia \& Frone, 2005; Maertz \& Boyar, 2011). Further, the episodic approach allows researchers to more directly link the experience of a workfamily conflict with acute outcomes. Finally, it allows researchers to capture the dynamic nature of work-family conflict episodes across time. Specifically, the episodic approach yields insights into when work-family conflict episodes occur across objective time and in relation to other episodes. Thus, we can appropriately examine how episodic work-family conflict accumulates, 
as well as changes in the outcomes associated with a single episodic work-family conflict (or multiple episodic work-family conflicts) over time.

The proposed study uses the episodic approach to better understand two aspects of episodic work-family conflict over time: 1) the timing of episodic work-family conflict occurrence during a given day or week, 2) the nature (psychological, behavioral, physiological), magnitude, and trajectory of acute strain associated with work-family conflict. I discuss each of these aims, their theoretical foundation, and the specific hypotheses in turn. In each hypothesis, I focus on both directions of work-family conflict: episodes of WIF (EWIF) and episodes of FIW (EFIW). The term EWIF/EFIW is used throughout the paper to denote an episodes that may be either direction (EWIF or EFIW).

\section{Timing of Episodic Work-Family Conflict}

The first goal of this research is to describe when EWIF/EFIW occurs in a given day and week. Although empirical studies have yet to explore this question, tenets from boundary theory and border theory (Ashforth et al., 2000; Clark, 2000) provide theoretical guidance. Both border and boundary theory describe the process and implications of transitioning between roles. A role is defined by the demands placed on individuals by others in their social system (i.e., "role senders") (Kahn, Wolfe, Quinn, Snoek, \& Rosenthal, 1964; Katz \& Kahn, 1978). For example, supervisors shape the work role by setting expectations for performance and defining work tasks. Similarly, children define the family role by placing caregiving demands on their parents. According to boundary theory, individuals actively categorize their roles, setting up boundaries that delineate the role's scope (Nippert-Eng, 1996). For example, individuals may keep separate 
email addresses or calendars for work and family obligations or adjust the physical space between work and home locations (Nippert-Eng, 1996; Kreiner, Hollensbe, \& Sheep, 2009).

Role transitions occur when individuals exit one role and enter another, crossing role boundaries (Greenhaus, 1988; Hall \& Richter, 1988). Transitions are most typically framed in terms of temporal, spatial, or psychological boundaries associated with a role (Allen, Cho, \& Meier, 2014; Ashforth et al., 2000; Clark, 2000; Greenhaus, 1988; Hall \& Richter, 1988). For example, a role transition might occur when individuals commute from their home to their work location, thereby crossing spatial work-home boundaries. Similarly, work scheduling represents the temporal work-home boundary. A shift worker crosses into her work role when she begins a work shift and crosses out of her work role when the shift ends. Finally, psychological boundaries are delineated by thoughts or emotions that are appropriate for one role, but not another (Clark, 2000; Hall \& Richter, 1988). For example, a clinical counselor crosses the psychological home-work boundary by mentally shelving her concerns at home in order to provide the clear, unbiased care that is best for her clients. For the current study, I focus on spatial and temporal transitions. Relative to psychological transitions, temporal and spatial transitions are simpler to report, which is important given the current study's intensive experience sampling design. Further, temporal transitions imply a type psychological shift in cognition, such that individuals must change their thinking and attention from work/family activities to activities in the alternative domain. Thus, psychological transitions in cognition are implied with temporal transitions.

The process of transitioning between roles is considered to be taxing as it requires physical and psychological disengagement from the exited role and the initiation of physical and psychological engagement in the entered role (Ashforth et al., 2000). Individuals must shut off 
thoughts, feelings, and behaviors from one role in an effort to engage in more appropriate thoughts, feelings, and behaviors for the alternative role (Ashforth et al., 2000; Allen et al., 2014). Failure to do so results in role spillover and potentially role conflict (Ashforth et al., 2000; Greenhaus \& Beutell, 1985; Williams \& Alliger, 1994). Thus, transitions between roles are time windows during which individuals are likely to experience an EWIF/EFIW.

In support, previous research has found boundary-spanning demands (e.g., bringing work home, commuting time, work-family multitasking) and inter-domain transitions (e.g., leaving work early to meet family demands, receiving work calls at home) are associated with increased levels of work-family conflict (Glavin \& Schieman, 2010; Matthews, Barnes-Farrell, \& Bulger, 2010; Matthews, Winkel, \& Wayne, 2014; Voydanoff, 2005; see Desrochers, Hilton, \& Larwood, 2005 for an exception). Similarly, research suggests the first two minutes upon returning home from work represent a critical transition period during which parents interact with spouses and children. The remainder of the evening is largely spent in isolation, particularly for fathers (Campos, Graesch, Repetti, Bradbury, \& Ochs, 2009). These post-work interactions are colored by workplace experiences, such that daily workload and interpersonal stress at work are associated with greater behavioral and emotional withdrawal (Repetti, 1994; Repetti \& Wood, 1997; Story \& Repetti, 2006). This study is the first to empirically test the relationship between work-family role transitions and conflict occurrence using episodic or daily designs. Based on this theoretical and empirical evidence, I predict when individuals cross work or family spatial boundaries, they are likely to experience an EWIF/EFIW relative to other time periods. Similarly, transitions in and out of work and family time will be associated with increased likelihood of EWIF/EFIW. 
Hypothesis 1a: EWIF/EFIW is more likely to occur during time windows in which participants spatially transition between work and family relative to time windows in which participants do not spatially transition between work and family.

Hypothesis 1b: EWIF/EFIW is more likely to occur during time windows in which participants temporally transition between work and family relative to time windows in which participants do not temporally transition between work and family.

In modern U.S. society, individuals typically work during the week (Monday-Friday) and during the day, between the hours of 8 AM and 6 PM. Such hours are often labeled "standard" working hours and used as the comparison for other types of work scheduling (e.g., shift work; Presser, 2003). Family responsibilities are taken care of primarily in the evenings on weekdays and on the weekends (Saturday, Sunday). Standard scheduling implies that workers' transitions to and from work likely occur in the morning on weekdays and in the evening on weekdays (Hall \& Richter, 1988). Additionally, weekly transitions are made on Mondays and Fridays as workers approach large blocks of work and family time, respectively. In support, research indicates major physical and cognitive transitions to/from work and family are points in which workers often experience spillover and conflict between work and family domains (Campos et al., 2009; Hall \& Richter, 1988). I therefore predict EWIF/EFIW occurrence will be associated with these daily and weekly transition times.

Hypothesis 2a: EWIF/EFIW is more likely to occur during time windows in which participants make scheduled morning transitions relative to other time windows during the weekday. 
Hypothesis 2b: EWIF/EFIW is more likely to occur during time windows in which participants make scheduled afternoon transitions relative to other time windows during the weekday.

Hypothesis 3a: EWIF/EFIW is more likely to occur on Monday relative to other days of the week.

Hypothesis 3b: EWIF/EFIW is more likely to occur on Friday relative to other days of the week.

\section{Episodic Work-Family Conflict and Strain}

The current study predominantly relies on two theoretical models of the stress process that have overlapping core tenets. First, I rely on the traditional stressor-strain model (Frese \& Zapf, 1988; Ganster \& Rosen, 2013; McGrath \& Beehr, 1990). This perspective conceptualizes stress as a process in which events or aspects of the environment (stressors) elicit psychological, behavioral, and/or physical reactions (strains) (Ganster \& Rosen, 2013). Much of the research on work-family conflict and strain is conducted from a stressor-strain perspective (Grzywacz, 2016). I integrate the stressor-strain model with the allostatic load model (McEwen, 1998; McEwen \& Seeman, 1999). The allostatic load model explicates how psychosocial stressors develop into diseases and disorders (Ganster \& Rosen, 2013; Juster, McEwen, \& Lupein, 2010). The concept of allostasis - the fluctuation of physiological set points or behavior in response to the environment - is a cornerstone of the allostatic load model (McEwen, 1998). Allostatic load is the cost of allostasis, which occurs when repeated strain reactions create wear and tear on the brain and body through a three step process (McEwen \& Seeman, 1999). First, stressors trigger acute physiological (e.g., elevated cortisol, heart rate), psychological (e.g., fear, excitement), and 
behavioral (e.g., withdrawal, alcohol consumption) reactions. When exposure to stressors is repeated, physiological, psychological, and behavioral reactions begin to exhibit dysfunctional reactivity patterns, such as prolonged or exaggerated response. Over time, dysfunctional reactivity patterns can move physiological, psychological, or behavioral set-points to unhealthy levels (e.g., high cholesterol, chronic depressed mood, excessive alcohol consumption) (Juster et al., 2010). Left untreated, sub-clinical set-points can continue to worsen, resulting in physical illness, psychological disorders, or mortality (Ganster \& Rosen, 2013; Juster et al., 2010).

Both perspectives of stress suggest strain reactions have two major components: reactivity (acute strain increases that occur at the time of stressor onset) and recovery (decrease in strain across time after stressor onset) (Brosschot, Pieper, \& Thayer, 2005; Frese \& Zapf, 1988; Linden, Earle, Gerin, \& Christenfeld, 1997; McEwen, 1998; McGrath \& Beehr, 1990; Schwartz et al., 2003). Reactivity is an indicator of strain magnitude, whereas recovery is an indicator of strain duration (Brosschot et al., 2005; Moseley \& Linden, 2006). Reactivity and recovery are related, but distinct indicators of healthy functioning (Linden et al., 1997; Moseley $\&$ Linden, 2006), and both accentuated reactivity and prolonged recovery patterns in response to acute stress are considered unhealthy strain reactions (Brosschot et al., 2005; Frese \& Zapf, 1988; McEwen \& Seeman, 1999). Empirical evidence shows reactivity magnitude and recovery duration are independently associated with long-term disease and mortality (e.g., Brosschot et al., 2005; Moseley \& Linden, 2006). I therefore examine reactivity at the time an EWIF/EFIW occurs and recovery patterns after an EWIF/EFIW occurs. 


\section{Episodic Work-Family Conflict and Acute Strain Reactivity}

Applied to the intersection of work and family, work-family conflict is positioned as a stressor that increases psychological, behavioral, and physiological strain (Grzywacz, 2016). Experiencing work-family conflict creates an undesirable and unpleasant state, due to difficulty in succeeding in both work and family roles (Greenhaus \& Beutell, 1985; Kahn et al., 1964). Further, when experiencing an EWIF/EFIW, individuals must make decisions (Shockley \& Allen, 2015) and potentially cross work or family boundaries (Ashforth et al., 2000), both of which are effortful process that deplete time, affective, or energy-based resources (Edwards \& Rothbard, 2000; Williams \& Alliger, 1994). EWIF/EFIW is therefore theoretically positioned as a stressor that produces psychological, behavioral, and physiological strain.

Psychological Strain. Psychological strains are subjective changes in affect or cognition that occur in response to a stressor (Ganster \& Rosen, 2013). Consistent with the stressor-strain perspective, meta-analytic research confirms the relationships between work-family conflict levels and psychological strains, including negative affect (Allen et al., 2012), depression, and somatic symptoms (Amstad et al., 2011). For the current study, I focus on two psychological strains: state psychological fatigue and state negative affect. I selected these two forms of psychological strain because they reflect distinct facets of psychological strain, namely energy and affective-based strains, respectively. Further, psychological fatigue and negative affect are both theoretically appropriate because they are acute strain responses that vary on a daily basis (e.g., Liu et al., 2015; Chi, Ying, \& Ling, 2016). In contrast, other forms of psychological strain would be relevant for measuring strain over the course of weeks or months (e.g., physical symptoms, depression, burnout). 
Fatigue is the subjective feeling of weariness or exhaustion (Lee, Hicks, \& Nino-Mura, 1991; Shen, Barbara, \& Shapiro, 2006). Fatigue can be defined as a chronic condition that remains stable over weeks or months (e.g., Melamed, Kushnir, \& Sharom, 1992) or as an acute state that fluctuates daily (e.g., McNair, Lorr, \& Droppelman, 1981; Cranford, Shrout, Iida, Rafaeli, Yip, \& Bolger, 2006). Because the current study is primarily focused on capturing variability in episodic stressor-strain phenomena, I focus on state fatigue. Navigating a workfamily conflict episode is a psychologically effortful process, involving decision making and/or control of behaviors or strain that spill over into the alternative work or family domain (Edwards \& Rothbard, 2000; Greenhaus \& Beutell, 1985; Shockley \& Allen, 2015). Thus, work-family conflict episodes are expected to deplete psychological resources, leaving individuals feeling fatigued. Extant research has found a positive association between chronic exhaustion and workfamily conflict (Sanz-Vergel, Demerouti, Moreno-Jiménez, \& Mayo, 2010). Further, daily studies have supported a positive association between work-family conflict and emotional exhaustion (a form of fatigue) on a daily level (Liu et al., 2015; Simbula, 2010; Wagner et al., 2014). I therefore propose EWIF/EFIW will be associated with a synchronous increase in fatigue.

Hypothesis 4a. When an EWIF/EFIW occurs, there is a synchronous increase in state fatigue.

Negative affect is defined as an unpleasant subjective emotional state (Watson, Clark, \& Tellegen, 1988). Negative affect can be described at the trait-level as an individual's tendency to experience unpleasant emotional states (Watson, 1988). Alternatively, negative affect can be described at the state-level as an individual's momentary unpleasant emotional experience (Watson, 1988). Consistent with the theoretical role of work-family conflict as a stressor that 
elicits unpleasant emotional states (Edwards \& Rothbard, 2000; Greenhaus \& Beutell, 1985; Grzywacz, 2016), trait negative affect is positively associated with work-family conflict levels (Allen et al., 2012; Michel, Clark, \& Jaramillo, 2011). Similarly, studies show a positive association between daily work-family conflict levels and state negative affect (Ilies, Schwind, Wagner, Johnson, DeRue, Ilgen, 2007; Chi, Yang, \& Lin, 2016), as well as a positive association between daily work-family conflict levels and daily negative emotions, such as guilt, hostility, and anxiety (Livingston \& Judge, 2008; Judge et al., 2006; Wagner et al., 2014). I therefore propose EWIF/EFIW will be associated with a synchronous increase in state negative affectivity.

Hypothesis $\mathbf{4 b}$. When an EWIF/EFIW occurs, there is a synchronous increase in state negative affect.

Physiological Strain. Physiological strains are changes that occur to physiological systems in response to a stressor (Ganster \& Rosen, 2013). Such strains typically measured using biomarkers associated with the functioning of specific bodily systems (Ganster \& Rosen, 2013). For example, cortisol reactivity and daily patterns are used as indicators of neuroendocrine stress response, and heart rate and blood pressure reactivity and recovery are used as indicators of cardiovascular stress response (Chida \& Hamer, 2008; Dickerson \& Kemeny, 2004; Ganster \& Rosen, 2013). Because work-family conflict is affectively and energetically taxing and often unexpected, EWCs should elicit a physiological stress response (Chida \& Hamer, 2008; Dickerson \& Kemeny, 2004; McEwen \& Seeman, 1999). Only a handful of studies have examined levels-based work-family conflict with objectively assessed physiological outcomes. Some evidence indicates levels-based work-family conflict is linked to hypertension (Frone et al., 1997), increased morning cortisol and shallow diurnal slope (Zilioli, Imami, \& Slatcher, 2016), mean cortisol levels (Krisor, Diebig, \& Rowald, 2015) and cardiometabolic risk (an 
aggregate of several physiological cardiovascular and metabolic risk factors; Berkman et al., 2015).

For the current study, I focus on heart rate, systolic blood pressure, and diastolic blood pressure as indicators of physiological strain associated with cardiovascular system functioning. I focus on the cardiovascular system because it is one of the first physiological systems to respond to an acute stressor, producing increased activity within seconds to minutes of a stressor's occurrence (Ganster \& Rosen, 2013; McEwen, 1998). The cardiovascular system is one of the most researched physiological systems because it is closely linked with autonomic nervous system response associated with acute stressors (Chida \& Hamer, 2008). Heart rate and blood pressure are also easily quantified and measured using ambulatory protocols, such as the one used in the current study. One published study examines the relationship between EWIF/EFIW and physiological strain (Shockley \& Allen, 2013). This study used a diary design to examine work-family conflict episodes and cardiovascular indicators of strain (heart rate, blood pressure). The authors found EWIF was directly linked to heart rate, and the occurrence of EFIW was positively associated with systolic and diastolic blood pressure when supervisor support for family was low. I therefore propose EWIF/EFIW will be associated with a synchronous increase in heart rate, systolic blood pressure, and diastolic blood pressure.

Hypothesis 5a. When an EWIF/EFIW occurs, there is a synchronous increase in heart rate.

Hypothesis 5b. When an EWIF/EFIW occurs, there is a synchronous increase in systolic blood pressure.

Hypothesis 5c. When an EWIF/EFIW occurs, there is a synchronous increase in diastolic blood pressure. 
Behavioral Strain. Behavioral strains are changes in behaviors that occur in response to stressor exposure (Ganster \& Rosen, 2013). For example, counterproductive work behavior, unhealthy eating, physical activity, and poor sleep quantity and quality are considered potential behavioral strains (Allen \& Armstrong, 2006; Crain et al., 2014; Fox, Spector, \& Miles, 2001; Johnson \& Allen, 2013). I focus on unhealthy eating because it is a well-established predictor of societal health issues, such as diabetes, obesity, cancer, and cardiovascular disease (American Heart Association, 2016). Eating behavior also occurs throughout an entire day and may theoretically change in response to daily stressors (Steptoe, Lipsey, \& Wardle, 1998). Further, eating is a universally enacted human health behavior, whereas behaviors such as exercise, smoking, and alcohol consumption are more elective. Finally, eating behavior is relatively underresearched within the work-family literature (Allen, 2012).

Eating behaviors can be described in a number of ways, including the number of calories consumed, the amount of specific foods or nutrients consumed, frequency of snacking between meals, and dietary styles or habits (e.g., Allen \& Armstrong, 2006; Newman, O’Connor, \& Conner, 2007; Sonnentag, Pundt, \& Venz, 2016; Steptoe et al., 1998; Steptoe, Pollard, \& Wardle, 1995). I focus on the amount of unhealthy, high fat and/or high sugar, foods consumed. Consumption of such foods is associated with the development of disorders and disease endpoints, such as obesity, diabetes, and cardiovascular disease (e.g., Howard \& Wylie-Rosett, 2002; Lichtenstein et al., 2006). Consequently, these foods are discouraged by national health and food organizations (American Heart Association, 2016; U.S. Department of Health and Human Services \& U.S. Department of Agriculture, 2015). Consumption of unhealthy foods is also an acute behavioral strain (McEwen, 1998; McEwen \& Seeman, 1999). Stressed individuals eat unhealthy foods due to depleted self-regulation resources (Muraven \& Baumeister, 2000), as 
an attempt to emotionally cope with the stressor (Steptoe et al., 1998; Sonnentag et al., 2016), or as a result of limited time to prepare healthy food (Devine, Jastran, Jabs, Wethington, Farell, \& Bisogni, 2006). In support, diary studies show daily hassles and workplace strain are associated with increased daily consumption of high fat and/or high sugar foods (Jones, O'Connor, Conner, \& Ferguson, 2007; O’Connor, Jones, Conner, McMillan, \& Ferguson, 2008; Steptoe et al., 1998).

Within the work-family literature, little research has directly examined the association between work-family conflict and eating behaviors. Qualitative work by Devine and colleagues $(2003 ; 2006)$ indicates work-family spillover limits time dedicated towards food preparation, resulting in unhealthy meals, such as fast food. Participants also reported coping with workfamily spillover by eating unhealthy foods. Quantitative research shows FIW levels are associated with increased fatty food consumption, although the relationship did not hold for WIF (Allen \& Armstrong, 2006). The current study is the first to examine the relationship between work-family conflict and eating behaviors using an episodic, within-persons approach. Eating decisions may occur throughout a day (i.e., snacking) and individuals may engage in eating immediately following a stressor as a means of coping (Newman et al., 2007; Steptoe et al., 1998). I therefore predict unhealthy eating increases when a work-family conflict occurs.

Hypothesis 6. When an EWIF/EFIW occurs, there is a synchronous increase in unhealthy food consumption.

\section{Episodic Work-Family Conflict and Strain Recovery Trajectory}

In addition to reactivity, the current study examines recovery trajectories for psychological, physiological, and behavioral strain following an EWIF/EFIW. The rate and 
duration of change in strain is largely ignored in the current occupational health literature (Brosschot et al., 2005; Ford et al., 2014; Schwartz et al., 2003). The dominant cross-sectional and lagged designs are unable to map changes in strain across time, and two-wave longitudinal designs are ill-equipped to examine a variety of change patterns (Ployhart \& Vandenberg, 2010). Although longitudinal designs with three or more waves are able to assess change across time, they are typically conducted with time lags of months to years (Ford et al., 2014; Sonnentag et al., 2014). As such, acute recovery patterns associated with workplace stressors are unknown. Together, stressor-strain theory and the allostatic load model suggest three possible strain trajectories may emerge: a normal reactivity pattern, a prolonged response pattern, and an inadequate response/sleeper pattern (Frese \& Zapf, 1988; McEwen, 1998). The allostatic load model also outlines reactivity and recovery patterns for exposure to multiple stressors (inadequate response and lack of adaptation patterns). Because I focus on reactivity and recovery following a single EWIF/EFIW, these patterns are outside the scope of this study. Figure 1 displays reactivity and recovery patterns from the stressor-strain perspective, Figure 2 displays reactivity and recovery patterns from the allostatic load perspective, and Table 1 outlines the overlap between these models and the hypothesized recovery patterns in the current study. 


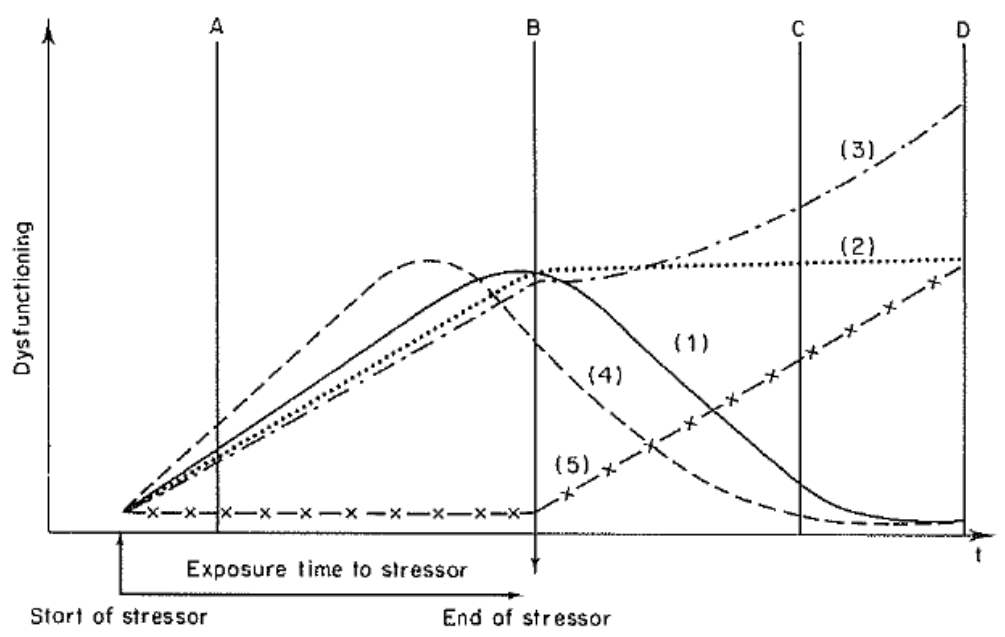

Figure 7 Variants of the exposure time model: (1) stress reaction model, (2) accumulation model, (3) dynamic accumulation model, (4) adjustment model, (5) sleeper effect model

Figure 1. Illustration of strain recovery patterns (Frese and Zapf, 1988, p. 389).

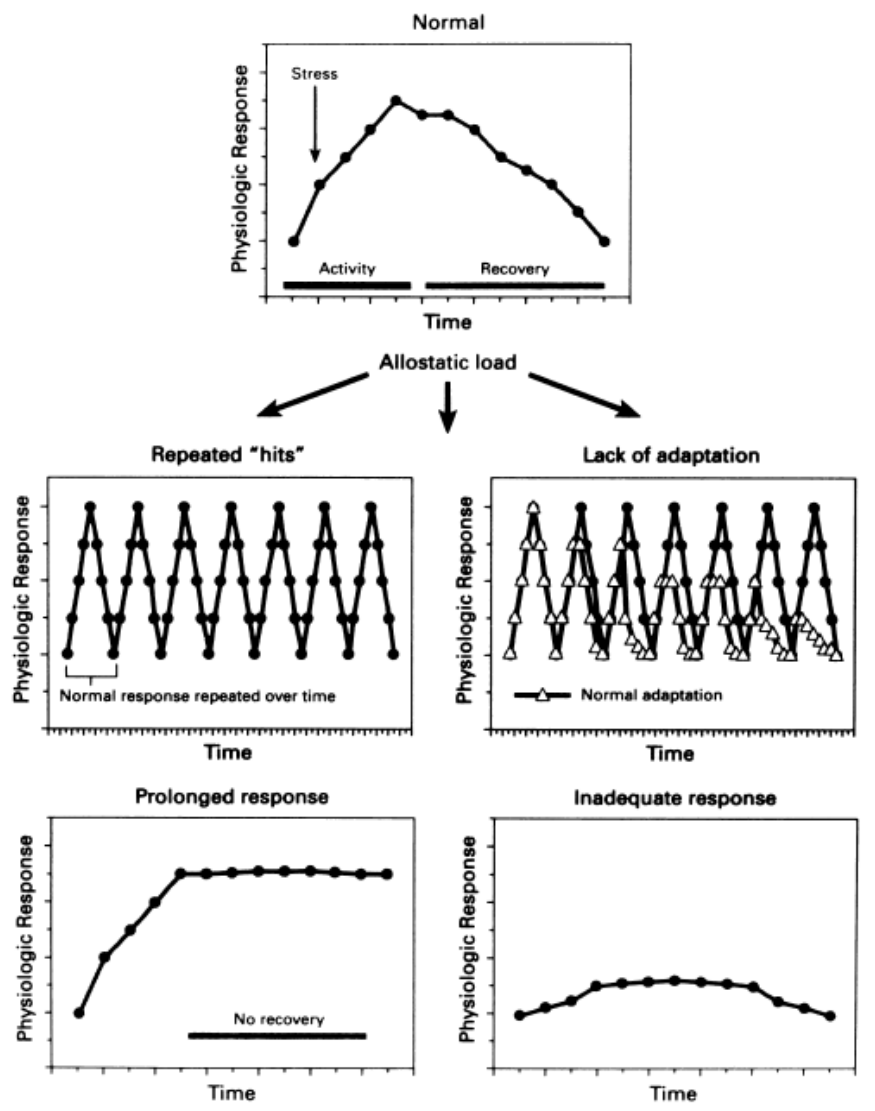

Figure 2. Illustration of the four allostatic load patterns (McEwen \& Seeman, 1999, p. 36). 
Table 1. Comparison of allostatic load and stressor-strain reactivity and recovery patterns.

\begin{tabular}{|c|c|c|c|c|c|c|c|}
\hline AL Pattern & $\begin{array}{c}\text { Number } \\
\text { of } \\
\text { Events }\end{array}$ & $\begin{array}{c}\text { Synchronous } \\
\text { Reaction }\end{array}$ & $\begin{array}{c}\text { Recovery } \\
\text { Pattern }\end{array}$ & S-S Pattern & $\begin{array}{c}\text { Number } \\
\text { of } \\
\text { Events }\end{array}$ & $\begin{array}{c}\text { Synchronous } \\
\text { Reaction }\end{array}$ & $\begin{array}{l}\text { Recovery } \\
\text { Pattern }\end{array}$ \\
\hline \multirow[t]{2}{*}{$\begin{array}{l}\text { Normal } \\
\text { reactivity }\end{array}$} & 1 & Increase & Decrease & $\begin{array}{l}\text { Stress reaction } \\
\text { model }\end{array}$ & 1 & Increase & $\begin{array}{l}\text { Decrease } \\
\text { post-stressor }\end{array}$ \\
\hline & & & & $\begin{array}{l}\text { Adjustment } \\
\text { model }\end{array}$ & 1 & Increase & $\begin{array}{l}\text { Decrease } \\
\text { immediately } \\
\text { following } \\
\text { reaction }\end{array}$ \\
\hline \multirow[t]{2}{*}{$\begin{array}{l}\text { Prolonged } \\
\text { reactivity }\end{array}$} & 1 & Increase & $\begin{array}{l}\text { No } \\
\text { change }\end{array}$ & $\begin{array}{l}\text { Accumulation } \\
\text { model }\end{array}$ & 1 & Increase & No change \\
\hline & & & & $\begin{array}{l}\text { Dynamic } \\
\text { accumulation } \\
\text { model }\end{array}$ & 1 & Increase & Increase \\
\hline $\begin{array}{l}\text { Inadequate } \\
\text { response }\end{array}$ & 1 & No change & $\begin{array}{l}\text { No } \\
\text { change }\end{array}$ & $\begin{array}{l}\text { Sleeper effect } \\
\text { model }\end{array}$ & 1 & No change & Increase \\
\hline $\begin{array}{l}\text { Lack of } \\
\text { adaptation }\end{array}$ & $\begin{array}{l}>2 \text { same } \\
\text { stressors }\end{array}$ & Increase & Decrease & None & & & \\
\hline $\begin{array}{l}\text { Repeated } \\
\text { hits }\end{array}$ & $\begin{array}{l}>2 \\
\text { different } \\
\text { stressors }\end{array}$ & Increase & Decrease & None & & & \\
\hline
\end{tabular}

Note. $\mathrm{AL}=$ Allostatic load pattern described in McEwen (1998), $\mathrm{S}-\mathrm{S}=$ Stressor-strain pattern described in Frese and Zapf (1988), $\mathrm{H}=$ Hypothesis

A normal strain response pattern is characterized by an increase in strain following a stressor, followed by immediate recovery such that strains return to baseline. For example, heart rate and negative mood might increase when a stressor occurs and return to normal when the stressor is resolved. Frese and Zapf's (1988) stress-reaction model proposes this synchronous relationship, such that stressor onset elicits a strain reaction; once stressor exposure is removed, strain decreases (Ford et al., 2014). Similarly, Frese and Zapf’s (1988) adjustment model suggests strain increases with the onset of a stressor, but then decreases as the individual adjusts to the stressor, even if the stressor is still ongoing. For EWIF/EFIWs brief in duration, the stressreaction and adjustment model trajectories are indistinguishable using field-based methodology. The stress-reaction and adjustment models are both consistent with the normal recovery pattern in the allostatic load framework, which also suggests a synchronous increase in strain, followed 
by a return to baseline (McEwen, 1998; McEwen \& Seeman, 1999). Support for a normal recovery pattern would be indicated by a significant increase in strain when EWIF/EFIW occurs, followed by a linear or curvilinear decline post-EWIF/EFIW, in which strain decreases to preEWIF/EFIW levels (see Figure 2 and Table 1).

Hypothesis 7a. After an EWIF/EFIW occurrence, state fatigue declines over time. Hypothesis 7 b. After an EWIF/EFIW occurrence, state negative affect declines over time.

Hypothesis 7c. After an EWIF/EFIW occurrence, heart rate declines over time.

Hypothesis 7d. After an EWIF/EFIW occurrence, systolic blood pressure declines over time.

Hypothesis 7e. After an EWIF/EFIW occurrence, diastolic blood pressure declines over time.

Hypothesis 7f. After an EWIF/EFIW occurrence, unhealthy eating declines over time. One unhealthy recovery pattern is failure to return to baseline, or a prolonged response pattern. For example, heart rate and negative mood might increase when a stressor occurs and fail to return back to normal throughout the remainder of the day, even if the stressor is resolved. Frese and Zapf's accumulation model (or dynamic accumulation model) describes this pattern, such that strain reactions occur at the onset of a stressor, but do not decrease even after the stressor is removed. The accumulation model is consistent with the dysfunctional prolonged response pattern in the allostatic load framework (McEwen, 1998; Juster et al., 2010). Support for the prolonged response pattern would be indicated by a significant increase in strain at the time point that an EWIF/EFIW occurs, followed by a non-significant change in strain or a curvilinear trajectory, in which strain remains stable and then slowly declines. 
A second unhealthy recovery pattern is failure to react to the stressor or a delayed stressor response. For example, heart rate and affectivity may remain unchanged when a stressor occurs. Frese and Zapf's (1988) sleeper effect model suggests strain indicators remain stable when stressors occur, although delayed increases in strain may occur after the stressor is resolved. Similarly, the inadequate response pattern describes a lack of reactivity, such that strain does not increase when a stressor occurs, but rather remains relatively stable (McEwen, 1988). The inadequate response pattern would be supported if there is no change in strain at the same time point that an EWIF/EFIW occurs, and the post-EWIF/EFIW trajectory of strain either remains stable or increases in a linear or curvilinear fashion post-EWIF/EFIW onset.

For the current study, I explore the extent each of these patterns are observed by examining reactivity and recovery variability. Variance across reactivity and recovery associated with an EWIF/EFIW would suggest individual responses to EWIF/EFIW differ from the normal hypothesized pattern. Thus, the existence of prolonged and inadequate response patterns may be explored by examining individual responses to conflict.

Hypothesis 8a. There is significant variability in state fatigue reactivity when an EWIF/EFIW occurs.

Hypothesis 8b. There is significant variability in state negative affect reactivity when an EWIF/EFIW occurs.

Hypothesis 8c. There is significant variability in heart rate reactivity when an EWIF/EFIW occurs.

Hypothesis 8d. There is significant variability in systolic blood pressure reactivity when an EWIF/EFIW occurs. 
Hypothesis 8e. There is significant variability in diastolic blood pressure reactivity when an EWIF/EFIW occurs.

Hypothesis 8f. There is significant variability in unhealthy eating reactivity when an EWIF/EFIW occurs.

Hypothesis 9a. There is significant variability in state fatigue recovery after an EWIF/EFIW occurs.

Hypothesis $\mathbf{9 b}$. There is significant variability in state negative affect recovery after an EWIF/EFIW occurs.

Hypothesis 9c. There is significant variability in heart rate recovery after an EWIF/EFIW occurs.

Hypothesis 9d. There is significant variability in systolic blood pressure recovery after an EWIF/EFIW occurs.

Hypothesis 9e. There is significant variability in diastolic blood pressure recovery after an EWIF/EFIW occurs.

Hypothesis 9f. There is significant variability in unhealthy eating recovery after an EWIF/EFIW occurs. 


\section{CHAPTER TWO: METHOD}

\section{Participants}

Participants for the current study included 100 full-time workers in the Tampa Bay area recruited through community fliers, emails, online postings, and word of mouth from April 2017 through August 2017. To be eligible for the study, all participants were required to be 1) at least 18 years of age, 2) working at least 30 hours per week between the hours of 7 AM and 7 PM, Monday-Friday at a paid job (full time, standard hour employment per the Internal Revenue Service, 2016), 3) have a spouse or cohabiting partner of at least one year and/or a dependent child living at home or caring for a dependent elder, and 4) own a smart phone that could receive texts. To participate, individuals emailed a study gmail account expressing interest. Individuals were then asked if they met the eligibility requirements, and if so, were asked to choose a time for their training appointment.

A total of 192 inquiries were sent to the study email address. Of these, 107 (54.31\% of total inquiries) participated in the study (see Table 2 for a breakdown of inquiries and Table 3 for a breakdown of how participants were recruited). This number exceeded the sample size goal of 100 participants (700 day-level observations, 2800 within-day observations), based on the results of power analyses using an effect size of $d=.30$ (small effect), alpha of .05 , and power of at least .50 for each variable (see Table 4). Published research and dissertations were used to determine plausible ICCs for the power analysis. Of the 107 participants, those who withdrew from the study before the end of the first day $(\mathrm{N}=3)$, worked an overnight shift $(\mathrm{N}=1)$, or worked less 
than 30 hours per week $(\mathrm{N}=3)$ were excluded from all analyses. Participants who indicated they were pregnant, had a history of cardiovascular disease, or were taking medication for cardiovascular conditions were excluded from cardiovascular analyses $(\mathrm{N}=15)$.

Analyses were completed with a final sample of 100 individual-level observations and 2,573 valid within-day observations $(2,220$ collected during the first three days of participation, 353 collected during the last four days of participation). Participants were predominantly female $(63 \%), 33.09$ years old on average ( $\mathrm{SD}=9.09)$, and racially diverse with White $(51 \%)$, followed by Hispanic or Latin (21\%), Black or African American (15\%), other (8\%), Asian (4\%), and American Indian or Alaskan Native (1\%). Participants worked an average of 40.59 hours each week $(\mathrm{SD}=6.22)$, with an average job tenure of 3.43 years $(\mathrm{SD}=4.12)$. Participants worked in a wide variety of occupations, including an assistant professor, administrative assistant, consultant, dental hygienist, grant administrator, hairstylist, cook, pharmacy technician, restaurant manager, sales engineer, server, vice president financial analyst, vlogger, and a worship pastor. Some participants had flexplace work conditions, such that they worked full or part time from a home office. The average household income was $\$ 77,598(\mathrm{SD}=\$ 55,689)$. Most participants had a bachelor's degree (30\%), followed by some college $(27 \%)$, a master's degree $(26 \%)$, a postsecondary, trade, or vocational school certification (8\%), doctoral or other professional degree (6\%), a high school diploma (2\%), or some high school (1\%). Participants were primarily married (47\%), 35\% were in a committed relationship or domestic partnership, $7 \%$ were divorced, and $11 \%$ were single. Most participants had at least one child (53\%), ranging between 1 and 5 children $($ Mean $=1.60)$. 
Table 2. Study inquiry breakdown.

\begin{tabular}{lcc}
\hline \multicolumn{1}{c}{ Inquiry Result } & Frequency & Percentage \\
\hline Participated in the study & 107 & 54.31 \\
Withdrew during training appointment & 1 & 0.51 \\
Set up an appointment, but did not show & 12 & 6.09 \\
No response after initial email & 31 & 15.74 \\
Not eligible & 24 & 12.18 \\
Opted out & 9 & 4.57 \\
Not an inquiry (e.g., childcare scam, tutoring) & 5 & 2.54 \\
Study was full & 3 & 1.52 \\
\hline
\end{tabular}

Table 3. Participant recruitment methods.

\begin{tabular}{lcc}
\hline \multicolumn{1}{c}{ Inquiry Result } & Frequency & Percentage \\
\hline Word of mouth & 29 & 27.10 \\
Flier - Business (e.g., Starbucks, Jimmy Johns) & 28 & 26.17 \\
Flier - USF & 15 & 14.02 \\
Craigslist & 14 & 13.08 \\
Flier - Apartment complexes & 8 & 7.48 \\
Reddit & 6 & 5.61 \\
Flier - Libraries & 6 & 5.61 \\
Facebook & 1 & 0.94 \\
\hline
\end{tabular}

Table 4. Power analysis results.

\begin{tabular}{lclccccc}
\hline $\begin{array}{c}\text { Dependent } \\
\text { Variable }\end{array}$ & $\begin{array}{c}\text { Proportion } \\
\text { Variance } \\
\text { Between }\end{array}$ & Information Source & $\begin{array}{c}\text { ES } \\
(d)\end{array}$ & $\begin{array}{c}\text { Within } \\
\text { N }\end{array}$ & $\begin{array}{c}\text { Between } \\
\text { N }\end{array}$ & $\begin{array}{c}\text { Total } \\
\text { N }\end{array}$ & Power \\
\hline EWIF/EFIW & 0.19 & Shockley \& Allen, 2015 & 0.30 & 28 & 100 & 2800 & $\mathbf{0 . 9 8}$ \\
State fatigue & 0.44 & Johnson, 2015 & 0.30 & 28 & 100 & 2800 & $\mathbf{0 . 6 0}$ \\
Negative affect & 0.21 & Ilies et al., 2007 & 0.30 & 28 & 100 & 2800 & $\mathbf{0 . 8 6}$ \\
Systolic BP & 0.21 & Shockley \& Allen, 2013 & 0.30 & 28 & 100 & 2800 & $\mathbf{0 . 8 6}$ \\
Diastolic BP & 0.42 & Shockley \& Allen, 2013 & 0.30 & 28 & 100 & 2800 & $\mathbf{0 . 6 2}$ \\
Heart rate & 0.31 & Shockley \& Allen, 2013 & 0.30 & 28 & 100 & 2800 & $\mathbf{0 . 7 4}$ \\
Unhealthy eating & 0.49 & Johnson, 2015 & 0.30 & 28 & 100 & 2800 & $\mathbf{0 . 5 6}$ \\
\hline
\end{tabular}




\section{Procedure}

Data was collected in two phases (see Figure 3). The first phase was a one-hour lab training session. Training sessions were most often completed in the lab on the USF Tampa campus (57\%), but were also conducted at local libraries (15\%), Starbucks locations (12\%), restaurants $(10 \%)$, and alternative locations on and off the USF campus (6\%). Participants signed informed consent (see Appendix A) and then the researcher took down participants' contact information for tracking purposes. Tracking information included participant responses to three identification (ID) questions used to link the baseline and daily diary data without compromising participant confidentiality. Next the researcher measured participants' height and weight using a stadiometer and a digital scale. Baseline heart rate and blood pressure were recorded using the OMRON HEM-637 ambulatory heart rate and blood pressure watches. Participants then completed a 25-35 minute baseline survey containing demographic information and control variables. Next, participants were given a 15-20 minute training presentation (adapted from Barnett, 2016 and Shockley \& Allen, 2013; see Appendix B). The training presentation included information on EWIF/EFIW, as well as heart rate and blood pressure. Participants were provided with multiple concrete examples of EWIF/EFIW and asked to provide their own examples so to confirm they understood what constituted an EWIF/EFIW. The researcher trained participants to use the OMRON HEM-637 monitors and provided instructions for completing the daily surveys. Participants were provided a reminder handout (see Appendix C) with the training information, and the trainer referred to the handout content while going through the training presentation. Finally, participants signed a monitor agreement form (adapted from Barnett, 2016; Shockley \& Allen, 2013; see Appendix D) and scheduled a time to return the monitor. Participants departed 
with their OMRON HEM-637 monitor, the reminder handout, and a copy of the informed consent.

The second phase was a seven-day experience sampling (ESM) data collection. Participants began reporting data the Monday $(\mathrm{N}=55)$ or Wednesday $(\mathrm{N}=45$, randomly assigned) following the in-lab training. Two start dates were used to ensure data in the sample covered the entire standard work week. Two start dates also allowed the possibility of disentangling effects due to day of participation from effects due to day of the week. At 6 PM the evening before participation, participants received an email reminder that the study was to begin the next day at $8 \mathrm{AM}$ (see Appendix E for email and text message scripts). The reminder email included an electronic version of the Reminder Handout in case participants had misplaced their hard copy.

For the first three days, participants completed eight surveys each day (8 AM, 10 AM, 12 PM, 2 PM, 4 PM, 6 PM, 8 PM, and 10 PM). Surveys were sent via text message to the participant's smartphone at each time using the online text messaging service Remind. Originally designed for teachers to contact their class' parents, Remind allows researchers to sign participants up for a "class" (i.e., study) using their cell phone number. Each start date had its own unique "class," with scheduled text message links that were sent to all enrolled participants within that given start date. Participants were able to directly communicate via text using the Remind application. A text message to Remind triggered three notifications: one to the study email address, one to the primary investigator's personal email, and one to the primary investigator's personal cell phone through the Remind app. This allowed for instant communication to troubleshoot potential issues (e.g., broken survey link, monitor malfunctions). 
For each survey, participants took their blood pressure and heart rate using the OMRON HEM-637 watches. Surveys are timed to create equal, short sampling intervals in order to capture acute fluctuations in EWIF/EFIW and strain during times in which participants are likely awake (see Goldstein, Jamner, \& Shapiro, 1992, Vrikjkotte et al., 2000 for similar ambulatory protocols). Short intervals also enabled responses as close as possible to an EWIF/EFIW without causing undue burden. Participants received a text every two hours over the three days to prompt responses (see Appendix E for email and survey scripts used for communicating with participants). Surveys were mobile-friendly and accessed on Qualtrics using the text messaged link. Participants answered the three unique ID questions on each survey, allowing their data to be linked across responses.

For the remaining four days, participants completed one survey at the end of each day. Survey items were nearly identical to the Monday-Wednesday surveys. Participants received a reminder at $6 \mathrm{PM}$ on Wednesday evening that the first portion of the experience sampling was nearing completion, and that they would only receive one survey at $10 \mathrm{PM}$ for the remaining four days. The use of once daily surveys for the last four days reduces participant burden while also tracking the timing of EWIF/EFIW throughout a full week. Before logging into each survey, participants took their blood pressure and heart rate using the OMRON HEM-637 watches. Participants answered the three unique ID questions on each survey to link their data across responses.

At $8 \mathrm{AM}$ the day after their last survey, participants received an email notifying them that their participation was complete and reminding them of their equipment return appointment date, time, and location. Participants returned their monitor directly to a researcher, who thanked the participant and answered any remaining questions or concerns. After participants successfully 
returned their monitor, they received up to $\$ 75$ compensation via emailed Amazon Gift Card codes within the next two days. Participants received $\$ 10$ total for the lab training, $\$ 15$ total for completing 14 or fewer surveys, $\$ 30$ total for completing $15-19$ surveys, $\$ 45$ total for completing 20-24 surveys, \$60 total for completing 25 or more surveys, and $\$ 75$ total for completing all 28 surveys. Participants also received a personalized Participant Health Report, detailing their health-related information collected throughout the study (see Appendix F for a sample report).

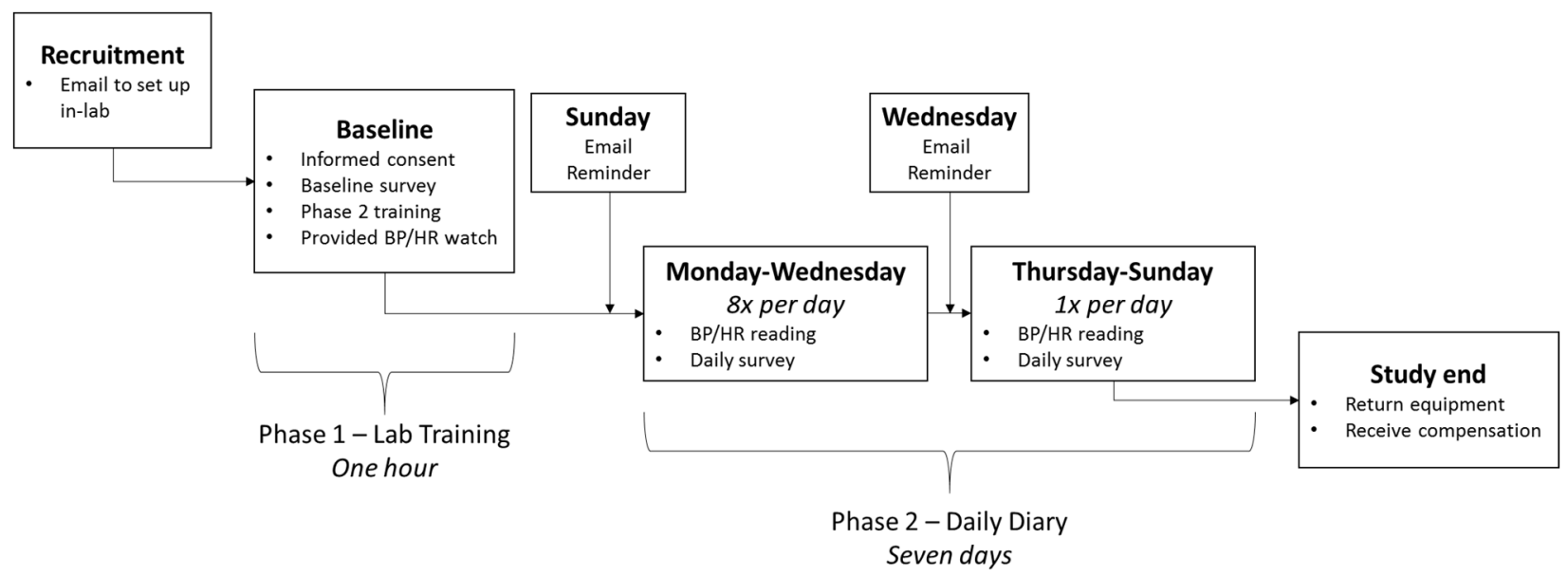

Figure 3. Graphic representation of study procedure for a participant with a Monday start day.

\section{Apparatus}

OMRON HEM-637 ambulatory heart rate and blood pressure monitors were used to assess blood pressure and heart rate throughout the study. This ambulatory monitor uses the oscillation technique to derive systolic blood pressure, diastolic blood pressure, and heart rate based on the movement of blood through the radial artery, located in the forearm. The cuff first contracts, restricting blood flood through the radial artery. As the cuff slowly deflates, blood pulsing through the artery creates a vibration that is detected by the watch. As the artery expands 
to normal width, this vibration becomes increasingly faint. The watch transduces the detected vibrations using proprietary algorithms to compute blood pressure and heart rate.

To use the monitor, participants placed the monitor on their left wrist and push the start button. The watch cuff then inflated and slowly deflated; the total time for a single reading is approximately thirty seconds. Measurements of systolic blood pressure, diastolic blood pressure, and heart rate were clearly displayed on the watch's digital interface following a reading for approximately thirty seconds. Participants were able to scroll through previous readings by pushing the memory button on the watch's display.

The oscillation method is common for ambulatory protocols, as it is simple and easy to use. Studies have indicated that wrist oscillation monitor readings are valid and comparable to alternative methods if the user follows uniform directions when taking their readings (Mourad, Gillies, \& Carney, 2005; Pickering et al., 2005; O’Brien et al., 2003). The OMRON HEM-637 monitors used in the current study have been validated according to the International Validation Protocol of the European Society of Hypertension recommendations (Topouchian, El Assad, Orobinskaia, El Feghali, \& Asmar, 2006). In addition, I correlated blood pressure and heart rate readings from 15 OMRON HEM-637 monitors to be used in the study with those from brachial oscillation monitors currently used in cardiovascular psychophysiology research (reported in Barnett, 2016). Readings were taken simultaneously on different arms. Correlations ranged from .73 (diastolic blood pressure) to 1.00 (heart rate), indicating high agreement between the OMRON HEM-637 readings and the established brachial oscillation monitors. Finally, the OMRON HEM-637 has been used in published research (Berkman, Buxton, Ertel \& Okechukwu, 2010; Berkman et al., 2015; Shockley \& Allen, 2013). To ensure valid readings, participants were instructed to take all readings in a seated position with their feet flat on the 
floor while remaining silent. Participants were also instructed to place their left hand on their chest for all readings to ensure the monitor position is uniform and at the level of the heart for all readings. The monitor had a built-in sensor to detect improper positioning of the monitor on the wrist and in relation to the heart. This sensor instructed participants to adjust the watch placement before taking a reading, and it produced an error message if the watch was improperly placed on the wrist or if there was substantial movement during the reading.

\section{Measures}

Items for baseline measures are listed in Appendix G, and items for daily measures are listed in Appendix H (Monday-Wednesday version) and Appendix I (Thursday-Sunday version).

\section{Baseline Measures}

ID Questions. Three questions were used to identify and link participant responses across baseline and daily surveys. Participants will report the first two letters of their middle name, the first two letters of their mother's maiden name, and the month and day of their birthday. These responses will be concatenated to form a unique eight digit identification number for each participant.

Demographics. Participants reported their gender, age, and ethnicity/race, and education level. For work-related demographics, participants reported their job title, industry, job tenure, average work hours per week, and household income. Participants also indicated work start/end times for each day during the week of study participation. For family-related demographics, participants reported their marital status, parental status, and child ages if applicable. Participants also reported any scheduled family events/responsibilities during the week of study participation. 
Cardiovascular Screening Items. Four questions were used to check screening criteria relevant for cardiovascular measures. Items assessed whether participants had cardiovascular problems, cardiovascular-related medication, hypertension, or were pregnant.

\section{Daily Measures}

ID Questions. Participants indicated the first two letters of their first middle name, the first two letters of their mother's maiden name, and their birth date (day and year) using four digits. The items were concatenated to create a unique eight digit ID for each participant.

Heart Rate and Blood Pressure. Immediately prior to logging into the survey, participants took their heart rate and blood pressure using the OMRON HEM-637 ambulatory wrist monitor. Participants reported their recording in designated fields on the online survey. If participants reported their monitor malfunctioned or broke, they were instructed to enter ' 30 ' for each reading. Reports of ' 30 ' for each reading were recoded as missing data for analyses.

Daily Temporal and Spatial Role Transitions. Four study-developed items assessed whether participants transitioned between work and family roles. First, temporal transitions were assessed with the following item: "In the last two hours ("Today" for Thursday-Sunday surveys), have you switched from engaging in work responsibilities to engaging in family responsibilities?" A parallel item assessed family to work temporal transitions. Temporal transition occurrence was computed, such that a "yes" on either item was computed as a "1," meaning a temporal transition occurred. A "no" on both items was computed as a " 0 ," meaning no temporal transition occurred. Second, spatial transitions were assessed with the following item: "In the last two hours (“Today" for Thursday-Sunday surveys), have you moved from a work location/space to a family location/space?" Spatial transition occurrence was computed, 
such that a "yes" on either item will be computed as a "1," meaning a spatial transition occurred. A "no" on both items was computed as a "0," meaning no spatial transition occurred.

Daily Scheduled Role Transitions. The eight time points were also coded into two additional daily transition variables: morning scheduled transitions and afternoon scheduled transitions. Participants' reported work schedules on the baseline survey were used to determine when participants were scheduled to begin and end work each day. For morning scheduled transitions, the time point during the participant's reported work start time was coded as " 1 ," indicating a morning scheduled transition between work and family; all other time points were coded as " 0 ." For afternoon scheduled transitions, the time point following the participant's reported work end time was coded as " 1 ," indicating an afternoon scheduled transition between work and family; all other time points were coded as "0".

Weekly Role Transition Days. The seven days were coded into two variables: beginning of week transition or an end of week transition. For beginning of week scheduled transition, Mondays were coded as "1," indicating a beginning of week scheduled transition between work and family; all other days were coded as " 0. ." For end of week scheduled transition, Fridays was coded as " 1 ," indicating a beginning of week scheduled transition between work and family; all other days were coded as " 0. ."

State Fatigue. A shortened, two-item version of the Profile of Mood States (POMS) fatigue scale was used in the current study (Cranford et al., 2006; Hülsheger, 2016). Participants indicated the extent that they currently felt "exhausted" or "fatigued" on a scale that ranged from 0 , very slightly or not at all, to 4 , extremely. Items were averaged to create a composite measure of fatigue at each time point $(\alpha=.80)$. This measure of fatigue was specifically developed for the purposes of daily diary methodology. Validation studies have shown sufficient reliability, 
variability both at the day and person level, and that fatigue increased in response to stressful events (Cranford et al., 2006).

State Negative Affect. Five negative affectivity items from Watson et al.'s (1988) Positive and Negative Affect Schedule (PANAS) scale were used to assess state negative affect. The original ten item scale was reduced by omitting conceptually similar items (e.g., "ashamed" and "guilty" are similar items, so only "guilty" was retained). Participants indicated the extent to which they were currently feeling or experiencing each affective adjective (e.g., "irritable," "distressed") on a five-point scale that ranges from 0 , very slightly or not at all, to 4 , extremely. Items were averaged to create a composite measure of state negative affect at each time point ( $\alpha$ $=.73$ ). The PANAS is a popular scale for measuring mood states (Wilhelm \& Schoebi, 2007), and has been used in diary studies examining daily work-family conflict levels (e.g., Ilies et al., 2007).

Unhealthy Eating. A list of six high fat and/or high sugar foods and beverages was adapted from Johnson (2015) for the current study to assess unhealthy eating (see Barnett, 2016; Johnson, 2015; Shockley \& Allen, 2013 for similar item-generating procedures for food consumption). This list of foods was reflective of those considered unhealthy in the United States Department of Agriculture dietary guidelines (2016), as well as those that contribute to cardiovascular disease (American Heart Association, 2016). Items were summed to create an index of unhealthy eating at each time point.

Episodic Work-Family Conflict. Participants reported the number of EWIF/EFIWs that occurred within the last two hours (Monday-Wednesday surveys) or within the past day (Thursday-Sunday surveys) using a checklist developed based on previous episodic research (Allen, Walvoord, Dorio, \& Cho, 2016; Barnett, 2016; Rothstein, Shockley, Boyd, \& Yuan, 
2016; Shockley \& Allen, 2013; 2015). For each conflict, participants reported the time the conflict occurred.

Data from these responses were used to code EWIF/EFIW occurrence (whether or not an episode occurred) and the EWIF/EFIW-response lag (time between the EWIF/EFIW and response). For Thursday-Sunday surveys, time of $E W I F / E F I W$ was recoded into a categorical variable, indicating during which time window the conflict occurred: before 8 AM, 8 AM-9:59 AM, 10 AM-11:59 AM, 12 PM - 1:59 PM, 2 PM - 3:59 PM, 4 PM - 5:59 PM, 6 PM - 7:59 PM, 8 PM 9:59 PM, 10 PM or later.

A checklist including both time and strain-based conflicts is used to cue participants' memories of recent conflicts. Although levels-based research indicates similar prevalence of time and strain-based conflict (e.g., Carlson, Kacmar, \& Williams, 2000), time-based conflicts appear to be predominant in extant episodic research (e.g., Barnett, 2016). This may be because time-based conflicts are most salient or easy to identify. Given that the focus of the current study was on interrole stressor-strain relationships, accurate detection of strain-based EWIF/EFIW is important. By cuing both time and strain-based conflict, I hoped to rectify under-reporting issues that may be contributing to the previously documented disparity in EWIF/EFIW types.

Cardiovascular Controls. Blood pressure and heart rate readings are influenced by a number of physical and behavioral factors (e.g., recent food consumption, physical activity, posture). It is therefore common practice to control for these factors for ambulatory protocols. Five controls will be assessed based on Kamarck et al.'s (1998) Diary of Ambulatory Behavior States and recommendations from the OMRON HEM-637 manual. All controls were recoded into a dichotomous variable, indicating whether or not the participant was compliant. 


\section{CHAPTER THREE: RESULTS}

\section{Preliminary Analyses}

Data cleaning, assumption checking, descriptive statistics and univariate analyses were completed in SPSS. Psychometric properties of each multi-item reflective scale (i.e., state negative affect, state fatigue) were examined by computing Cronbach's alpha in SPSS, as reported in the measures section.

\section{Data Cleaning}

A visual display of the cleaning process and data used for each analysis is shown in Figure 4. Before screening and analysis, participants' data were altered where necessary based on notes from the participant sent via email or left on the survey (e.g., "It didn't let me answer the food question I did not have any of those foods"). I also cleaned ID data to ensure IDs were clearly matched for each participant between data sets and that no two IDs between participants were identical.

The 100 participants logged a total of 2,668 responses (2,292 collected during the first three days of participation, 376 collected during the last four days of participation). All daily responses were screened to ensure they occurred at the appropriate time, and that no participant had multiple responses per any one time point. In order to be counted as a valid response, participants had to $\log$ in to the survey within two hours and five minutes of receiving a text message. Two hours allowed for multiple responses throughout the day needed to test the study hypotheses, while also keeping in mind burden to participants. The extra five minutes was used as a grace period for participants who intended to respond, but waited until the very end of their 
two hour window. Three within-person responses were not omitted due to the grace period.

When participants responded multiple times within one time window, the most complete

observation or the first observation logged was used for final analyses. After removing duplicate and invalid responses, the final data set included 2,573 valid within-day observations, spanning 651 days. A total of 2,220 responses occurred during the first three days of participation, and 353 occurred during the last four days of participation).

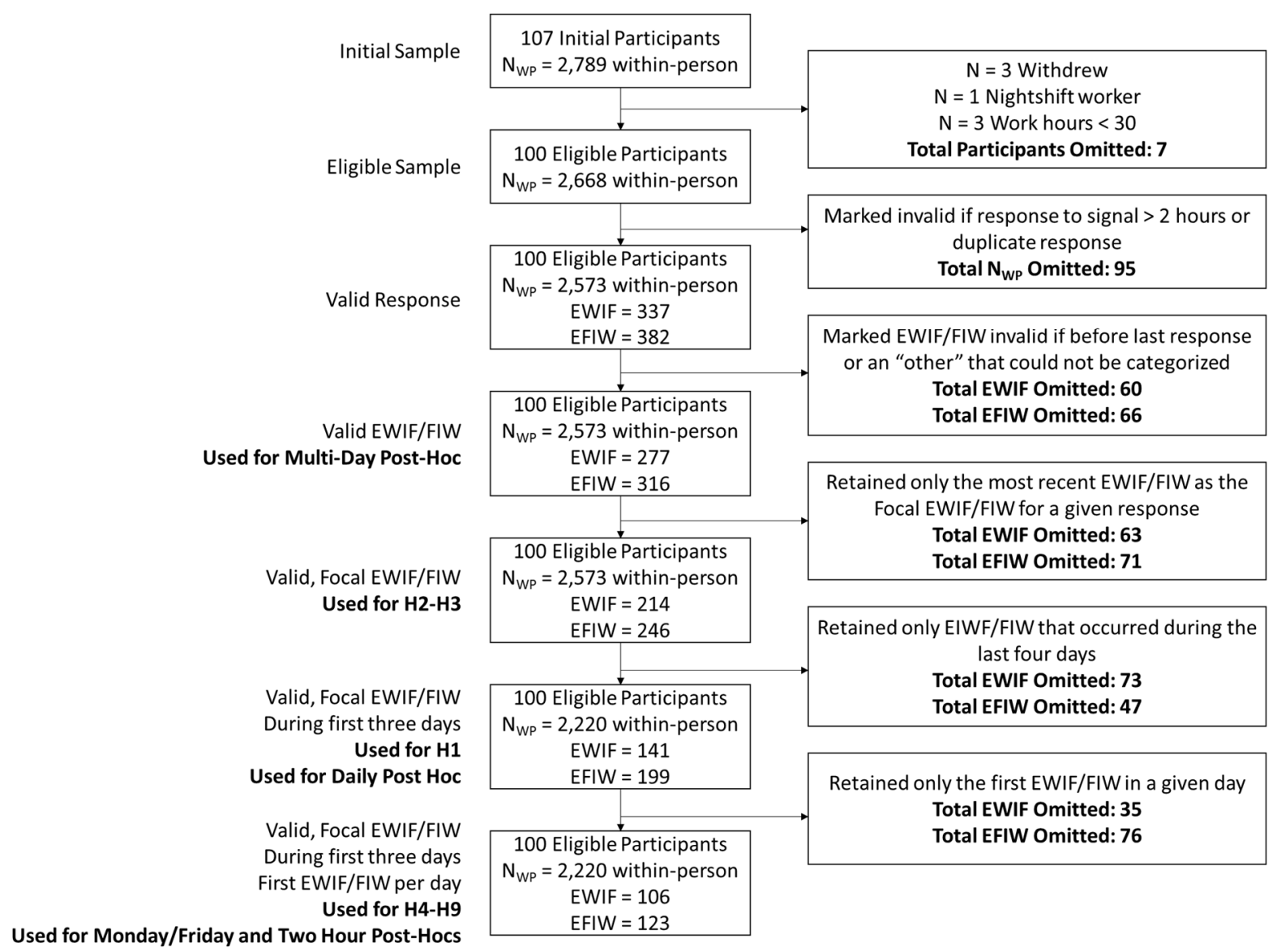

Figure 4. Flow chart displaying the cleaning process and samples used for each analysis.

I then cleaned EWIF/EFIWs to ensure that the reported EWIF/EFIW occurred after the previous response but before or during the current response. Any EWIF/EFIWs that occurred 
before the previous response (i.e., not within the time period for that response) were omitted from the analysis. If the participant missed the previous response, EWIF/EFIWs that occurred more than four hours and five minutes before the response (for the first three days) or 26 hours before the response (for the last four days) were omitted. These times were chosen because they reflect the maximum possible time in between two valid responses. For the first response, EWIF/EFIWs that occurred more than two hours and five minutes prior to the signal were omitted from the analysis. When participants did not report the time of an EWIF/EFIW, the EWIF/EFIW was omitted. These exclusion criteria allowed me to be sure analyses capturing reactivity coincided with the onset of a conflict. I also examined all reports of "other" EWIF/EFIW and when possible categorized the conflicts into their relevant categories. For example, one participant stated, "Coworker late had to stay later." This conflict was recategorized as an EWIF in which the participant missed all or part of a family activity (for example, leave early or arrive late) due to your job." Six “other" EWIF/EFIWs were recategorized. The remaining 31 "other" EWIF/EFIWs were unable to be categorized due to lack of information provided in the description (e.g., "Not working" and "Helping a family member"). Because the remaining "other" EWIF/EFIWs could not be confirmed as work-family conflicts, they were considered invalid and omitted from analyses. Before removing invalid EWIF/EFIW reports, there were 337 EWIF and 382 EFIW. After removing invalid reports, there were 277 EWIFs and 316 EFIWs. Out of 100 participants, 70 reported at least one EWIF and 65 reported at least one FIW. On average, participants reported 2.77 EWIFs (Median $=2, \mathrm{SD}=$ 3.26, Minimum $=0$, Maximum $=14)$ and 3.16 EFIWs $($ Median $=2, S D=4.17$, Minimum $=0$, Maximum $=28)$. 


\section{Data Screening}

Next, I checked the data for assumptions of normality, outliers, linearity, homogeneity of variance, homoscedasticity, and systematic missingness. Normality and the presence of outliers were assessed using descriptive statistics and by reviewing frequency tables and histograms for each variable. Except for dichotomous variables, all data were approximately normally distributed. No outliers were detected. Descriptive statistics for EWIF/EFIW are presented in Table 5, frequencies for the number of total EWIF/EFIW reported per response are presented in Table 6, and descriptive statistics for all dependent variables and controls are presented in Table

7.

Table 5. Descriptive statistics and missingness for EWIF/EFIW.

\begin{tabular}{|c|c|c|c|c|c|c|c|c|c|}
\hline Variable & Mean & Median & SD & Min & Max & Skew & Kurtosis & $\begin{array}{c}\mathrm{N} \\
\mathrm{Obs}^{3} \\
\end{array}$ & $\begin{array}{c}\% \\
\text { Obs }^{3} \\
\end{array}$ \\
\hline EWIF Occurrence $^{1}$ & 0.08 & 0.00 & 0.28 & 0.00 & 1.00 & 3.02 & 7.13 & 2573 & $100 \%$ \\
\hline EWIF Time-Based Occurrence ${ }^{1}$ & 0.06 & 0.00 & 0.24 & 0.00 & 1.00 & 3.76 & 12.13 & 2573 & $100 \%$ \\
\hline EWIF Strain-Based Occurrence ${ }^{1}$ & 0.04 & 0.00 & 0.19 & 0.00 & 1.00 & 4.97 & 22.75 & 2573 & $100 \%$ \\
\hline EWIF Total $^{2}$ & 0.11 & 0.00 & 0.41 & 0.00 & 6.00 & 5.53 & 43.71 & 2573 & $100 \%$ \\
\hline EWIF Time-Based Total ${ }^{2}$ & 0.07 & 0.00 & 0.29 & 0.00 & 5.00 & 6.07 & 55.21 & 2573 & $100 \%$ \\
\hline EWIF Strain-Bas & 0.04 & 0.00 & 022 & 0.00 & 3.00 & 6.43 & 50.14 & 2573 & $100 \%$ \\
\hline EFIW Occurrence $^{1}$ & 0.10 & 0.00 & 0.29 & 0.00 & 1.00 & 2.75 & 5.58 & 2573 & $100 \%$ \\
\hline EFIW Time-Based Occurrence ${ }^{1}$ & 0.08 & 0.00 & 0.27 & 0.00 & 1.00 & 3.05 & 7.30 & 2573 & $100 \%$ \\
\hline EFIW Strain-Based Occurrence ${ }^{1}$ & 0.02 & 0.00 & 0.14 & 0.00 & 1.00 & 6.62 & 41.89 & 2573 & $100 \%$ \\
\hline EFIW Total ${ }^{2}$ & 0.12 & 0.00 & 0.43 & 0.00 & 5.00 & 4.83 & 31.57 & 2573 & $100 \%$ \\
\hline EFIW Time-Be & 0.10 & 0.00 & 0.37 & 0.00 & 4.00 & 4.50 & 25.15 & 2573 & $100 \%$ \\
\hline EFIW Strain-Based Total ${ }^{2}$ & 0.02 & 0.00 & 0.15 & 0.00 & 2.00 & 7.15 & 54.11 & 2573 & $100 \%$ \\
\hline
\end{tabular}

${ }^{1} 1=$ EWIF/EFIW occurred at the given time point $(1=$ Yes, $0=$ No $) .{ }^{2}$ Total number of EWIF/EFIWs reported at the given time point. ${ }^{3}$ Two observations had no data. I assumed that participants had no EWIF/EFIW for these data points and imputed a " $0 . "$

Table 6. Frequencies of EWIF/EFIW Total reported in a single response.

\begin{tabular}{crrrrrr}
\hline $\begin{array}{c}\text { Number of } \\
\text { EWIF/EFIW }\end{array}$ & $\begin{array}{c}\text { EWIF } \\
\text { Total }\end{array}$ & $\begin{array}{c}\text { EWIF } \\
\text { Time-Based }\end{array}$ & $\begin{array}{c}\text { EWIF } \\
\text { Strain-Based }\end{array}$ & $\begin{array}{c}\text { EFIW } \\
\text { Total }\end{array}$ & $\begin{array}{c}\text { EFIW } \\
\text { Time-Based }\end{array}$ & $\begin{array}{c}\text { EFIW } \\
\text { Strain-Based }\end{array}$ \\
\hline 0 & 2359 & 2422 & 2480 & 2327 & 2362 & 2518 \\
1 & 171 & 137 & 83 & 197 & 172 & 53 \\
2 & 31 & 9 & 8 & 36 & 32 & 2 \\
3 & 7 & 4 & 2 & 7 & 5 & 0 \\
4 & 3 & 0 & 0 & 4 & 2 & 0 \\
5 & 1 & 1 & 0 & 2 & 0 & 0 \\
6 & 1 & 0 & 0 & 0 & 0 & 0 \\
1 or More & 214 & 151 & 93 & 246 & 211 & 55 \\
\hline
\end{tabular}


Table 7. Descriptive statistics and missingness for dependent and control variables.

\begin{tabular}{|c|c|c|c|c|c|c|c|c|c|}
\hline Variable & Mean & Median & SD & Min & Max & Skew & Kurtosis & N Obs & $\%$ Obs \\
\hline $\begin{array}{l}\text { Temporal Transition } \\
\text { Occurrence }^{3}\end{array}$ & 0.30 & 0.00 & 0.46 & 0.00 & 1.00 & 0.87 & -1.24 & 2562 & $99.57 \%$ \\
\hline $\begin{array}{l}\text { Spatial Transition } \\
\text { Occurrence }^{3}\end{array}$ & 0.28 & 0.00 & 0.45 & 0.00 & 1.00 & 0.96 & -1.09 & 2568 & $99.81 \%$ \\
\hline $\begin{array}{l}\text { Morning Scheduled } \\
\text { Transition }^{3}\end{array}$ & 0.16 & 0.00 & 0.37 & 0.00 & 1.00 & 1.88 & 1.53 & 2573 & $100.00 \%$ \\
\hline $\begin{array}{l}\text { Afternoon Scheduled } \\
\text { Transition }^{3}\end{array}$ & 0.16 & 0.00 & 0.37 & 0.00 & 1.00 & 1.91 & 1.64 & 2573 & $100.00 \%$ \\
\hline $\begin{array}{l}\text { Beginning of Week } \\
\text { Transition }{ }^{3}\end{array}$ & 0.18 & 0.00 & 0.39 & 0.00 & 1.00 & 1.65 & 0.71 & 2573 & $100.00 \%$ \\
\hline End of Week Transition ${ }^{3}$ & 0.14 & 0.00 & 0.35 & 0.00 & 1.00 & 2.08 & 2.32 & 2573 & $100.00 \%$ \\
\hline State Fatigue & 1.65 & 1.50 & 0.80 & 1.00 & 5.00 & 1.37 & 1.64 & 2572 & $99.96 \%$ \\
\hline State Negative Affect & 1.20 & 1.00 & 0.36 & 1.00 & 3.80 & 2.79 & 9.92 & 2572 & $99.96 \%$ \\
\hline Heart Rate & 77.99 & 78.00 & 16.42 & 30.00 & 152.00 & -0.19 & 1.42 & 2573 & $100.00 \%$ \\
\hline Systolic Blood Pressure & 113.53 & 112.00 & 14.41 & 67.00 & 199.00 & 0.74 & 1.03 & 2501 & $97.20 \%$ \\
\hline Diastolic Blood Pressure & 71.30 & 70.00 & 10.98 & 41.00 & 120.00 & 0.42 & 0.62 & 2501 & $97.20 \%$ \\
\hline Unhealthy Eating ${ }^{4}$ & 0.79 & 0.00 & 1.12 & 0.00 & 6.00 & 1.75 & 3.13 & 2501 & $97.20 \%$ \\
\hline Posture $^{5}$ & 0.09 & 0.79 & 0.28 & 0.00 & 1.00 & 2.92 & 6.50 & 2563 & $99.61 \%$ \\
\hline Physical Activity ${ }^{6}$ & 0.89 & 1.00 & 0.79 & 0.00 & 3.00 & 0.60 & -0.13 & 2556 & $99.34 \%$ \\
\hline Caffeine Consu & 0.18 & 0.00 & 0.39 & 0.00 & 1.00 & 1.66 & 0.78 & 2572 & $99.96 \%$ \\
\hline Meal Consum & 0.26 & 0.00 & 0.44 & 0.00 & 1.00 & 1.11 & -0.77 & 2572 & $99.96 \%$ \\
\hline Talking During Reading ${ }^{2}$ & 0.02 & 0.00 & 0.15 & 0.00 & 1.00 & 0.15 & 37.26 & 2572 & $99.96 \%$ \\
\hline
\end{tabular}

Next I examined linearity by looking at scatterplots in which EWIF/EFIW occurrence was plotted against each outcome. Scatterplots did not indicate non-linearity for the associations between EWIF/EFIW occurrence and outcomes.

Homogeneity of variance was tested by examining box and whisker plots for each participant on each outcome. Box and whisker plots were overlapping and relatively similar in size for each outcome, further confirming no issues for this assumption.

Homoscedasticity assumes error variance is normally distributed. I tested homoscedasticity by regressing EWIF/EFIW occurrence on each outcome and visually inspecting scatterplots of the predicted values against the residuals. Scatterplots did not indicate any residual outliers or abnormalities. 
Few observations had missing data on the variables of interest within-participants (maximum of 3.8\% missing data; see Table 5 and Table 6). When missing data are rare (less than 5\%), missing data are considered missing at random and missing data treatments are generally equivalent (Tabachnick \& Fidell, 2007). I opted to use pairwise deletion, which omits the missing data from relevant analyses. I used pairwise deletion, because it did not require any assumptions about how participants may have intended to respond, and it retained the most possible information for each analysis. Additionally, estimators used in the analyses (i.e., restricted maximum likelihood) are robust to missing data.

Not all participants had all 28 valid responses (see Table 8 and Table 9 below for valid response frequencies by person and time point, respectively; Mean valid responses $=25.73, \mathrm{SD}=$ 4.30). I examined the extent that participant-level response missingness was systematic by correlating the number of valid responses for each participant with baseline measures of each dependent variable (identical measures used with references altered to "in the last 30 days" where applicable; baseline negative affect $\alpha=.74$, baseline fatigue $\alpha=.86$ ). To examine factors that might explain why some participants may have more missing data than others, I also correlated the number of responses per person with baseline work-family conflict (Netemeyer, Boles, \& McMurrian, 1996; WIF $\alpha=.90$, FIW $\alpha=.87$ ), job demands (Spector $\&$ Jex, 1998; $\alpha=$ .87), family demands (marital status and parental status), and ESM start day of the week (Monday or Wednesday). Correlations are displayed in Table 10. The number of valid responses is only correlated with ESM start day of the week. Participants who started on Monday had more valid responses than those who started on Wednesday $(p<.05)$. Overall, I conclude missingness at the participant level was not associated with the outcomes of interest. 
To justify multilevel modeling, I computed unconditional models for each dependent variable (EWIF occurrence, EFIW occurrence, state fatigue, state negative affect, heart rate, systolic blood pressure, diastolic blood pressure, and unhealthy eating). Unconditional models were specified as having a level-1 (within day) outcome with no predictors and random intercepts. To determine whether multilevel modeling is statistically warranted, I compared the 2 log likelihood (i.e., deviance) statistics from a null model to a corresponding fixed-intercept general linear model. A chi square test was used to statistically compare the difference in $-2 \log$ likelihood; degrees of freedom were determined by computing the difference in the number of estimated parameters. A statistically significant $-2 \log$ likelihood difference indicates there is significant variability in the intercept, and multilevel modeling is warranted (Bliese \& Ployhart, 2002). Unconditional models were also used to examine the amount of variance at each of three possible nested levels (within day level, day level, person level). ICC(1)s indicating the amount of variance at each level were estimated by dividing the level-specific variability by the total variability (Raudenbush \& Bryk, 2002). The results of the $-2 \log$ likelihood comparisons and ICC(1)s are displayed in Table 11.

Table 8. Frequencies for number of valid responses per participant $(\mathrm{N}=100)$.

\begin{tabular}{ccc}
\hline Number of Responses & Frequency & Cumulative $\%$ \\
\hline 28 & 50 & $50 \%$ \\
27 & 15 & $65 \%$ \\
26 & 17 & $82 \%$ \\
24 & 2 & $84 \%$ \\
23 & 4 & $88 \%$ \\
22 & 2 & $90 \%$ \\
21 & 1 & $91 \%$ \\
19 & 1 & $92 \%$ \\
17 & 1 & $93 \%$ \\
16 & 1 & $94 \%$ \\
13 & 3 & $97 \%$ \\
12 & 1 & $98 \%$ \\
11 & 1 & $99 \%$ \\
7 & 1 & $100 \%$ \\
\hline
\end{tabular}


Table 9. Frequencies for number of valid responses per time point (possible total $\mathrm{N}=2800$ ).

\begin{tabular}{|c|c|c|c|c|c|c|c|c|}
\hline \multirow{3}{*}{$\begin{array}{l}\text { Response } \\
\text { Time }\end{array}$} & \multicolumn{2}{|c|}{ Day 1} & \multicolumn{2}{|c|}{ Day 2} & \multicolumn{2}{|c|}{ Day 3} & \multicolumn{2}{|c|}{ Days 4-7 } \\
\hline & Frequency & $\%$ of Total & Frequency & $\%$ of Total & Frequency & $\%$ of Total & Frequency & $\%$ of Total \\
\hline & $\begin{array}{r}\text { Responses } \\
95\end{array}$ & Possible & $\begin{array}{r}\text { Responses } \\
9 ?\end{array}$ & Possible & Responses & Possible & & Possible \\
\hline 8 AM & 95 & $95.00 \%$ & 92 & $92.00 \%$ & 96 & $96.00 \%$ & & \\
\hline $10 \mathrm{AM}$ & 95 & $95.00 \%$ & 94 & $94.00 \%$ & 94 & $94.00 \%$ & & \\
\hline $12 \mathrm{PM}$ & 96 & $96.00 \%$ & 95 & $95.00 \%$ & 94 & $94.00 \%$ & & \\
\hline 2 PM & 94 & $94.00 \%$ & 89 & $89.00 \%$ & 88 & $88.00 \%$ & & \\
\hline $4 \mathrm{PM}$ & 93 & $93.00 \%$ & 92 & $92.00 \%$ & 89 & $89.00 \%$ & & \\
\hline $6 \mathrm{PM}$ & 95 & $95.00 \%$ & 92 & $92.00 \%$ & 88 & $88.00 \%$ & & \\
\hline $8 \mathrm{PM}$ & 92 & $92.00 \%$ & 95 & $95.00 \%$ & 91 & $91.00 \%$ & & \\
\hline $10 \mathrm{PM}$ & 92 & $92.00 \%$ & 92 & $92.00 \%$ & 87 & $87.00 \%$ & 88 & $88.00 \%$ \\
\hline $10 \mathrm{PM}$ & & & & & & & 88 & $88.00 \%$ \\
\hline $10 \mathrm{PM}$ & & & & & & & 86 & $86.00 \%$ \\
\hline 10 PM & & & & & & & 91 & $91.00 \%$ \\
\hline
\end{tabular}

Table 10. Correlations between number of valid responses, dependent variables, baseline work-family conflict, job demands, and family demands, and ESM start day of the week $(\mathrm{N}=100)$.

\begin{tabular}{|c|c|c|c|c|c|c|c|c|c|c|c|c|c|c|}
\hline Variable & 1 & 2 & 3 & 4 & 5 & 6 & 7 & 8 & 9 & 10 & 11 & 12 & 13 & 14 \\
\hline 1. Valid responses & & & & & & & & & & & & & & \\
\hline 2. Baseline Negative Affect & .00 & & & & & & & & & & & & & \\
\hline 3. Baseline Fatigue & -.01 & $.49^{*}$ & & & & & & & & & & & & \\
\hline 4. Baseline Heart Rate & -.09 & .05 & .11 & & & & & & & & & & & \\
\hline 5. Baseline Systolic Blood Pressure & -.13 & .10 & -.08 & .05 & & & & & & & & & & \\
\hline 6. Baseline Diastolic Blood Pressure & .04 & .19 & -.01 & $.22 *$ & $.80 *$ & & & & & & & & & \\
\hline 7. Baseline Food Consumption & .02 & -.12 & -.05 & $.28 *$ & .07 & -.00 & & & & & & & & \\
\hline 8. Baseline WIF & -.08 & $.32 *$ & $.37 *$ & .07 & -.10 & -.13 & .08 & & & & & & & \\
\hline 9. Baseline FIW & -.05 & $.24 *$ & .16 & .07 & .06 & .04 & .06 & $.65 *$ & & & & & & \\
\hline 10. Job Demands & -.17 & .09 & $.26^{*}$ & .11 & .07 & .04 & -.01 & $.33^{*}$ & .10 & & & & & \\
\hline 11. Sex & -.05 & .07 & $.27 *$ & .18 & $-.31 *$ & $-.24 *$ & -.01 & -.04 & -.09 & .01 & & & & \\
\hline 12. Age & -.10 & -.05 & -.13 & .01 & .13 & .10 & -.05 & -.07 & .09 & .10 & .06 & & & \\
\hline 13. Marital Status & .20 & -.14 & -.06 & .03 & -.18 & -.03 & .08 & -.16 & -.10 & .07 & -.05 & -.09 & & \\
\hline 14. Parental Status & -.04 & -.01 & .12 & .19 & $.26 *$ & $.23 *$ & .08 & .04 & $.34 *$ & -.05 & .03 & $.42 *$ & -.05 & \\
\hline 15. ESM Start Day & $-.22 *$ & -.04 & .05 & -.09 & .05 & -.09 & -.16 & -.03 & -.12 & -.13 & -.02 & -.07 & -.18 & .05 \\
\hline
\end{tabular}


Table 11. Unconditional model parameters, ICCs, -2 log likelihood difference for each dependent variable.

\begin{tabular}{|c|c|c|c|c|c|c|c|c|}
\hline Parameter & $\begin{array}{c}\text { EWIF } \\
\text { Occurrence }\end{array}$ & $\begin{array}{c}\text { EFIW } \\
\text { Occurrence }\end{array}$ & State FA & State NA & HR & SBP & DBP & $\begin{array}{l}\text { Unhealthy } \\
\text { Eating }\end{array}$ \\
\hline Intercept & $0.08^{*}$ & $0.10^{*}$ & $1.72 *$ & $1.22 *$ & $79.19 *$ & $113.19 *$ & $70.93 *$ & $1.34 *$ \\
\hline$\sigma^{2}$ & 0.07 & 0.08 & 0.33 & 0.06 & 107.87 & 86.37 & 61.70 & 0.60 \\
\hline$\tau_{00}$ & 0.00 & 0.00 & 0.11 & 0.03 & 14.23 & 0.00 & 0.00 & 1.24 \\
\hline$\tau_{000}$ & 0.01 & 0.01 & 0.23 & 0.06 & 88.76 & 99.13 & 46.26 & 0.26 \\
\hline$-2 \mathrm{LL}$ & 635.25 & 850.60 & 5181.34 & 836.34 & 16258.92 & 15661.18 & 14918.47 & 796.20 \\
\hline \multicolumn{9}{|l|}{ ICC } \\
\hline Level 2 & .00 & .00 & .16 & .20 & .07 & .00 & .00 & .59 \\
\hline Level 3 & .13 & .11 & .34 & .40 & .42 & .53 & .43 & .12 \\
\hline$\Delta-2 \mathrm{LL}$ & $77.82 *$ & $181.42 *$ & $969.67 *$ & $1144.97 *$ & $1030.50 *$ & $1281.37^{*}$ & $868.18^{*}$ & $577.27^{*}$ \\
\hline \multicolumn{9}{|c|}{$\begin{array}{l}\text { Note. } \sigma^{2}=\text { Within day (level 1) variance. } \tau_{00}=\text { Day }(\text { level } 2) \text { variance. } \tau_{000}=\text { Person (level 3) variance. }-2 \mathrm{LL}=-2 \\
\log \text { likelihood (deviance) for the unconditional model. ICC }=\text { Intraclass correlation. } \Delta-2 \mathrm{LL}=\text { Difference in }-2 \\
\log \text { likelihood from the random effects unconditional model compared to the fixed-effects general linear model. } \\
* p<.01 . \text { EWIF = Episodic work-to-family conflict. EFIW = Episodic family-to-work conflict. NA = Negative } \\
\text { affect. FA = Fatigue. HR = Heart rate. SBP = Systolic blood pressure. DBP = Diastolic blood pressure. All } \\
\text { models estimated using REML to allow for comnarison to a general linear model. }\end{array}$} \\
\hline
\end{tabular}

All comparisons of $-2 \log$ likelihood were significant $(p<.01)$, indicating that multilevel modeling was warranted for all outcomes. Consistent with previous research (Barnett, 2016; Shockley \& Allen, 2013), there was little to no day-level variability for EWIF occurrence, EFIW occurrence, systolic blood pressure, or diastolic blood pressure). All subsequent analyses for these outcomes were specified as two level models (time nested within person). As an exception, Hypotheses $3 \mathrm{a}$ and $3 \mathrm{~b}$ predicted day of the week was associated with EWIF/EFIW occurrence. Because Hypotheses $3 \mathrm{a}$ and $3 \mathrm{~b}$ were a priori hypotheses that concerned the effects of the second (day) level on the first (time) level, I tested them using three-level models. There was substantial day level variance for state fatigue, state negative affect, heart rate, and unhealthy eating, with a minimum of $6.75 \%$ variability accounted for at the day level. All subsequent analyses for these outcomes were specified as three level models (time nested within days nested within person). 


\section{Hypothesis Testing}

Hypothesis testing was conducted using multi-level (i.e., mixed) modeling in R using the 'multilevel' package (Bliese, 2016a) or the 'lme4' package when analyzing binary outcomes (Bates, Maechler, Bolker, \& Walker, 2015). Analytical procedures were guided by the 'multilevel' and 'Ime4' package user guides (Bliese, 2016b; Bates et al., 2015) and published guidelines (Bliese \& Ployhart, 2002; Bliese \& Lang, 2016). Multi-level modeling allows estimation of the relationship between boundary crossing time windows and EWIF/EFIW occurrence while accounting for the nested nature of the data (Raudenbush \& Bryk, 2002). In addition, multilevel modeling is a common method to examine change across time (Raudenbush \& Bryk, 2002; Singer \& Willett, 2003).

All analyses with cardiovascular dependent variables were run with and without cardiovascular controls to examine effects when controlling for error variability that is known to influence cardiovascular readings (see Planned Post-Hoc Analyses). No other controls were used in the following analyses.

\section{Timing of EWIF/EFIW Hypotheses}

Hypotheses 1-3 regarding timing of conflict were tested using logistic multilevel models. The outcome variables (EWIF, EFIW) were dichotomously scored, such that $0=$ no conflict and $1=$ a conflict occurrence. EWIF, EFIW, and all transition variables were specified as factors in R to reflect the fact that they were categorical. Data from the first three days were used to test Hypothesis 1, and data from all seven days were used to test Hypothesis 2 and Hypothesis 3 (see Figure 4). Transitions were left uncentered to aid interpretation of the dichotomous outcome (Bliese, 2016; Tofighi \& Enders, 2007). For each analysis, coefficients can be interpreted as change in EWIF/EFIW when a transition occurs relative to no transition occurrence (i.e., 1 vs. 0 ). 
All models included random intercepts. To test Hypothesis 1, temporal and spatial transition occurrence were each entered separately as level 1 uncentered predictors of EWIF/EFIW occurrence. Morning and afternoon scheduled transitions were also entered separately as a level 1 uncentered predictors of EWIF/EFIW occurrence (Hypothesis 2). Finally, beginning of week and end of week transitions were entered separately as level 2 uncentered predictors of level 1 EWIF/EFIW occurrence (Hypothesis 3). Results are presented in the form of odds ratios. Odds ratios describe the likelihood of an occurrence. For Hypotheses 1-3, an odds ratio with a confidence interval above and excluding 1.00 indicated a greater likelihood of experiencing an EWIF/EFIW and support of the hypotheses.

Results for Hypothesis 1-3 are presented in Table 12. Hypothesis 1 stated that EWIF/EFIW are more likely to occur during time windows in which participants (a) spatially or (b) temporally transition between work and family compared to times in which participants do not transition. This hypothesis was fully supported. Individuals who temporally transitioned between work and family were approximately 8.90 times more likely to experience an EWIF and 7.27 times more likely to experience an EFIW than individuals who did not experience a temporal transition $(p<.01)$. In addition, those who transitioned between work and family spaces were 4.01 times more likely to experience EWIF and 3.29 times more likely to experience EFIW than when there was no transition between work and family spaces $(p<.01)$.

Hypothesis 2 stated that individuals were more likely to experience EWIF/EFIW during morning (a) and afternoon (b) scheduled transitions compared to non-transition times. Individuals were 2.77 times more likely to experience EFIW during a morning transition compared to a non-morning transition time $(\mathrm{p}<.01)$; however morning transitions were not associated with EWIF $(O R=0.87, p=.51)$. Afternoon transitions were associated with EWIF 
$(O R=1.53, p=.02)$ and with EFIW $(O R=0.54, p<.01)$. However, the directionality for EFIW was in the opposite of the predicted direction, such that individuals were less likely to have an EFIW during afternoon transitions compared to other times of the day. Thus, Hypothesis 2 received partial support. Finally, Hypothesis 3 stated that individuals were more likely to experience EWIF/EFIW during beginning and end of the week transition days compared to other days. This hypothesis was not supported by the data, as all odds ratio confidence intervals included $1.00(p>.05)$.

Table 12. Results for Hypotheses 1-3.

\begin{tabular}{|c|c|c|c|c|c|c|c|}
\hline Hypothesis & Intercept & $\begin{array}{l}\text { Odds } \\
\text { Ratio }\end{array}$ & $\begin{array}{c}95 \% \\
\text { CI LL }\end{array}$ & $\begin{array}{c}95 \% \\
\text { CI UL }\end{array}$ & $\begin{array}{c}\text { Level } 2 \\
\text { variance }\end{array}$ & $\begin{array}{c}\text { Level } 3 \\
\text { variance }\end{array}$ & $\begin{array}{c}\text { Hypothesis } \\
\text { Testing } \\
\text { Results }\end{array}$ \\
\hline 1a. EWIF and Temporal & $.02 * *$ & $8.90 * *$ & 5.88 & 13.46 & 0.88 & NA & Supported \\
\hline 1a. EFIW and Temporal & $.02 * *$ & $7.27 * *$ & 5.09 & 10.38 & 0.92 & NA & Supported \\
\hline 1b. EWIF and Spatial & $.03 * *$ & $4.01 * *$ & 2.77 & 5.79 & 1.07 & NA & Supported \\
\hline 1b. EFIW and Spatial & $.04 * *$ & $2.39 * *$ & 1.70 & 3.35 & 1.84 & NA & $\begin{array}{l}\text { Supported } \\
\text { Not }\end{array}$ \\
\hline 2a. EWIF and Morning & $.06 * *$ & 0.87 & 0.57 & 1.33 & 1.06 & NA & Supported \\
\hline 2a. EFIW and Morning & $.05^{* *}$ & $2.77 * *$ & 1.98 & 3.89 & 1.81 & NA & Supported \\
\hline 2b. EWIF and Afternoon & $.06^{* *}$ & $1.53 *$ & 1.06 & 2.21 & 1.07 & NA & $\begin{array}{l}\text { Supported } \\
\text { Not }\end{array}$ \\
\hline 2b. EFIW and Afternoon & $.06^{* *}$ & $0.54 * *$ & 0.34 & 0.86 & 1.70 & NA & $\begin{array}{l}\text { Supported } \\
\text { Not }\end{array}$ \\
\hline 3a. EWIF and Beginning of Week & $.06 * *$ & 0.95 & 0.64 & 1.41 & 0.00 & 1.03 & $\begin{array}{l}\text { Supported } \\
\text { Not }\end{array}$ \\
\hline 3a. EFIW and Beginning of Week & $.06^{* *}$ & 1.15 & 0.79 & 1.68 & 0.07 & 1.62 & $\begin{array}{l}\text { Supported } \\
\text { Not }\end{array}$ \\
\hline 3b. EWIF and End of Week & $.06 * *$ & 0.89 & 0.57 & 1.40 & 0.00 & 1.03 & $\begin{array}{l}\text { Supported } \\
\text { Not }\end{array}$ \\
\hline 3b. EFIW and End of Week & $.06 * *$ & 0.67 & 0.41 & 1.10 & 0.05 & 1.62 & supported \\
\hline
\end{tabular}
$* p<.05 . * * p<.01$.

\section{EWIF/EFIW and Strain Hypotheses}

Hypotheses 4-9 regarding EWIF/EFIW and strain reactivity and recovery were tested using discontinuous random coefficients growth modeling (see Llabre et al., 2001 for a similar approach to examining reactivity and recovery; Bliese \& Ployhart, 2002; Raudenbush \& Bryk, 
2002; Singer \& Willett, 2003). Only data from the first three days (Monday-Wednesday) were used for these analyses. Because missing data was relatively rare, and the nature of missingness was random (see Tables 8 and 9 above; see for example Table 13, Participant 2, Day 1), all participants' available observations were used. Participants who experienced no EWIF/EFIWs during the first three days ( $\mathrm{N}=41$ for EWIF and $\mathrm{N}=41$ for EFIW) were included in the analysis to estimate pre-conflict trajectories (for an example of coding for non-conflict days, see Table 13, Participant 1, Day 2; Singer \& Willett, 2003).

Because data from only the first three days were used, 73 focal EWIFs and 47 focal EFIWs were omitted because they were reported during the last four days of the week. Thus, 141 focal EWIFs and 199 focal EFIWs occurred during the first three days. Some participants also reported EWIF/EFIW at multiple time points in one day. Multiple daily focal EWIFs occurred on 27 days across 20 participants, and multiple daily focal EFIWs occurred on 42 days across 30 participants. In these cases, only the first conflict of the day was included for the hypothesized analyses (see for example Table 13, Participant 2, Day 2). After omitting multiple focal EWIF/EFIWs within a day, 106 focal EWIFs and 123 focal EFIWs were retained. Figure 4 visually outlines each of these steps.

Table 14 displays frequencies regarding when the first focal EWIF/EFIWs occurred throughout the three days. The average length of recovery for the first focal EWIF of the day was 1.25 time points, and the average length of recovery for the first focal EFIW of the day was 1.70 time points. Detailed frequencies for the length of recovery are displayed in Table 15. EWIFs occurred 61 minutes and one second before a participant's response on average ( $\mathrm{SD}=00: 39: 36$, Minimum $=00: 00: 01$, Maximum $=3: 12: 52$ ), and EFIWs occurred 53 minutes and 41 seconds before a participant's response on average $(\mathrm{SD}=00: 42: 15$, Minimum $=00: 00: 01$, Maximum $=$ 
3:42:16). Frequencies for the lagged time between an EWIF/EFIW occurrence and response to a signal are displayed in Table 16.

Several time parameters were computed for growth modeling analyses. Linear time was centered at the first time point of the day ( $8 \mathrm{AM})$; thus, the intercept reflects the value of strain at the beginning of the day. The linear time coding assumes days are interchangeable. This assumption is made due to evidence showing circadian patterns in physiology and psychology, with sleep positioned as a restorative event that resets these daily patterns (de Castro, 1987; Dijk, Duffy, \& Czeisler, 1992; Golder \& Macy, 2011; Guo \& Stein, 2003; Hülsheger, 2016). In support, previous research shows little day-level variability in strain outcomes (e.g., Barnett, 2016; Shockley \& Allen, 2013; Hülsheger, 2016). To test the reactivity hypotheses (Hypotheses 4-6), a discontinuous intercept parameter (i.e., reactivity) was computed to examine the synchronous change in strain when an EWIF/EFIW occurs (Table 12). To test the recovery hypotheses (Hypotheses 7-9), piecewise slopes (i.e., linear recovery, quadratic recovery, and cubic recovery) and were coded and entered as predictors of strain to examine post-EWIF/EFIW trajectories (Table 3; Bliese \& Lang, 2016; Raudenbush \& Bryk, 2002; Singer \& Willett, 2003). 
Table 13. Sample coding for discontinuous growth modeling.

\begin{tabular}{|c|c|c|c|c|c|c|c|c|c|c|c|}
\hline \multirow[b]{3}{*}{ Participant } & \multirow[b]{3}{*}{ Time } & \multirow[b]{3}{*}{$\begin{array}{l}\text { EWIF/ } \\
\text { EFIW }\end{array}$} & \multicolumn{7}{|c|}{ Discontinuous } & \multirow{2}{*}{\multicolumn{2}{|c|}{ Accumulation Slopes }} \\
\hline & & & \multicolumn{2}{|c|}{ Time } & \multirow{2}{*}{$\begin{array}{c}\text { DV } \\
\text { Heart } \\
\text { Rate }\end{array}$} & \multirow{2}{*}{$\begin{array}{l}\text { Intercept } \\
\text { Reactivity }\end{array}$} & \multicolumn{3}{|c|}{ Piecewise Slopes } & & \\
\hline & & & Daily & $\begin{array}{l}\text { Three } \\
\text { Day }\end{array}$ & & & $\begin{array}{c}\text { Linear } \\
\text { Recovery }\end{array}$ & $\begin{array}{l}\text { Quadratic } \\
\text { Recovery }\end{array}$ & $\begin{array}{c}\text { Cubic } \\
\text { Recovery }\end{array}$ & $\begin{array}{l}\text { Linear Daily } \\
\text { Accumulation }\end{array}$ & $\begin{array}{c}\text { Linear Three Day } \\
\text { Accumulation }\end{array}$ \\
\hline 1 (Day 1) & $8: 00$ & 0 & 0 & 0 & 78 & 0 & 0 & 0 & 0 & 0 & 0 \\
\hline 1 (Day 1$)$ & $10: 00$ & 0 & 1 & 1 & 79 & 0 & 0 & 0 & 0 & 0 & 0 \\
\hline 1 (Day 1) & $12: 00$ & 0 & 2 & 2 & 74 & 0 & 0 & 0 & 0 & 0 & 0 \\
\hline 1 (Day 1) & $14: 00$ & 0 & 3 & 3 & 76 & 0 & 0 & 0 & 0 & 0 & 0 \\
\hline 1 (Day 1) & $16: 00$ & 1 & 4 & 4 & 89 & 1 & $\mathbf{0}$ & $\mathbf{0}$ & $\mathbf{0}$ & 1 & 1 \\
\hline 1 (Day 1) & $18: 00$ & 0 & 5 & 5 & 82 & 1 & 1 & 1 & 1 & 1 & 1 \\
\hline 1 (Day 1) & $20: 00$ & 0 & 6 & 6 & 81 & 1 & 2 & 4 & 8 & 1 & 1 \\
\hline 1 (Day 1) & $22: 00$ & 0 & 7 & 7 & 74 & 1 & 3 & 9 & 27 & 1 & 1 \\
\hline 1 (Day 2) & $8: 00$ & 0 & 0 & 12 & 67 & 0 & 0 & 0 & 0 & 0 & 1 \\
\hline 1 (Day 2) & $10: 00$ & 0 & 1 & 13 & 68 & 0 & 0 & 0 & 0 & 0 & 1 \\
\hline 1 (Day 2) & $12: 00$ & 0 & 2 & 14 & 74 & 0 & 0 & 0 & 0 & 0 & 1 \\
\hline 1 (Day 2) & $14: 00$ & 0 & 3 & 15 & 88 & 0 & 0 & 0 & 0 & 0 & 1 \\
\hline 1 (Day 2) & $16: 00$ & 0 & 4 & 16 & 76 & 0 & 0 & 0 & 0 & 0 & 1 \\
\hline 1 (Day 2) & $20: 00$ & 0 & 6 & 18 & 75 & 0 & 0 & 0 & 0 & 0 & 1 \\
\hline 1 (Day 2) & $22: 00$ & 0 & 7 & 19 & 72 & 0 & 0 & 0 & 0 & 0 & 1 \\
\hline 2 (Day 1) & $8: 00$ & 0 & 0 & 0 & 66 & 0 & 0 & 0 & 0 & 0 & 0 \\
\hline 2 (Day 1) & $10: 00$ & 0 & 1 & 1 & 70 & 0 & 0 & 0 & 0 & 0 & 0 \\
\hline 2 (Day 1) & $12: 00$ & 2 & 2 & 2 & 75 & 1 & 0 & $\mathbf{0}$ & $\mathbf{0}$ & 2 & 2 \\
\hline 2 (Day 1) & $14: 00$ & 0 & 3 & 3 & 80 & 1 & 1 & 1 & 1 & 2 & 2 \\
\hline 2 (Day 1) & $16: 00$ & 0 & 4 & 4 & 85 & 1 & 2 & 4 & 8 & 2 & 2 \\
\hline 2 (Day 1) & $22: 00$ & 0 & 7 & 7 & 84 & 1 & 5 & 25 & 125 & 2 & 2 \\
\hline 2 (Day 2) & $8: 00$ & 0 & 0 & 12 & 67 & 0 & 0 & 0 & 0 & 0 & 2 \\
\hline 2 (Day 2) & $10: 00$ & 1 & 1 & 13 & 68 & 1 & $\mathbf{0}$ & $\mathbf{0}$ & $\mathbf{0}$ & 1 & 3 \\
\hline 2 (Day 2) & $12: 00$ & 0 & 2 & 14 & 74 & 1 & 1 & 1 & 1 & 1 & 3 \\
\hline 2 (Day 2) & $14: 00$ & 0 & 3 & 15 & 88 & 1 & 2 & 4 & 8 & 1 & 3 \\
\hline 2 (Day 2) & $16: 00$ & 0 & 4 & 16 & 76 & 1 & 3 & 9 & 27 & 1 & 3 \\
\hline 2 (Day 2) & $18: 00$ & 1 & 5 & 17 & 68 & $\mathbf{0}$ & 3 & 9 & 27 & 2 & 4 \\
\hline 2 (Day 2) & $20: 00$ & 0 & 6 & 18 & 75 & 0 & 3 & 9 & 27 & 2 & 4 \\
\hline 2 (Day 2$)$ & $22: 00$ & 0 & 7 & 19 & 72 & 0 & 3 & 9 & 27 & 2 & 4 \\
\hline
\end{tabular}


Table 14. Frequencies of EWIF/EFIW by signal time and day.

\begin{tabular}{|c|c|c|c|c|c|c|c|c|}
\hline \multirow{2}{*}{$\begin{array}{c}\text { Signal } \\
\text { Reported }\end{array}$} & \multicolumn{2}{|c|}{$\begin{array}{c}\text { Day } 1 \\
\text { Frequencies }\end{array}$} & \multicolumn{2}{|c|}{$\begin{array}{c}\text { Day } 2 \\
\text { Frequencies }\end{array}$} & \multicolumn{2}{|c|}{$\begin{array}{c}\text { Day } 3 \\
\text { Frequencies } \\
\end{array}$} & \multicolumn{2}{|c|}{$\begin{array}{c}\text { Total } \\
\text { Frequencies }\end{array}$} \\
\hline & EWIF & EFIW & EWIF & EFIW & EWIF & EFIW & EWIF & EFIW \\
\hline $8 \mathrm{AM}$ & 14 & 9 & 3 & 6 & 6 & 10 & 23 & 25 \\
\hline $10 \mathrm{AM}$ & 6 & 17 & 2 & 15 & 4 & 13 & 12 & 45 \\
\hline 12 PM & 2 & 3 & 1 & 4 & 6 & 8 & 9 & 15 \\
\hline $2 \mathrm{PM}$ & 2 & 9 & 4 & 5 & 2 & 1 & 8 & 15 \\
\hline $4 \mathrm{PM}$ & 3 & 6 & 2 & 1 & 2 & 5 & 7 & 12 \\
\hline $6 \mathrm{PM}$ & 4 & 1 & 13 & 1 & 5 & 1 & 22 & 3 \\
\hline $8 \mathrm{PM}$ & 3 & 1 & 7 & 3 & 4 & 1 & 14 & 5 \\
\hline $10 \mathrm{PM}$ & 6 & 1 & 1 & 0 & 4 & 0 & 11 & 1 \\
\hline Total: & 40 & 47 & 33 & 35 & 33 & 39 & 106 & 121 \\
\hline
\end{tabular}

Note. Total frequencies bolded for ease of interpretation.

Table 15. Frequencies for number of EWIF/EFIW per day and length of recovery.

\begin{tabular}{|c|c|c|c|c|c|c|c|c|c|c|c|}
\hline \multirow[b]{2}{*}{$\begin{array}{c}\text { Conflict } \\
\text { Direction }\end{array}$} & \multirow[b]{2}{*}{$\begin{array}{c}\mathrm{N}^{\text {th }} \text { EWIF/EFIW } \\
\text { each Day }\end{array}$} & \multirow[b]{2}{*}{ Frequency } & \multicolumn{9}{|c|}{ Recovery Length in Time Points } \\
\hline & & & 1 & 2 & 3 & 4 & 5 & 6 & 7 & 8 & Mean \\
\hline \multirow{5}{*}{ EWIF } & 0 & 192 & & & & & & & & & \\
\hline & 1 & 107 & 23 & 21 & 19 & 13 & 8 & 9 & 7 & 7 & 1.25 \\
\hline & 2 & 27 & 7 & 6 & 4 & 7 & 3 & 0 & 0 & 0 & 2.74 \\
\hline & 3 & 7 & 1 & 1 & 4 & 1 & 0 & 0 & 0 & 0 & 2.71 \\
\hline & 4 & 1 & 0 & 1 & 0 & 0 & 0 & 0 & 0 & 0 & 2.00 \\
\hline \multirow[t]{7}{*}{ EFIW } & 0 & 178 & & & & & & & & & \\
\hline & 1 & 121 & 28 & 14 & 7 & 14 & 12 & 13 & 26 & 7 & 1.70 \\
\hline & 2 & 42 & 16 & 6 & 7 & 4 & 4 & 4 & 2 & 0 & 2.88 \\
\hline & 3 & 19 & 9 & 1 & 4 & 3 & 2 & 0 & 0 & 0 & 2.37 \\
\hline & 4 & 11 & 5 & 1 & 1 & 4 & 0 & 0 & 0 & 0 & 2.36 \\
\hline & 5 & 4 & 2 & 1 & 0 & 1 & 0 & 0 & 0 & 0 & 2.00 \\
\hline & 6 & 2 & 0 & 1 & 1 & 0 & 0 & 0 & 0 & 0 & 2.50 \\
\hline
\end{tabular}

Table 16. Frequencies of time between EWIF/EFIW and response.

\begin{tabular}{lrrrrr}
\hline \multirow{2}{*}{ Time between EWIF/EFIW and } & \multicolumn{2}{c}{ EWIF } & & \multicolumn{2}{c}{ EFIW } \\
\cline { 2 - 3 } \cline { 5 - 6 } \multicolumn{1}{c}{ Response } & Frequency & Cumulative $\%$ & & Frequency & Cumulative \% \\
\hline Less than 15 minutes & 9 & $8.49 \%$ & & 15 & $12.40 \%$ \\
$15-30$ minutes & 13 & $20.75 \%$ & & 19 & $28.10 \%$ \\
$30-45$ minutes & 18 & $37.74 \%$ & & 24 & $47.93 \%$ \\
$45-60$ minutes & 13 & $50.00 \%$ & & 19 & $63.64 \%$ \\
$60-75$ minutes & 19 & $67.92 \%$ & & 18 & $78.51 \%$ \\
$75-90$ minutes & 11 & $78.30 \%$ & & 6 & $83.47 \%$ \\
$90-105$ minutes & 5 & $83.02 \%$ & & 7 & $89.26 \%$ \\
$105-120$ minutes & 9 & $91.51 \%$ & & 5 & $93.39 \%$ \\
$120-135$ minutes & 5 & $96.23 \%$ & & 2 & $95.04 \%$ \\
$135-150$ minutes & 1 & $97.17 \%$ & & 0 & $95.04 \%$ \\
$150-165$ minutes & 2 & $99.06 \%$ & & 1 & $95.87 \%$ \\
$165-180$ minutes & 0 & $99.06 \%$ & & 2 & $97.52 \%$ \\
More than 180 minutes & 1 & $100.00 \%$ & & 3 & $100.00 \%$ \\
\hline
\end{tabular}


For each strain outcome, models were built from most simple (unconditional model with no time parameters) to most complex (all reactivity and recovery parameters), following published recommendations (Bliese \& Lang, 2016; Singer \& Willett, 2003). Models were estimated using restricted maximum likelihood, because it is more conservative and less biased than maximum likelihood (Bliese \& Ployhart, 2002). One limitation is that restricted maximum likelihood can only be used to compare models that differ on random effects, but not fixed effects. For interpreting significance of fixed effects, I focused on the statistical significance of individual fixed parameters (Bliese \& Ployhart, 2002). The model for each outcome with the most complex significant reactivity and recovery terms was retained for interpretation. In the event that no reactivity or recovery parameters were significant, I defaulted to the most parsimonious model containing reactivity and linear recovery for exploring variability (Bliese \& Lang, 2016). A positive, significant reactivity parameter indicated support for Hypotheses 4-6. A significant reactivity parameter would be interpreted as the increase on the dependent variable when an EWIF/EFIW occurs compared to when there is no EWIF/EFIW (Bliese \& Lang, 2016). A significant reactivity parameter showing decline across time indicated support for Hypotheses 7. For interpreting significance of random effects, retained fixed effects models were compared to counterpart models in which the reactivity and recovery slopes were allowed to vary. Models were compared using the $-2 \log$ likelihood ratio test, AIC, and BIC (Bliese \& Ployhart, 2002; Bliese, 2016). A significant improvement in model fit when varying the reactivity parameter indicated support for Hypothesis 8, and a significant improvement in model fit when varying the recovery parameter indicated support for Hypothesis 9. 
Substantial day level variability was found for state fatigue, state negative affect, heart rate, and unhealthy eating. State negative affect, state fatigue, heart rate, and unhealthy eating were therefore modeled in the following analyses by specifying all three levels (within day, day, person). Systolic blood pressure and diastolic blood pressure were modeled by specifying only two levels (within day, person). I also examined figures displaying each participant's data points within a day to visually assess variability in each outcome's intercept and change over time. The figures are displayed below for state fatigue (Figure 5), state negative affect (Figure 6), heart rate (Figure 7), systolic blood pressure (Figure 8), diastolic blood pressure (Figure 9), and unhealthy food consumption (Figure 10). Overall the unconditional models and figures support examining change each outcome over time.

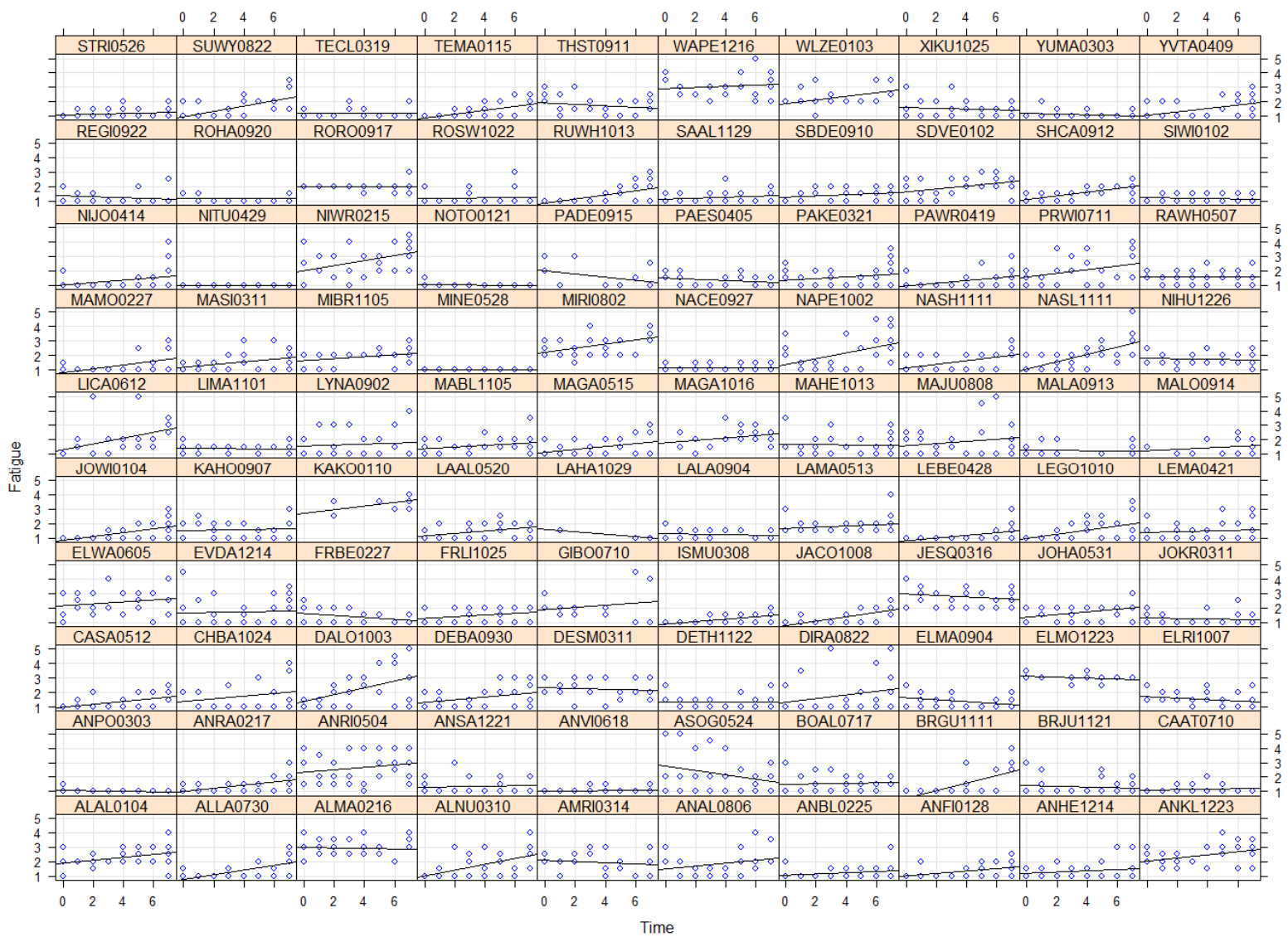

Figure 5. State fatigue over the first three days by participant ID. 


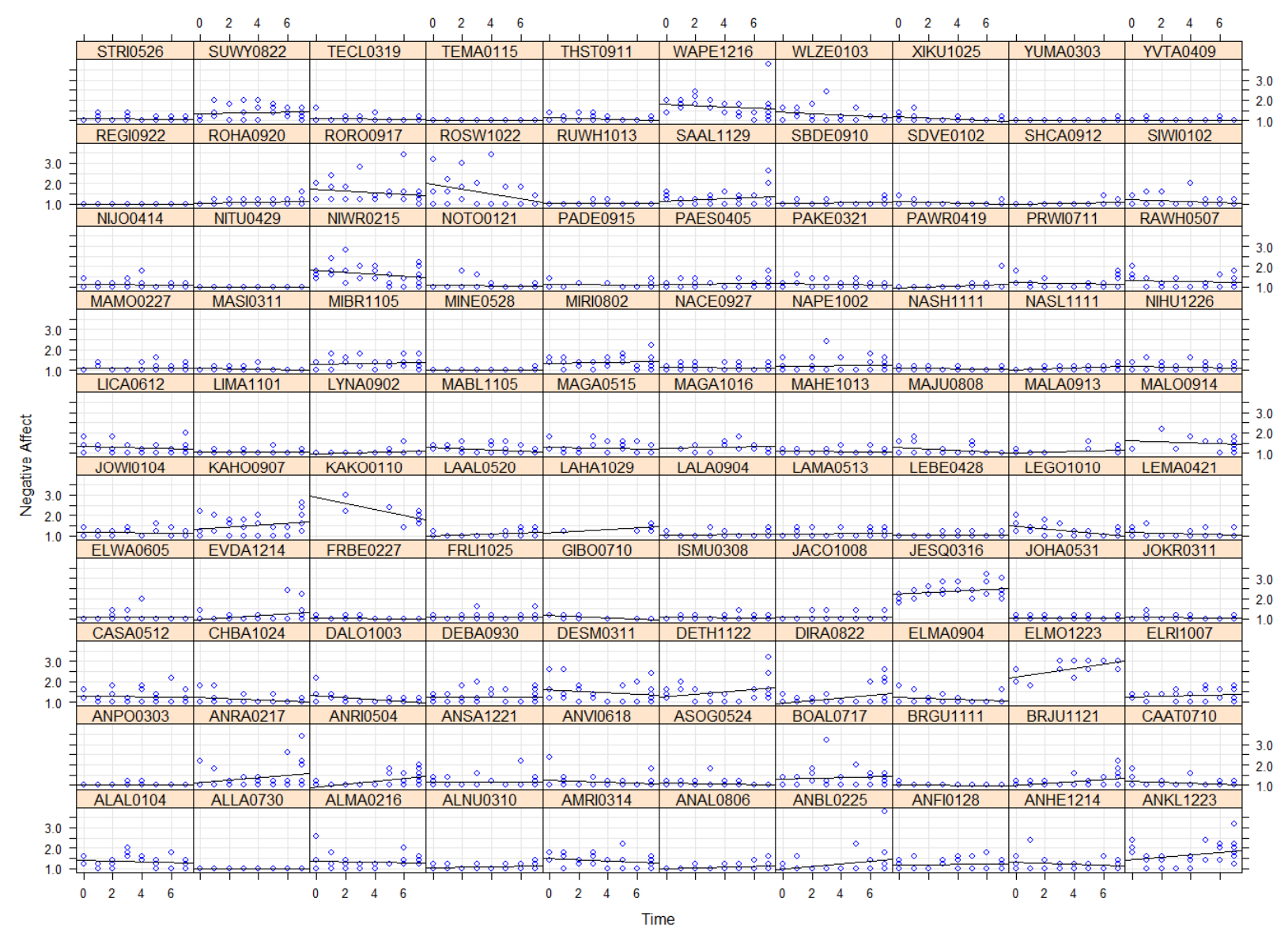

Figure 6. State negative affect over the first three days by participant ID. 


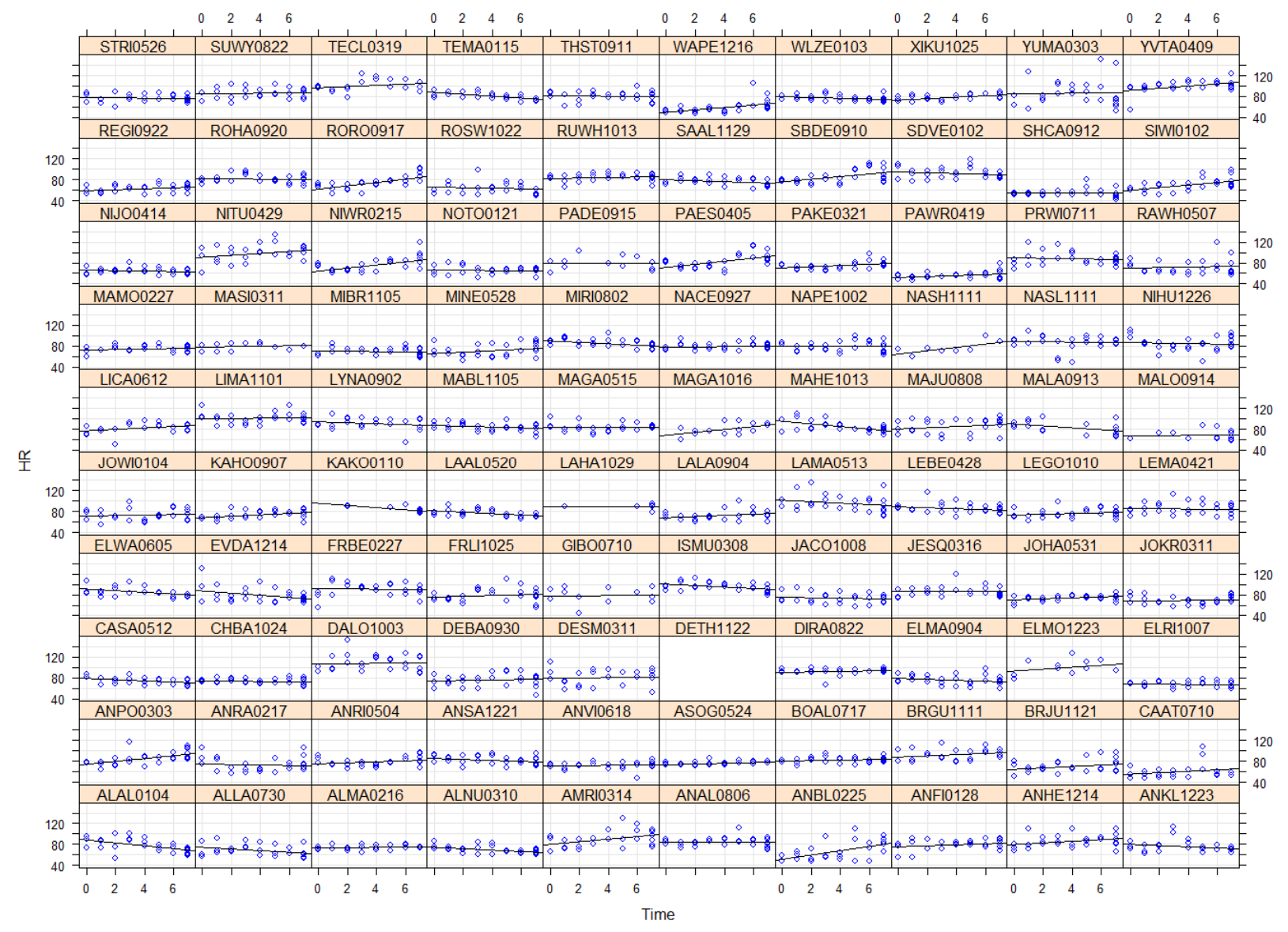

Figure 7. Heart rate over the first three days by participant ID. 


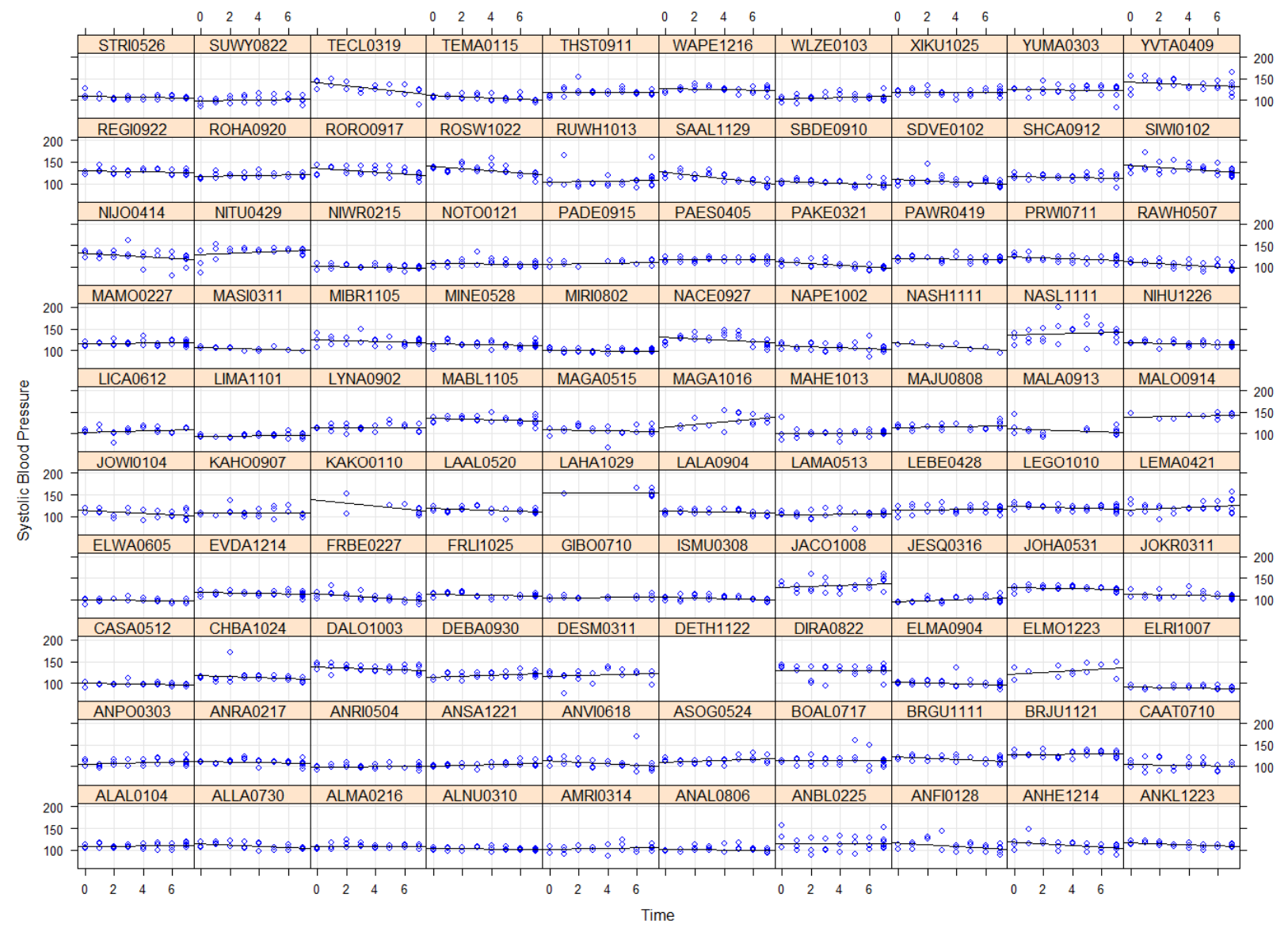

Figure 8. Systolic blood pressure over the first three days by participant ID. 


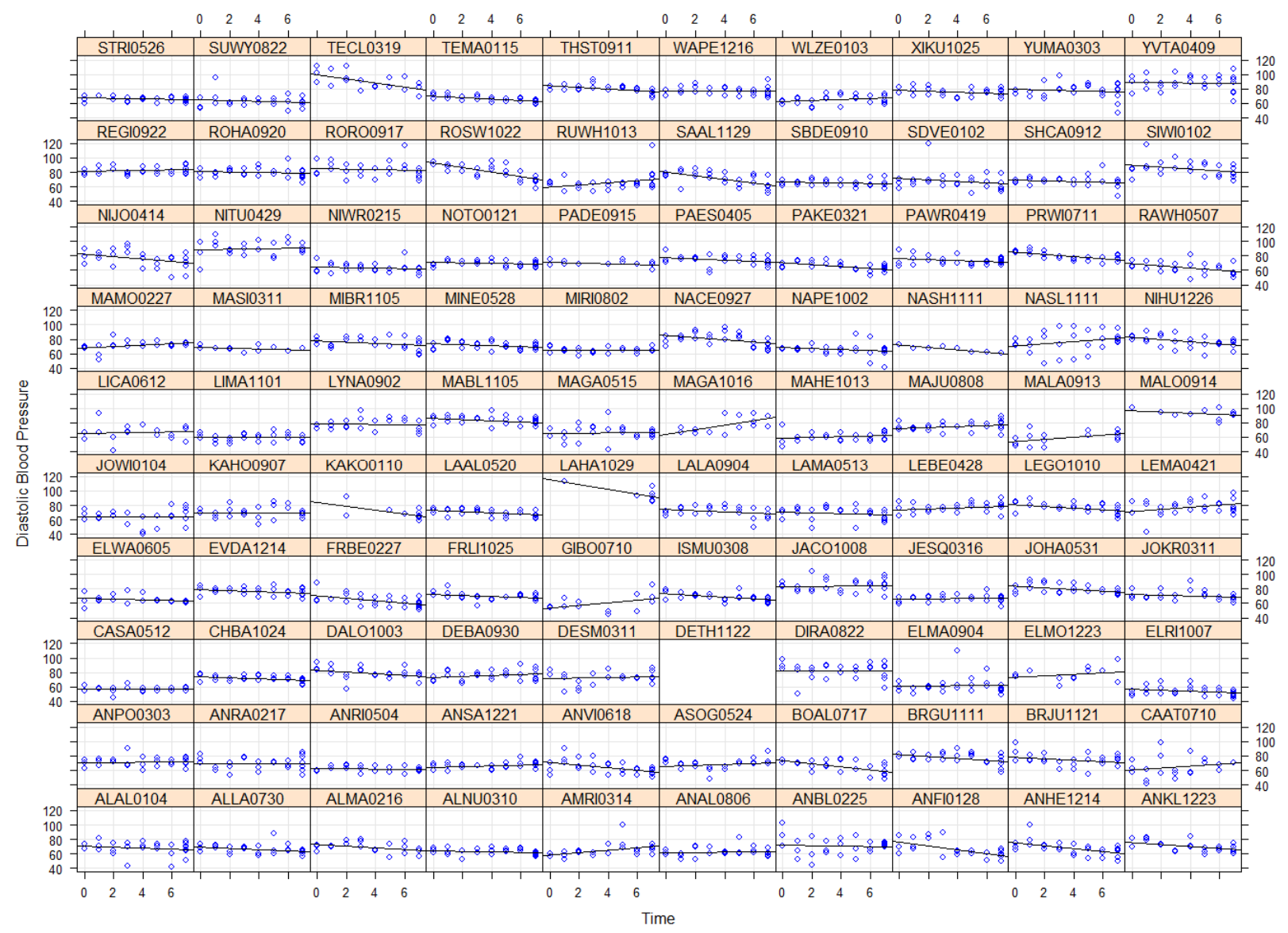

Figure 9. Diastolic blood pressure over the first three days by participant ID. 


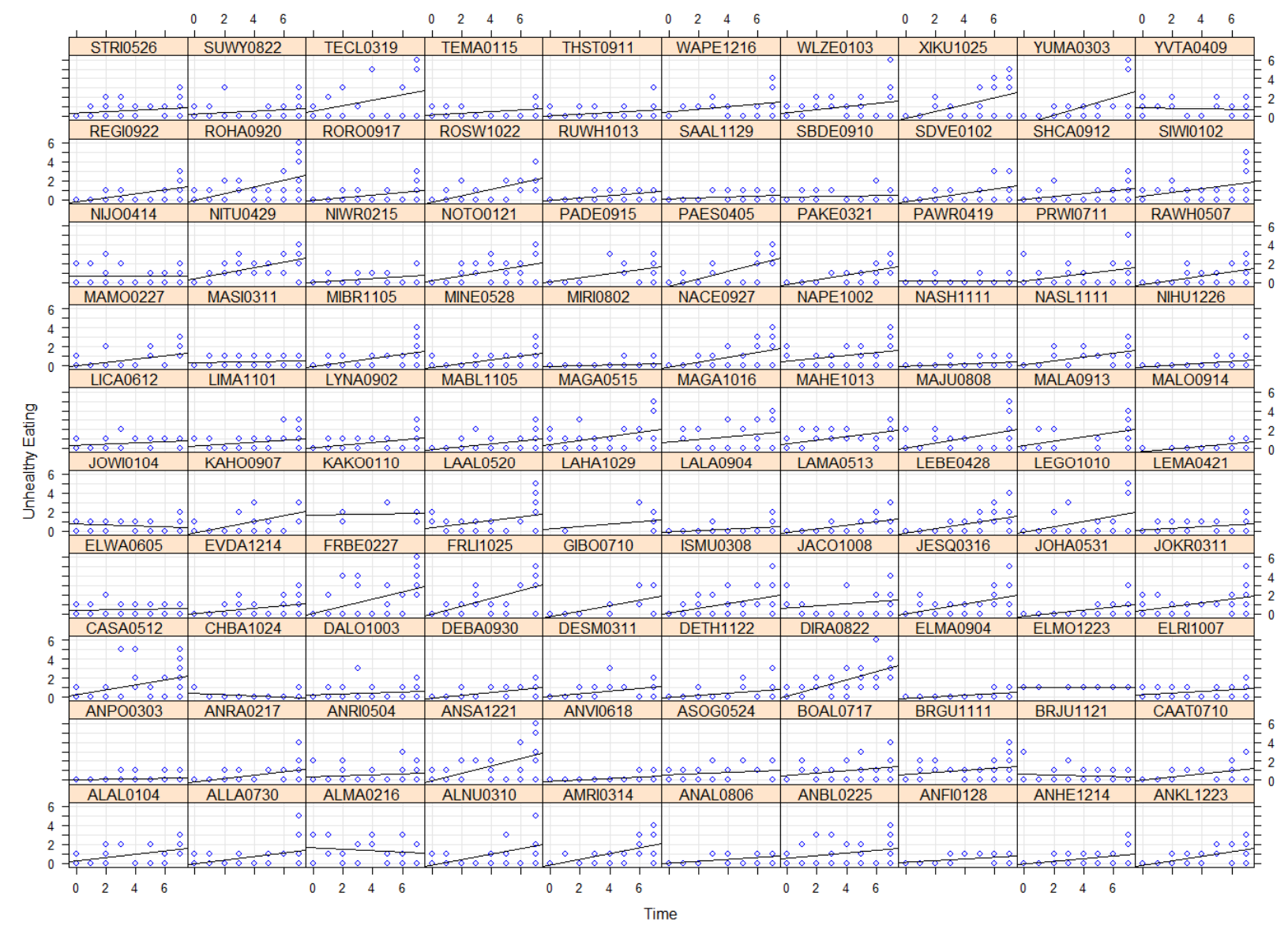

Figure 10. Unhealthy eating over the first three days by participant ID.

Next, I entered linear time as a level 1 fixed effects predictor of each outcome to control for linear increase in time (Bliese \& Ployhart, 2002; Singer \& Willett, 2003). State fatigue $\left(\beta_{1 j}=\right.$ $0.05, p<.01)$, heart rate $\left(\beta_{1 \mathrm{j}}=0.37, p=.02\right)$, and unhealthy eating $\left(\beta_{1 \mathrm{j}}=0.06, p<.01\right)$ increased throughout the day, and state negative affect $\left(\beta_{1 \mathrm{j}}=-0.01, p<.01\right)$, systolic blood pressure $\left(\beta_{1 \mathrm{j}}=\right.$ $0.43, p<.01)$ and diastolic blood pressure $\left(\beta_{1 \mathrm{j}}=-0.42, p<.01\right)$ decreased throughout the day.

To test Hypotheses 4-6, I then entered three parameters one at a time for each outcome: discontinuous intercept (labeled EWIF Model 3, EFIW Model 4), linear recovery (labeled EWIF Model 5, EFIW Model 6), quadratic recovery (labeled EWIF Model 7, EFIW Model 8), and cubic recovery (labeled EWIF Model 9, EFIW Model 10). Hypothesis 4 predicted synchronous 
increases in (a) fatigue and (b) negative affect at the time of an EWIF/EFIW. Results for this hypothesis are displayed in Table 17 (state fatigue) and Table 18 (state negative affect). The retained models for state fatigue (Model 7, Model 6) showed a significant increase in state fatigue at the time of an $\operatorname{EWIF}\left(\beta_{2 \mathrm{j}}=0.11, p<.01\right)$ and a significant decrease in state fatigue at the time of an EFIW $\left(\beta_{2 \mathrm{j}}=-0.10, p=.04\right)$. The models for state negative affect (Model 5, Model 6) showed no significant reactivity $\left(\mathrm{EWIF} \beta_{2 \mathrm{j}}=0.00, p=.84\right.$, EFIW $\beta_{2 \mathrm{j}}=0.02, p=.43$ ). Hypothesis 4a was partially supported, and Hypothesis $4 \mathrm{~b}$ was not supported.

Hypothesis 5 predicted synchronous increases in (a) heart rate, (b) systolic blood pressure, and (c) diastolic blood pressure at the time of an EWIF/EFIW. Results for this hypothesis are displayed in Table 19 (heart rate), Table 20 (systolic blood pressure), and Table 21 (diastolic blood pressure). The retained models for heart rate (Model 5, Model 6) showed no significant reactivity for EWIF $\left(\beta_{2 \mathrm{j}}=0.69, p=.47\right)$, and significant decrease in heart rate at the time of an EFIW $\beta_{2 j}=-1.97, p=.03$ ). Systolic blood pressure (Model 5, Model 6) showed no significant reactivity (EWIF $\beta_{2 \mathrm{j}}=-1.40, p=.09$, EFIW $\beta_{2 \mathrm{j}}=-0.11, p=.88$ ), and diastolic blood pressure (Model 5, Model 6) showed no significant reactivity (EWIF $\beta_{2 \mathrm{j}}=0.46, p=.50, \mathrm{EFIW}$ $\left.\beta_{2 \mathrm{j}}=-0.93, p=.15\right)$. Hypothesis 5 was not supported.

Hypothesis 6 predicted synchronous increases in unhealthy eating at the time of an EWIF/EFIW. Results for this hypothesis are displayed in Table 22 (refer to Model 9, Model 6). There was no synchronous association between unhealthy eating and EWIF occurrence $\left(\beta_{2 \mathrm{j}}=\right.$ $0.01, p=.83)$ or EFIW occurrence $\left(\beta_{2 \mathrm{j}}=0.03, p=.64\right)$. Hypothesis 6 was therefore not supported. 
Table 17. State fatigue discontinuous growth modeling fixed effects results.

\begin{tabular}{|c|c|c|c|c|c|c|c|c|c|}
\hline \multirow[b]{2}{*}{ Fixed Parameters } & \multirow[b]{2}{*}{ Model 2} & \multicolumn{4}{|c|}{ EWIF } & \multicolumn{4}{|c|}{ EFIW } \\
\hline & & Model 3 & Model 5 & Model 7 & Model 9 & Model 4 & Model 6 & Model 8 & Model 10 \\
\hline Intercept & $1.47 * *$ & $1.47 * *$ & $1.47 * *$ & $1.47 * *$ & $1.47 * *$ & $1.48 * *$ & $1.49 * *$ & $1.48 * *$ & $1.49 * *$ \\
\hline Time & $0.05 * *$ & $0.05 * *$ & $0.05 * *$ & $0.05 * *$ & $0.05 * *$ & $0.05 * *$ & $0.04 * *$ & $0.04 * *$ & $0.04 * *$ \\
\hline Reactivity & & 0.04 & 0.03 & $0.11 *$ & $0.11^{*}$ & -0.05 & $-0.10 *$ & -0.07 & -0.06 \\
\hline Linear Recovery & & & 0.01 & $-0.19 * *$ & $-0.21 *$ & & $0.03 *$ & -0.02 & -0.13 \\
\hline Quadratic Recovery & & & & $0.04 * *$ & 0.05 & & & 0.01 & $0.06^{*}$ \\
\hline Cubic Recovery & & & & & -0.00 & & & & -0.01 \\
\hline \multicolumn{10}{|l|}{ Random Parameters } \\
\hline$\sigma^{2}$ & 0.3229 & 0.3229 & 0.323 & 0.3194 & 0.3195 & 0.3225 & 0.3221 & 0.3219 & 0.3215 \\
\hline$\tau_{00}$ & 0.0961 & 0.0964 & 0.0965 & 0.0951 & 0.0950 & 0.0977 & 0.0950 & 0.0964 & 0.0966 \\
\hline$\tau_{000}$ & 0.1992 & 0.1981 & 0.198 & 0.1972 & 0.1973 & 0.1977 & 0.1995 & 0.1987 & 0.1987 \\
\hline AIC & 4321.15 & 4326.81 & 4334.79 & 4319.04 & 4330.17 & 4326.19 & 4329.61 & 4337.98 & 4346.19 \\
\hline $\mathrm{BIC}$ & 4349.67 & 4361.03 & 4374.71 & 4364.67 & 4381.49 & 460.42 & 4369.53 & 4383.60 & 4397.51 \\
\hline Log Likelihood & -2155.58 & -2157.40 & -2160.39 & -2151.52 & -2156.08 & -2157.10 & -2157.80 & -2160.99 & -2164.09 \\
\hline N Parameters & 5 & 6 & 7 & 8 & 9 & 6 & 7 & 8 & 9 \\
\hline $\mathrm{R}^{2}$ level 1 & & 0.00 & 0.00 & 0.01 & 0.00 & 0.00 & 0.00 & 0.00 & 0.00 \\
\hline $\mathrm{R}^{2}$ level 2 Intercept & & 0.00 & 0.00 & 0.01 & 0.00 & -0.02 & 0.03 & 0.00 & 0.00 \\
\hline $\mathrm{R}^{2}$ level 3 Intercept & & 0.01 & 0.00 & 0.00 & 0.00 & 0.01 & 0.00 & 0.00 & 0.00 \\
\hline Hypothesis 4a supported? & & & & Supported & & & Not Supported & & \\
\hline Hypothesis 7 supported? & & & & Supported & & & Not Supported & & \\
\hline
\end{tabular}


Table 18. State negative affect discontinuous growth modeling fixed effects results.

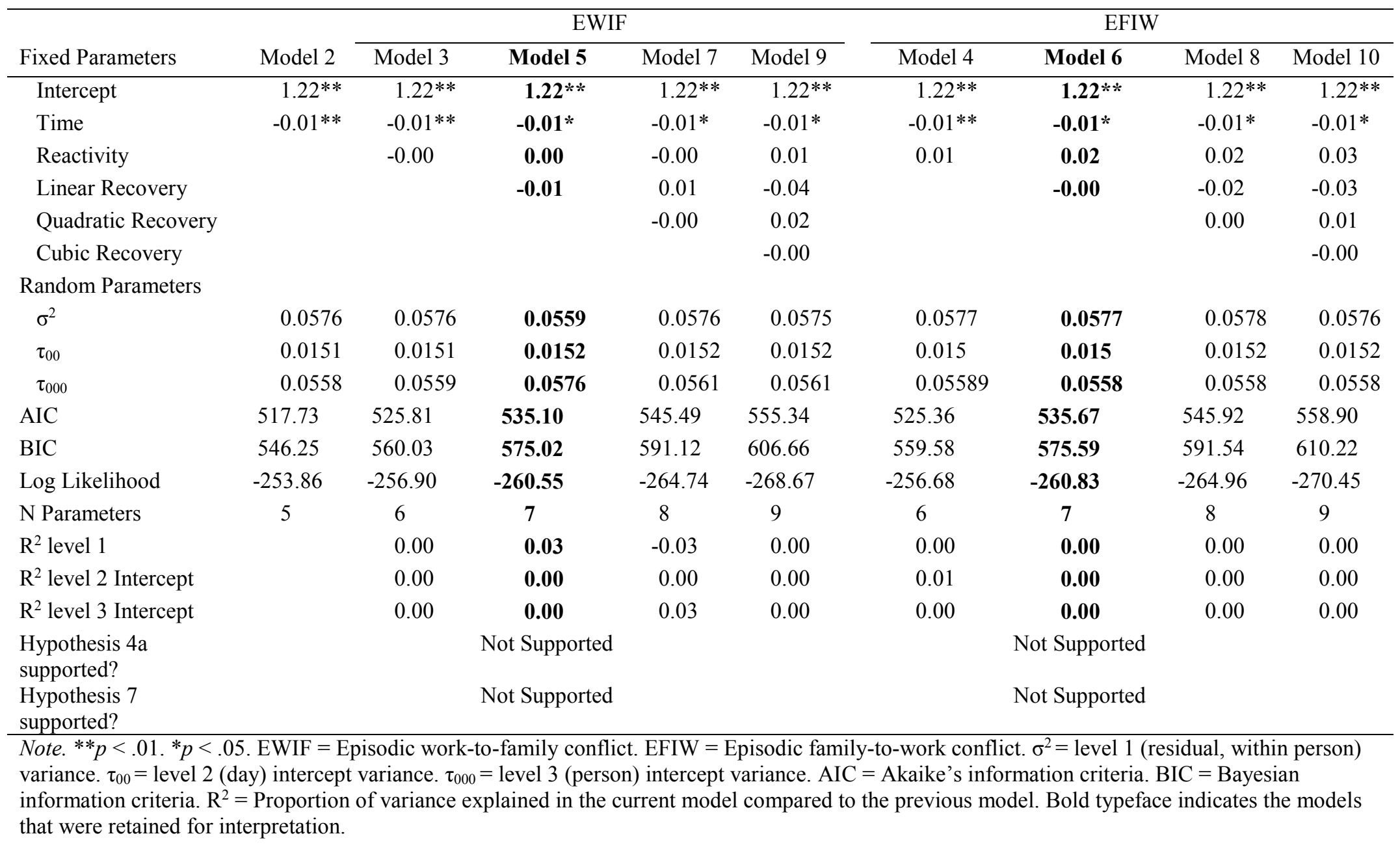


Table 19. Heart rate discontinuous growth modeling fixed effects results.

\begin{tabular}{|c|c|c|c|c|c|c|c|c|c|}
\hline \multirow[b]{2}{*}{ Fixed Parameters } & \multirow[b]{2}{*}{ Model 2} & \multicolumn{4}{|c|}{ WIF } & \multicolumn{4}{|c|}{ FIW } \\
\hline & & Model 3 & Model 5 & Model 7 & Model 9 & Model 4 & Model 6 & Model 8 & Model 10 \\
\hline Intercept & $78.17 * *$ & $78.18^{* *}$ & $78.07 * *$ & $78.07 * *$ & $78.07 * *$ & $78.46^{* *}$ & 78.48** & $78.48^{* *}$ & $78.50 * *$ \\
\hline Time & $0.37 * *$ & $0.37 * *$ & $0.45 * *$ & $0.45 * *$ & $0.45 * *$ & $0.41 * *$ & $0.40 * *$ & $0.41 * *$ & $0.42^{* *}$ \\
\hline Reactivity & & -0.21 & 0.69 & 0.75 & 0.72 & $-1.89 *$ & $-1.97^{*}$ & -1.70 & -1.40 \\
\hline Linear Recovery & & & $-0.93 *$ & -1.07 & -0.92 & & 0.06 & -0.50 & -2.55 \\
\hline Quadratic Recovery & & & & 0.29 & -0.05 & & & 0.10 & 1.08 \\
\hline Cubic Recovery & & & & & 0.01 & & & & -0.11 \\
\hline Random Parameters & & & & & & & & & \\
\hline$\sigma^{2}$ & 107.94 & 107.98 & 107.51 & 107.56 & 107.62 & 107.81 & 107.97 & 108.00 & 107.77 \\
\hline$\tau_{00}$ & 12.53 & 12.58 & 12.88 & 12.93 & 12.93 & 11.72 & 11.79 & 11.77 & 12.09 \\
\hline$\tau_{000}$ & 98.07 & 98.07 & 97.65 & 97.64 & 97.62 & 97.69 & 98.98 & 99.03 & 98.84 \\
\hline AIC & 14103.22 & 14103.55 & 14099.12 & 14102.92 & 14107.97 & 14098.42 & 14101.07 & 14104.73 & 14107.69 \\
\hline BIC & 14130.77 & 14136.61 & 14137.68 & 14146.98 & 14157.53 & 14131.48 & 14139.62 & 14148.79 & 14157.25 \\
\hline Log Likelihood & -7046.61 & -7045.78 & -7042.56 & -7043.46 & -7044.98 & -7043.21 & -7043.53 & -7044.37 & -7044.84 \\
\hline N Parameters & 5 & 6 & 7 & 8 & 9 & 6 & 7 & 8 & 9 \\
\hline $\mathrm{R}^{2}$ level 1 & & 0.00 & 0.00 & 0.00 & 0.00 & 0.00 & 0.00 & 0.00 & 0.00 \\
\hline $\mathrm{R}^{2}$ level 2 Intercept & & 0.00 & 0.00 & 0.00 & 0.00 & 0.06 & 0.00 & 0.00 & 0.00 \\
\hline $\mathrm{R}^{2}$ level 3 Intercept & & 0.00 & 0.00 & 0.00 & 0.00 & 0.00 & 0.00 & 0.00 & 0.00 \\
\hline $\begin{array}{l}\text { Hypothesis } 4 \mathrm{~b} \\
\text { supported? } \\
\text { Hypothesis } 7 \\
\text { supported? }\end{array}$ & 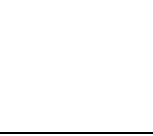 & & $\begin{array}{c}\text { Not } \\
\text { Supported } \\
\text { Supported }\end{array}$ & 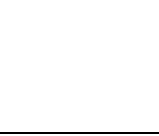 & & & $\begin{array}{c}\text { Not } \\
\text { Supported } \\
\text { Not } \\
\text { Supported } \\
\end{array}$ & 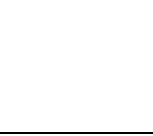 & \\
\hline
\end{tabular}


Table 20. Systolic blood pressure discontinuous growth modeling fixed effects results.

\begin{tabular}{|c|c|c|c|c|c|c|c|c|c|}
\hline \multirow[b]{2}{*}{ Fixed Parameters } & \multirow[b]{2}{*}{ Model 2} & \multicolumn{4}{|c|}{ WIF } & \multicolumn{4}{|c|}{ FIW } \\
\hline & & Model 3 & Model 5 & Model 7 & Model 9 & Model 4 & Model 6 & Model 8 & Model 10 \\
\hline Intercept & $114.84^{* *}$ & $114.93 * *$ & $114.94 * *$ & $114.93 * *$ & $114.93 * *$ & $114.99 * *$ & $114.79 * *$ & $114.79 * *$ & $114.78^{* *}$ \\
\hline I1me & $-0.43 * *$ & $-0.40 * *$ & $-0.40 * *$ & $-0.41 * *$ & $-0.41 * *$ & $-0.41 * *$ & $-0.33 * *$ & $-0.33 * *$ & $-0.34 * *$ \\
\hline Reactivity & & -1.28 & -1.40 & $-1.76^{*}$ & $-1.94 *$ & -0.95 & -0.11 & -0.28 & -0.38 \\
\hline Linear Recovery & & & 0.10 & 1.00 & 2.14 & & -0.46 & -0.13 & 0.56 \\
\hline Quadratic Recovery & & & & -0.18 & -0.75 & & & -0.06 & 0.39 \\
\hline Cubic Recovery & & & & & 0.06 & & & & 0.04 \\
\hline Random Parameters & & & & & & & & & \\
\hline$\sigma^{2}$ & 85.84 & 85.74 & 85.79 & 85.74 & 85.76 & 85.81 & 85.72 & 85.75 & 85.77 \\
\hline$\tau_{00}$ & 99.14 & 98.78 & 98.91 & 99.14 & 99.00 & 98.25 & 97.53 & 97.67 & 97.72 \\
\hline AIC & 13598.21 & 13595.93 & 13598.37 & 13600.77 & 13605.36 & 13596.51 & 13600.81 & 13606.24 & 13585.60 \\
\hline BIC & 13620.25 & 13623.48 & 13631.42 & 13639.32 & 13649.42 & 13629.56 & 13639.36 & 13650.29 & 13629.67 \\
\hline Log Likelihood & -6795.11 & -6792.97 & -6793.18 & -6793.38 & -6794.68 & -6792.26 & -6793.41 & -6795.12 & -6784.80 \\
\hline N Parameters & 5 & 6 & 7 & 8 & 9 & 6 & 7 & 8 & 9 \\
\hline $\mathrm{R}^{2}$ level 1 & & 0.00 & 0.00 & 0.00 & 0.00 & 0.00 & 0.00 & 0.00 & 0.01 \\
\hline $\mathrm{R}^{2}$ level 2 Intercept & & 0.00 & $\mathbf{0 . 0 0}$ & 0.00 & 0.01 & 0.01 & 0.00 & 0.00 & 0.01 \\
\hline $\begin{array}{l}\text { Hypothesis } 4 \mathrm{~b} \\
\text { supported? } \\
\text { Hypothesis } 7 \\
\text { supported? }\end{array}$ & & & $\begin{array}{c}\text { Not } \\
\text { Supported } \\
\text { Not } \\
\text { Supported } \\
\end{array}$ & & & & $\begin{array}{c}\text { Not } \\
\text { Supported } \\
\text { Not } \\
\text { Supported } \\
\end{array}$ & & \\
\hline
\end{tabular}


Table 21. Diastolic blood pressure discontinuous growth modeling fixed effects results.

\begin{tabular}{|c|c|c|c|c|c|c|c|c|c|}
\hline \multirow[b]{2}{*}{ Fixed Parameters } & \multirow[b]{2}{*}{ Model 2} & \multicolumn{4}{|c|}{ WIF } & \multicolumn{4}{|c|}{ FIW } \\
\hline & & Model 3 & Model 5 & Model 7 & Model 9 & Model 4 & Model 6 & Model 8 & Model 10 \\
\hline Intercept & $72.54 * *$ & $72.51^{* *}$ & $72.50 * *$ & $72.50^{* *}$ & $72.49 * *$ & $72.71 * *$ & $72.66 * *$ & $72.66 * *$ & $72.66 * *$ \\
\hline Time & $-0.42 * *$ & $-0.43 * *$ & $-0.42 * *$ & $-0.42 * *$ & $-0.43 * *$ & $-0.40 * *$ & $-0.38^{* *}$ & $-0.38 * *$ & $-0.39 * *$ \\
\hline Reactivity & & 0.35 & 0.46 & 0.38 & 0.16 & $-1.12 *$ & -0.93 & -1.14 & -1.18 \\
\hline Linear Recovery & & & -0.09 & 0.14 & 1.45 & & -0.10 & 0.32 & 0.57 \\
\hline Quadratic Recovery & & & & -0.05 & -0.71 & & & -0.08 & -0.19 \\
\hline Cubic Recovery & & & & & 0.07 & & & & 0.01 \\
\hline Random Parameters & & & & & & & & & \\
\hline$\sigma^{2}$ & 59.80 & 59.81 & 59.84 & 59.87 & 59.86 & 59.71 & 59.74 & 59.75 & 59.78 \\
\hline$\tau_{00}$ & 47.56 & 47.77 & 47.68 & 47.73 & 47.58 & 47.06 & 46.97 & 47.08 & 47.09 \\
\hline AIC & 12909.12 & 12909.94 & 12912.73 & 12917.07 & 12921.33 & 12906.21 & 12909.32 & 12913.56 & 12919.68 \\
\hline BIC & 12931.16 & 12937.48 & 12945.78 & 12955.63 & 12965.39 & 12933.75 & 12942.36 & 12952.11 & 12963.74 \\
\hline Log Likelihood & -6450.56 & -6449.97 & -6450.37 & -6451.54 & -6452.66 & -6448.11 & -6448.66 & -6449.78 & -6451.84 \\
\hline N Parameters & 5 & 6 & 7 & 8 & 9 & 6 & 7 & 8 & 9 \\
\hline $\mathrm{R}^{2}$ level 1 & & 0.00 & 0.00 & 0.00 & 0.00 & 0.00 & 0.00 & 0.00 & 0.00 \\
\hline $\begin{array}{l}\text { Hypothesis } 7 \\
\text { supported? }\end{array}$ & & & Not Supported & & & & $\begin{array}{c}\text { Not } \\
\text { Supported }\end{array}$ & & \\
\hline
\end{tabular}


Table 22. Unhealthy eating discontinuous growth modeling fixed effects results.

\begin{tabular}{|c|c|c|c|c|c|c|c|c|c|}
\hline \multirow[b]{2}{*}{ Fixed Parameters } & \multirow[b]{2}{*}{ Model 2} & \multicolumn{4}{|c|}{ WIF } & \multicolumn{4}{|c|}{ FIW } \\
\hline & & Model 3 & Model 5 & Model 7 & Model 9 & Model 4 & Model 6 & Model 8 & Model 10 \\
\hline Intercept & $0.35 * *$ & $0.36^{* *}$ & $0.36^{* *}$ & $0.36^{* *}$ & $0.36 * *$ & $0.35 * *$ & $0.35 * *$ & $0.36^{* *}$ & $0.35 * *$ \\
\hline Time & $0.06^{* *}$ & $0.06^{* *}$ & $0.06^{* *}$ & $0.06^{* *}$ & $0.06 * *$ & $0.06^{* *}$ & $0.06 * *$ & $0.06^{* *}$ & $0.06^{* *}$ \\
\hline Reactivity & & -0.02 & -0.03 & -0.02 & 0.01 & 0.03 & 0.03 & 0.04 & 0.03 \\
\hline Linear Recovery & & & 0.01 & -0.01 & $-0.23 *$ & & -0.00 & -0.02 & 0.62 \\
\hline Quadratic Recovery & & & & 0.00 & $0.11^{*}$ & & & 0.00 & -0.04 \\
\hline Cubic Recovery & & & & & $-0.01 *$ & & & & 0.00 \\
\hline \multicolumn{10}{|l|}{ Random Parameters } \\
\hline$\sigma^{2}$ & 0.5688 & 0.5688 & 0.5692 & 0.5692 & 0.5681 & 0.5688 & 0.5691 & 0.5694 & 0.5694 \\
\hline$\tau_{00}$ & 0.0074 & 0.0075 & 0.0074 & 0.0076 & 0.0076 & 0.0073 & 0.0073 & 0.0073 & 0.0071 \\
\hline$\tau_{000}$ & 0.0663 & 0.0666 & 0.0665 & 0.0667 & 0.0664 & 0.0671 & 0.0671 & 0.0669 & 0.0674 \\
\hline AIC & 5058.59 & 5064.60 & 5072.24 & 5081.54 & 5086.68 & 5064.58 & 5072.78 & 5082.38 & 5092.36 \\
\hline BIC & 5086.95 & 5098.64 & 5111.94 & 5126.91 & 1537.72 & 5098.61 & 5112.49 & 517.76 & 5143.41 \\
\hline Log Likelihood & -2524.29 & -2526.3 & -2529.12 & -2532.77 & -2534.34 & -2526.29 & -2529.39 & -2533.19 & -2537.18 \\
\hline N Parameters & 5 & 6 & 7 & 8 & 9 & 6 & 7 & 8 & 9 \\
\hline $\mathrm{R}^{2}$ level 1 & & 0.00 & 0.00 & 0.00 & 0.00 & 0.00 & 0.00 & 0.00 & 0.00 \\
\hline $\mathrm{R}^{2}$ level 2 Intercept & & 0.00 & 0.01 & 0.00 & 0.00 & 0.01 & 0.27 & 0.00 & 0.03 \\
\hline $\mathrm{R}^{2}$ level 3 Intercept & & 0.00 & 0.00 & 0.00 & 0.00 & 0.00 & 0.04 & 0.00 & 0.00 \\
\hline $\begin{array}{l}\text { Hypothesis } 4 \mathrm{c} \\
\text { supported? }\end{array}$ & & & & & Not Supported & & Not Supported & & \\
\hline $\begin{array}{l}\text { Hypothesis } 7 \\
\text { supported? }\end{array}$ & & & & & Supported & & Not Supported & & \\
\hline
\end{tabular}


Hypothesis 7 predicted a decline in each outcome over time following the onset of an EWIF/EFIW. For state fatigue, Model 7 indicated a significant quadratic change after an EWIF $\left(\beta_{4 \mathrm{j}}=0.04, p<.01\right)$. Model 6 indicated a significant linear change after an EFIW $\left(\beta_{3 \mathrm{j}}=0.03, p=\right.$ .02). State fatigue trends are graphed in Figure 11 (EWIF) and Figure 12 (EFIW). Consistent with the hypothesis, graphs show a decline in fatigue following an EWIF. Contrary to the hypothesis, Figure 12 shows an incline in fatigue following an EFIW. For negative affect, the recovery parameters were not significant (Model 5 and Model 6, EWIF $\beta_{3 \mathrm{j}}=-0.01, p=.39$, EFIW $\left.\beta_{3 \mathrm{j}}=-0.00, p=.80\right)$. Regarding heart rate, there was a significant decrease following an EWIF (Model 5, $\beta_{3 \mathrm{j}}=-0.93, p=.01$ ), but no change following an EFIW (Model 6, $\beta_{3 \mathrm{j}}=0.06, p=$ .84 ). For systolic blood pressure (Model 5 and Model 6, EWIF $\beta_{3 \mathrm{j}}=0.10, p=.74$, EFIW $\beta_{3 \mathrm{j}}=-$ $0.46, p=.06$ ) and diastolic blood pressure (Model 5 and Model 6, EWIF $\beta_{3 \mathrm{j}}=-0.09, p=.73$, EFIW $\left.\beta_{3 j}=-0.10, p=.62\right)$, there were no significant recovery parameters. Finally, regarding unhealthy eating, there was a significant cubic change in unhealthy eating following an EWIF (Model 9, $\beta_{5 \mathrm{j}}=-0.01, p=.02$ ); there was no significant change in unhealthy eating following an EFIW (Model $6, \beta_{3 j}=-0.00, p=1.00$ ). In sum, Hypothesis 7 received partial support. The hypothesis was partially supported for state fatigue (when recovering from EWIF), partially supported for heart rate (when recovering from EWIF), and partially supported for unhealthy eating (when recovering from EWIF). 


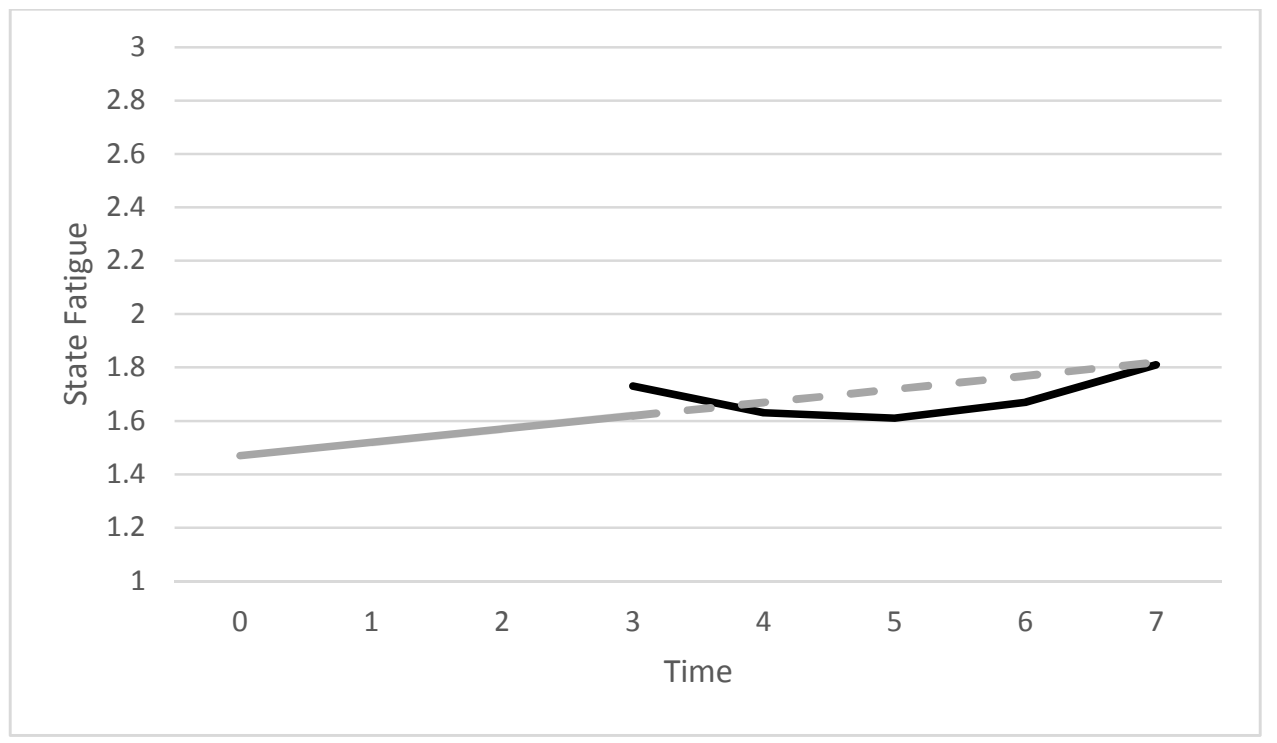

Figure 11. Graphic representation of state fatigue change when an EWIF occurs.

Note. Graphed EWIF occurs at time point three (2 PM). The solid grey line represents the predicted linear change in state fatigue over time before a conflict occurs. The solid black line represents the synchronous reactivity and post-EWIF recovery pattern in state fatigue. The dotted grey line represents the predicted change in state fatigue if a conflict had not occurred.

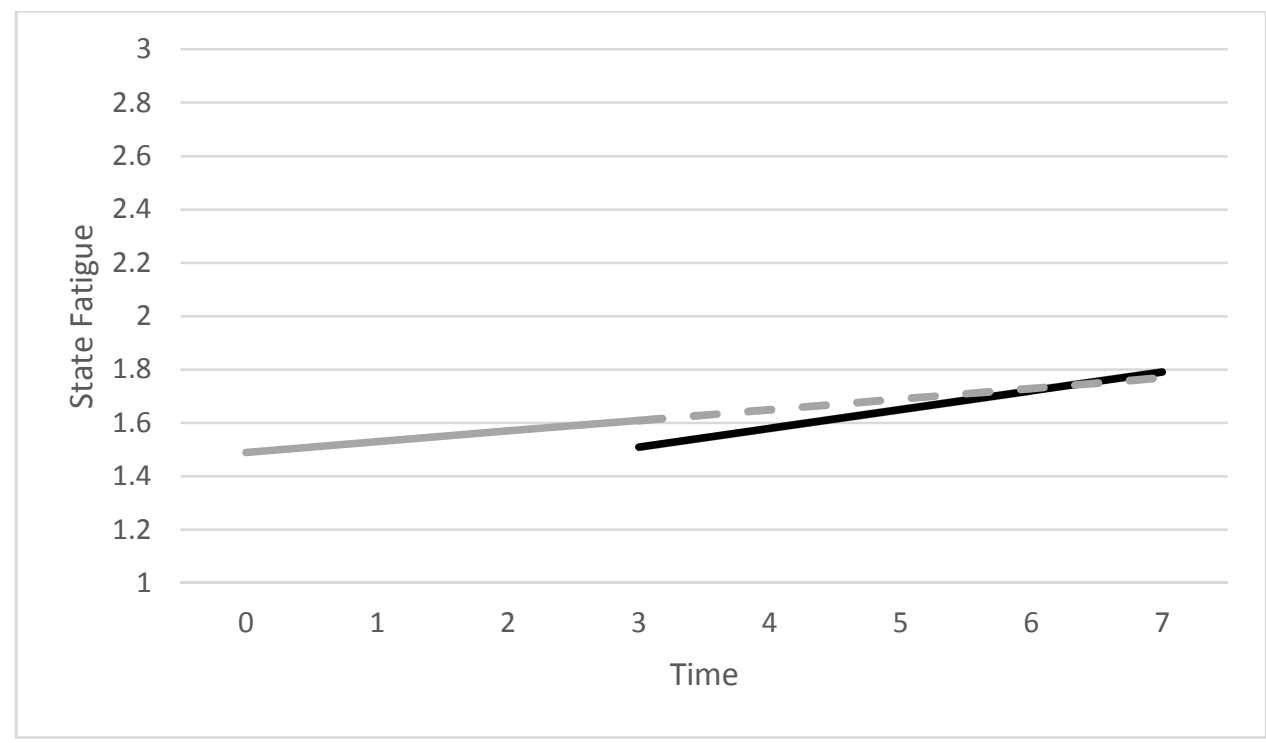

Figure 12. Graphic representation of state fatigue change when an EFIW occurs.

Note. Graphed EFIW occurs at time point three (2 PM). The solid grey line represents the predicted linear change in state fatigue over time before a conflict occurs. The solid black line represents the synchronous reactivity and post-EFIW recovery pattern in state fatigue. The dotted grey line represents the predicted change in state fatigue if a conflict had not occurred. 


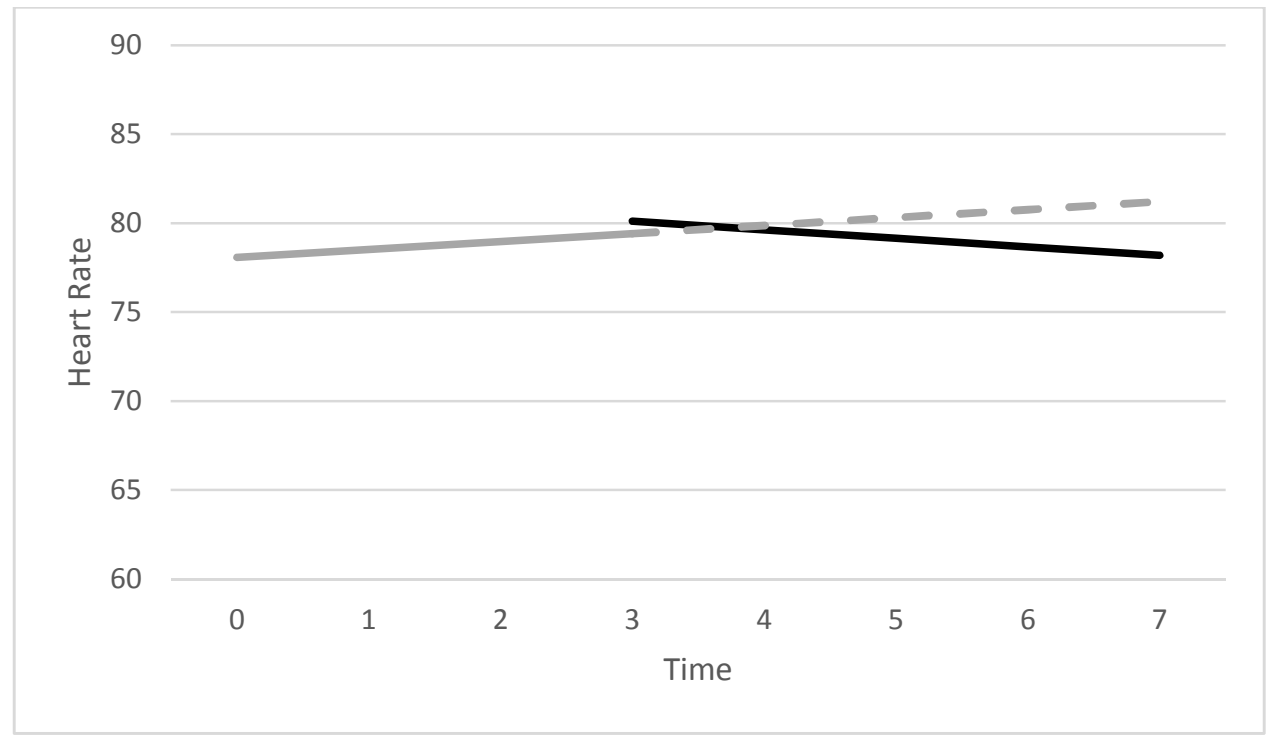

Figure 13. Graphic representation of heart rate change when an EWIF occurs.

Note. Graphed EWIF occurs at time point three (2 PM). The solid grey line represents the predicted linear change in heart rate over time before a conflict occurs. The solid black line represents the synchronous reactivity and post-EWIF recovery pattern in heart rate. The dotted grey line represents the predicted change in heart rate if a conflict had not occurred.

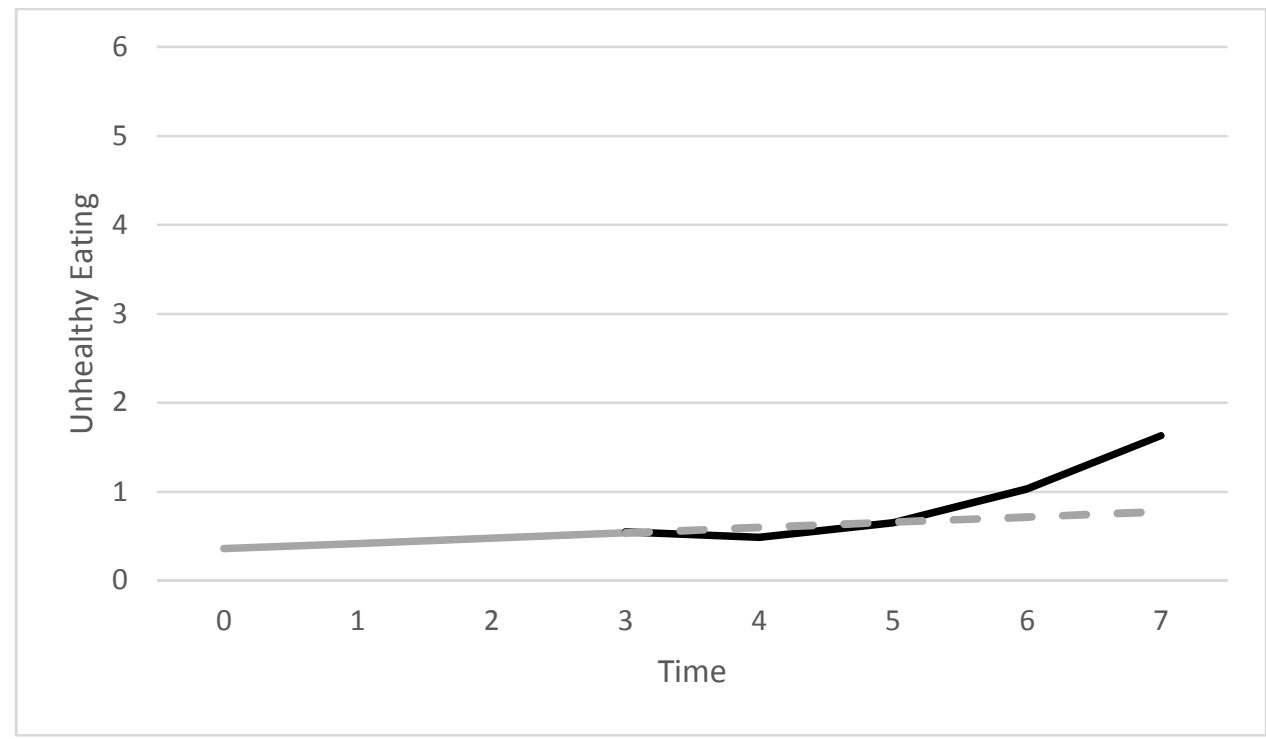

Figure 14. Graphic representation of unhealthy eating change when an EWIF occurs.

Note. Graphed EWIF occurs at time point three (2 PM). The solid grey line represents the predicted linear change in unhealthy eating over time before a conflict occurs. The solid black line represents the synchronous reactivity and post-EWIF recovery pattern in unhealthy eating. The dotted grey line represents the predicted change in unhealthy eating if a conflict had not occurred. 
Hypothesis 8 predicted significant variability in the magnitude of reactivity across each outcome. Log likelihood difference tests showed significant variance in the reactivity parameters for state fatigue reactivity to EWIF ( $p=.01)$, but not EFIW $(p=.93)$ (Table 23). Similarly state negative affect reactivity varied for EWIF $(p<.01)$, but not EFIW $(p=.64)$ (Table 24). Heart rate (Table 25), systolic blood pressure (Table 26), diastolic blood pressure (Table 27), and unhealthy food consumption (Table 28) did not show variance in reactivity $(p>.05$, ranging from $p=.13$ to $p=.93$ ). Thus, Hypothesis 8 was partially supported. State fatigue and state negative affect reactivity showed significant variation in response to EWIF, but all other reactivity parameters did not significantly vary.

Hypothesis 9 predicted significant variability in the recovery parameters across each outcome. Regarding state fatigue, $\log$ likelihood difference tests showed significant variability in recovery parameters for EWIF $(p<.01)$, but not EFIW $(p=.48)$ (Table 23). Similarly for state negative affect, log likelihood difference tests showed significant variability in recovery parameters for EWIF $(p<.02)$, but not EFIW (the model failed to converge; Table 24). There was no significant variance in recovery for heart rate (Table 25), systolic blood pressure (Table 26), diastolic blood pressure (Table 27), or unhealthy eating (Table 28) (significance ranged from $p=.27$ to $p=1.00$ ). Thus Hypothesis 9 was partially supported. 
Table 23. State fatigue discontinuous growth modeling random effects results.

\begin{tabular}{|c|c|c|c|c|c|c|c|c|c|}
\hline \multirow[b]{2}{*}{ Fixed Parameters } & \multicolumn{5}{|c|}{ WIF } & \multicolumn{4}{|c|}{ FIW } \\
\hline & Model 7 & Model 7.1 & Model 7.2 & Model 7.3 & Model 7.4 & Model 6 & Model 6.1 & Model 6.2 & Model 6.3 \\
\hline Intercept & $1.47 * *$ & $1.47 * *$ & $1.47 * *$ & $1.48^{* *}$ & $1.48 * *$ & $1.49 * *$ & $1.48^{* *}$ & $1.48 * *$ & $1.49 * *$ \\
\hline Time & $0.05 * *$ & $0.05 * *$ & $0.05 * *$ & $0.05 * *$ & $0.05 * *$ & $0.04 * *$ & $0.04 * *$ & 0.04 & $0.04 * *$ \\
\hline Reactivity & $0.11^{*}$ & 0.10 & $0.12 *$ & 0.11 & 0.08 & $-0.10^{*}$ & -0.06 & -0.05 & -0.06 \\
\hline Linear Recovery & $-0.19 * *$ & $-0.21 * *$ & $-0.20 * *$ & $-0.19 * *$ & $-0.13 *$ & $0.03^{*}$ & $0.04 *$ & $0.04 *$ & 0.04 \\
\hline Quadratic Recovery & $0.04 * *$ & $0.04 * *$ & $0.04 * *$ & $0.04 * *$ & $0.03 * *$ & & & & \\
\hline \multicolumn{10}{|l|}{ Random Parameters } \\
\hline$\sigma^{2}$ & 0.3194 & 0.2629 & 0.2597 & 0.2557 & 0.2483 & 0.3221 & 0.2661 & 0.2663 & 0.2652 \\
\hline$\tau_{00}$ & 0.0951 & 0.1593 & 0.1529 & 0.1557 & 0.1584 & 0.0950 & 0.1548 & 0.1525 & 0.1527 \\
\hline$\tau_{11}$ & & 0.0073 & 0.0073 & 0.0033 & 0.0067 & & 0.0070 & 0.0070 & 0.0065 \\
\hline$\tau_{22}$ & & & 0.0552 & 0.0336 & 0.0279 & & & 0.0000 & 0.0000 \\
\hline$\tau_{33}$ & & & & 0.0006 & 0.0000 & & & & 0.0154 \\
\hline$\tau_{44}$ & & & & & 0.0000 & & & & \\
\hline$\tau_{000}$ & 0.1972 & 0.1771 & 0.1738 & 0.1708 & 0.1754 & 0.1995 & 0.1769 & 0.1669 & 0.172 \\
\hline$\tau_{111}$ & & 0.0025 & 0.0024 & 0.0040 & 0.0038 & & 0.0028 & 0.0027 & 0.0037 \\
\hline$\tau_{222}$ & & & 0.0177 & 0.0395 & 0.0744 & & & 0.0071 & 0.0033 \\
\hline$\tau_{333}$ & & & & 0.0148 & 0.1300 & & & & 0.0036 \\
\hline$\tau_{444}$ & & & & & 0.0027 & & & & \\
\hline AIC & 4319.04 & 4195.99 & 4194.50 & 4191.24 & 4182.77 & 4329.61 & 4207.51 & 4217.68 & 4226.13 \\
\hline BIC & 4364.67 & 4264.43 & 4297.15 & 4339.52 & 4388.07 & 4369.53 & 4270.24 & 4314.64 & 4368.72 \\
\hline Log Likelihood & -2151.52 & -2086 & -2079.25 & -2069.62 & -2055.38 & -2157.80 & -2092.75 & -2091.84 & -2088.07 \\
\hline N Parameters & 8 & 12 & 18 & 26 & 36 & 7 & 11 & 17 & 25 \\
\hline$-2 *$ LL Difference & & $131.04 * *$ & $13.50 *$ & $19.26^{* *}$ & $28.48 * *$ & & $130.10^{* *}$ & 1.82 & 7.54 \\
\hline $\begin{array}{l}\text { df LL Difference } \\
\text { Hypothesis } 8\end{array}$ & & 4 & 6 & 8 & 10 & & 4 & 5 & 8 \\
\hline $\begin{array}{l}\text { Supported? } \\
\text { Hypothesis } 9\end{array}$ & & & Supported & & & & & & \\
\hline Supported? & & & & Supported & Supported & & & Not Supported & Not Supported \\
\hline
\end{tabular}


Table 24. State negative affect discontinuous growth modeling random effects results.

\begin{tabular}{|c|c|c|c|c|c|c|c|}
\hline \multirow[b]{2}{*}{ Fixed Parameters } & \multicolumn{4}{|c|}{ WIF } & \multicolumn{3}{|c|}{ FIW } \\
\hline & Model 5 & $\begin{array}{c}\text { Model } \\
5.1 \\
\end{array}$ & Model 5.2 & Model 5.3 & Model 6 & Model 6.1 & Model 6.2 \\
\hline Intercept & $1.22 * *$ & $1.22 * *$ & $1.23 * *$ & $1.23 * *$ & $1.22 * *$ & $1.22 * *$ & $1.22 * *$ \\
\hline Time & $-0.01 *$ & $-0.01 *$ & $-0.01 *$ & $-0.01 *$ & $-0.01 *$ & $-0.01 *$ & $-0.01 *$ \\
\hline Reactivity & 0.00 & 0.01 & 0.02 & 0.03 & 0.02 & 0.02 & 0.03 \\
\hline $\begin{array}{l}\text { Linear Recovery } \\
\text { Random } \\
\text { Parameters }\end{array}$ & -0.01 & -0.01 & -0.01 & -0.01 & -0.00 & -0.00 & -0.00 \\
\hline$\sigma^{2}$ & 0.0559 & 0.0544 & 0.0524 & 0.0517 & 0.0577 & 0.0544 & 0.0541 \\
\hline$\tau_{00}$ & 0.0152 & 0.0224 & 0.0213 & 0.0211 & 0.0150 & 0.0220 & 0.0241 \\
\hline$\tau_{11}$ & & 0.0004 & 0.0003 & 0.0002 & & 0.0040 & 0.0030 \\
\hline$\tau_{22}$ & & & 0.0271 & 0.0170 & & & 0.0025 \\
\hline$\tau_{33}$ & & & & 0.0000 & & & \\
\hline$\tau_{000}$ & 0.0576 & 0.057 & 0.0579 & 0.0577 & 0.0558 & 0.0570 & 0.0583 \\
\hline$\tau_{111}$ & & 0.0002 & 0.0001 & 0.0002 & & 0.0002 & 0.0002 \\
\hline$\tau_{222}$ & & & 0.0037 & 0.0226 & & & 0.0048 \\
\hline$\tau_{333}$ & & & & 0.0035 & & & \\
\hline AIC & 535.10 & 526.16 & 512.44 & 510.51 & 535.67 & 526.18 & 533.91 \\
\hline $\mathrm{BIC}$ & 575.02 & 588.89 & 609.40 & 653.09 & 575.59 & 588.92 & 630.87 \\
\hline Log Likelihood & -260.55 & -252.08 & -239.22 & -230.25 & -260.83 & -252.09 & -249.96 \\
\hline N Parameters & 7 & 11 & 17 & 25 & 7 & 11 & 17 \\
\hline$-2 *$ LL Difference & & $16.94 * *$ & $25.72 * *$ & $17.94 *$ & & $17.48 * *$ & 4.26 \\
\hline $\begin{array}{l}\text { df LL Difference } \\
\text { Hypothesis } 8 \\
\text { Supported? } \\
\text { Hypothesis } 9 \\
\text { Supported? }\end{array}$ & & 4 & $\begin{array}{c}6 \\
\text { Supported }\end{array}$ & Supported & & 4 & $\begin{array}{c}6 \\
\text { Not } \\
\text { Supported } \\
\text { Not } \\
\text { Supported }^{1} \\
\end{array}$ \\
\hline $\begin{array}{l}\text { Note. }{ }^{* *} p<.01 .{ }^{*} p \\
\text { level } 1 \text { (residual, w } \\
\tau_{22}=\text { level } 2 \text { (day) } \mathrm{r} \\
\text { variance. } \tau_{111}=\text { leve } \\
\text { linear recovery vari } \\
\text { likelihood. } \mathrm{df}=\mathrm{deg} \\
\text { support for the hyp }\end{array}$ & $\begin{array}{l}.05 . \mathrm{EWIF}= \\
\text { in person) ve } \\
\text { ctivity varian } \\
3 \text { (person) lin } \\
\text { ce. AIC = A } \\
\text { es of freedor } \\
\text { hesis. }\end{array}$ & $\begin{array}{l}\text { Episodic wo } \\
\text { riance. } \tau_{00}= \\
\text { ce. } \tau_{33}=\text { leve } \\
\text { ear time vari } \\
\text { aike's infor } \\
{ }^{1} \text { Model } 6 .\end{array}$ & $\begin{array}{l}\text { k-to-family } \\
\text { evel } 2 \text { (day) } \\
2 \text { (day) linea } \\
\text { nce. } \tau_{222}=\text { le } \\
\text { ation criteria } \\
\text { to test Hypo }\end{array}$ & $\begin{array}{l}\text { nflict. EFIW } \\
\text { tercept varian } \\
\text { recovery vari } \\
\text { el } 3 \text { (person) } \\
\text { BIC = Bayes } \\
\text { esis } 9 \text { did not }\end{array}$ & $\begin{array}{l}\text { pisodic fami } \\
\tau_{11}=\text { level } 2 \\
\text { e. } \tau_{000}=\text { leve } \\
\text { tivity varian } \\
\text { information } \\
\text { nverge. Ther }\end{array}$ & $\begin{array}{l}\text {-to-work col } \\
\text { day) linear ti } \\
3 \text { (person) in } \\
\text { e. } \tau_{333}=\text { level } \\
\text { riteria. } L L= \\
\text { fore, I conclu }\end{array}$ & $\begin{array}{l}\text { flict. } \sigma^{2}= \\
\text { he variance. } \\
\text { ercept } \\
3 \text { (person) } \\
\text { og } \\
\text { led no }\end{array}$ \\
\hline
\end{tabular}


Table 25. Heart rate discontinuous growth modeling random effects results.

\begin{tabular}{|c|c|c|c|c|c|c|c|c|}
\hline \multirow[b]{2}{*}{ Fixed Parameters } & \multicolumn{4}{|c|}{ WIF } & \multicolumn{4}{|c|}{ FIW } \\
\hline & Model 5 & Model 5.1 & Model 5.2 & Model 5.3 & Model 6 & Model 6.1 & Model 6.2 & Model 6.3 \\
\hline Intercept & $78.07 * *$ & $77.99 * *$ & $78.02 * *$ & $78.03 * *$ & $1.22 * *$ & $78.44 * *$ & $78.45 * *$ & $78.45 * *$ \\
\hline Time & $0.45^{* *}$ & $0.45 * *$ & $0.45 * *$ & $0.45^{* *}$ & $-0.01 *$ & $0.41 * *$ & $0.41 *$ & $0.41 * *$ \\
\hline Reactivity & 0.69 & 0.99 & 0.82 & 0.79 & 0.02 & $-2.15^{*}$ & $-2.12^{*}$ & $-2.13 *$ \\
\hline Linear Recovery & $-0.93 *$ & $-0.87 *$ & -0.80 & -0.84 & -0.00 & 0.06 & 0.06 & 0.06 \\
\hline \multicolumn{9}{|l|}{ Random Parameters } \\
\hline$\sigma^{2}$ & 107.5146 & 96.1355 & 94.9002 & 94.6905 & 0.0577 & 96.2147 & 96.3314 & 96.3566 \\
\hline$\tau_{00}$ & 12.8807 & 17.6310 & 17.1123 & 17.4292 & 0.0150 & 17.3988 & 16.8326 & 16.9458 \\
\hline$\tau_{11}$ & & 0.9974 & 1.0155 & 1.0127 & & 0.9688 & 0.9545 & 0.9558 \\
\hline$\tau_{22}$ & & & 6.0492 & 4.7562 & & & 0.0365 & 0.0093 \\
\hline$\tau_{33}$ & & & & 0.0002 & & & & 0.0000 \\
\hline$\tau_{000}$ & 97.65 & 115.8967 & 115.0059 & 113.1707 & 0.0558 & 116.8967 & 119.9428 & 119.344 \\
\hline$\tau_{111}$ & & 0.9974 & 0.8618 & 0.7823 & & 1.0840 & 1.0657 & 1.06765 \\
\hline$\tau_{222}$ & & & 2.0387 & 25.0039 & & & 2.9563 & 2.5699 \\
\hline$\tau_{333}$ & & & & 0.8755 & & & & 0.0000 \\
\hline AIC & 14099.12 & 14053.24 & 14055.46 & 14069.21 & 535.67 & 14052.23 & 14062.35 & 14078.25 \\
\hline $\mathrm{BIC}$ & 14137.68 & 14113.83 & 14149.10 & 14206.91 & 575.59 & 14112.82 & 14155.99 & 14215.95 \\
\hline Log Likelihood & -7042.56 & -7015.62 & -7010.73 & -7009.6 & -260.83 & -7015.12 & -7014.17 & -7014.13 \\
\hline N Parameters & 7 & 11 & 17 & 25 & 7 & 11 & 17 & 25 \\
\hline$-2 *$ LL Difference & & $53.88 * *$ & 9.78 & 2.26 & & $56.82 * *$ & 1.90 & 0.08 \\
\hline df LL Difference & & 4 & 6 & 8 & & 4 & 6 & 8 \\
\hline Hypothesis 8 Supported? & \multicolumn{4}{|c|}{ Not Supported } & \multicolumn{4}{|c|}{ Not Supported } \\
\hline Hypothesis 9 Supported? & & & & Not Supported & & & & Not Supportec \\
\hline
\end{tabular}

Note. ${ }^{* *} p<.01 .{ }^{*} p<.05$. EWIF = Episodic work-to-family conflict. EFIW = Episodic family-to-work conflict. $\sigma^{2}=$ level 1 (residual, within person) variance. $\tau_{00}=$ level 2 (day) intercept variance. $\tau_{11}=$ level 2 (day) linear time variance. $\tau_{22}=$ level 2 (day) reactivity variance. $\tau_{33}=$ level 2 (day) linear recovery variance. $\tau_{000}=$ level 3 (person) intercept variance. $\tau_{111}=$ level 3 (person) linear time variance. $\tau_{222}=$ level 3 (person) reactivity variance. $\tau_{333}=$ level 3 (person) linear recovery variance. $\mathrm{AIC}=$ Akaike's information criteria. $\mathrm{BIC}=$ Bayesian information criteria. $\mathrm{LL}=\mathrm{Log}$ likelihood. $\mathrm{df}=\mathrm{degrees}$ of freedom. 
Table 26. Systolic blood pressure discontinuous growth modeling random effects results.

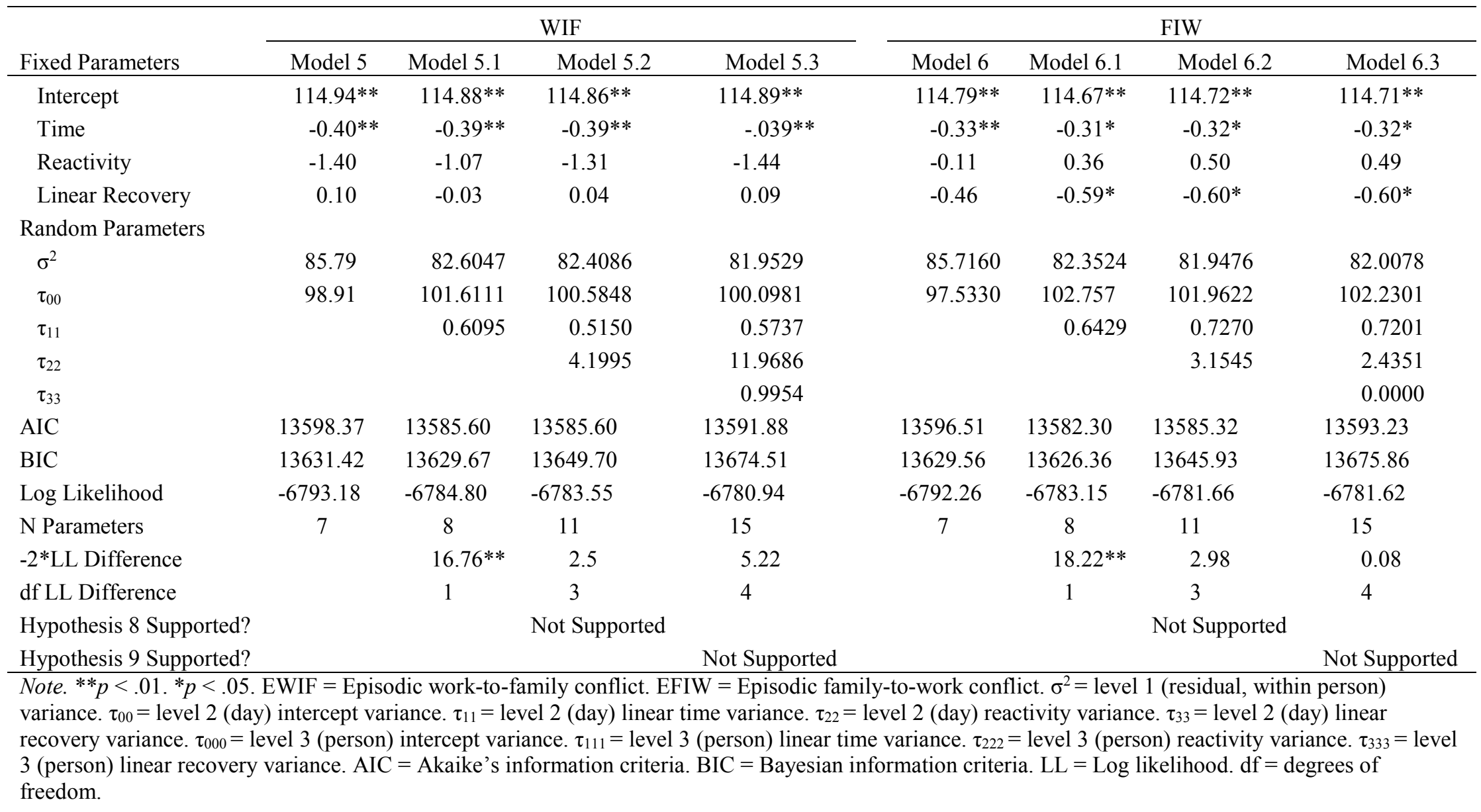


Table 27. Diastolic blood pressure discontinuous growth modeling random effects results.

\begin{tabular}{|c|c|c|c|c|c|c|c|c|}
\hline \multirow[b]{2}{*}{ Fixed Parameters } & \multicolumn{4}{|c|}{ WIF } & \multicolumn{4}{|c|}{ FIW } \\
\hline & Model 5 & Model 5.1 & Model 5.2 & Model 5.3 & Model 6 & Model 6.1 & Model 6.2 & Model 6.3 \\
\hline Intercept & $72.50 * *$ & $75.46^{* *}$ & $72.43 * *$ & $72.42 * *$ & $72.66^{* *}$ & $72.60 * *$ & $72.61 * *$ & $72.60 * *$ \\
\hline Time & $-0.42 * *$ & $-0.40 * *$ & $-0.40 * *$ & $-0.39 * *$ & $-0.38 * *$ & $-0.37 * *$ & $-0.36 * *$ & $-0.35 * *$ \\
\hline Reactivity & 0.46 & 0.72 & 0.80 & 0.82 & -0.93 & -0.66 & -0.60 & -0.64 \\
\hline Linear Recovery & -0.09 & -0.22 & -0.21 & -0.17 & -0.10 & -0.19 & -0.20 & -0.20 \\
\hline \multicolumn{9}{|l|}{ Random Parameters } \\
\hline$\sigma^{2}$ & 59.8448 & 56.9736 & 56.5978 & 56.4934 & 59.7442 & 56.9511 & 56.7984 & 56.6359 \\
\hline$\tau_{00}$ & 47.6800 & 63.9902 & 62.9519 & 63.9939 & 46.9690 & 63.2037 & 60.7309 & 60.4934 \\
\hline$\tau_{11}$ & & 0.5583 & 0.4855 & 0.54408 & & 0.5412 & 0.5529 & 0.6210 \\
\hline$\tau_{22}$ & & & 5.2027 & 6.8187 & & & 1.5609 & 1.3012 \\
\hline$\tau_{33}$ & & & & 0.2676 & & & & 0.2802 \\
\hline AIC & 12912.73 & 12887.98 & 12888.43 & 12894.84 & 12909.32 & 12885.62 & 2887.57 & 12894.14 \\
\hline $\mathrm{BIC}$ & 12945.78 & 12932.05 & 12949.02 & 12977.46 & 12942.36 & 12929.68 & 12948.16 & 12976.77 \\
\hline Log Likelihood & -6450.37 & -6435.99 & -6433.22 & -6432.42 & -6448.66 & -6434.81 & -6432.78 & -6432.07 \\
\hline N Parameters & 7 & 8 & 11 & 15 & 7 & 8 & 11 & 15 \\
\hline$-2 *$ LL Difference & & $28.76^{* *}$ & 5.54 & 1.60 & & $27.70^{* *}$ & 4.06 & 1.42 \\
\hline $\begin{array}{l}\text { df LL Difference } \\
\text { Hypothesis } 8\end{array}$ & & 1 & 3 & 4 & & 1 & 3 & 4 \\
\hline $\begin{array}{l}\text { Supported? } \\
\text { Hypothesis } 9\end{array}$ & & & Not Supported & & & & Not Supported & \\
\hline Supported? & & & & Not Supported & & & & Not Supported \\
\hline
\end{tabular}

Note. ${ }^{* *} p<.01 .{ }^{*} p<.05 . \mathrm{EWIF}=$ Episodic work-to-family conflict. EFIW = Episodic family-to-work conflict. $\sigma^{2}=$ level 1 (residual, within person) variance. $\tau_{00}=$ level 2 (day) intercept variance. $\tau_{11}=$ level 2 (day) linear time variance. $\tau_{22}=$ level 2 (day) reactivity variance. $\tau_{33}=$ level 2 (day) linear recovery variance. $\tau_{000}=$ level 3 (person) intercept variance. $\tau_{111}=$ level 3 (person) linear time variance. $\tau_{222}=$ level 3 (person) reactivity variance. $\tau_{333}=$ level 3 (person) linear recovery variance. AIC = Akaike's information criteria. BIC = Bayesian information criteria. $\mathrm{LL}=\mathrm{Log}$ likelihood. $\mathrm{df}=\mathrm{degrees}$ of freedom. 
Table 28. Unhealthy eating discontinuous growth modeling random effects results.

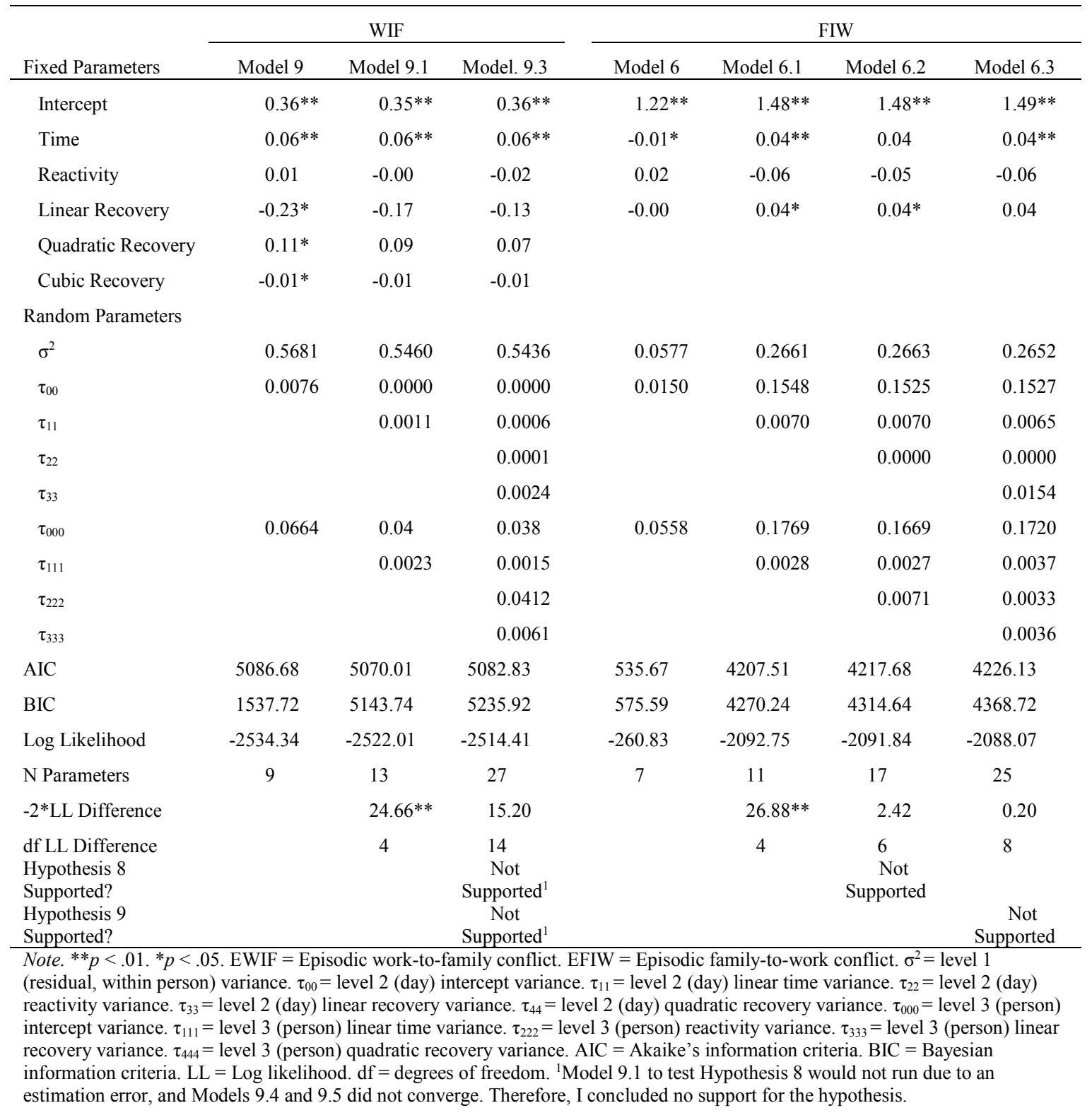

\section{Planned Post-Hoc Analyses}

The hypothesized analyses explored timing of EWIF/EFIWs, as well as acute strain reactivity and recovery in response to a single EWIF/EFIW. However, they did not explore what happens to strain as EWIF/EFIWs accumulate over time. The accumulation of stressors is a key tenet of the allostatic load model (McEwen, 1998), which theoretically should result in 
accumulation of strain (i.e., allostatic load). The following analyses examine whether accumulation of EWIF/EFIW elicits increased strain reactions across four time spans. First, I explore whether strain reactivity and recovery patterns differ when they occur at the beginning of the week (Mondays, prior to weekly accumulation) or the end of the week (Fridays, after weekly accumulation). Second, I examine whether acute accumulation of multiple EWIF/EFIWs that occur in short succession accentuate recovery or prolong reactivity (i.e., maladaptive strain patterns indicative of allostatic load). Third, I examine whether daily accumulation of EWIF/EFIWs results in accumulation of strain throughout the day. Finally, I examine whether EWIF/FIW accumulation across the first three days of participation results in accumulation of strain. A summary of all hypothesized and post-hoc growth modeling results can be found in Table 29. 
Table 29. Summary of growth modeling hypothesized and post-hoc results.

\begin{tabular}{|c|c|c|c|c|c|c|c|c|c|c|c|c|c|}
\hline \multirow[b]{2}{*}{ Hypothesized Results } & \multirow{2}{*}{$\begin{array}{c}\text { Indicates Support for } \\
\text { Theory }\end{array}$} & \multicolumn{2}{|c|}{ State Fatigue } & \multicolumn{2}{|c|}{$\begin{array}{c}\text { State Negative } \\
\text { Affect }\end{array}$} & \multicolumn{2}{|c|}{ Heart Rate } & \multicolumn{2}{|c|}{$\begin{array}{l}\text { Systolic Blood } \\
\text { Pressure }\end{array}$} & \multicolumn{2}{|c|}{$\begin{array}{c}\text { Diastolic Blood } \\
\text { Pressure }\end{array}$} & \multicolumn{2}{|c|}{ Unhealthy Eating } \\
\hline & & EWIF & EFIW & EWIF & EFIW & EWIF & EFIW & EWIF & EFIW & EWIF & EFIW & EWIF & EFIW \\
\hline Reactivity & + & + & - & 0 & 0 & 0 & - & 0 & 0 & 0 & 0 & 0 & 0 \\
\hline Recovery & - & - & + & 0 & 0 & - & 0 & 0 & 0 & 0 & 0 & $+*$ & 0 \\
\hline Variability & Yes & Yes & No & Yes & No & No & No & No & No & No & No & No & No \\
\hline \multicolumn{14}{|l|}{ Post-Hoc Results } \\
\hline Reactivity Different on Monday & - & - & & 0 & & & & & & & & & \\
\hline Recovery Different on Monday & - & 0 & & 0 & & & & & & & & & \\
\hline Reactivity Different on Friday & + & 0 & & 0 & & & & & & & & & \\
\hline Recovery Different on Friday & + & 0 & & 0 & & & & & & & & & \\
\hline Two Hour Accumulation & + & 0 & & 0 & & & & & & & & & \\
\hline Daily Accumulation & + & + & - & + & 0 & 0 & - & 0 & + & 0 & 0 & 0 & 0 \\
\hline Multi-Day Accumulation & + & + & + & 0 & + & 0 & - & 0 & 0 & 0 & - & 0 & 0 \\
\hline
\end{tabular}




\section{Reactivity and Recovery on Monday and Friday}

The hypothesized reactivity and recovery analyses assume that EWIF/EFIW experiences across days are interchangeable. However, days of the week may vary systematically in terms of stress accumulation or routine. Mondays were chosen as a start day in the current study, as they represent the start of a weekly rhythm. Because Mondays follow a weekend-long respite, reactivity and recovery to a conflict on Monday may be smaller than one experienced after the accumulation of a full week managing work and family. Similarly, Friday reflects a unique endof-week transition day after EWIF/EFIW has had the opportunity to accumulate. Thus EWIF/FIW on Fridays may have accentuated reactivity and recovery patterns. I tested whether reactivity and recovery patterns were different on Mondays or on Fridays compared to other days of the week. A significant interaction term would indicate reactivity to or recovery from EWIF are different for Mondays (of for Fridays) compared to other days of the week. The analysis was only run for state fatigue and state negative affect regressed on EWIF, because these were the only outcomes to show significant variance in reactivity and recovery (Table 23, Model 7.4 and Table 24, Model 5.3). Building on Model 7.4 (state fatigue) and Model 5.3 (state negative affect), I entered Monday (dummy coded $1=$ Monday, $0=$ not Monday) or Friday (dummy $\operatorname{coded} 1=$ Friday, $0=$ not Friday) as a level 2 fixed predictor of reactivity and recovery parameters.

Regarding state fatigue, Monday moderated reactivity $\left(\gamma_{31}=-.30, p<.01\right)$, but not recovery (linear $\gamma_{41}=-.01, p=.46$; quadratic $\gamma_{51}=-.01, p=.47$ ). The significant result indicates fatigue is less reactive to EWIF on Mondays compared to other days of the week. There was no main effect of Monday on state fatigue $\left(\beta_{4 \mathrm{j}}=.06, p=.31\right)$. Friday did not moderate reactivity $\left(\gamma_{31}\right.$ 
$=-.01, p=.97$ ) or recovery (linear $\gamma_{41}=.08, p=.12$; quadratic $\gamma_{51}=.01, p=.36$ ). However, Friday had a significant main effect on state fatigue $\left(\beta_{4 \mathrm{j}}=-.14, p=.03\right)$, such that state fatigue was lower on Fridays compared to other days of the week. Regarding state negative affect, reactivity $\left(\gamma_{31}=-.00, p=.99\right)$ and recovery $\left(\gamma_{41}=-.02, p=.34\right)$ were not different on Mondays compared to other days of the week. Monday also had no significant main effect on state negative affect $\left(\beta_{4 \mathrm{j}}=-.00, p=.34\right)$. Reactivity and recovery were also not different on Fridays compared to other days of the week (reactivity $\gamma_{31}=-.00, p=.94$; recovery $\gamma_{41}=.02, p=.25$ ). However, Friday had a significant main effect on state negative affect, such that state negative affect was lower on Fridays compared to other days of the week $\left(\beta_{4 j}=-.06, p=.03\right)$. Based on these results, I conclude EWIFs that occur on Monday and Friday elicit similar reactivity and recovery patterns compared to other days of the week.

\section{Two Hour Accumulation of EWIF/EFIWs}

Several participants reported more than one instance of conflict within a two hour window on the Monday-Wednesday surveys (see Table 15 for frequencies). Given that there were a sufficient number of reports $(>30)$ with two or more reported EWIF/EFIWs, I tested whether individuals who experienced a high number of EWIF/EFIWs within a given two hour window differed in their reactivity and recovery patterns relative to those with fewer EWIF/EFIWs. A significant, positive interaction term would support the allostatic load model, indicating that multiple EWIFs occurring in short-term succession (within 2 hours) creates an accentuated reaction or prolonged recovery to the most recent EWIF. The analysis was only run for state fatigue and state negative affect regressed on EWIF, because these were the only outcomes to show significant variance in reactivity and recovery (Table 23, Model 7.4 and Table 24, Model 5.3). Building upon each final model (Model 7.4 for state fatigue, Model 5.3 for state 
negative affect), the number of EWIF occurring at the same time as the first focal EWIF was entered as a fixed level 2 predictor of reactivity, then as a fixed level 2 predictor of recovery parameters. In each model, the non-moderated reactivity or recovery parameters were fixed to achieve model convergence.

State fatigue reactivity $\left(\gamma_{31}=-.07, p=.27\right)$ and recovery $\left(\right.$ linear $\gamma_{41}=.04, p=.15$; quadratic $\gamma_{51}=.00, p=.48$ ) were not modified by the number of EWIFs at the time of the first focal EWIF. In each model, there was no main effect of number of EWIFs at the first focal time point on daily state fatigue $(p>.40)$. The number of EWIFs at the time of the first EWIF also did not modify state negative affect reactivity $\left(\gamma_{31}=-.01, p=.71\right)$, or recovery $\left(\gamma_{41}=.02, p=.12\right)$. However, the number of EWIFs occurring at the first focal time point had a significant main effect on state negative affect $\left(\beta_{4 \mathrm{j}}=.05, p<.01\right)$. This main effect suggests that negative affect was higher on days when the first focal time point had more EWIFs compared to fewer EWIFs.

\section{Daily Accumulation of EWIF/EFIWs}

Several participants also reported more than one EWIF/EFIW per day (58 days with 2 or more EWIF $($ Mean $=0.42$ EWIF per day, Maximum $=8$ EWIF per day $), 68$ days with 2 or more EFIW (Mean $=0.48$ EFIW per day, Maximum $=12$ EFIW per day). Given that there were a sufficient number of reports $(>30)$ with two or more reported EWIF/EFIWs per day, I tested whether accumulation of EWIF/EFIWs throughout the day predicted change in strain outcomes throughout the day. EWIF/EFIW daily accumulation was computed by adding all of the EWIF/EFIW occurrences at or before a given time each day (see Table 13 for an example). Building off of Model 2 for each outcome, I added EWIF/EFIW linear daily accumulation, quadratic daily accumulation (linear accumulation squared), and cubic daily accumulation (linear accumulation cubed) as fixed level 1 predictors. Each parameter was added to the model one at a 
time (Bliese \& Ployhart, 2002). Consistent with published recommendations (Bliese, 2016; Bliese \& Ployhart, 2002), I focused on the significance of the fixed parameters to determine a final model. The model for each outcome with the most complex significant accumulation term was retained for interpretation. A significant, positive accumulation slope would support the allostatic load model, indicating that as EWIF/EFIWs accumulate through the day, strain also increases throughout the day.

State fatigue was positively associated with EWIF daily accumulation (linear $\beta_{2 \mathrm{j}}=.05, p$ $=.046)$. However, state fatigue decreased as EFIW accumulated throughout the day (quadratic $\beta_{3 \mathrm{j}}=.01, p<.01$; see Figure 15$)$. State negative affect was positively associated with EWIF daily accumulation (linear $\left.\beta_{2 \mathrm{j}}=.03, p=.01\right)$, but not EFIW daily accumulation $\left(\beta_{2 \mathrm{j}}=.01, p=.14\right)$. Heart rate was not associated with EWIF daily accumulation $\left(\beta_{2 \mathrm{j}}=-.54, p=.26\right)$. Similar to fatigue, heart rate decreased as EFIW accumulated throughout the day (linear $\beta_{2 \mathrm{j}}=-.92, p<.01$ ). Systolic blood pressure was not associated with EWIF daily accumulation $\left(\beta_{2 \mathrm{j}}=.18, p=.63\right)$ and significantly increased as EFIW accumulated throughout the day $\left(\beta_{2 \mathrm{j}}=.68, p<.01\right)$. Diastolic blood pressure was not associated with EWIF or EFIW daily accumulation $\left(\beta_{2 \mathrm{j}}=-.01, p=.98 ; \beta_{2 \mathrm{j}}\right.$ $=.24, p=.24$, respectively). Finally, unhealthy eating was not associated with EWIF or EFIW daily accumulation $\left(\beta_{2 \mathrm{j}}=.01 . p=.51 ; \beta_{2 \mathrm{j}}=-.01, p=.42\right.$, respectively). 


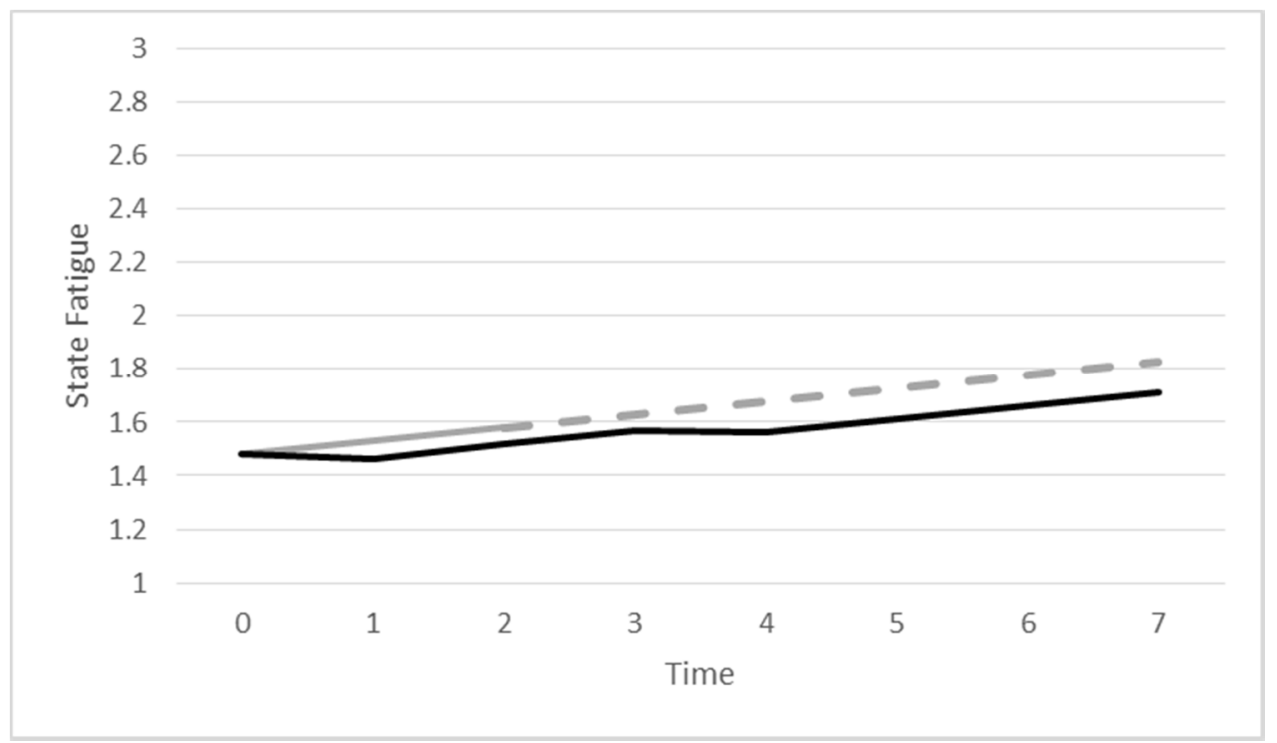

Figure 15. Graphic representation of state fatigue change as EFIW accumulates.

Note. One graphed EFIW occurs at time point two (10 AM), and two additional graphed EFIW occur at time point four (4 PM). The solid grey line represents the predicted linear change in state fatigue over time before a conflict occurs. The solid black line represents the change in state fatigue as EFIW accumulates. The dotted grey line represents the predicted change in state fatigue if an EFIW had not occurred.

\section{Multi-Day Accumulation of EWIF/EFIWs}

Several participants reported more than one EWIF $(\mathrm{N}=42)$ or EFIW $(\mathrm{N}=48)$ throughout their first three days of participation $(E W I F$ Mean $=1.73, \mathrm{SD}=2.26$, Maximum $=10$; EFIW Mean $=2.50, \mathrm{SD}=3.67$, Maximum $=26$ ). Given that there were a sufficient number of participants reporting multiple EWIF/EFIWs, I examined the relationship between EWIF/EFIW accumulation and strain across the first three days of participation. This analysis used recoded linear time, such that time was continuous throughout the participant's first three days; an increase of 1 reflected 2 hours (see Table 13, three day time parameter). Therefore, the following models were tested with only two levels: within-person level and person level. EWIF/EFIW three day accumulation was computed by adding all of the EWIF/EFIW occurrences at or before a given time for each participant (see Table 13 for an example). Building off of Model 2 for each 
outcome, I added EWIF/EFIW linear three day accumulation, quadratic three day accumulation (linear accumulation squared), and cubic three day accumulation (linear accumulation cubed) as fixed level 1 predictors. Each parameter was added to the model one at a time. The significance of the fixed parameters was used to determine the final model (Bliese, 2016; Bliese \& Ployhart, 2002). The model for each outcome with the most complex significant accumulation term was retained for interpretation. A significant, positive three day accumulation slope would support the allostatic load model, indicating that as EWIF/EFIWs accumulate across multiple days, strain also increases.

State fatigue was positively associated with EWIF three day accumulation (linear $\beta_{2 \mathrm{j}}=$ $.07, p<.01$ ) and EFIW three day accumulation (linear $\beta_{2 \mathrm{j}}=.04, p<.01$ ). State negative affect not associated with EWIF accumulation over three days $\left(\beta_{2 \mathrm{j}}=.00, p=.60\right)$; however state negative affect increased with EFIW accumulation over three days (quadratic $\beta_{3 \mathrm{j}}=-.001, p=.04$; see Figure 16). Heart rate was not related to EWIF accumulation over three days $\left(\beta_{2 \mathrm{j}}=-.64, p=\right.$ .07 ), and heart rate decreased as EFIW accumulated (linear $\beta_{2 \mathrm{j}}=-.53, p<.01$ ). Systolic blood pressure was not related to EWIF or EFIW accumulation over three days $\left(\beta_{2 \mathrm{j}}=.01, p=.97 ; \beta_{2 \mathrm{j}}=\right.$ $.07, p=.66$, respectively). Diastolic blood pressure was not related to EWIF accumulation over three days $\left(\beta_{2 \mathrm{j}}=-.00, p=.99\right)$; however, diastolic blood pressure significantly decreased as EFIW accumulated (quadratic $\beta_{3 \mathrm{j}}=.02, p=.049$; see Figure 17). Unhealthy eating was not related to EWIF or EFIW accumulation over three days $\left(\beta_{2 \mathrm{j}}=.01, p=.58 ; \beta_{2 \mathrm{j}}=.01, p=.28\right.$, respectively). 


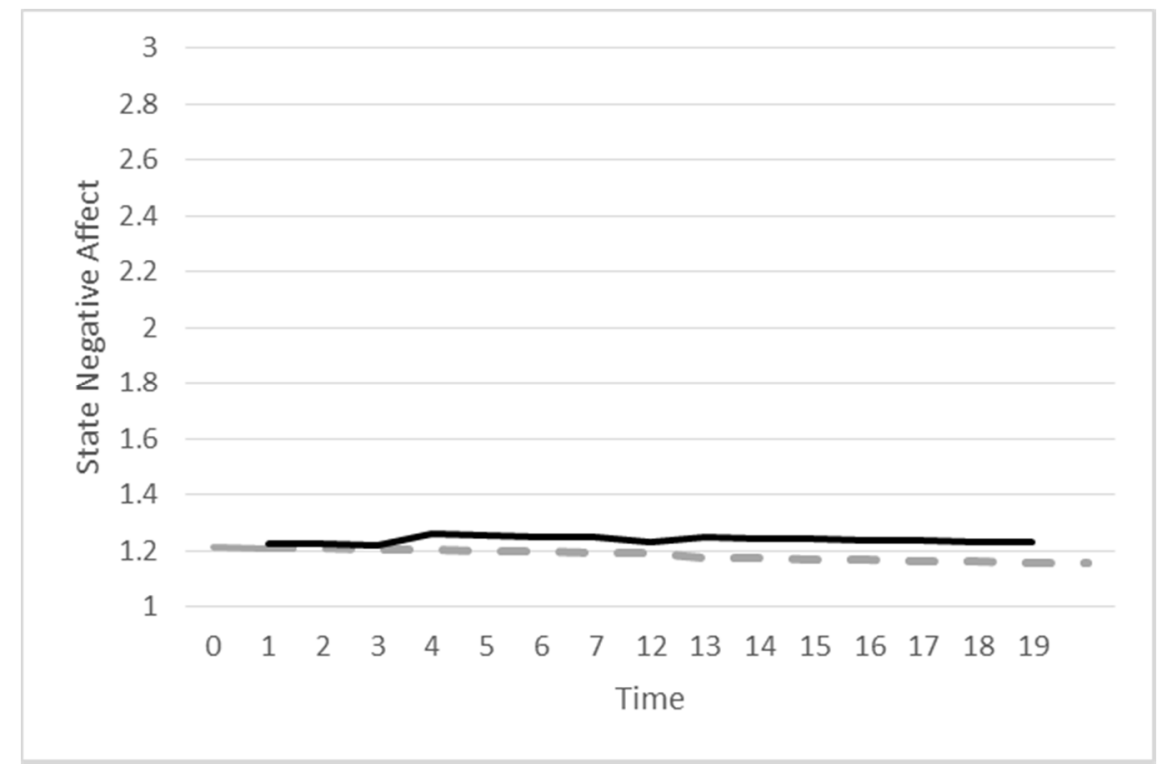

Figure 16. Graphic representation of state negative affect change as EFIW accumulates.

Note. One graphed EFIW occurs at time point two (10 AM, Day 1), two additional graphed EFIW occur at time point four (4 PM, Day 1), and one additional graphed EFIW occurs at time point 13 (10 AM, Day 2). The solid grey line represents the predicted linear change in state negative affect over time before a conflict occurs. The solid black line represents the change in state negative affect as EFIW accumulates. The dotted grey line represents the predicted change in state negative affect if an EFIW had not occurred.

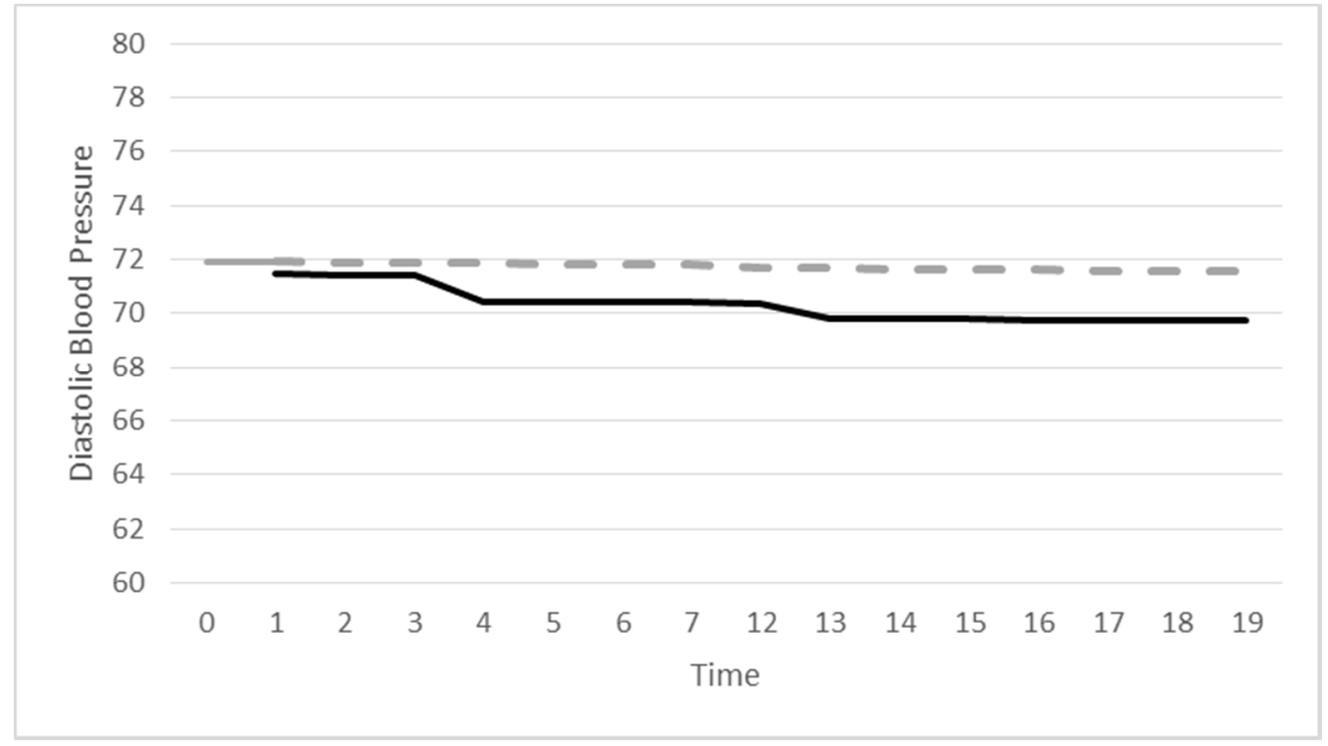

Figure 17. Graphic representation of diastolic blood pressure change as EFIW accumulates.

Note. One graphed EFIW occurs at time point two (10 AM, Day 1), two additional graphed EFIW occur at time point four (4 PM, Day 1), and one additional graphed EFIW occurs at time point 13 (10 AM, Day 2). The solid grey line represents the predicted linear change in diastolic blood pressure over time before a conflict occurs. The solid black line represents the change in 
diastolic blood pressure as EFIW accumulates. The dotted grey line represents the predicted change in diastolic blood pressure if an EFIW had not occurred.

\section{Hypothesized Analyses with Controls}

Cardiovascular measures are susceptible to a wide range of error, due to recent activities (e.g., caffeine intake) or activities during the heart rate/blood pressure reading (e.g., body position). I ran the hypothesized reactivity, recovery, and post-hoc accumulation analyses for heart rate, systolic blood pressure, and diastolic blood pressure controlling for each cardiovascular control item. Only two results were significantly different after entering cardiovascular controls. Specifically, the three day accumulation relationship for EWIF and heart rate became statistically significant $(p<.05)$. After accounting for cardiovascular controls, heart rate increased as EWIF accumulated over three days. The three day accumulation relationship for EFIW and diastolic blood pressure became non-significant $(p>.05)$. After accounting for cardiovascular controls, diastolic blood pressure was not associated with EFIW accumulation.

Finally, all strain outcomes may be susceptible to change due to other strenuous events during the day. To account for these events, I ran all hypothesized reactivity, recovery, and posthoc accumulation analyses, controlling for whether or not participants encountered a stressful event within the last two hours (coded $1=$ stressful event occurred, $0=$ no stressful event occurred). None of the original conclusions changed after adding this item as a control. 


\section{CHAPTER FOUR: DISCUSSION}

The present study examined the temporal nature of episodic work-family conflict. There were two primary study aims: to understand when work-family conflict episodes occur in objective time, and to understand acute reactivity and recovery patterns to a single conflict episode over the course of a day. Overall, this study adds to theoretical and empirical understanding of work-family conflict as an episodic process that unfolds in real time.

\section{Timing of Episodic Work-Family Conflict.}

The results suggest EWIF/EFIWs occur when individuals transition between work and family domains. When switching between spending time on work versus spending time on family, individuals were nearly 9 times more likely to experience an EWIF and over 7 times more likely to experience an EFIW compared to non-transition times. When individuals transition between work/family locations, they were 4 times more likely to experience EWIF and nearly 2.5 times more likely to experience EFIW than times when they stayed within a single domain location. Similarly, the odds of having an EFIW increased 2.5 fold when making a scheduled transition to work, and the odds of having an EWIF increased 1.5 fold when making a scheduled transition from work to home.

Although the results support the relationship between micro transitions and EWIF/EFIW, weekly transition days (Mondays, Fridays) were not associated with EWIF/EFIW. To the contrary, none of the variability in EWIF or EFIW was attributable to the day level. Consistent 
with previous research, the majority of variance appears to be within-person, suggesting EWIF/EFIW occurrence depends primarily on day-to-day events (Barnett, 2016; Shockley \& Allen, 2014). Differences between days of the week may only emerge if each day's events are meaningfully distinct from other days, but also consistent across participants. For example, a sample of faculty members who all teach on Mondays and Wednesdays may show differences between days of the week, because the whole sample not only has similarity in schedule, but also in the behaviors, time, and cognitive energy necessary for carrying out that work. This idea would imply that individuals have weekly EWIF/EFIW patterns, but that those patterns differ at the person level, depending on characteristics of work and/or family. A comparison of weekdays versus weekends may also be more likely to yield significant differences, as weekdays are likely to have more frequent transitions compared to weekend days for all participants. A final reason for lack of findings may be error variance due to random occurrences. For example, participants reported events such as getting sick, taking a child to the hospital, court appointments, a death in the family, and teenager driving test drama. Such random life events tend to alter an entire day or more, contributing random variance to day of the week and masking possible effects.

\section{Episodic Work-Family Conflict and Strain}

In general, the results did not support the notion that EWIF/EFIW elicit acute strain reactions, nor that strain recovers throughout the rest of the day after an EWIF/EFIW has occurred. However, post-hoc analyses showed accumulation of EWIF/EFIW over the course of single or multiple days was associated with increased psychological strain. The latter finding is consistent with the allostatic load model, which asserts that accumulation of stressors fosters strain (McEwen, 1998). The accumulation findings are also consistent with correlational findings 
that examine average work-family conflict (e.g., Amstad et al., 2011; Allen \& Armstrong, 2006), as well as levels-based daily research, which has supported direct relationships between daily work-family conflict levels and daily negative affect (Almeida, Davis, Lee, Lawson, Walter, \& Moen, 2016; Chi et al., 2016; Garrosa-Hernández et al., 2013; Ilies, Huth, Ryan, \& Dimotakis, 2015; Ilies et al., 2007), anxiety (McEwen \& Barling, 1994), daily and momentary distress (Bono, Glomb, Shen, Kim, \& Koch, 2013; Williams \& Alliger, 1994), and daily negative emotions such as guilt and hostility (Judge, Ilies, \& Scott, 2006).

Few findings indicated relationships between either acute EWIF/EFIW reactivity and recovery or accumulation and physiological or behavioral outcomes. Thus, our findings run counter to the few studies that demonstrate relationships between work-family conflict levels and unhealthy eating (Allen \& Armstrong, 2006), momentary heart rate (Shockley \& Allen, 2012), and daily systolic blood pressure (Bono et al., 2013). It may be that EWIF/EFIW simply do not generate strong cardiovascular or eating responses. The present study outcomes were chosen based on responses that might show acute reactivity and recovery based on laboratory stress studies (e.g., Chida \& Hamer, 2008). However, given the lack of support for momentary reactions, physiological and behavioral responses that have a slower, or more lagged time frame, may be more appropriate. For example, recently published work from the Work, Family, and Health Network shows daily work-family conflict is associated with day-level sleep onset latency (Lee, Crian, McHale, Almeida, \& Buxton, 2017), as well is diurnal cortisol patterns (Almeida et al., 2016). Perhaps a shift in longer term outcomes that respond after strain accumulation has developed would yield more significant findings.

A few notable exceptions supported the reactivity and recovery hypotheses. State fatigue showed the expected reactivity and recovery pattern when an EWIF occurred, such that fatigue 
increased at the time of an EWIF, decreased in the time point following the EWIF, then continued to increase throughout the remainder of the day. This pattern is consistent with a normal reactivity (McEwen \& Seeman, 1999) or a stress-reaction pattern (Frese \& Zapf, 1988). Although heart rate and unhealthy eating did not show significant reactivity as predicted, each showed recovery after an EWIF. Heart rate linearly decreased following an EWIF, consistent with the recovery hypothesis. Unhealthy eating remained fairly stable at the next time point, then increased at an accelerated rate such that individuals who had an EWIF were increasingly likely to eat unhealthy foods at the end of the day compared to those who did not have an EWIF. This pattern is consistent with the sleeper effect response identified by Frese \& Zapf (1988). In addition, significant variation in reactivity and recovery patterns was found for both psychological strains (state fatigue, state negative affect), albeit not for physiological or behavioral strain. Thus, a variety of psychological strain reactivity and recovery patterns are plausible beyond the fixed effects estimated for the sample.

Two reactivity results were opposite of the predicted direction. Specifically, heart rate decreased at the time of an EWIF, and fatigue decreased at the time of an EFIW. Research on cardiovascular reactivity shows heart rate is likely to increase in response to a stressor as long as effort is required, individuals perceive they may successfully resolve the stressor, and there is a perceived benefit of success (Brehm \& Self, 1989; Richter, Gendolla, \& Wright, 2016). Cardiovascular responses are also likely to occur in response to unexpected, or socially threatening stressors (Chida \& Hamer, 2008). It may be that EWIF/EFIWs in the present study do not fit this criteria. For example EWIF/EFIWs may be relatively benign in nature, taking little or no effort to mitigate (e.g., quickly ending a spouse's phone call at work by promising to call back at a more opportune time). It may also be that there is little benefit to navigating 
EWIF/EFIW successfully, or that conflicts involve fairly little potential threat to oneself. It is also plausible that main EIWF/FIWs are private events that affect only the individual (e.g., being mentally distracted by a family argument while at work), rather than a social event that may be evaluated by others. Finally, cardiovascular reactivity tends to weaken in response to reoccurring, yet resolved, stressors as individuals adapt and develop effective coping strategies (Matthews, Gump, \& Owens, 2001; McEwen, 1998). The accumulation findings in present study similarly show decreases in heart rate and diastolic blood pressure as EFIW accumulates. It may be that individuals simply have adjusted to reoccurring EWIF/EFIW as a stressor and therefore show a blunted cardiovascular response.

Fatigue also showed an unexpected decrease at the time of an EFIW. Accumulation of EFIW is similarly associated with decreased state fatigue and heart rate throughout the day, as well as decreased heart rate and diastolic blood pressure over three days. Although EWIF daily accumulation was associated with increased state negative affect, EFIW daily accumulation was not. Combined, these trends imply that EFIW is potentially rejuvenating, or energizing instead of depleting. At the very least, evidence shows EFIW engenders a weaker strain reaction compared to EWIF. Perhaps EFIWs are perceived as welcome respites during the work day, rather than unwelcome intrusions. It may also be that EFIW reports are actually purposeful work breaks taken by participants to catch up with family members, commiserate work hassles, or take care of family to-dos. 


\section{Theoretical Implications}

\section{Timing of Episodic Work-Family Conflict}

The present results lend strong support to border and boundary theory, which suggest that role transitions create the potential for role spillover and conflict (Ashforth et al., 2000; Clark, 2000). The results also complement previous levels-based research, which suggests self-reported levels of boundary-spanning behavior and inter-domain transitions are associated with increased work-family conflict (Galvin \& Schieman, 2010; Matthews et al., 2010; Matthews et al., 2014). Specifically, the results extend this work by examining transitions and work-family conflict as they co-occur in real time to more precisely and rigorously test the propositions in boundary theory. Moreover, previous work primarily focuses on temporal transitions (e.g., Butts, Becker, \& Boswell, 2015; Glavin \& Schieman, 2010; Kossek, Ruderman, Braddy, Hannum, 2012) or mixes temporal and spatial transitions into a single measure of transition activity (e.g., Matthews et al., 2010). The present study separates the two types of transitions. In doing so, I demonstrate that both spatial and temporal transitions are associated with EWIF/EFIW. Interestingly, the relationships between temporal transitions and EWIF/EFIW are significantly stronger and more than double the effect size of spatial transition relationships with EWIF/EFIW. Theoretically, the difference in effect sizes suggests spatial and temporal transitions are unique and possibly operate in distinct ways. For example, temporal transitions may be quick, abrupt, or unexpected (e.g., attending to an unsolicited work email during dinner), primarily reflecting task switching within a single domain. In contrast, spatial transitions may be planned or scheduled, and take time to enact (e.g., commute to work in the morning). It is this contrast in timing and expectation that may make temporal transitions more effortful to navigate or more prone to spillover. In 
support of this idea, the scheduled transitions in our study had similar effect sizes to spatial transitions.

Present findings also have implications for boundary management strategies. Generally, boundary management strategies are measured as personal characteristics on a continuum ranging from segmentation to integration (Ashforth et al., 2000; Allen, Cho, \& Meier, 2014), although some research investigates more complex strategy combinations (e.g., Kreiner et al., 2009; Kossek et al., 2012). Segmentors keep work and family separate and maintain rigid, distinct role boundaries which do not permit permeations of work into family or vice versa. For example, segmentors may only complete work during scheduled working hours and may be reluctant to take family calls while at work. Integrators blend their work and family responsibilities together, frequently altering role boundaries and allowing cross-domain permeation. For example, integrators may work from home in the evenings, and may frequently discuss personal family matters with coworkers. Previous research suggests integration is associated with increased work-family conflict (Allen et al., 2014). Our results suggests it may be the permeation aspect of integration which facilitates work-family conflict. Allowing work/home to permeate the alternative domain theoretically allows for temporal transitions between work and family while in a single domain. Thus, the frequency of temporal transitions (or switching between work and family tasks) explains why integrators experience more workfamily conflict compared to their segmentor counterparts.

Finally, the scheduled transition results theoretically support the cross-domain hypothesis, which suggests WIF originates in the work domain and interferes with activities in the family domain, while FIW originates in the family domain and interferes with activities in the work domain. Consistent with this notion, individuals were likely to experience EFIW when 
entering the work domain in the morning and were likely to experience EWIF when entering the family domain in the afternoon. Thus the pattern suggests EWIF/EFIW originates in the previous, pre-transition domain and interferes with activities in the current, or post-transition domain. The transition results in combination with frequencies of EWIF/EFIW throughout the day (Table 14) also suggest EWIF and EFIW follow a daily pattern, such that EFIW is primarily experienced in the morning and early afternoon (while at work), and EWIF is primarily experienced in the late afternoon and evening (while at home).

\section{Episodic Work-Family Conflict and Strain}

Both the stressor-strain model (Frese \& Zapf, 1988) and the allostatic load model (McEwen, 1998) suggest stressors elicit acute strain reactivity and recovery patterns. However, few such patterns were found in the present study when isolating a single EWIF/EFIW. Instead, accumulation of EWIF/EFIW throughout the course of one or more days were associated with increased strain. This finding sheds important light onto theory used to link work-family conflict with strain. Theoretical perspectives hinge on the notion that experiencing a work-family conflict depletes resources (e.g., resource drain, Edwards \& Rothbard, 2000; conservation of resources, Hobfoll, 1989; job demands-resources, Demerouti, Bakker, Nachreiner, \& Schaufeli, 2001) and elicits emotional or strain reactions (e.g., transactional model of stress, Lazarus \& Folkman, 1984; affective events theory, Weiss \& Cropanzano, 1996; effort-recovery theory; Meijman \& Mulder, 1998). The present findings suggest a single EWIF/EFIW does not elicit a detectable strain reaction. Rather, multiple EWIF/EFIW in succession are needed to see a significant strain reaction. This pattern is similar to theoretical accumulation framed as "allostatic load" (McEwen, 1998) or the process of "loss spirals" (Hobfoll, 1989). 
It is possible that acute strain reactivity and recovery were not detected due to the episodic measurement, which classified EWIF/EFIWs dichotomously (occurred vs. did not occur). Theory suggests events must be negatively appraised in order to elicit a strain reaction (e.g., Lazarus \& Folkman, 1984; McEwen, 1998; Weiss \& Cropanzano, 1999). Thus, appraisals of EWIF/EFIW may be needed in order to link work-family conflict with momentary strain. Importantly, the lack of momentary reactivity and recovery suggests work-family conflict may not always be interpreted as a stressor, as is often assumed in theory and empirical work.

It is also possible strains in the present study do not respond acutely to EWIF/EFIW, but change may be seen if examining accumulation over the course of a single or multiple days. The latter would suggest strain responses to EWIF/EFIW are appropriately assessed at the day level, after EWIF/EFIWs have built upon one another and influenced events or later in the day. The post-hoc results support this idea, showing significant increases in strain throughout 1-3 days as EWIF and EFIW accumulate. Additionally, the number of EWIFs was significantly associated with daily-level state negative affect. Similarly, Bono and colleagues (2013) found FIW was related to daily systolic blood pressure, but not momentary systolic blood pressure. Finally, recently published work from the Work, Family, and Health Network shows significant associations between daily work-family conflict is and day-level strains such as sleep quality (Lee, Crian, McHale, Almeida, \& Buxton, 2017) and diurnal cortisol patterns (Almeida et al., 2016).

Among the few significant findings, EWIF, but not EFIW, elicited acute strain reactions and changes in recovery. Similarly, accumulation findings for EWIF were most consistent with stress theories, in that accumulation of EWIF over a single or multiple days was associated with increased psychological strain (e.g., Frese \& Zapf, 1988; Hobfoll, 1989; McEwen, 1989). These 
results suggest EWIF has greater potential to induce strain compared to EFIW. In fact, EFIW only elicited one change in acute strain: a simultaneous decrease in fatigue at the time of a conflict. With some exceptions, EFIW accumulation also tended to have beneficial, rather than detrimental relationships with psychological and physiological strain. The contrast between EWIF and EFIW findings is especially interesting given that EFIW was reported just as often as EWIF. Theoretically, the results suggest EWIF and EFIW are distinct, and that EFIW may not necessarily play the role of a stressor. It may be that EWIF is perceived as a negative hassle, whereas EFIW is perceived as an energizing break from work. In support, one experience sampling study (Williams \& Alliger, 1994) found daily family-to-work conflict was associated with elation, while daily work-to-family conflict was not. Effect sizes with negative states (distress, fatigue) were also weaker for family-to-work conflict compared to work-to-family conflict (Williams \& Alliger, 1994). Because EWIFs are perceived as negative, they may also be more salient when responding to levels measures compared to their more positive EFIW counterparts. This difference in EWIF/EFIW perception might therefore also explain why levelsbased research consistently shows individuals report more WIF compared to FIW, despite equivalent episodic frequencies.

When examining strain outcomes, fatigue reactions were most consistently significant and aligned with the study hypotheses. This pattern suggests EWIF/EFIW tends to most strongly alter energy resources, compared to affective, physiological, or behavioral resources.

Researchers have called for specific attention to energy depletion (Greenhaus, Allen, \& Spector, 2006). In response, experience sampling studies have shown level-based daily work-to-family conflict is associated with increased daily fatigue (Ilies et al., 2015; Van Hoof, Geurts, Kompier, \& Taris, 2006; Williams \& Alliger, 1996). Williams and Alliger's (1994) findings also align with 
the present study in that daily work-to-family conflict was most strongly related to state fatigue, compared to distress, elation, and calmness states. The present findings show energy depletion may be the primary acute strain reaction elicited by EWIF. Energy depletion may therefore also be the primary mechanism linking EWIF with downstream outcomes, such as health behaviors (e.g., unhealthy eating) and work/family role performance (Greenhaus et al., 2006).

The present study found significant variance in reactivity and recovery for psychological strain in response to an EWIF. This suggests not all EWIFs are created equally, and that responses to EWIF may vary within and between individuals. With the exception of specifying type of conflict, previous levels-based research largely ignores the specific content of conflicts. The finding that individual EWIF/EFIW responses differ warrants a deeper dive into what it is like to experience an EWIF/EFIW, and what aspects of EWIF/EFIW may drive differences in reactivity and recovery. In contrast, EFIW did not show variance in reactivity and recovery patterns, suggesting individuals react fairly consistently, regardless of individual differences or characteristics of the EFIW.

The present study addresses the question of when strain reactions to EWIF/EFIW occur. By using episodic measurement several times a day over the course of several days, the present study was uniquely positioned to explore strain reactions using momentary, daily, and multi-day time frames. Stress-relevant theory regarding when strain reactions onset or how long strain reactions last is notoriously vague. Experience sampling studies most typically call upon affective events theory (Weiss \& Cropanzano, 1996), effort-recovery theory (Meijman \& Mulder, 1998), the transactional model of stress (Lazarus \& Folkman, 1984) (Allen et al., 2017). The allostatic load model also suggests stressors elicit acute responses, yet the time frame that qualifies as "acute" is ambiguous (McEwen, 1998; Ganster \& Rosen, 2013). Similarly, theories 
that suggest stressors accumulate never define how long the accumulation period must be in order to see changes in strain (e.g., Hobfoll, 1989; McEwen, 1998). Each of these theories suggests stressors elicit short-term and cumulative strain responses, but no time frames are given. The present findings suggest momentary responses to EWIF/EFIW are small, and often nonsignificant, in magnitude. Instead, strain reactions snowball over the course of the day (or multiple days) as EWIF/EFIW accumulates. Thus, the present study suggests accumulation of EWIF/EFIW over at least one day is needed to see significant changes in strain, and that accumulation may spill over into multiple days. Interestingly, strain reactions that occur at these different time frames are not equivalent. For example, acute and cumulative EFIW reduced psychological strain over shorter time frames (momentary, one day), but increased psychological strain as EFIW accumulated across multiple days.

\section{Practical Implications}

The findings have clear practical implications for organizational practice and policy. The results speak to flexibility initiatives designed to alleviate tensions between work and family. Flexibility can take two forms: flextime, which allows workers to choose when they work, and flexplace, which allows workers to choose where they work (Kossek \& Michel, 2010). The strong effect sizes for temporal transitions suggest flextime may be a more effective strategy for reducing EWIF/EFIW compared to flexplace. Although temporal transitions would still occur, flextime would allow workers to exert control over when temporal transitions are made, potentially dampening their effects on EWIF/EFIW (Kossek \& Michel, 2010). This conclusion aligns with previous meta-analytic work, which shows a stronger relationship between flextime and levels of WIF compared to flexplace (Allen, Johnson, Kiburz, \& Shockley, 2013). Trends in 
effect sizes also indicated transitions had stronger relationships with EWIF compared to EFIW. Thus, our results suggest flextime may be the most effective for reducing EWIF, compared to EFIW. This result also aligns with meta-analytic work (Allen et al., 2013; Byron, 2005), which shows flexibility initiatives are more strongly associated with levels of WIF compared to FIW.

The results show flexibility initiatives, which are designed to ease scheduled transitions, may not necessarily be the most effective means for reducing EWIF/EFIW. Effect sizes for temporal transitions were nearly four times the size of scheduled transitions, suggesting informal task switching is a potent trigger point for EWIF/EFIW. Organizational practices and policies that clearly define work-home communication boundaries may be effective at reducing such transitions. For example, having email curfews that limit when work emails may be sent may help to reduce WIF (Butts et al., 2015). Such policies would also facilitate detachment, which reduces levels of work-family conflict and improves well-being in individuals and their partners (Hahn \& Dormann, 2013; Moreno-Jiménez, Mayo, Sanz-Vergel, Geurts, Rodríguez-Muñoz, \& Garrosa, 2009). On an individual level, the results imply boundary management strategies which reduce temporal transitions may also be effective. For example, individuals may thoughtfully plan blocks of time in which they can focus on tasks for one domain or the other and take steps to minimize interruptions (e.g., turning off cell phone notifications).

The results also suggest EFIW may be an energizing break during the work day, rather than a stressful work deterrent. Employers might structure in breaks to allow employees to catch up with family members while at work or allow employees to text or email with family members when they are not otherwise busy with work obligations. Although such policies and practices may increase EFIW, they may also help to reduce employee fatigue throughout the workday. 
There was significant variability in psychological strain reactivity and recovery, suggesting psychological reactions to EWIF/EFIW could be altered through interventions. Further, the majority of the variance for psychological strain resided at the within-person level and a smaller, yet substantial amount of variance resided at the between-person level. This finding suggests both external, organizational intervention strategies and individual-level strategies may be capable of altering psychological strain reactions to EWIF/EFIW.

Results showed accumulation of EWIF/EFIW over time was more consistently associated with changes in strain, compared to a single EWIF/EFIW episode. This result underlies the importance of strategies or resources that may prevent accumulation from occurring as opposed to resources that target single work-family conflict episodes. For example, flextime may effectively prevent a morning or evening work-family conflict by allowing individuals arrange convenient temporal transition times. However, if the individual is overloaded with work and needs to continue working into the evening, this flextime does little to control accumulation of EWIF/EFIW into the evening. In contrast, a supportive supervisor who works with her employees to ensure their work and family needs are met may be willing to negotiate role expectations, such that workers are able to adjust both work timing and workload. Recovery is another broad strategy, which theoretically allows individuals to detach from work and replenish physical and psychological resources (Sonnentag \& Fritz, 2015). When individuals are able to detach, they may be less likely to experience work-family spillover, thus preventing further accumulation of EWIF/EFIW throughout the day.

Finally, my results have practical implications for research design. EWIF/EFIW occur throughout the entire day, as early as 6:00 AM and as late as 11:45 PM. Nearly half of all experience sampling studies in the work-family literature use one time point, with an average of 
2.82 time points per study (Allen, French, Braun, \& Fletcher, 2017). Among studies that have more than one time point, work-family conflict is most often measured only once at the end of the day (e.g., Ilies et al., 2015; Wagner et al., 2014) or in the afternoon after work (e.g., GarrosaHernández, Carmona-Cobo, Ladstätter, Blanco, \& Cooper-Thomas, 2013). Such infrequent within-day sampling has the potential to miss meaningful within-day variation in work-family conflict (and correlates). Further, end-of-day reports may reflect EWIF/EFIW that happened any time throughout the day, including in the morning before work. Researchers interested in workfamily conflict that during a specific segment of the day (e.g., after work) may consider controlling for work-family conflict that occurs earlier in the day. Finally, the high frequency of EWIF/EFIWs found in the present study compared to previous work (e.g., Barnett, 2016; Shockley \& Allen, 2012; Shockley \& Allen, 2014) suggests participants may forget or fail to report conflicts with wider sampling time intervals.

\section{Limitations}

The present study has several limitations. First, there was no theoretical rationale for the week chosen for participation. Moreover, I did not account for each participant's current workfamily context or their work-family conflict preceding their participation week. By limiting inclusion to only participants with family and full-time, standard work responsibilities I attempted to control for factors that might influence chronic work-family conflict. However, participants' current or recent life events, particularly for those pertaining to work and family were not taken into account. Thus it is not clear if the week of participation was during a particularly tumultuous or banal time in participants' lives. Relatedly, the first time point is assumed as the start of an accumulation process, yet the first day might have been in the middle or towards the end of an accumulation spiral (Mitchell \& James, 2001). The ebb and flow of 
work-family conflict change over time is under-explored, and consequently we have limited empirical understanding of when a good starting point might be to capture change in EWIF/EFIW over time. Theoretically, the change in work or family status might be appropriate discrete starting points, as such changes require redefining, learning, and negotiating role behaviors and expectations (Allen \& Finkelstein, 2014; Bauer \& Erdogan, 2011).

Although effect sizes for work-family transitions ranged from medium to large, effect sizes regarding EWIF/EFIW and strain were small in magnitude. For example, state fatigue demonstrated the most consistent changes, but coefficients showed only a maximum increase of .07 on a five point scale. These effect sizes are smaller than those estimated in levels-based research, particularly those using cross-sectional research (e.g., Amstad et al., 2011). It is likely that levels-based measures are confounded with strain, inflating correlations between workfamily conflict and strain outcomes (González-Morales et al., 2012). Stronger effect sizes may emerge if taking into account nuances of EWIF/EFIW, such as perceived distress associated with the EWIF/EFIW.

The measures in the current study relied all relied upon self-reports. Although EWIF/EFIW was a simple yes/no checklist, episodes had to be perceived and reported by individuals. The checklist used was a simple measure of EWIF/EFIW that allowed for quick response, coding, and analysis. However, the checklist format made it difficult to tell when EWIF/EFIWs were consistent across time, and whether or not a given EWIF/EFIW was new or ongoing. Further, participants had to recognize an EWIF/EFIW in order to report it. Several measures were taken to ensure accurate reporting. During training, participants were required to give personal examples of EWIF/EFIW to ensure they understood and could apply the construct. In addition, participants were given a hard copy of the checklist, which the research assistant 
ensured they understood. Finally, participants had the opportunity to document confusion or mistyped information on an open response item at the end of each survey. Despite these measures, it is possible that EWIF/EFIWs were underreported or misreported.

The sample size for heart rate and blood pressure analyses was less than ideal, particularly given the small effect sizes expected for physiological response. Small sample size was due to two primary factors. First, participants were not screened well during the recruitment phase for disqualifying factors (e.g., taking blood pressure mediation). Second, there were several instances of malfunctioning heart rate and blood pressure monitors. Participants were trained on the monitors they took with them, provided extra batteries, provided instruction manual materials, and asked to text the researcher in the event that s/he needed help troubleshooting the monitor. In some cases of malfunctioning monitors, participants were provided a new monitor during their week of participation. Despite these measures, several data points were missing on blood pressure and heart rate outcomes.

Ideally measurement observations would be even more fine-grained in order to capture reactivity and recovery. In lab settings, reactivity and recovery may occur over a matter of minutes (Chida \& Hamer, 2008; Dickerson \& Kemeny, 2004). This level of granularity is difficult to achieve given the current study's equipment and field-based setting. Bringing workfamily conflict episodes into a controlled lab setting may help to better capture acute reactivity and recovery. An event-contingent method in which people respond only during and shortly after an EWIF/EFIW may also help to capture EWIF/EFIW acute reactions as they occur in real time and throughout peoples' daily lives. 


\section{Future Research Directions}

The present study findings suggest FIW may be a positive experience, or may at least be more positive than WIF. This study is not the first to suggest a silver lining to work-family conflict. For example, Cunningham (2011) suggested work-family conflicts serve a motivational purpose, encouraging individuals to balance both work and family rather than focusing on a single domain. Williams and Alliger (1994) also found FIW was associated with feeling elated, suggesting FIW may foster positive emotions. This positive aspect of FIW may be previously undetected due to levels-based measurement, which uses wording with a negative connotation (e.g., "I have to put off doing things at work because of demands on my time at home" Netemeyer et al., 1996; "tension and anxiety from my family life often weakens my ability to do my job" Carlson et al., 2000). It is only when disentangling the EFIW event from interpretation that positive outcomes emerge. Future research might explore this idea of work-family conflict, and particularly FIW as potentially beneficial and fulfilling.

In a similar vein, the present study highlights an important question for episodic workfamily conflict research: are there differences in what individuals classify as EWIF/EFIW? For example, a family phone conversation at work would be classified as an EFIW. However, if the conversation is a welcome break, would an individual still classify this episode as an EFIW? The checklist measures used in the present study aim to reduce some of this ambiguity compared to previous free-response items. However, even the checklist items may not necessarily be perceived as a conflict to the participant. It might be that participants have different thresholds for classifying conflicts. It would be interesting to see how often "objective" EWIF/EFIWs are correctly classified, and whether individual differences predict classification. An experience sampling study with couples could also tackle this question. Couples could report EWIF/EFIWs, 
and reports could be matched to determine the extent to which couples agree that an EWIF/EFIW occurred.

The present study also warrants future research examining both temporal and spatial micro-transitions as unique transition behaviors. Transitions could also be incorporated with flexibility and permeability dimensions of boundary theory to provide a complete picture of how individuals with varying boundary management preferences manage work and family domains. Combining spatial and temporal transitions with flexibility and permeability could also provide a full test of border/boundary theory (Ashforth et al., 2000; Clark, 2000). For example, Ashforth and colleageus (2000) suggest integrators more easily transition to/from work and family. Thus, we might predict transitions are less likely to be associated with EWIF/EFIW for integrators compared to segmentors. It would also be insightful to align individuals' transition patterns with their family members. For example, do couples tend to align the micro transitions? And do couples with synced transitions show differences in terms of family functioning, division of labor, or family satisfaction compared to those whose transitions are not in sync?

More theoretical nuance is needed to posit when strain changes and develops over time in response to both acute and cumulative EWIF/EFIW. Such theory could also be helpful for studying other episodic phenomenon, such as workplace aggression, mentoring interactions, or spousal interactions. Inductive empirical studies that explore timing, such as the present study, are also needed to shed some empirical light on when workplace events and when and how long their effects onset.

Finally, the present study findings raise questions as to how episodic measurement maps onto levels-based measurement. Several researchers have questioned what levels-based measurement captures, given time frame and content ambiguity (Maertz \& Boyar, 2011), items 
that confound work-family conflict with strain (Bellavia \& Frone, 2005; González-Morales et al., 2012), measurement invariance issues (Agars \& French, 2016), and counter-intuitive findings (Grzywacz, Arcury, Marín, Carrillo, Burke, Coates, \& Quandt, 2007). Given that the present accumulation findings most directly align with levels-based research, this study suggests levelsbased measures might reflect EWIF/EFIW accumulation. This is similar to Maertz and Boyar's (2011) theoretical work, which suggested individuals reflect on recent work-family conflict and work-family enrichment episodes when evaluating work-family balance. Another possibility is that individuals evaluate their level of work-family conflict based on the most recent episodes, or the most distressing episodes within the last few days or weeks. A final possibility is that levelsbased work-family conflict reflects chronic affect, or enduring emotion that individuals feel when they reflect on juggling work and family (e.g., guilt). Future research might use a similar design in combination with levels-based daily or weekly work-family conflict measurement to determine the construct overlap between episodes and levels measures. Such research could also be used to better understand work-family balance, which is inherently a levels-based construct that reflects both positive and negative work-family domain interactions.

\section{Conclusion}

The present study explored EWIF/EFIW as a dynamic construct, embedded within the context of time. The findings indicate WIF and FIW each follow a unique daily rhythm, guided by scheduled and impromptu transitions. Further, WIF and FIW have little-to-no relationship with momentary strain, but rather increase strain as each accumulates over the course several hours to days. For years, time has been an overlooked and downplayed contextual factor within organizational research (Mitchell \& James, 2001; Shipp \& Fried, 2014). By using time a 
centerpiece, the present findings yield novel theoretical and empirical insights into the how and when work-family conflict is experienced. 


\section{REFERENCES}

Agars, M. D. \& French, K. A. (2016). Underrepresented populations in work-family research. In T.D. Allen \& L. T. Eby (Eds.), The oxford handbook of work and family. (pp. 362-375). New York: Oxford University Press.

Allen, T. D. (2012). The work and family interface. In S. J. Kozlowski, S. J. Kozlowski (Eds.), The Oxford handbook of organizational psychology, Vol. 2 (pp. 1163-1198). New York, NY, US: Oxford University Press.

Allen, T. D., \& Armstrong, J. (2006). Further examination of the link between work-family conflict and physical health the role of health-related behaviors. American Behavioral Scientist, 49, 1204-1221.

Allen, T. D., Cho, E., \& Meier, L. L. (2014). Work-family boundary dynamics. Annual Review of Organizational Psychology and Organizational Behavior, 1, 99-121.

Allen, T. D., \& Finkelstein, L. M. (2014). Work-family conflict among members of full-time dual-earner couples: An examination of family life stage, gender, and age. Journal of Occupational Health Psychology, 19, 376-384.

Allen, T. D., French, K. A., Braun, M. T., \& Fletcher, K. A. (2017). The passage of time in workfamily research: A review. Manuscript in preparation.

Allen, T. D., Johnson, R. C., Kiburz, K. M., \& Shockley, K. M. (2013). Work-family conflict and flexible work arrangements: Deconstructing flexibility. Personnel Psychology, 66, 345-376. 
Allen, T. D., Walvoord, A. G., Dorio, J., \& Cho, E. (2016). Work interference with family events: A new assessment tool. Manuscript in preparation.

Almeida, D. M., Davis, K. D., Lee, S., Lawson, K. M., Walter, K. N., \& Moen, P. (2016). Supervisor support buffers daily psychological and physiological reactivity to work-tofamily conflict. Journal of Marriage and Family, 78, 165-179.

Amstad, F. T., Meier, L. L., Fasel, U., Elfering, A., \& Semmer, N. K. (2011). A meta-analysis of work-family conflict and various outcomes with a special emphasis on cross-domain versus matching-domain relations. Journal of Occupational Health Psychology, 16, 151169.

Aryee, S., \& Luk, V. (1996). Balancing two major parts of adult life experience: Work and family identity among dual-earner couples. Human Relations, 49, 465-487.

Ashforth, B. E., Kreiner, G. E., \& Fugate, M. (2000). All in a day's work: Boundaries and micro role transitions. Academy of Management Review, 25, 472-491.

Barnett, C. N. (2016). Work-family-school conflict and cardiovascular health (Unpublished undergraduate honors thesis). University of South Florida, Tampa, FL.

Bates, D., Maechler, M., Bolker, B., \& Walker, S. (2015). Fitting linear mixed-effects models using lme4. Journal of Statstical Software, 67, 1-48. Doi:10.18637/jss.v067.i01.

Bauer, T. N., \& Erdogan, B., (2011). Organizational socialization: The effective onboarding of new employees. In Zedeck, S. (Ed.). APA handbook of industrial and organizational psychology: Maintaining, expanding, and contracting the organization (Vol. 3., pp. 5164). Washington, DC: American Psychology Association.

Bellavia, G., \& Frone, M. R. (2005). Work-family conflict. In J. Barling, E. K. Kelloway, \& M. R. Frone (Eds.), Handbook of work stress (pp. 113-147). Thousand Oaks, CA: Sage. 
Berkman, L. F., Buxton, O., Ertel, K., \& Okechukwu, C. (2010). Managers' practices related to work-family balance predict employee cardiovascular risk and sleep duration in extended care settings. Journal of Occupational Health Psychology, 15, 316-329.

Berkman, L. F., Liu, S. Y., Hammer, L., Moen, P., Klein, L. C., Kelly, E., \& ... Buxton, O. M. (2015). Work-family conflict, cardiometabolic risk, and sleep duration in nursing employees. Journal of Occupational Health Psychology, 20, 420-433.

Bliese, P. D. (2016a). Multilevel: Multilevel functions. R package version 2.6. https://CRAN.Rproject.org $/$ package $=$ multilevel

Bliese, P. D. (2016b). Multilevel modeling in R (2.6): A brief introduction to R, the multilevel package and the nlme package. Retrieved from https://cran.rproject.org/doc/contrib/Bliese_Multilevel.pdf

Bliese, P. D., \& Lang, J. W. (2016). Understanding relative and absolute change in discontinuous growth models coding alternatives and implications for hypothesis testing. Organizational Research Methods. Advance online publication. doi: 1094428116633502 .

Bliese, P. D., \& Ployhart, R. E. (2002). Growth modeling using random coefficient models: Model building, testing, and illustration. Organizational Research Methods, 5, 362-387.

Bono, J. E., Glomb, T. M., Shen, W., Kim, E., \& Koch, A. J. (2013). Building positive resources: Effects of positive events and positive reflection on work stress and health. Academy of Management Journal, 56, 1601-1627.

Brehm, J. W., \& Self, E. A. (1989). The intensity of motivation. Annual Review of Psychology, 40, 109-131. 
Brosschot, J. F., Pieper, S., \& Thayer, J. F. (2005). Expanding stress theory: Prolonged activation and perseverative cognition. Psychoneuroendocrinology, 30, 1043-1049.

Butts, M. M., Becker, W. J., \& Boswell, W. R. (2015). Hot buttons and time sinks: The effects of electronic communication during nonwork time on emotions and work-nonwork conflict. Academy of Management Journal, 58, 763-788.

Byron, K. (2005). A meta-analytic review of work-family conflict and its antecedents. Journal of Vocational Behavior, 67, 169-198.

Campos, B., Graesch, A. P., Repetti, R., Bradbury, T., \& Ochs, E. (2009). Opportunity for interaction? A naturalistic observation study of dual-earner families after work and school. Journal of Family Psychology, 23, 798-807.

Carlson, D. S., Kacmar, K. M., \& Williams, L. J. (2000). Construction and initial validation of a multidimensional measure of work-family conflict. Journal of Vocational behavior, 56, 249-276.

Chi, N., Yang, J., \& Lin, C. (2016). Service workers' chain reactions to daily customer mistreatment: Behavioral linkages, mechanisms, and boundary conditions. Journal of Occupational Health Psychology. Advanced online publication. doi:10.1037/ocp0000050

Chida, Y., \& Hamer, M. (2008). Chronic psychosocial factors and acute physiological responses to laboratory-induced stress in healthy populations: A quantitative review of 30 years of investigations. Psychological Bulletin, 134, 829-885.

Clark, S. C. (2000). Work/family border theory: A new theory of work/family balance. Human Relations, 53, 747-770. 
Crain, T. L., Hammer, L. B., Bodner, T., Kossek, E. E., Moen, P., Lilienthal, R., \& Buxton, O. M. (2014). Work-family conflict, family-supportive supervisor behaviors (FSSB), and sleep outcomes. Journal of Occupational Health Psychology, 19, 155-167.

Cranford, J. A., Shrout, P. E., Iida, M., Rafaeli, E., Yip, T., \& Bolger, N. (2006). A procedure for evaluating sensitivity to within-person change: Can mood measures in diary studies detect change reliably?. Personality and Social Psychology Bulletin, 32, 917-929.

Cunningham, C. J. L. (2011). How interrole conflict research can have a greater impact. Industrial and Organizational Psychology: Perspectives on Science and Practice, 4, 370-374.

de Castro, J. M. (1987). Circadian rhythms of the spontaneous meal pattern, macronutrient intake, and mood of humans. Physiology \& Behavior, 40, 437-446.

Demerouti, E., Bakker, A. B., Nachreiner, F., \& Schaufeli, W. B. (2001). The job demandsresources model of burnout. Journal of Applied Psychology, 86, 499-512.

Desrochers, S., Hilton, J. M., \& Larwood, L. (2005). Preliminary validation of the work-family integration-blurring scale. Journal of Family Issues, 26, 442-466.

Devine, C. M., Connors, M. M., Sobal, J., \& Bisogni, C. A. (2003). Sandwiching it in: Spillover of work onto food choices and family roles in low-and moderate-income urban households. Social Science \& Medicine, 56, 617-630.

Devine, C. M., Jastran, M., Jabs, J., Wethington, E., Farell, T. J., \& Bisogni, C. A. (2006). “A lot of sacrifices:" Work-family spillover and the food choice coping strategies of low-wage employed parents. Social Science \& Medicine, 63, 2591-2603.

Dickerson, S. S., \& Kemeny, M. E. (2004). Acute stressors and cortisol responses: A theoretical integration and synthesis of laboratory research. Psychological Bulletin, 130, 355-391. 
Dijk, D. J., Duffy, J. F., \& Czeisler, C. A. (1992). Circadian and sleep/wake dependent aspects of subjective alertness and cognitive performance. Journal of Sleep Research, 1, 112-117.

Edwards, J. R., \& Rothbard, N. P. (2000). Mechanisms linking work and family: Clarifying the relationship between work and family constructs. Academy of Management Review, 25, 178-199.

Enders, C. K., \& Tofighi, D. (2007). Centering predictor variables in cross-sectional multilevel models: A new look at an old issue. Psychological methods, 12, 121-138.

Ford, M. T., Heinen, B. A., \& Langkamer, K. L. (2007). Work and family satisfaction and conflict: A meta-analysis of cross-domain relations. Journal of Applied Psychology, 92, $57-80$.

Ford, M. T., Matthews, R. A., Wooldridge, J. D., Mishra, V., Kakar, U. M., \& Strahan, S. R. (2014). How do occupational stressor-strain effects vary with time? A review and metaanalysis of the relevance of time lags in longitudinal studies. Work \& Stress, 28, 9-30.

Fox, S., Spector, P. E., \& Miles, D. (2001). Counterproductive work behavior (CWB) in response to job stressors and organizational justice: Some mediator and moderator tests for autonomy and emotions. Journal of Vocational Behavior, 59, 291-309.

Frese, M., \& Zapf, D. (1988). Causes, coping and consequences of stress at work. Methodological issues in the study of work stress: Objective vs. subjective measurement of work stress and the question of longitudinal studies, 375-412.

Frone, M. R., Russell, M., \& Cooper, M. L. (1997). Relation of work-family conflict to health outcomes: A four-year longitudinal study of employed parents. Journal of Occupational and Organizational Psychology, 70, 325-335. 
Ganster, D. C., \& Rosen, C. C. (2013). Work stress and employee health: A multidisciplinary review. Journal of Management, 39, 1085-1122.

Garrosa-Hernández, E., Carmona-Cobo, I., Ladstätter, F., Blanco, L. M., \& Cooper-Thomas, H. D. (2013). The relationships between family-work interaction, job-related exhaustion, detachment, and meaning in life: A day-level study of emotional well-being. Revista de Psicología del Trabajo y de las Organizaciones, 29, 169-177.

Glavin, P., \& Schieman, S. (2010). Interpersonal context at work and the frequency, appraisal, and consequences of boundary-spanning demands. The Sociological Quarterly, 51, 205225.

Garst, H., Frese, M., \& Molenaar, P. M. (2000). The temporal factor of change in stressor-strain relationships: A growth curve model on a longitudinal study in East Germany. Journal Of Applied Psychology, 85, 417-438.

Golder, S. A., \& Macy, M. W. (2011). Diurnal and seasonal mood vary with work, sleep, and daylength across diverse cultures. Science, 333, 1878-1881.

Goldstein, I. B., Jamner, L. D., \& Shapiro, D. (1992). Ambulatory blood pressure and heart rate in healthy male paramedics during a workday and a nonworkday. Health Psychology, 11, 48-54.

González-Morales, M.G., Tetrick, L.E, \& Ginter, R. (2012) Measurement issues in work-family research. Research methods in occupational health psychology: State of the art in measurement, design, and data analysis. New York: Routledge.

Greenhaus, J. H. (1988). The intersection of work and family roles: Individual, interpersonal, and organizational issues. Journal of Social Behavior and Personality, 3, 23-44. 
Greenhaus, J. H., Allen, T. D., \& Spector, P. E. (2006). Health consequences of work-family conflict: The dark side of the work-family interface. In Employee health, coping and methodologies (pp. 61-98). Emerald Group Publishing Limited.

Greenhaus, J. H., \& Beutell, N. J. (1985). Sources of conflict between work and family roles. Academy of Management Review, 10, 76-88.

Grzywacz, J. G. (2016). Work, family, and employee health. In T. D. Allen \& L. T. Eby (Eds.), The oxford handbook of work and family, (pp. 389-400). New York: Oxford University Press.

Grzywacz, J. G., Arcury, T. A., Marín, A., Carrillo, L., Burke, B., Coates, M. L., \& Quandt, S. A. (2007). Work-family conflict: Experiences and health implications among immigrant Latinos. Journal of Applied Psychology, 92, 1119-1130.

Guo, Y. F., \& Stein, P. K. (2003). Circadian rhythm in the cardiovascular system: Chronocardiology. American Heart Journal, 145, 779-786.

Hahn, V. C., \& Dormann, C. (2013). The role of partners and children for employees' psychological detachment from work and well-being. Journal of Applied Psychology, 98, 26-36.

Hall, D. T., \& Richter, J. (1988). Balancing work life and home life: What can organizations do to help?. The Academy of Management Executive, 2, 213-223.

Hobfoll, S. E. (1989). Conservation of resources: A new attempt at conceptualizing stress. American Psychologist, 44, 513-524.

Howard, B. V. \& Wylie-Rosett, J. (2002). Sugar and cardiovascular disease. Circulation, 106, $523-527$. 
Ilies, R., Huth, M., Ryan, A. M., \& Dimotakis, N. (2015). Explaining the links between workload, distress, and work-family conflict among school employees: Physical, cognitive, and emotional fatigue. Journal of Educational Psychology, 107, 1136-1149.

Ilies, R., Schwind, K. M., Wagner, D. T., Johnson, M. D., DeRue, D. S., \& Ilgen, D. R. (2007). When can employees have a family life? The effects of daily workload and affect on work-family conflict and social behaviors at home. Journal of Applied Psychology, 92, 1368-1379.

Internal Revenue Service. (2016). Identifying full-time employees. Retrieved from https://www.irs.gov/affordable-care-act/employers/identifying-full-time-employees

Johnson, R. C. (2015). Exploring the energy link between emotion regulation at work and health behaviors. Dissertation Abstracts International, 75

Johnson, R. C., \& Allen, T. D. (2013). Examining the links between employed mothers' work characteristics, physical activity, and child health. Journal of Applied Psychology, 98, $148-157$.

Jones, F., O'Connor, D. B., Conner, M., McMillan, B., \& Ferguson, E. (2007). Impact of daily mood, work hours, and iso-strain variables on self-reported health behaviors. Journal of Applied Psychology, 92, 1731-1740.

Judge, T. A., Ilies, R., \& Scott, B. A. (2006). Work-family conflict and emotions: Effects at work and at home. Personnel Psychology, 59, 779-814.

Juster, R., McEwen, B. S., \& Lupien, S. J. (2010). Allostatic load biomarkers of chronic stress and impact on health and cognition. Neuroscience and Biobehavioral Reviews, 35, 2-16.

Kahn, R. L., Wolfe, D. M., Quinn, R. P., Snoek, J., \& Rosenthal, R. A. (1964). Organizational stress: Studies in role conflict and ambiguity. Oxford England: John Wiley. 
Kamarck, T. W., Shiffman, S. M., Smithline, L., Goodie, J. L., Paty, J. A., Gnys, M., \& Jong, J. Y. (1998). Effects of task strain, social conflict, and emotional activation on ambulatory cardiovascular activity: Daily life consequences of recurring stress in a multiethnic adult sample. Health Psychology, 17, 17-29.

Katz, D., \& Kahn, R. L. (1978). The social psychology of organizations. New York: John Wiley \& Sons.

Kossek, E., \& Michel, J. (2010). Flexible work schedules. Handbook of industrial-organizational psychology, 1, 535-72.

Kossek, E., Ruderman, M., Braddy, P., \& Hannum, K. (2012). Work-nonwork boundary management profiles: A person-centered approach. Journal of Vocational Behavior, 81, 112-128. http://dx.doi.org/10.1016/j.jvb.2012.04.003

Kreiner, G. E., Hollensbe, E. C., \& Sheep, M. L. (2009). Balancing borders and bridges: Negotiating the work-home interface via boundary work tactics. Academy of Management Journal, 52, 704-730.

Krisor, S.M., Diebig, M., \& Rowold, J. (2015). Is cortisol as a biomarker of stress influenced by the interplay of work-family conflict, work-family balance and resilience? Personnel Review, 44, 648-661.

Lapierre, L. M. \& McMullan, A.D. (2016). A review of methodological and measurement approaches to the study of work and family. In T. D. Allen \& L. T. Eby (Eds.), The oxford handbook of work and family, (pp. 349-361). New York: Oxford University Press.

Lazarus, R. S. \& Folkman, S. (1984). Cognitive appraisal processes. In R. S. Lazarus \& S. Folkman, Stress, appraisal and coping (pp. 22-54). New York: Springer. 
Lee, S., Crain, T. L., McHale, S. M., Almeida, D. M., \& Buxton, O. M. (2017). Daily antecedents and consequences of nightly sleep. Journal of Sleep Research, 26, 498-509.

Lichtenstein, A. H., Appel, L. J., Brands, M., Carnethon, M., Daniels, S., Franch, H. A., ... \& Wylie-Rosett, J. (2006). Diet and lifestyle recommendations revision 2006. Circulation, 114, 82-96.

Linden, W. L. E. T., Earle, T. L., Gerin, W., \& Christenfeld, N. (1997). Physiological stress reactivity and recovery: conceptual siblings separated at birth?. Journal of Psychosomatic Research, 42, 117-135.

Livingston, B. A., \& Judge, T. A. (2008). Emotional responses to work-family conflict: An examination of gender role orientation among working men and women. Journal of Applied Psychology, 93, 207-216.

Liu, Y., Wang, M., Chang, C., Shi, J., Zhou, L., \& Shao, R. (2015). Work-family conflict, emotional exhaustion, and displaced aggression toward others: The moderating roles of workplace interpersonal conflict and perceived managerial family support. Journal of Applied Psychology, 100, 793-808.

Llabre, M. M., Spitzer, S. B., Saab, P. G., \& Schneiderman, N. (2001). Piecewise latent growth curve modeling of systolic blood pressure reactivity and recovery from the cold pressor test. Psychophysiology, 38, 951-960.

MacDermid, S. M. 2005. (Re)considering conflict between work and family. In E. E. Kossek \& S. J. Lambert (Eds.), Work and life integration (pp. 19-40). Mahwah, NJ: Lawrence Erlbaum Associates.

Maertz, C. P., \& Boyar, S. L. (2011). Work-family conflict, enrichment, and balance under "levels" and "episodes" approaches. Journal of Management, 37, 68-98. 
Matthews, K. A., Gump, B. B., \& Owens, J. F. (2001). Chronic stress influences cardiovascular and neuroendocrine responses during acute stress and recovery, especially in men. Health Psychology, 20, 403-410.

Matthews, R. A., Barnes-Farrell, J. L., \& Bulger, C. A. (2010). Advancing measurement of work and family domain boundary characteristics. Journal of Vocational Behavior, 77, 447460.

Matthews, R. A., Winkel, D. E., \& Wayne, J. H. (2014). A longitudinal examination of role overload and work-family conflict: The mediating role of interdomain transitions. Journal of Organizational Behavior, 35, 72-91.

McEwen, B. S. (1998). Stress, adaptation, and disease: Allostasis and allostatic load. Annals of the New York Academy of Sciences, 840, 33-44.

McEwen, B. S., \& Seeman, T. (1999). Protective and damaging effects of mediators of stress: elaborating and testing the concepts of allostasis and allostatic load. Annals of the New York Academy of Sciences, 896, 30-47.

McGrath, J. E., \& Beehr, T. A. (1990). Time and the stress process: Some temporal issues in the conceptualization and measurement of stress. Stress Medicine, 6, 93-104.

McNair, D. M., Lorr, M., \& Droppleman, L. F. (1981). Profile of mood states (pp. 1-29). San Diego, CA: Educational and Industrial Testing Service.

Meijman, T. F., \& Mulder, G. (1998). Psychological aspects of workload. Handbook of work and organizational psychology (Vol. 2, pp. 5-33). Hove, U.K.: Psychology Press.

Melamed, S., Kushnir, T., \& Shirom, A. (1992). Burnout and risk factors for cardiovascular diseases. Behavioral Medicine, 18, 53-60. 
Michel, J. S., Clark, M. A., \& Jaramillo, D. (2011). The role of the Five Factor Model of personality in the perceptions of negative and positive forms of work-nonwork spillover: A meta-analytic review. Journal of Vocational Behavior, 79, 191-203.

Michel, J. S., Kotrba, L. M., Mitchelson, J. K., Clark, M. A., \& Baltes, B. B. (2011). Antecedents of work-family conflict: A meta-analytic review. Journal of Organizational Behavior, 32, 689-725.

Mitchell, T. R., \& James, L. R. (2001). Building better theory: Time and the specification of when things happen. Academy of Management Review, 26, 530-547.

Moreno-Jiménez, B., Mayo, M., Sanz-Vergel, A. I., Geurts, S., Rodríguez-Muñoz, A., \& Garrosa, E. (2009). Effects of work-family conflict on employees' well-being: The moderating role of recovery strategies. Journal of Occupational Health Psychology, 14, 427-440.

Moseley, J. V., \& Linden, W. (2006). Predicting blood pressure and heart rate change with cardiovascular reactivity and recovery: results from 3-year and 10-year follow up. Psychosomatic Medicine, 68, 833-843.

Mourad, A., Gillies, A., \& Carney, S. (2005). Inaccuracy of wrist-cuff oscillometric blood pressure devices: an arm position artefact?. Blood Pressure Monitoring, 10, 67-71.

Muraven, M., \& Baumeister, R. F. (2000). Self-regulation and depletion of limited resources: Does self-control resemble a muscle?. Psychological Bulletin, 126, 247-259.

Netemeyer, R. G., Boles, J. S., \& McMurrian, R. (1996). Development and validation of workfamily conflict and family-work conflict scales. Journal of Applied Psychology, 81, 400410. 
Newman, E., O’Connor, D. B., \& Conner, M. (2007). Daily hassles and eating behaviour: The role of cortisol reactivity status. Psychoneuroendocrinology, 32, 125-132.

O'Brien, E., Asmar, R., Beilin, L., Imai, Y., Mallion, J. M., Mancia, G., ... \& Parati, G. (2003). European Society of Hypertension recommendations for conventional, ambulatory and home blood pressure measurement. Journal of Hypertension, 21, 821-848.

O'Connor, D. B., Jones, F., Conner, M., McMillan, B., \& Ferguson, E. (2008). Effects of daily hassles and eating style on eating behavior. Health Psychology, 27, S20-S31.

Pickering, T. G., Hall, J. E., Appel, L. J., Falkner, B. E., Graves, J., Hill, M. N., ... \& Roccella, E. J. (2005). Recommendations for blood pressure measurement in humans and experimental animals part 1: Blood pressure measurement in humans: A statement for professionals from the Subcommittee of Professional and Public Education of the American Heart Association Council on High Blood Pressure Research. Hypertension, 45, 142-161.

Ployhart, R. E., \& Vandenberg, R. J. (2010). Longitudinal research: The theory, design, and analysis of change. Journal of Management, 36, 94-120.

Presser, H. B. (2003). Race-ethnic and gender differences in nonstandard work shifts. Work and Occupations, 30, 412-439.

Raudenbush, S. W., \& Bryk, A. S. (2002). Hierarchical linear models: Applications and data analysis methods (Vol. 1). Sage.

Repetti, R. L. (1994). Short-term and long-term processes linking job stressors to father-child interaction. Social Development, 3, 1-15.

Repetti, R. L., \& Wood, J. (1997). Effects of daily stress at work on mothers' interactions with preschoolers. Journal of Family Psychology, 11, 90-108. 
Richter, M., Gendolla, G. H. E., \& Wright, R. A. (2016). Three decades of research on motivational intensity theory: What we have learned about effort and what we still don't know. Advances in Motivation Science, 3, 149-186.

Roe, R. A. (2008). Time in applied psychology: The study of "what happens" rather than "what is". European Psychologist, 13, 37-52.

Rothstein, E., Shockley, K.M., Boyd, E., \& Yuan, Z. (April 2017) Not all work-family conflicts are created equal: An episodic analysis. Poster to be presented at 2017 annual SIOP conference. Orlando, FL.

Sanz-Vergel, A. I., Demerouti, E., Moreno-Jiménez, B., \& Mayo, M. (2010). Work-family balance and energy: A day-level study on recovery conditions. Journal Of Vocational Behavior, 76, 118-130.

Schwartz, A. R., Gerin, W., Davidson, K. W., Pickering, T. G., Brosschot, J. F., Thayer, J. F., ... \& Linden, W. (2003). Toward a causal model of cardiovascular responses to stress and the development of cardiovascular disease. Psychosomatic Medicine, 65, 22-35.

Shipp, A. J. \& Fried, Y. (2014). Time and work, Vol. 1: How time impacts individuals. New York, NY, US: Psychology Press.

Shockley, K. M., \& Allen, T. D. (2015). Deciding between work and family: An episodic approach. Personnel Psychology, 68, 283-318.

Shockley, K. M., \& Allen, T. D. (2013). Episodic work-family conflict, cardiovascular indicators, and social support: An experience sampling approach. Journal of Occupational Health Psychology, 18, 262-275. 
Simbula, S. (2010). Daily fluctuations in teachers' well-being: A diary study using the Job Demands-Resources model. Anxiety, Stress \& Coping: An International Journal, 23, $563-584$.

Singer, J. D., \& Willett, J. B. (2003). Applied longitudinal data analysis: Modeling change and event occurrence. New York, NY, US: Oxford University Press.

Sonnentag, S., Binnewies, C., \& Mojza, E. J. (2008). " Did you have a nice evening?" A daylevel study on recovery experiences, sleep, and affect. Journal of Applied Psychology, 93, 674.-684.

Sonnentag, S., \& Fritz, C. (2015). Recovery from job stress: The stressor-detachment model as an integrative framework. Journal of Organizational Behavior, 36, S72-S103.

Sonnentag, S., Pundt, A., \& Albrecht, A. (2014). Temporal perspectives on job stress. In A. J. Shipp, Y. Fried (Eds.), Time and work, Vol. 1: How time impacts individuals (pp. 111140). New York, NY, US: Psychology Press.

Sonnentag, S., Pundt, A., \& Venz, L. (2016). Distal and proximal predictors of snacking at work: A daily-survey study. Journal of Applied Psychology. Advance online publication. doi:10.1037/ap10000162

Spector, P. E., \& Jex, S. M. (1998). Development of four self-report measures of job stressors and strain: Interpersonal Conflict at Work Scale, Organizational Constraints Scale, Quantitative Workload Inventory, and Physical Symptoms Inventory. Journal of Occupational Health Psychology, 3, 356-367.

Steptoe, A., Lipsey, Z., \& Wardle, J. (1998). Stress, hassles and variations in alcohol consumption, food choice and physical exercise: A diary study. British Journal of Health Psychology, 3, 51-63. 
Steptoe, A., Pollard, T. M., \& Wardle, J. (1995). Development of a measure of the motives underlying the selection of food: The food choice questionnaire. Appetite, 25, 267-284.

Story, L. B., \& Repetti, R. (2006). Daily occupational stressors and marital behavior. Journal of Family Psychology, 20, 690-700.

Tabachnick, B. G., \& Fidell, L. S. (2007). Using multivariate statistics (5th ed.). Boston, MA: Pearson Education, Inc.

Topouchian, J. A., El Assaad, M. A., Orobinskaia, L. V., El Feghali, R. N., \& Asmar, R. G. (2006). Validation of two automatic devices for self-measurement of blood pressure according to the International Protocol of the European Society of Hypertension: the Omron M6 (HEM-7001-E) and the Omron R7 (HEM 637-IT). Blood Pressure Monitoring, 11, 165-171.

U.S. Department of Health and Human Services and U.S. Department of Agriculture. 2015 2020 Dietary Guidelines for Americans. 8th Edition. December 2015. Retrieved from http://health.gov/dietaryguidelines/2015/guidelines/.

Vrijkotte, T. G., Van Doornen, L. J., \& De Geus, E. J. (2000). Effects of work stress on ambulatory blood pressure, heart rate, and heart rate variability. Hypertension, 35, 880886.

Wagner, D. T., Barnes, C. M., \& Scott, B. A. (2014). Driving it home: How workplace emotional labor harms employee home life. Personnel Psychology, 67, 487-516.

Watson, D. (1988). Intraindividual and interindividual analyses of positive and negative affect: Their relation to health complaints, perceived stress, and daily activities. Journal of Personality and Social Psychology, 54, 1020-1030. 
Watson, D., Clark, L. A., \& Tellegen, A. (1988). Development and validation of brief measures of positive and negative affect: The PANAS scales. Journal of Personality and Social Psychology, 54, 1063-1070.

Weiss, H. (2012). Working as human nature. An essay in honor of the careers of Daniel Ilgen and Neal Schmitt.

Weiss, H. M., \& Cropanzano, R. (1996). Affective events theory: A theoretical discussion of the structure, causes and consequences of affective experiences at work. In B. M. Staw \& L. L. Cummings (Eds.), Research in Organizational Behavior (Vol. 19, pp. 1-74). Greenwich, CT: JAI Press.

Wilhelm, P., \& Schoebi, D. (2007). Assessing mood in daily life. European Journal of Psychological Assessment, 23, 258-267.

Williams, K. J., \& Alliger, G. M. (1994). Role stressors, mood spillover, and perceptions of work-family conflict in employed parents. Academy of Management Journal, 34, 837868.

Zilioli, S., Imami, L., \& Slatcher, R. B. (2016). The impact of negative family-work spillover on diurnal cortisol. Health Psychology. Advance online publication. doi.org/10.1037/hea0000380 
APPENDICES 


\section{Appendix A: Informed Consent Form}

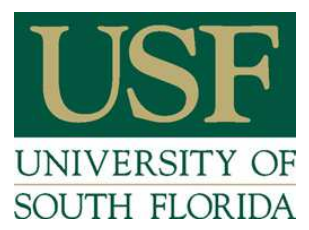

Informed Consent to Participate in Research Involving Minimal Risk

Pro \# 00028866

You are being asked to take part in a research study. Research studies include only people who choose to take part. This document is called an informed consent form. Please read this information carefully and take your time making your decision. Ask the researcher or study staff to discuss this consent form with you, please ask him/her to explain any words or information you do not clearly understand. The nature of the study, risks, inconveniences, discomforts, and other important information about the study are listed below.

We are asking you to take part in a research study called:

\section{"Work, Family, and Health Study"}

The person who is in charge of this research study is Kimberly French. This person is called the Principal Investigator. However, other research staff may be involved and can act on behalf of the person in charge. She being guided in this research by Dr. Tammy Allen.

The research will be conducted at the University of South Florida Psychology and Communication Disorders building, and during your daily activities at work and home.

This research is being sponsored by the Society for Industrial-Organizational Psychology, the American Psychological Association, and the National Institutes of Occupational Safety and Health/Centers for Disease Control.

\section{Purpose of the study}

The purpose of this study is to understand when conflicts between work and family occur, as well as examine changes in psychological and cardiovascular health throughout a week. 


\section{Why are you being asked to take part?}

We are asking you to take part in this research study because you are at least 18 years old, working at least 30 hours per week, with a spouse or cohabiting partner of at least one year and/or a dependent child living at home and/or a dependent elder.

\section{Study Procedures:}

If you take part in this study, you will be asked to:

- Meet with a researcher for an in-person 60 minute training session and a survey on Qualtrics. The survey will include questions about your work and family responsibilities and health.

- Participate in 28 total surveys over the next 7 days. You will be asked to respond to 8 surveys per day for the first three days, then 1 survey per day for the next 4 days. Each survey is approximately 5 minutes long. The survey will include questions about your work and family responsibilities and health.

- Take your heart rate and blood pressure using an ambulatory wrist monitor and report the readings on each survey.

- Wear an actigraph watch for the duration of the study (7 days).

- Return lab materials at the end of the study to the researcher.

- You will be creating a unique identifier to keep your responses anonymous; all data will be kept under a password-protected file.

\section{Total Number of Participants}

About 150 individuals will take part in this study.

\section{Alternatives / Voluntary Participation / Withdrawal}

You do not have to participate in this research study.

You should only take part in this study if you want to volunteer. You should not feel that there is any pressure to take part in the study. You are free to participate in this research or withdraw at any time. There will be no penalty or loss of benefits you are entitled to receive if you stop taking part in this study. Your decision to participate or not to participate will not affect your job status, employment record, employee evaluations, or advancement opportunities.

\section{Benefits}

You will receive a report about your health based on your responses over the week of participation. This report will include summary information about your activity levels, sleep hours, sleep quality, mood, and eating behaviors.

\section{Risks or Discomfort}


This research is considered to be minimal risk. That means that the risks associated with this study are the same as what you face every day. There are no known additional risks to those who take part in this study.

\section{Compensation}

You will be compensated up to $\$ 75$ for completing this study. In order to receive compensation, you must return the blood pressure/heart rate monitor and Actigraph GT9X LINK watch provided to you during study training in working condition.

Compensation will be pro-rated based on your rates of survey completion. Specifically, you will receive $\$ 10$ total for the training session, $\$ 15$ total for completing 1-14 surveys, $\$ 30$ total for completing 15-19 surveys, $\$ 45$ total for completing 20-24 surveys, $\$ 60$ total for completing 25 or more surveys, and $\$ 75$ total for completing all 28 surveys. Compensation will be distributed via email in the form of Amazon gift cards.

If you withdraw for any reason from the study before completion your compensation will be prorated based on the number of surveys completed.

\section{Costs}

It will not cost you anything to take part in the study. You will be required to use your smartphone for this study to access text messaged online survey links. Standard text messaging and/or data costs may be incurred.

\section{Privacy and Confidentiality}

We must keep your study records as confidential as possible. You will create and enter a unique identifier on each survey. This unique identifier allows us to connect your responses across surveys while also assuring the data cannot be directly linked to your identifying information.

It is possible that unauthorized individuals could gain access to your responses. Confidentiality will be maintained to the degree permitted by the technology used. No guarantees can be made regarding the interception of data sent via the Internet. However, your participation in this online survey involves risks similar to a person's everyday use of the Internet. If you complete and submit an anonymous survey and later request your data be withdrawn, this may or may not be possible as the researcher may be unable to extract anonymous data from the database.

Remind is the text messaging service that will be used to send survey links. Because participants only provide survey response data once they have been directed to the respective survey site in Qualtrics, Remind does not have access to participants' survey response data. Participant response data will be stored on the Qualtrics servers. Remind only keeps study signup data and researcher account information on their secure server. Remind will not - under any circumstances - sell, rent, distribute or give away any of this information to any third party. All Remind data is stored in password-protected secure data centers that only the research team account holders can access. 
Qualtrics is the survey host used to create and collect survey response data. All surveys for this study are completed and stored on Qualtrics. Qualtrics uses Transport Layer Security (TLS) encryption (also known as HTTPS) for all transmitted data. They also protect surveys with passwords and HTTP referrer checking. Qualtrics data is hosted by third party data centers that are SSAE-16 SOC II certified. All data at rest are encrypted, and data on deprecated hard drives are destroyed by U.S. DOD methods and delivered to a third-party data destruction service. Qualtrics deploys the general requirements set forth by many Federal Acts including the FISMA Act of 2002 and meets or exceeds the minimum requirements as outlined in FIPS Publication 200.

We will keep your study records private and confidential. Certain people may need to see your study records. Anyone who looks at your records must keep them confidential. These individuals include:

- The research team, including the Principal Investigator, study coordinator, and all other research staff.

- Certain government and university people who need to know more about the study, and individuals who provide oversight to ensure that we are doing the study in the right way.

- Any agency of the federal, state, or local government that regulates this research.

- The USF Institutional Review Board (IRB) and related staff who have oversight responsibilities for this study, including staff in USF Research Integrity and Compliance.

- The sponsors of this study and contract research organization.

We may publish what we learn from this study. If we do, we will not include your name. We will not publish anything that would let people know who you are.

\section{You can get the answers to your questions, concerns, or complaints}

If you have any questions, concerns or complaints about this study, or experience an unanticipated problem, call Kimberly French at 847-989-9564.

If you have questions about your rights as a participant in this study, or have complaints, concerns or issues you want to discuss with someone outside the research, call the USF IRB at (813) 974-5638 or contact by email at RSCH-IRB@usf.edu.

\section{Consent to Take Part in this Research Study}

I freely give my consent to take part in this study. I understand that by signing this form I am agreeing to take part in research. I have received a copy of this form to take with me. 
Printed Name of Person Taking Part in Study

\section{Statement of Person Obtaining Informed Consent}

I have carefully explained to the person taking part in the study what he or she can expect from their participation. I confirm that this research subject speaks the language that was used to explain this research and is receiving an informed consent form in their primary language. This research subject has provided legally effective informed consent.

Signature of Person Obtaining Informed Consent

Date

Printed Name of Person Obtaining Informed Consent 


\section{Appendix B: Lab Training Slides}

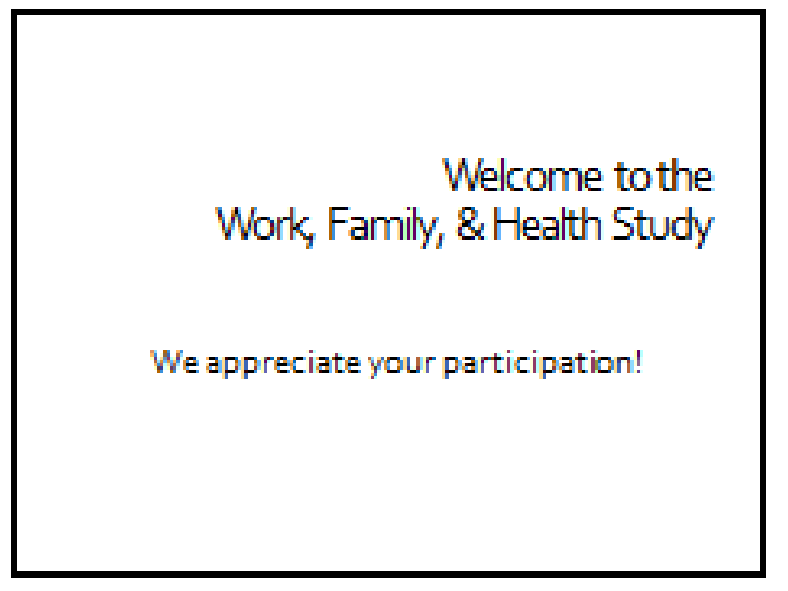

\section{About Us}

- Introductions to the research team

- Principal investigator Kimberly French

- Faculty advisor: Tammy Allen, PhD

- Research assistants: Alexandra Blume

$$
\begin{aligned}
& \text { Allegra Campbell } \\
& \text { Suje Chen } \\
& \text { Molly Darby } \\
& \text { Wednesday Radke }
\end{aligned}
$$

Overview of the Training Session
•Purpose of the study
- Procedure
- How to use the blood pressure monitors
•How to use the daily Qualtrics survey
-After the study ends...
•Paperwork
•Health measurements

\section{Purpose}

- The purpose of this study is to examine daily work, family, and health experiences of working adults

-We will focus most on:

- Work-family conflict

- Blood pressure and heart rate

What are blood pressure and

What is work-family conflict?

- Occurs when work and family produce competing demands

- May be time or psychological/strain conflict

- Examples

- Distinct from work - leisur e conflict

heart rate?

- BP; Pressure that keeps blocd flowing through the arteries

- Two types:

- Systolic ithigher number represents the pressure when the hert Systolicinight
is beding.

- Diastolic ilower number represents the pressure when the heart is resting between bests.

- HR: Number of times the heart contracts per minute

- BP and HR are very important indicators of cardiovascular health 


\section{Hypertension}

- Hypertension, also referred to as high blood pressure, is a condition in which the arteries have persistently elevated blood pressure.

- Normal BP: $120 / 80$

- Hypertensive BP: 14,0/go

- If you get a reading this high you should wait 2 minutes and then retake it. If it remains the same you should contact your physician.
What do / do?

\section{Procedure}

\begin{tabular}{|c|c|c|c|c|c|c|c|}
\hline \multicolumn{8}{|c|}{ Daily Sequence of Events } \\
\hline & Mondwy & Tuandry & Wednaddvy & Thuradvy & Midry & Sestrdy & Sundry \\
\hline AM & Sunven & 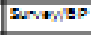 & $\operatorname{sen} x=0$ & & & & \\
\hline$g$ AM & $2 u x=0$ & $2 \mu n=0$ & $2 u+v_{n}=8$ & & & & \\
\hline$=2 P M$ & $\operatorname{sen} 20$ & $2 \pi, w_{n}=0$ & $\operatorname{sen} x_{n}=0$ & & & & \\
\hline PM & $2 u n=0$ & $2 \mu N=0$ & $2 \mu N x_{n}=0$ & & & & \\
\hline PM & $2 \operatorname{sen} x_{n}=0$ & $\sin x_{n} \theta 0$ & $2 u N v_{n}=8$ & & & & \\
\hline PMM & $2 \mu w_{n}=0$ & $2 \mu N w_{n} \theta 0$ & $\operatorname{sen} x_{n}=0$ & & & & \\
\hline FM & $2 \pi N x_{n}=0$ & $2 \pi \times n=0$ & $2 \pi N x_{n}=0$ & & & & \\
\hline$=P M$ & $\operatorname{sen} w \theta 0$ & $2 \pi \times n=9$ & $2 \sin ^{2} \geq 8$ & 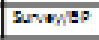 & suventep & $2 \pi n w_{n} \theta 0$ & 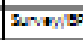 \\
\hline & & $\begin{array}{l}\text { You } \\
\text { Taxt }\end{array}$ & 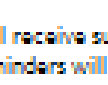 & inent: & ech tim & & \\
\hline
\end{tabular}

\section{How to Use the Wristwatch}

\section{Monitor}

- Duing measuremert, sit still with feet flat on flece. and don't talk.

- Mace montor on vor Lef wrix

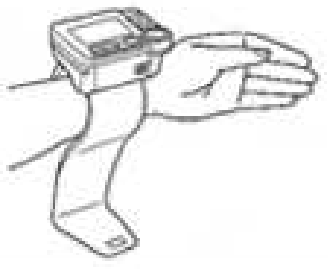

How do they work?

\section{Blood Pressure Monitors}




\section{Taking Your Measurement}

Push START/STOP

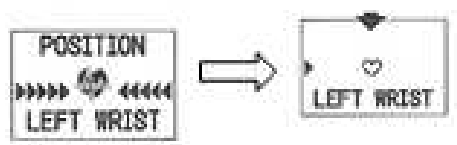

Raise wrist in line with your heart $\rightarrow$ arrow to the left means too low, to the right means too high

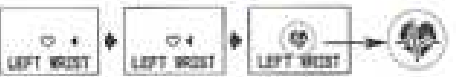

Taking Your Measurement, cont.

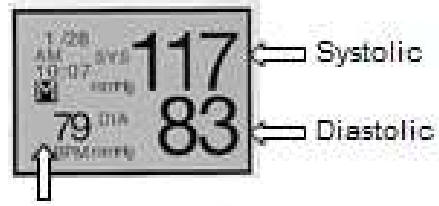

Heart rate

To record blood pressure, say: $117 / 83$

\section{Memory Function}

- The monitor automatically stores readings

- Press M button

- Use the arrows to scroll through

- If you ever come to a screen that asks you to delete all data, press NO

What to do if...

-You are still having problems:

- Read the manufacturer's instruction booklet

- Contact the research team at

USFWorkFamilyHealth(a)qmail.com

- Note: Please do not change any of the settings on the blood pressure monitor!

What to do if...

- Your blood pressure reading is abnormally hightow $\because 140 / 90$

-<

- Wait 2 minutes and take ancther reading.

- In place of numbers, an "Ev appears

- An error ocourred in measurement, probably due to improper arm placement or movement during reading

- Wait 2 minutes and tabe ancther reading.

- The monitor randomly stops working and displays strange characters

- Replace batteries-ycu vill have to reset timeidate isee manufacturer instruation bocklet for detalss
How do / respond and what will be oskod?

\section{Daily Survey}


How do l access the survey?

You will recewe text. messages with survey links - Monday-Wednesday 8 timesper day, every two hours, starting at B AM

- Thursday-5unday 1 time per day at 20 PM

Please respond to these links as soon as youcan
How do l access the survey?

Please check your phore now to be sure youare regitered for Remind

\section{remind}

\section{Step 2: Health}

- Heart rate and blood pressure readings

-Cument feelings (e.g., imitable, fatigue\}

- Sleeping since the last survey (how much, quality)

- Questions relevant for readings (e.g., sittingistanding posture)

Step 3: Work-Family Conflict

-Work-family confict may occur at any time throughout the day.

juice)

- Sugary food (e.g, chocolate, syrup, pastries, cahe)

- Fried food (e.9, French frie, friedvegetables, fried chicken)

- Chips or bagged snacks(e.9, Doritog, Laya, Combos)

- Full-fat dairy products (e.9, af redo sauce, cheese, butter, ice creami)

-Red meat (e.9, steak, sausages, bacon, hamburger) -Can also say "7 have not eitenany of these"

- If afoodibeverage fall into more than one sategory, please ondy acket one. 


\section{Step 3: Work-Family Conflict}

\section{- Checklist resporee format:}

- 1 hou missed all orpart of your family acovioes for

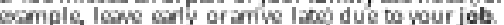

- 2. Wu had to delay job-ndirod activites dueto yourfamily.

- 3au ware mentally preaccupied ar distracted by work

issues whileyou were oying to engage in family ictivities.

- One corflict may fall into multiple cateoories plesse only select the one thet best ceptures your conflict.

- Follow up questions time, ongoing, distress, who was involved

\section{Missed Entries}

- You must respond to each text within two hours in order for your entry to count

-If you miss a day of entries, we will send an email.

-If you miss a survey you will not be rewarded for full compliance at the end of the study.

\section{Quick Overview}

- Before the study starts:

-Take lab pre-survey

-For the 7 study days:

-Monday-Wednesday: Respond to 8 surveys

each day, one every two hours

-Thursday-Sunday: Respond to 1 survey each day, at the end of the day

- Surveys will arrive via text message

\section{After the Study}

\section{Returning your blood pressure}

\section{monitor}

Please sign the monitor retum form and schedule your retum time and location.

You will receive your compensation via email when the monitors are retumed.

$\$ 60$ for completing the study with a minimum of 25 compliant responses.

\section{Compensation}

\section{EXTRA INCENTIVE!} -If you take yqur blood pressure readings on time
each day ard fill out al af the survers, you will receive an extra $\$ 15$

-Withdraw early?

- Receive pro-rated arnount according to the arnount of tirne you participated

-Participant Health Report will be ennailed within one week of watch retum 


\begin{tabular}{l} 
Questions? \\
Now? \\
During the Study? \\
Contact us at: \\
WFHealthUSF@gmail.com \\
OR \\
Text us back! \\
\hline
\end{tabular}




\section{Appendix C: Reminder Handout}

ID:

\section{Work, Family, and Health Study Reminder Handout}

\section{How to Participate}

Respond to the text messaged survey links. You will start on

- For the first three days - every two hours, starting at $8 \mathrm{AM}$ and ending at $10 \mathrm{PM}$.

- For the next four days - every evening at 10 PM.

- Respond as soon as possible after receiving each link.

- You will need internet access.

- It should take approximately 2-5 minutes to respond.

Take your blood pressure and heart rate each time you respond.

- Please take your blood pressure and heart rate in a seated position with your left hand on your chest and do not talk. Do not cross your legs.

Wear the Actigraph actigraphy watch on your right hand.

- Do not remove the watch, even when wet.

\section{How to Take your Blood Pressure and Heart Rate}

1. While during measurement sit still with feet flat on floor, and don't talk. Do not cross your legs.

2. Place monitor on your LEFT wrist like in the image.

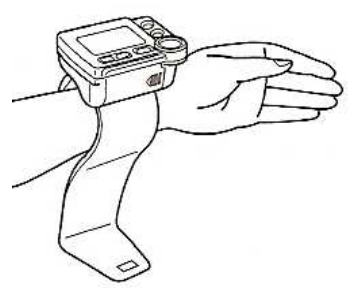

3. Place your left hand on your chest like you are saying the Pledge of Allegiance with your left hand.

4. Adjust until the watch beeps several times and begins contracting. Arrow to the left means too low, to the right means too high. 


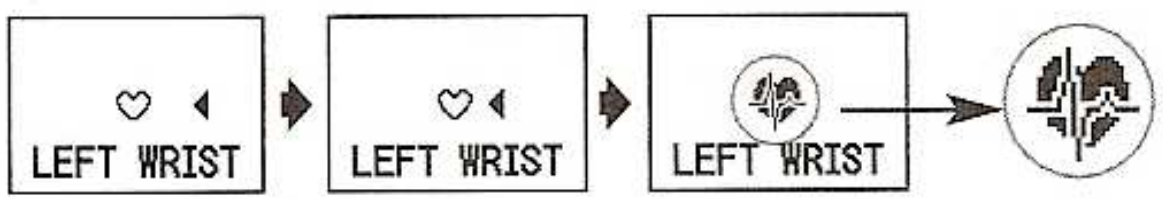

5. Type in your readings on the survey when it asks for blood pressure and heart rate.

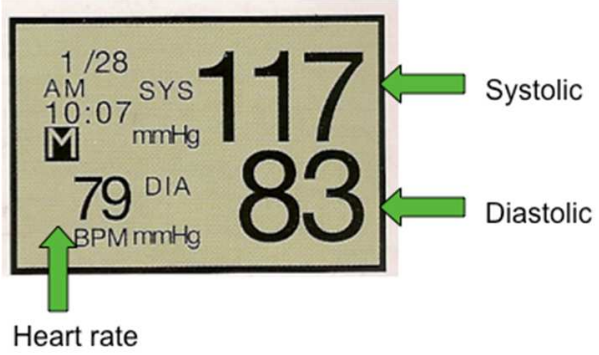

- If your blood pressure reading is abnormally high/low (> 140/90 or < 90/60), wait 2 minutes and take another reading.

- If in place of numbers, an " $E$ " appears, an error occurred in measurement, probably due to improper arm placement or movement during reading. Wait 2 minutes and take another reading.

- If the monitor randomly stops working and displays strange characters, replace batteries. You will have to reset time/date (see manufacturer instruction booklet for details)

\section{Work-Family Conflict Episodes - What to Look For}

For each survey, you will be asked to identify if you had any of the following conflicts between work and family. Please be on the lookout for the following:

\section{Work makes it difficult to meet demands of family}

- You missed all or part of a family activity (for example, leave early or arrive late) due to your job.

- You had to delay a family activity due to your job.

- You had to take care of something for your work while at home.

- You were mentally preoccupied or distracted by a work issue while you were trying to engage in a family activity.

- You did job-related work while you were engaged in a family activity.

- You were interrupted by something work-related while you were engaged in a family activity.

- You were in a bad mood about your job while you were engaged in a family activity.

- Your job left you tired or out of energy, which limited your engagement in a family activity. 


\section{Family makes it difficult to meet the demands of work}

- You missed all or part of a work responsibility (for example, leave early or arrive late) due to your family.

- You had to delay working on a job task due to your family.

- You had to take care of something for your family while at work.

- You were mentally preoccupied or distracted by a family issue while you were trying to perform one of your work tasks.

- You did family-related work while you were performing one of your work tasks.

- You were interrupted by something family-related while you were performing a work task.

- You were in a bad mood about your family while you were performing a work task.

- Your family left you tired or out of energy, which limited your engagement in a job task.

\section{Need Help? Have a Question?}

Contact the research team at WFHealthUSF@gmail.com

Text us back! We receive notifications when you respond to the text messaged survey links. 


\section{Appendix D: Monitor Return Agreement \\ Wrist Monitor Return Agreement}

$\mathrm{I}$, , agree to return the OMRON HEM-637

ambulatory wrist blood pressure monitor and the Actigraph GT9X LINK to the researcher (Kim French or a member of her research team) at time,

location within two weeks of ending my participation in the Work, Family, and Health study.

This requires scheduling an appointment to return the equipment using the email provided in the reminder handout. If I do not return the study equipment, or return it broken I am responsible for paying the full price to replace the OMRON HEM-637 watch or the Actigraph GT9X LINK.

I fully understand and agree to the above terms. 


\section{Appendix E: Email and Text Scripts}

\section{Email and Text Scripts}

The following are scripts for texts to be sent throughout the study. Please copy and paste these scripts exactly as they appear in the times described.

\section{Response to Inquiry}

When: To be sent in response to an initial inquiry from a potential participant. Please email from the study address (WFHealthUSF@gmail.com). Text in red should be filled in with the appropriate information.

\section{Dear NAME:}

In order to participate, you must:

1. Be at least 18 years old

2. Be working at a paid job at least 30 hours per week during standard hours (between 7 AM and 7 PM, Monday-Friday)

3. Have either a spouse, a cohabiting partner of at least 1 year, or a dependent child or elder who you are caring for

4. Have a smartphone capable of accessing the internet and receiving texts in order to receive the surveys during the week

If you are eligible, we will need to set up a one hour training session with a researcher. Please choose one hour within any of the following time blocks. If none of these times work, please indicate what would be a good time, and I can work with our research team to try and fill that time.

Thursday (April 6th): 8 AM - 12 PM or 2 PM - 8 PM

Friday (April 7th): 4 PM - 6 PM

Saturday (April 8th): 3 PM - 8 PM

Sunday (April 9th): 8 AM - 8 PM

Tuesday (April 11th): 8 AM - 8 PM

Wednesday (April 12th): 8 AM - 9 AM or 12 PM - 8 PM

Thursday (April 13th): 8 AM - 8 PM

Our lab is located on the University of South Florida campus, 4202 E. Fowler Ave. in Tampa. Building PCD, room 3112. However, if it is more convenient we would be happy to meet you in a community location of your choosing (e.g., coffee shop, library near you). 
Please let me know what time and place works best for you.

Best,

YOUR NAME

Work, Family, and Health Research Team

University of South Florida

\section{Appointment Confirmation (Location in our lab)}

When: To be sent when the participant confirms a time and location for the training appointment and has chosen to complete training in the lab. Send from the study email address (WFHealthUSF@gmail.com). Text in red should be filled in with the appropriate information.

Attachments: Campus map AND Directions to lot 9A (located in the Drive)

To-do: Schedule the Reminder for Training Meeting email, schedule Google calendar appointment with appropriate researcher, order parking pass (if necessary), update recruitment tracking sheet.

Hi NAME,

That would be perfect. I've written down your appointment for 5:45 PM on Wednesday, April 19th. Please plan for a 60 minute session.

We will meet in our lab, located on the USF campus (4202 Fowler Ave., Tampa), building PCD, room 3110D. I've attached a campus map with our building and parking lot highlighted, as well as directions to get to lot 9A. Please park in lot 9A in one of the spots marked "USF PSY/CSD CLINIC." I will be outside 10 minutes prior to the appointment with a parking pass.

Please let me know if you have any questions or concerns as the time approaches. Looking forward to seeing you then!

Best,

YOUR NAME

Work, Family, and Health Research Team

University of South Florida

\section{Appointment Confirmation (Location in the community)}

When: To be sent when the participant confirms a time and location for the training appointment and has chosen to complete training in a community location. Send from the study email address (WFHealthUSF@gmail.com). Text in red should be filled in with the appropriate information. 
Hi NAME,

That would be perfect. I've written down your appointment for 5:45 PM on Wednesday, April 19th. Please plan for a 60 minute session.

We will meet in at LOCATION (ADDRESS). The researcher will be ready to greet you at the front door 10 minutes before your scheduled time (MAY CHANGE DEPENDING ON

LOCATION. FOR LIBRARIES, SEE IF YOU CAN RENT A STUDY ROOM AND GIVE THE ROOM LOCATION).

Please let me know if you have any questions or concerns as the time approaches. Looking forward to seeing you then!

Best,

YOUR NAME

Work, Family, and Health Research Team

University of South Florida

\section{Reminder for Training Meeting}

When: To be sent at noon the day before the in-person meeting. Please email from the study address (WFHealthUSF@gmail.com).

Subject: WF Health Study: Appointment Reminder

Attachments: If coming to the lab, attach campus map and directions to lot 9A (located in the Drive)

Text in red should be filled in with the appropriate information.

"Greetings!

This is a reminder that you will be participating in the Work, Family, and Health Study. You are scheduled to meet with RESEARCHER at LOCATION at TIME tomorrow, DATE. CONSIDER ADDING HELPFUL IDENTIFICATION INFO (E.G., "I WILL BE WAITING AT THE FRONT ENTRANCE OF THE COFFEE SHOP WITH A BINDER”). Please plan for a one hour session, including a brief survey and training on study procedures. Please also bring your cell phone; there is no need to prepare anything additional in advance.

If you have any questions, you may email us at WFHealthUSF@gmail.com.

Sincerely,

YOUR NAME

The Work, Family, and Health Research Team 
University of South Florida"

\section{Pre-survey Email - Reminder to Begin}

When: To be sent Sunday (or Tuesday) evening before the participant's start date at 6 PM. Please email from the study email address (WFHealthUSF@gmail.com).

Subject: WF Health Study: Reminder to Begin

Attachments: Reminder Handout (located in Drive)

"Greetings!

This is a reminder that you will be participating in the Work, Family, and Health Study. Starting tomorrow, you will receive one survey via text every two hours for three days, starting at 8 AM each day. For the rest of the week, you will receive one evening survey at 10 PM. For each survey, we ask that you take your blood pressure and heart rate on your left arm using the provided cuff. In addition, be sure you are wearing the provided Actiwatch on your right wrist.

If you have not already, please put your Actiwatch on now, and place your blood pressure monitor in a place where you will remember to take it with you.

Please refer to the reminder handout for a quick overview of the study procedures (also attached here). If you have any questions throughout the study, you may respond to the text messages or email us at WFHealthUSF@gmail.com. Thank you for your participation, and best of luck in the study!

Sincerely,

The Work, Family, and Health Research Team

University of South Florida"

\section{Two Hour Texts}

When: 8 AM text Monday (or Wednesday)

Good morning! Welcome to the Work, Family, and Health Study. Click the link to fill out your first survey of the day:

https://usf.az1.qualtrics.com/SE/?SID=SV_9Rj0x8hly16VJdP

When: 8 AM text Tuesday-Wednesday (or Thursday-Friday)

Good morning! Please take your heart rate and blood pressure, then click here for your first survey of the day: https://usf.az1.qualtrics.com/SE/?SID=SV_9Rj0x8hly16VJdP

When: 10 AM, 12 PM, 2 PM, 4 PM, 6 PM, 8 PM texts Monday-Wednesday (or WednesdayFriday) 
It is time for your next survey. Please take your heart rate and blood pressure, then click here: https://usf.az1.qualtrics.com/SE/?SID=SV_9Rj0x8hly16VJdP Thank you!

When: 10 PM text Monday-Wednesday (or Wednesday-Friday)

This is your last survey of the day. Please take your heart rate and blood pressure, then click here: https:/usf.az1.qualtrics.com/SE/?SID=SV_9Rj0x8hly16VJdP. Thank you!

\section{Daily Texts}

When: 10 PM Thursday-Sunday (or Saturday-Tuesday)

Greetings! It is time for your daily evening survey. Please take your heart rate and blood pressure, then click here: https://usf.az1.qualtrics.com/SE/?SID=SV_8rkWpI9Usuxq3ZP

\section{Pre-Survey Email - Reminder}

When: To be sent Wednesday (or Friday) evening before the participant's final four days of participation at 6 PM. Please email from the study email address (WFHealthUSF@gmail.com).

Subject: WF Health Study: Reminder

"Greetings!

This is a reminder that you are participating in the Work, Family, and Health Study. Thank you for your participation so far! Starting tomorrow, you will receive only one evening survey at 10 PM. For each survey, we ask that you take your blood pressure and heart rate on your left arm using the provided cuff. In addition, be sure you are till wearing the provided Actiwatch on your right wrist.

Please refer to the reminder handout for a quick overview of the study procedures. If you have any questions throughout the study, you may respond to the text messages or email us at WFHealthUSF@gmail.com. Thank you for your participation, and best of luck in the study!

Sincerely,

The Work, Family, and Health Research Team

University of South Florida"

\section{Final Email - Equipment Return Reminder}

When: $8 \mathrm{AM}$ the day following study completion.

Subject: WF Health Study: Equipment Return Reminder

"Greetings! 
Thank you for participating in the Work, Family, and Health Study. We appreciate your time and efforts over the past week.

Please be sure to meet us at $\mathrm{XX}$ time at $\mathrm{XX}$ location to return the study equipment, as discussed in your training meeting. If this date or time no longer work for you, please let us know so that we can arrange a more convenient time or place. Please be advised that we will not distribute compensation until you return the study equipment.

Thank you, and we look forward to seeing you soon.

Sincerely,

The Work, Family, and Health Research Team

University of South Florida"

\section{Reminder Email - Not Participating}

When: The day after a full day of missed surveys.

Subject: WF Health Study: Participation Reminder

"Greetings!

This is a reminder that you are participating in the Work, Family, and Health Study. Please respond to the text messaged survey links sent to your smartphone. For each survey, we ask that you take your blood pressure and heart rate on your left arm using the provided cuff. In addition, be sure you are wearing the provided Actiwatch on your right wrist.

We have attached the reminder handout for a quick overview of the study procedures. If you are having problems or have questions, you may respond to the text messages or email us at WFHealthUSF@gmail.com. Thank you for your participation.

Sincerely,

The Work, Family, and Health Research Team

University of South Florida"

\section{Gift Card Message}

When: After the study is complete.

Only Kim sends this.

Thank you for your participation in the Work, Family, and Health Study! According to our records, you responded to all 28 signals for a total of $\$ 75$ compensation. IF MISSING DATA 
POINTS, DESCRIBE WHICH ONES. IF LATE, NOTE AS LATE (AND THEREFORE NOT VALID. PASTE SCREENSHOTS OF MISSED/LATE TIME STAMPS BELOW).

Please find your Amazon Gift Card codes below. To redeem your gift card, follow these steps: Visit www.amazon.com/redeem.

Enter the Claim Code when prompted.

Gift card funds will be applied automatically to eligible orders during the checkout process.

You must pay for any remaining balance on your order with another payment method. Your gift card claim code may also be entered when prompted during checkout. To redeem your gift card using the Amazon.com 1-Click ${ }^{\circledR}$ service, first add the gift card funds to Your account. If you have questions about redeeming your gift card, please visit www.amazon.com/gc-redeem.

You will receive your Participant Health Report via email within the next 1-2 weeks. Please let us know if you have any more questions or concerns.

Thank you!

The Work, Family, and Health Research Team 
Appendix F: Participant Health Report.

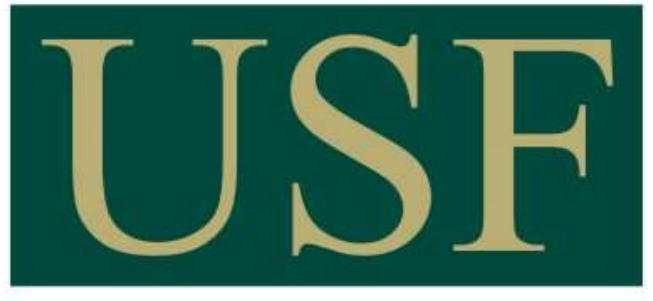

UNIVERSITY OF

SOUTH FLORIDA

The Work, Family, and Health Study

Participant Health Report

Participant: ALAL0104

August 3, 2017 


\section{Overview}

Thank you for your participation in the Work, Family, and Health Study! You have helped us to better understand how managing work and family influences daily health, including the foods we eat, how we feel, and how hard our heart is working. In addition to contributing to this important cause, we gladly provide you with this health report as a thank you for your participation.

The information in this report is drawn from your survey responses, blood pressure/heart rate monitor information, and activity monitor information. In some cases, your information is compared with averages found in research or recommendations to give you a point of comparison.

We hope you find this health report informative and beneficial. If you have any questions or concerns about the information displayed in the report, please feel free to contact the primary investigator, Kimberly French (KFrench0429@gmail.com).

Enjoy! 


\section{Table of Contents}

Work and Family

Error! Bookmark not defined.

Conflict between Work and Family

Error! Bookmark not defined.

Importance of Work and Family

Error! Bookmark not defined.

Blending Work and Family

Error! Bookmark not defined.

Psychological Health

Error! Bookmark not defined.

Bad Mood and Tiredness

Error! Bookmark not defined.

Mindfulness Error! Bookmark not defined.

Body Mass Index

Error! Bookmark not defined.

Unhealthy Eating 157

Cardiovascular Health

Error! Bookmark not defined.

Heart Rate and Blood Pressure Error! Bookmark not defined.

Physical Activity Error! Bookmark not defined. Amount of Physical Activity. Error! Bookmark not defined. Number of Steps Error! Bookmark not defined.

Sleep Error! Bookmark not defined. Hours of Sleep Error! Bookmark not defined. Sleep Quality Error! Bookmark not defined.

Resources Error! Bookmark not defined. 


\section{WORK AND FAMILY}

\section{CONFLICT BETWEEN WORK AND FAMILY}

Work-family conflict happens when demands of work and family compete with one another. This can happen when there are time conflicts between work and family. For example, if your boss asks you to stay late at work, you may not be able to make it home in time to make dinner. Conflicts can also be psychological. For instance, an argument at home may be distracting you at work, making it difficult to get things done. Work can make it difficult to do family things; this is called work interference with family. On the other hand, family can make it difficult to do work things; this is called family interference with work.

Below, we've shown your overall work-family conflict in comparison to the average workfamily conflict reported by 92 Tampa community members in a similar study at USF. In general, work-family conflict is unpleasant and sometimes stressful, so lower work-family conflict, or fewer work-family conflicts are better.

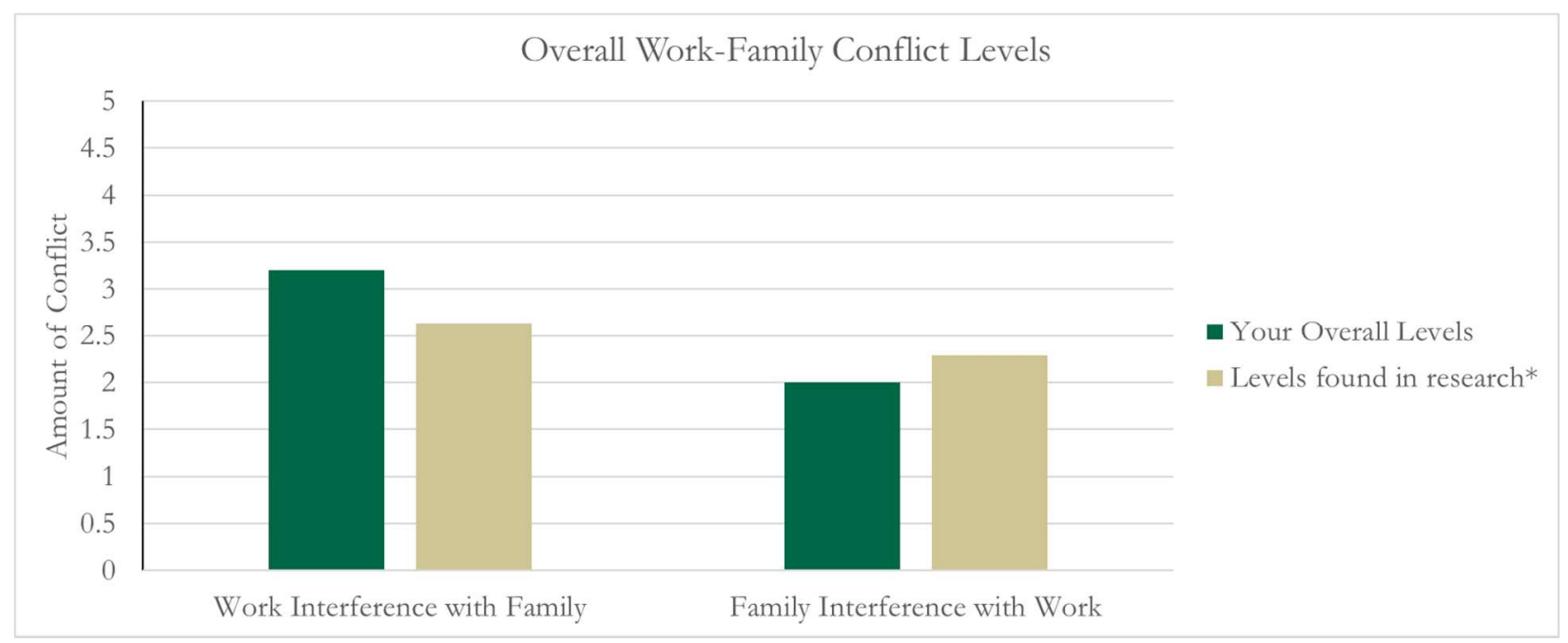

* Shockley, K. M., \& Allen, T. D. (2015). Deciding between work and family: An episodic approach. Personnel Psychology, 68(2), 283-318.

\section{Importance of Work and Family}

People differ in how much work and family are important to them as a person. People who are work-centric find a lot of meaning through work, spend much of their time on work, and feel work is a key part of their identity. On the other hand, people who are family-centric find a lot of meaning in doing things for family, like to spend time with family, and feel that family is core to their identity. These two are not a trade-off. Both work and family may be very important to you, or you may place little importance on both work and family. Below, we've shown how much importance you placed on work and family. 


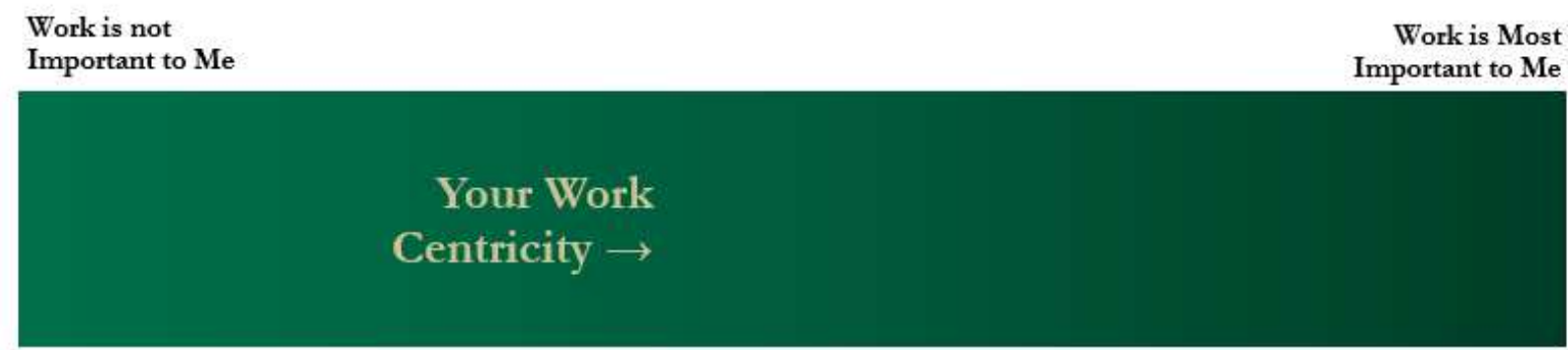

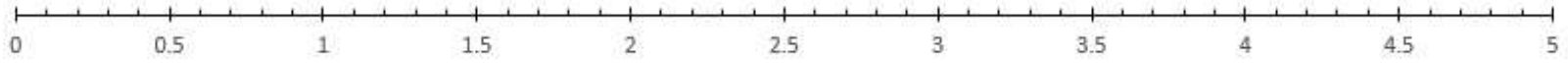

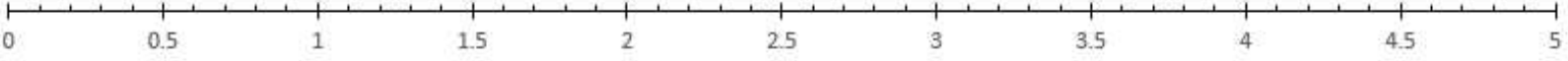

\section{Blending Work and Family}

People differ in how they manage work and family. Some people tend to mix work and family together. They like to take work home, or work on family chores while they are at their work place. They might also like to talk about work problems or events with family members, and similarly share personal stories about their family with coworkers. Individuals who tend to blend work and family are called integrators. Others prefer to keep work and family separate. Their coworkers or supervisors likely know very little about their home life, and they like to completely forget about work after they clock out for the day and head home. People who like to keep work and family separate are called segmentors.

Below, we've shown where you fall on the spectrum from integrator to segmentor. Both sides of the spectrum can be healthy for managing work and family. It's all a matter of arranging work and family so that you are happy. If you are towards the segmentor end of the spectrum, you are probably most satisfied when work stays at work, and family stays at home. If you are towards the integrator side of the spectrum, you probably enjoy having your work and family worlds blended together. 


\section{Your Blending Level $\rightarrow$}

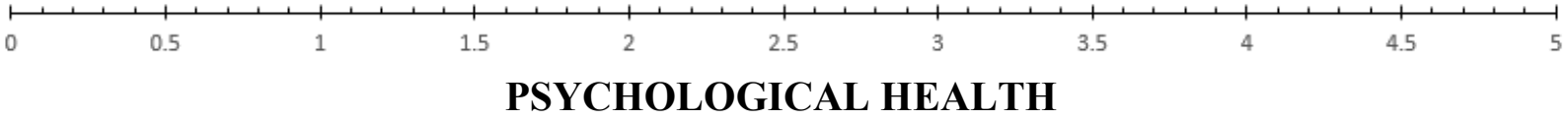

\section{Bad Mood and Tiredness}

In this study, we asked you to describe how you felt in general and throughout the week. People who tend to be in a bad mood feel angry, distressed, or anxious. People who are tired tend to feel sluggish and sleepy. Both bad mood and tiredness are undesirable signs of stress. Below, we've shown to what extent you generally tend to be in a bad mood or tired, as well as the pattern of your mood and energy throughout your week of participation and across an average day.
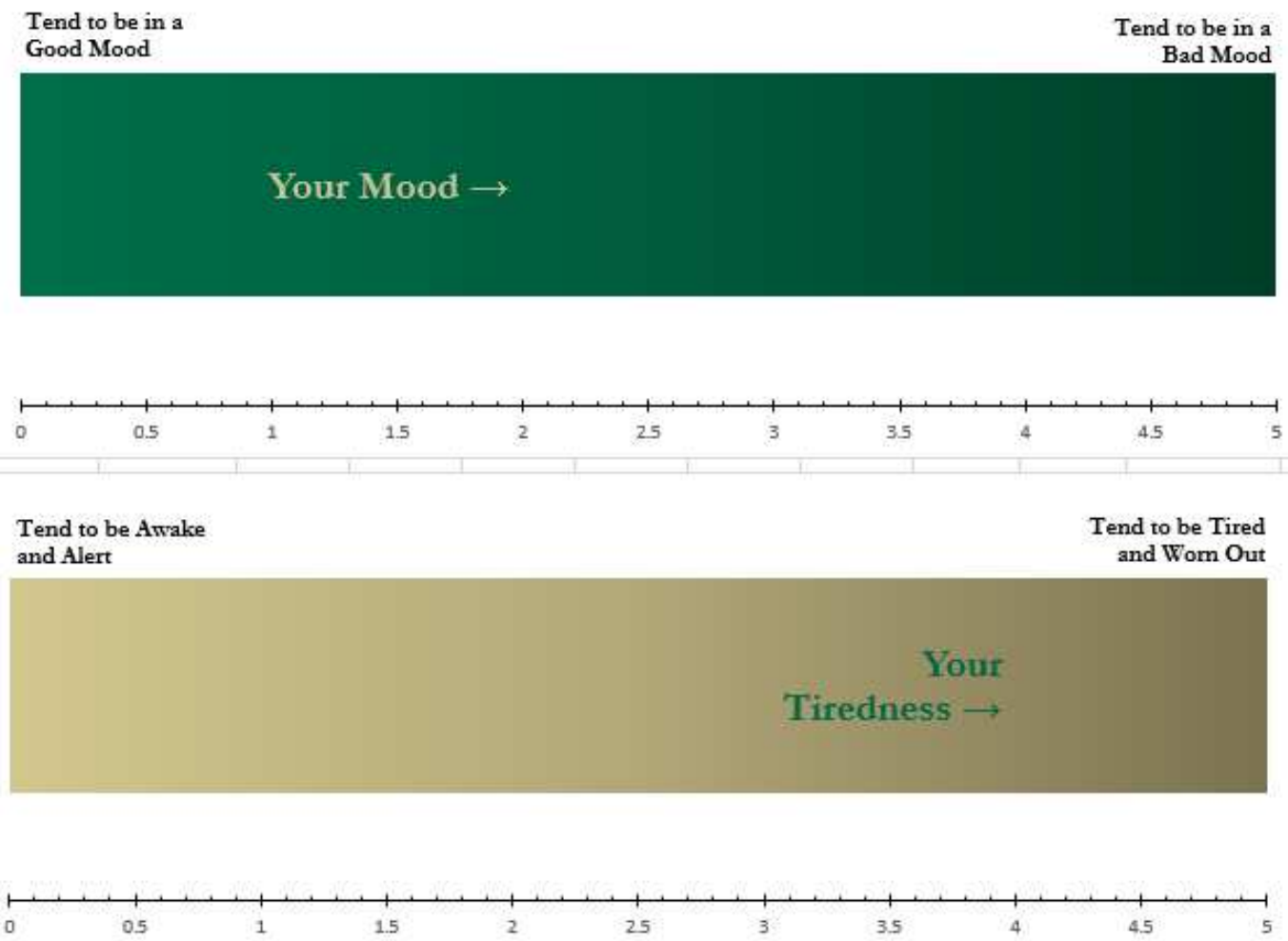


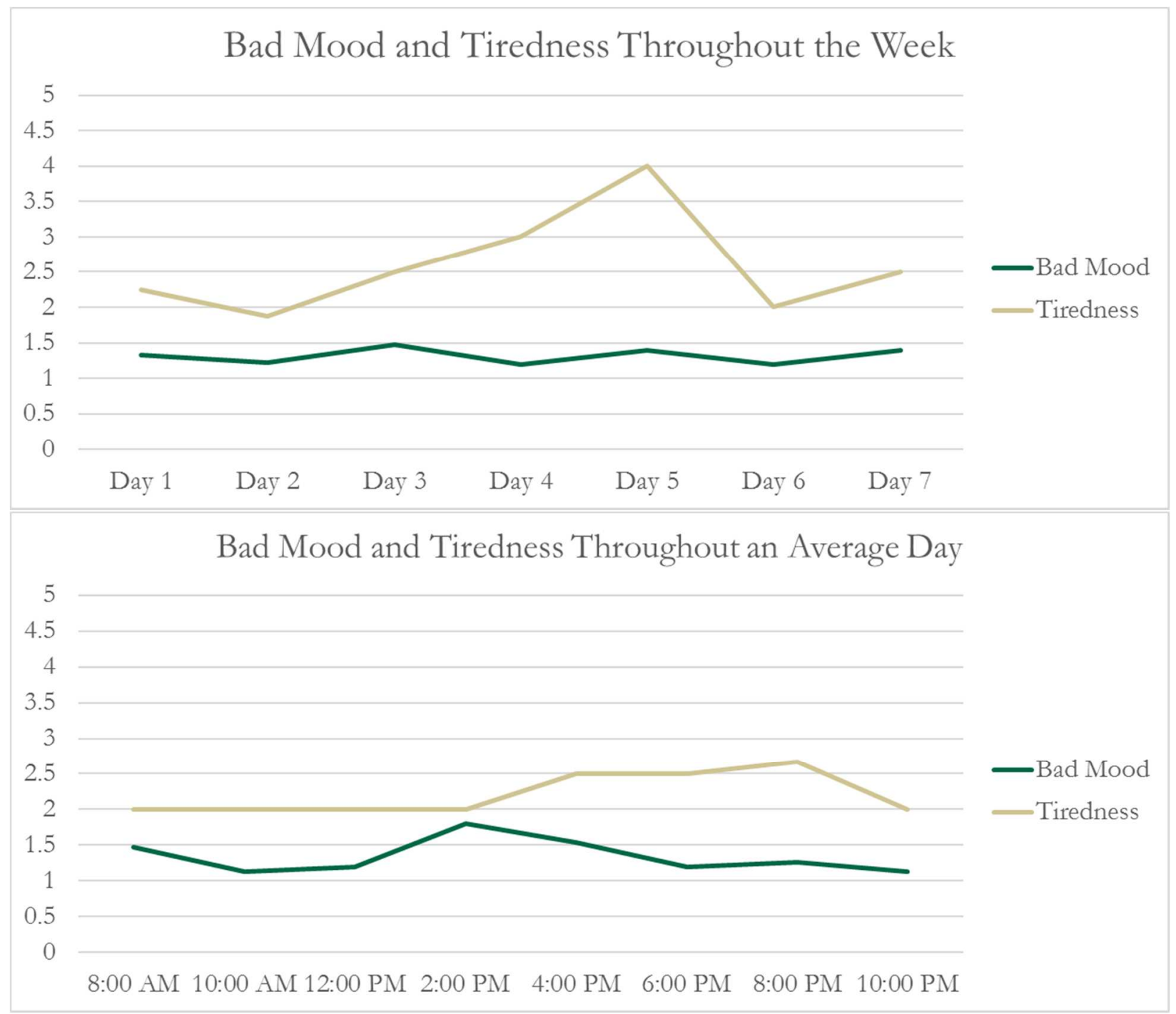

\section{Mindfulness}

Mindfulness is a state of mind in which you are aware of what is happening during the present moment within your mind and body and around you. When you are mindful, you simply notice what is happening, rather than judging or criticizing. Recent research has shown being mindful helps to improve happiness, emotion control, and decreases things like getting stressed or burnt out. Some studies even show mindfulness alters brain matter in areas that involve learning and emotions! Below, we show how mindful you tend to be in general. Based on the current research, more mindfulness tends to be better for well-being and reducing stress. 

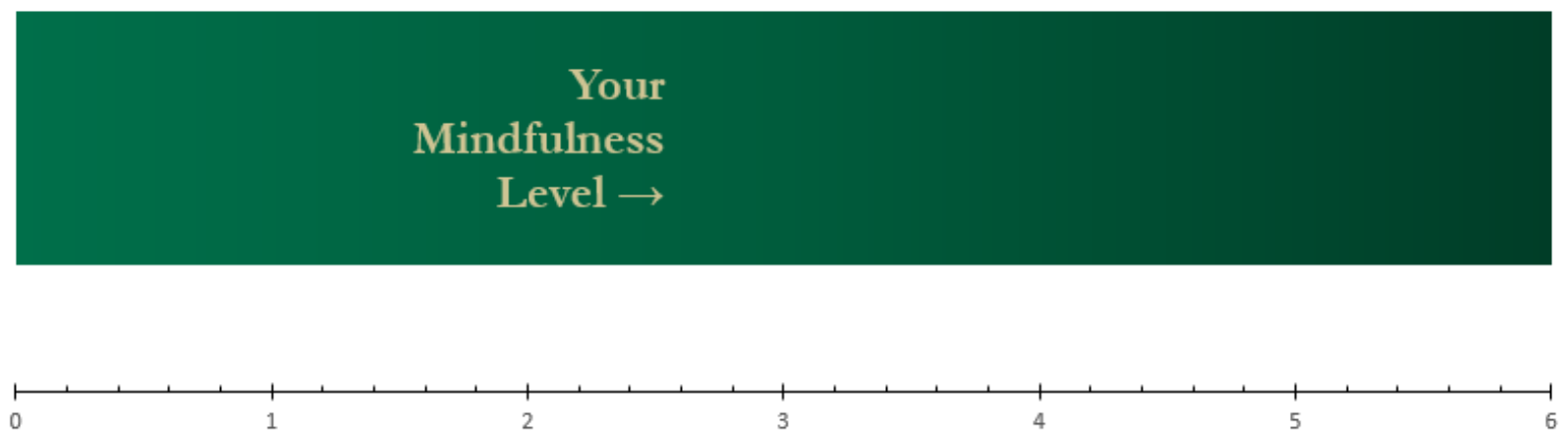

\section{BODY MASS INDEX}

Body mass index (BMI) is a quick, easy, and cost-effective way to estimate body fat. BMI is calculated by dividing a person's weight in kilograms by the square of his or her height in meters. BMI is typically divided into four categories:

Underweight - Below 18.5

Normal or Healthy Weight - $18.5-24.9$

Overweight $-25.0-29.9$

Obese -30.0 and above

In general, normal or healthy weight is recommended by health and wellness experts. However, BMI is only a rough estimate and should be considered in light of other health behaviors and measures, such as exercise, diet, proportion of muscle to fat.

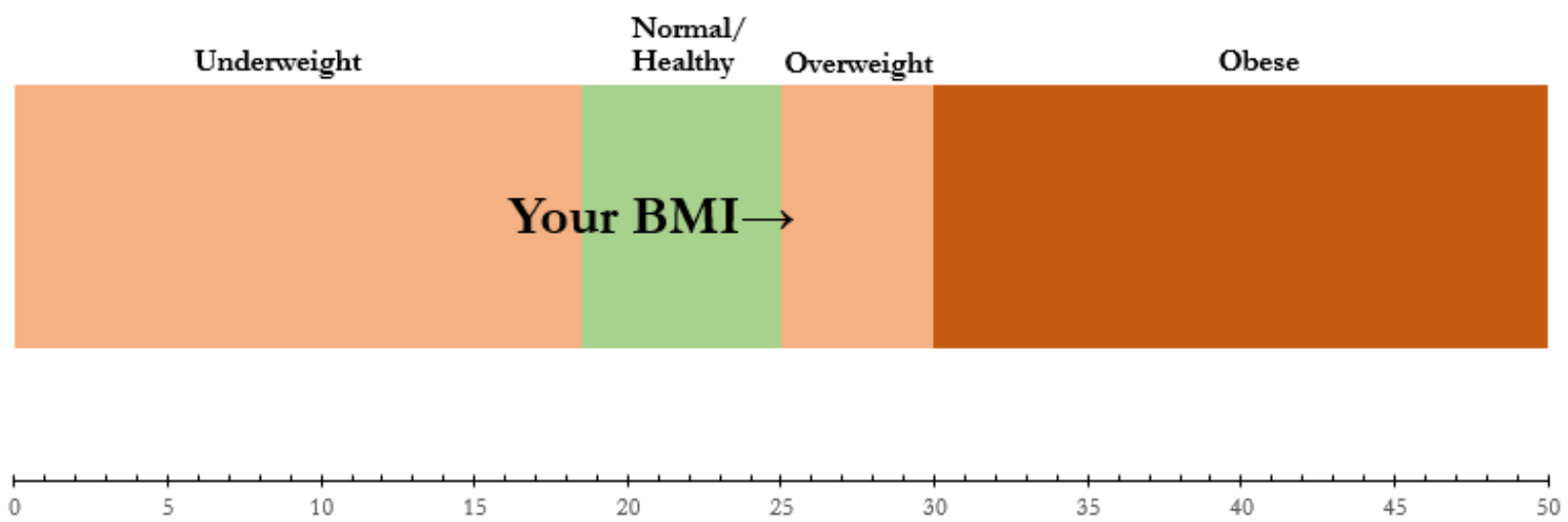




\section{UNHEALTHY EATING}

Eating is an important part of staying healthy and preventing cardiovascular disease. The American Heart Association recommends eating a variety of nutritious foods, such as fruits and vegetables, whole grains, low-fat dairy products, poultry and fish, nuts, legumes, and nontropical vegetable oil. On the other hand, it is good to avoid foods that are high in fats, sodium, or sugar. These foods are often low in nutrients but high in calories. Below, we've displayed how often your reported eating these unhealthy foods per month, and throughout the week you participated in this study.

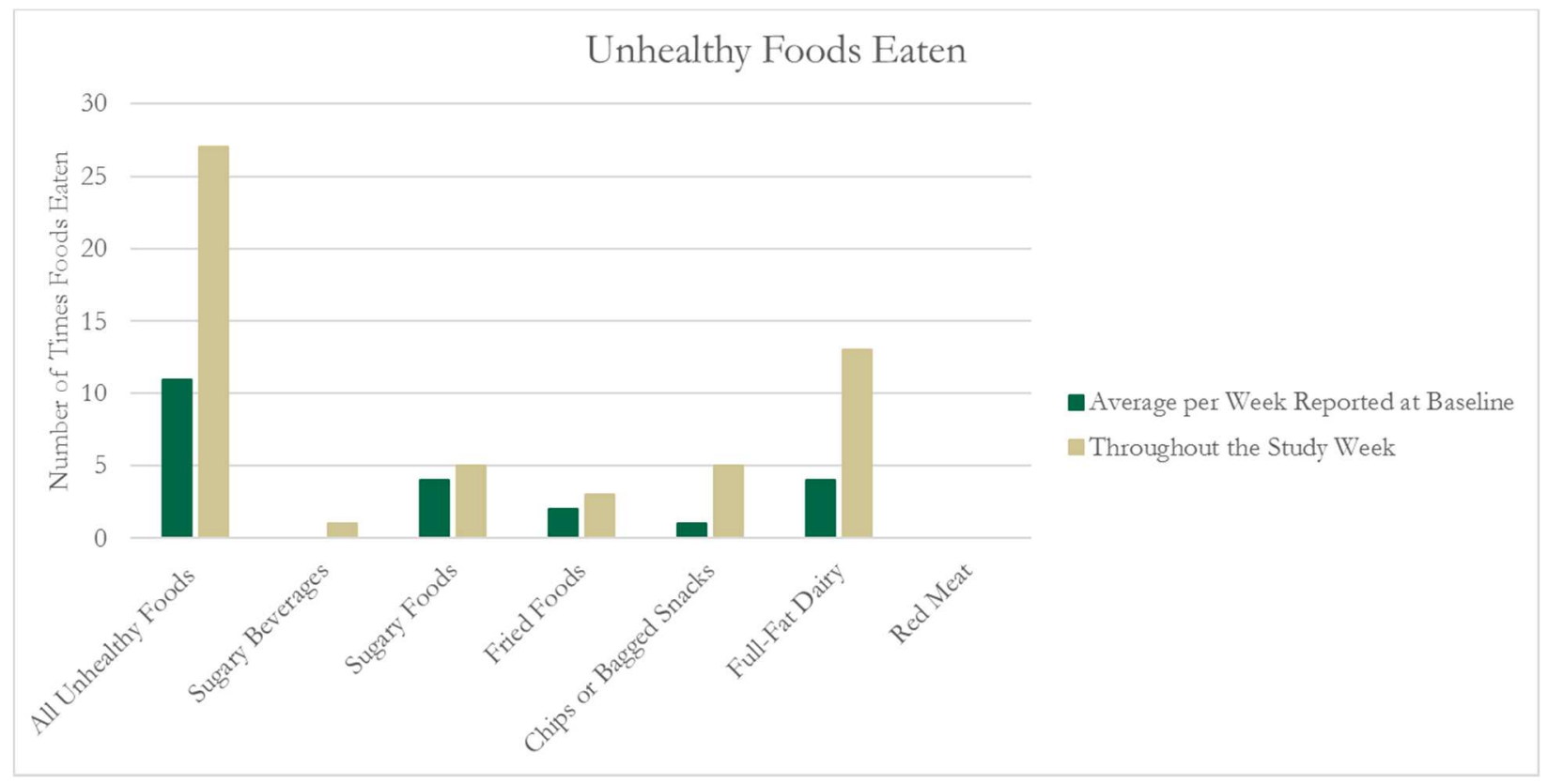

\section{CARDIOVASCULAR HEALTH}

\section{Heart Rate and Blood Pressure}

Heart rate is the number of times your heart beats per minute. Blood pressure is the pressure that keeps your blood flowing through your veins and arteries. Blood pressure is determined by how forcefully and how often your heart beats, in addition to the elasticity of your veins and arteries. Your blood pressure reading has two numbers: systolic (pressure when your heart beats), and diastolic (pressure when your heart is at rest between beats). The American Heart Association categorizes resting blood pressure into the following groups:

Normal - Systolic is less than 120 or diastolic is less than 80

Prehypertension - Systolic is $120-139$ or diastolic is $80-89$

High blood pressure (Hypertension) Stage 1 - Systolic is 140-159 or diastolic is 90-99 High blood pressure (Hypertension) Stage 2 - Systolic is 160 or higher or diastolic is 100 or higher

Hypertensive crisis (emergency care needed) - Systolic is higher than 180 or diastolic is higher than 110 . 
Importantly, a diagnosis of hypertension can only be made by a medical professional. If you had consistently high blood pressure readings throughout the study, we recommend that you contact a physician. Below, we've displayed your blood pressure readings at the end of the day throughout the week, as well as your readings throughout an average day.
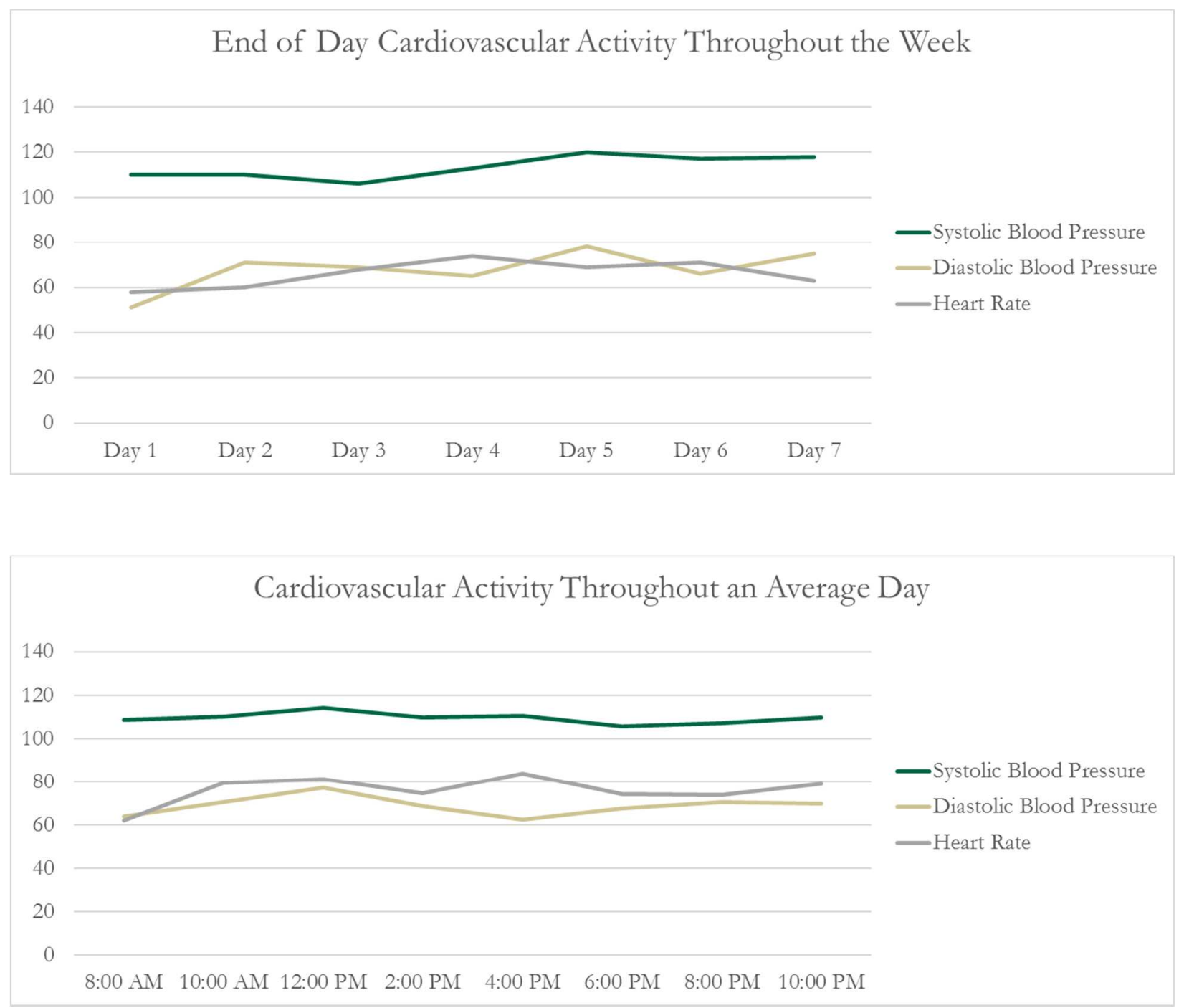


\section{PHYSICAL ACTIVITY}

\section{Amount of Physical Activity}

Daily physical activity is recommended in order to improve health and reduce risk of illness and disease. The Centers for Disease Control and the World Health Organization recommends adults age 18-64 should get:

At least 2 hours and 30 minutes of moderate activity (such as brisk walking, playing tennis, or mowing the lawn)

OR

At least 1 hour and 15 minutes of vigorous activity (such as running, swimming, or playing basketball)

OR

An equivalent mix of moderate and vigorous activity

Activities should be done for at least 10 minutes at a time. Muscle strengthening activities should also be included at least 2 days each week. Recently, researchers have turned their attention to sedentary activity, which are periods of inactivity (e.g., sitting, laying down). Although there are no official government recommendations, having a lot of sedentary activity is consistently related to obesity and cardiovascular disease. Research recommends people get up and move consistently throughout the day to avoid long bouts of inactivity.

Below, we've displayed your activity levels and the time spent as sedentary activity for each day during your participation. These activity levels were recorded by your actigraphy watch.

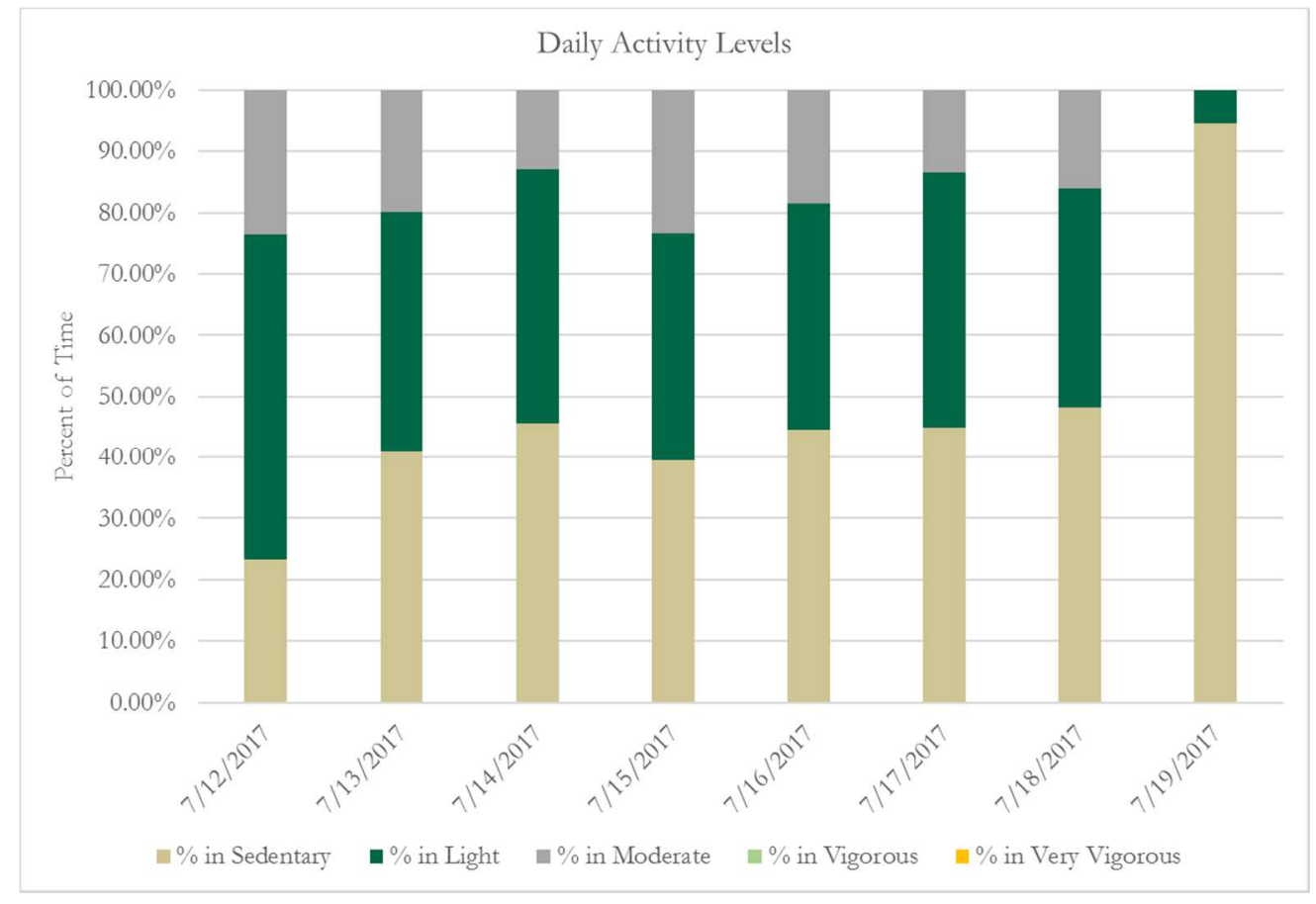




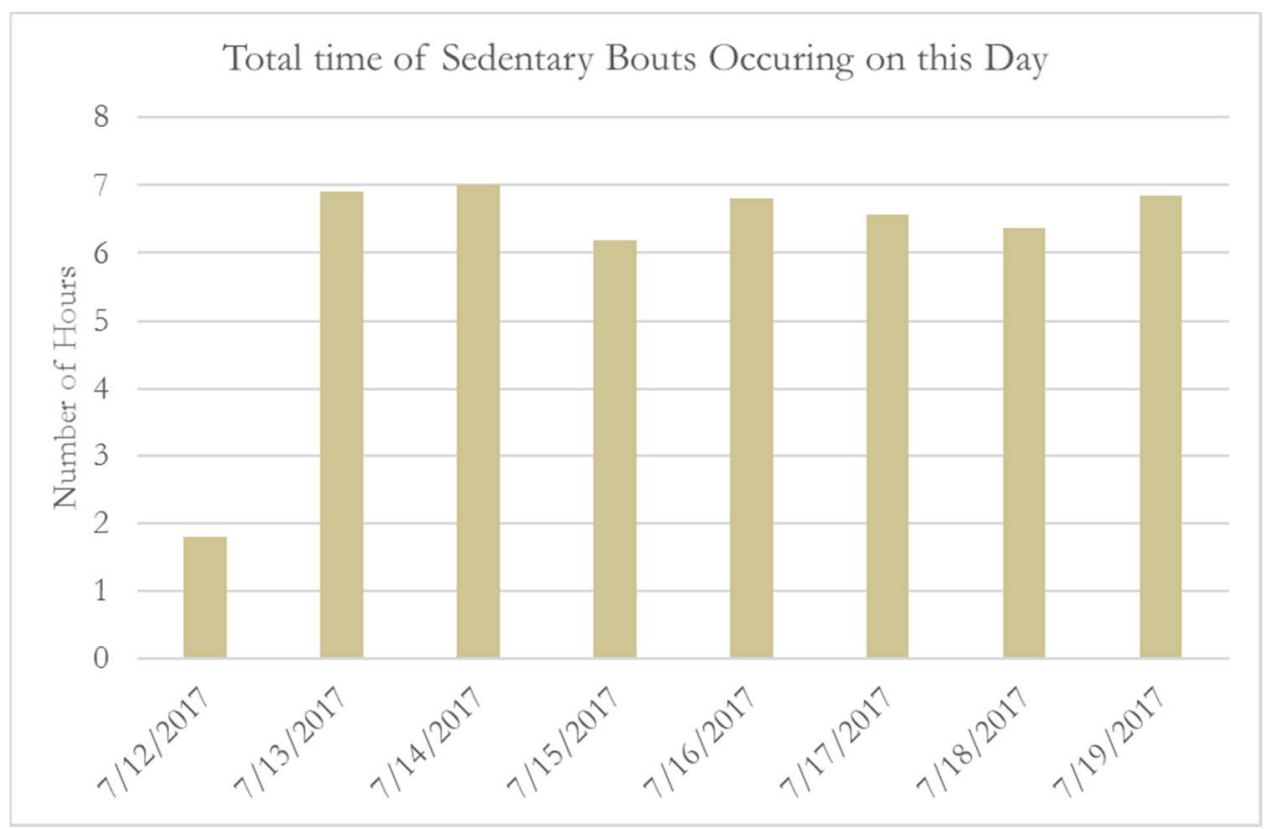

\section{Number of Steps}

There are no official health recommendations for the number of steps taken in a day. However, researchers have found between 8,000 and 10,000 steps corresponds to the amount of moderate activity recommended by the Centers for Disease Control. Below, we've shown your total number of steps taken throughout your week of participation.

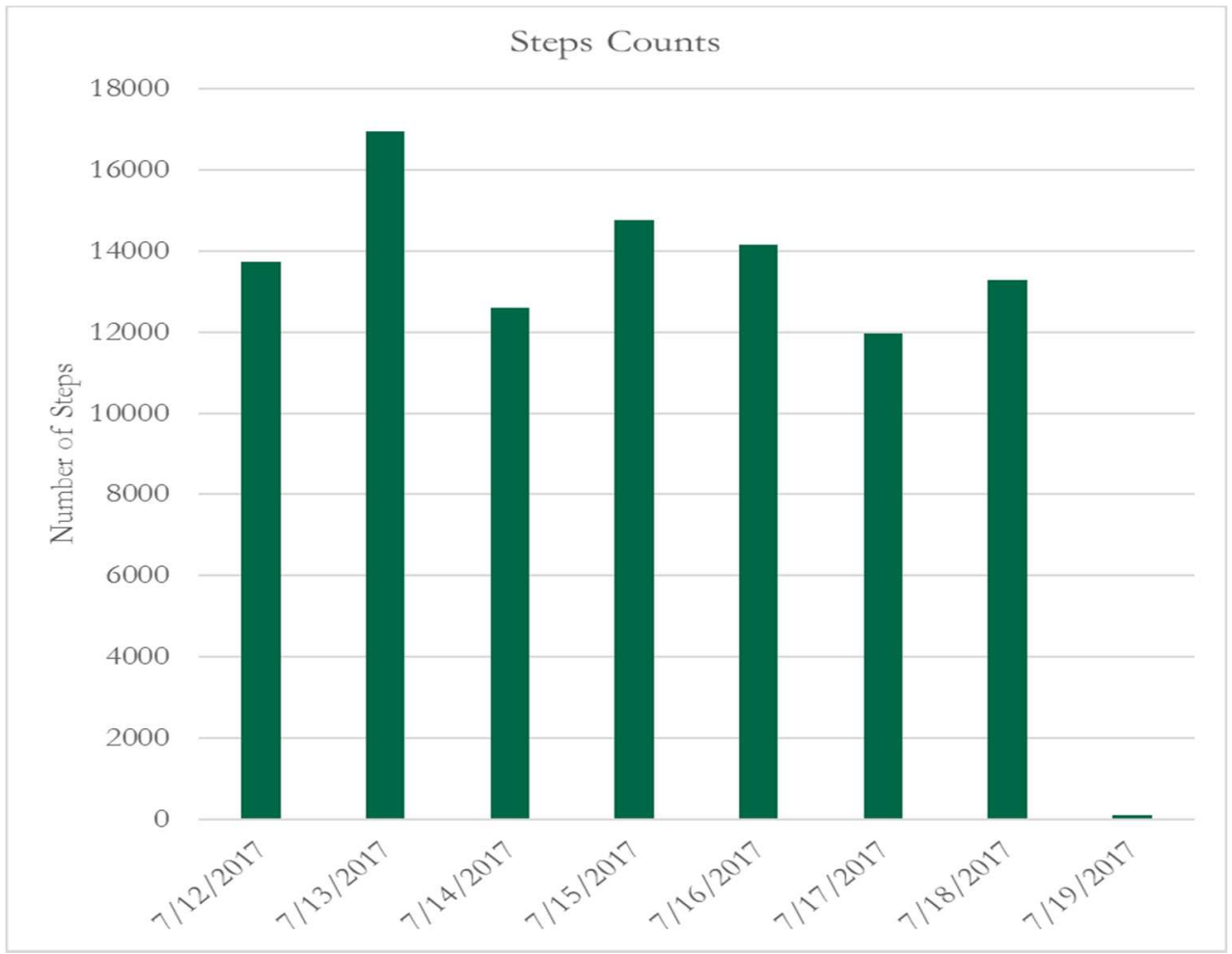


Wednesday

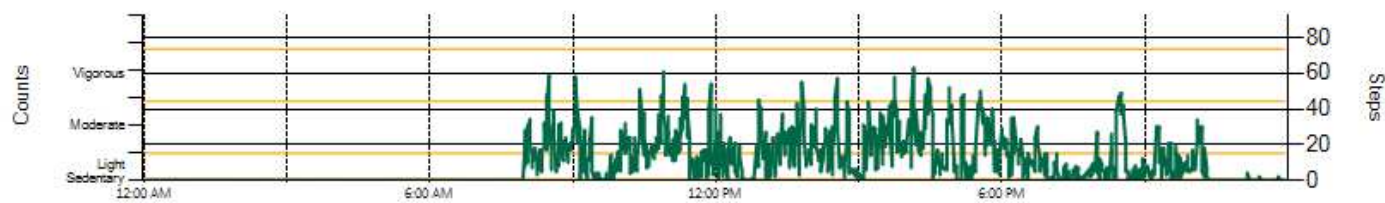

Thursday 7/13/2017

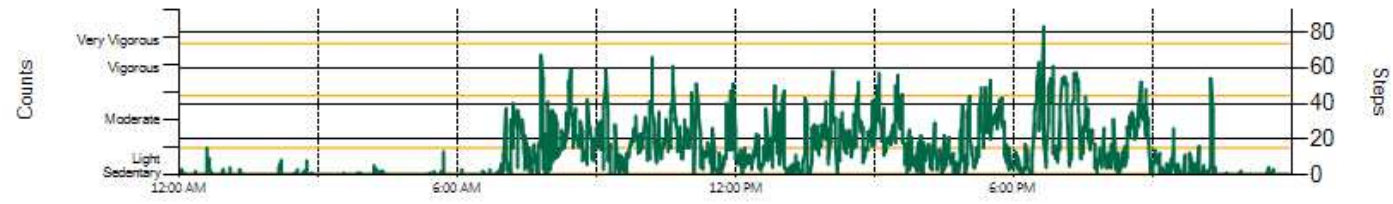

Friday 7/14/2017

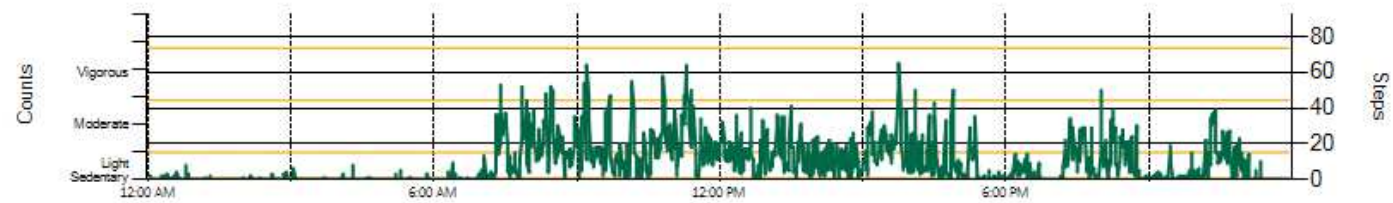

Saturday 7/15/2017

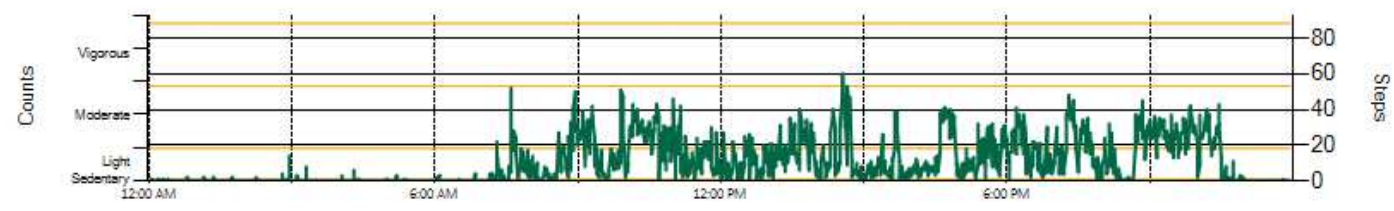

Sunday 7/16/2017

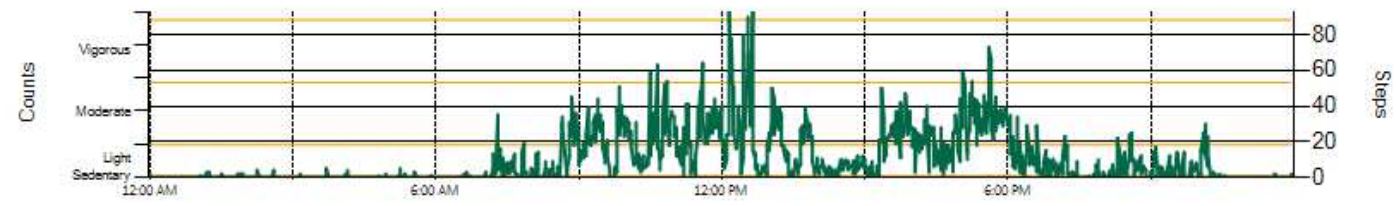

Monday 7/17/2017

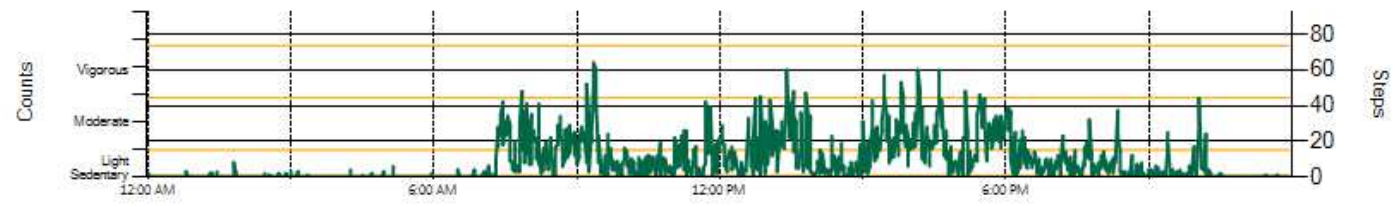

Tuesday 7/18/2017

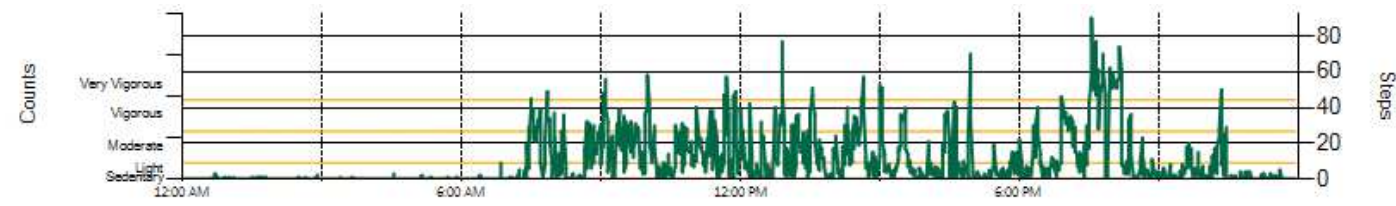

Wednesday 7/19/2017

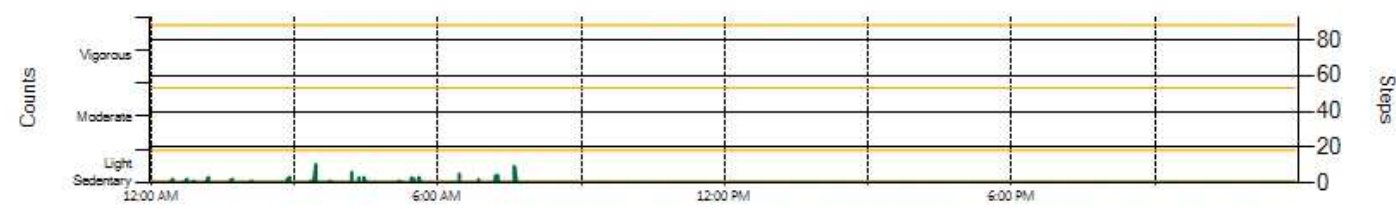




\section{SLEEP}

\section{Hours of Sleep}

Sleep is important for maintaining psychological and physical health. The National Sleep Foundation recommends adults (ages 18-64) get 7-9 hours of sleep per night. Below, we've shown your total hours of sleep each evening during the study. These estimates of sleep time were taken from the data on your actigraphy watch.

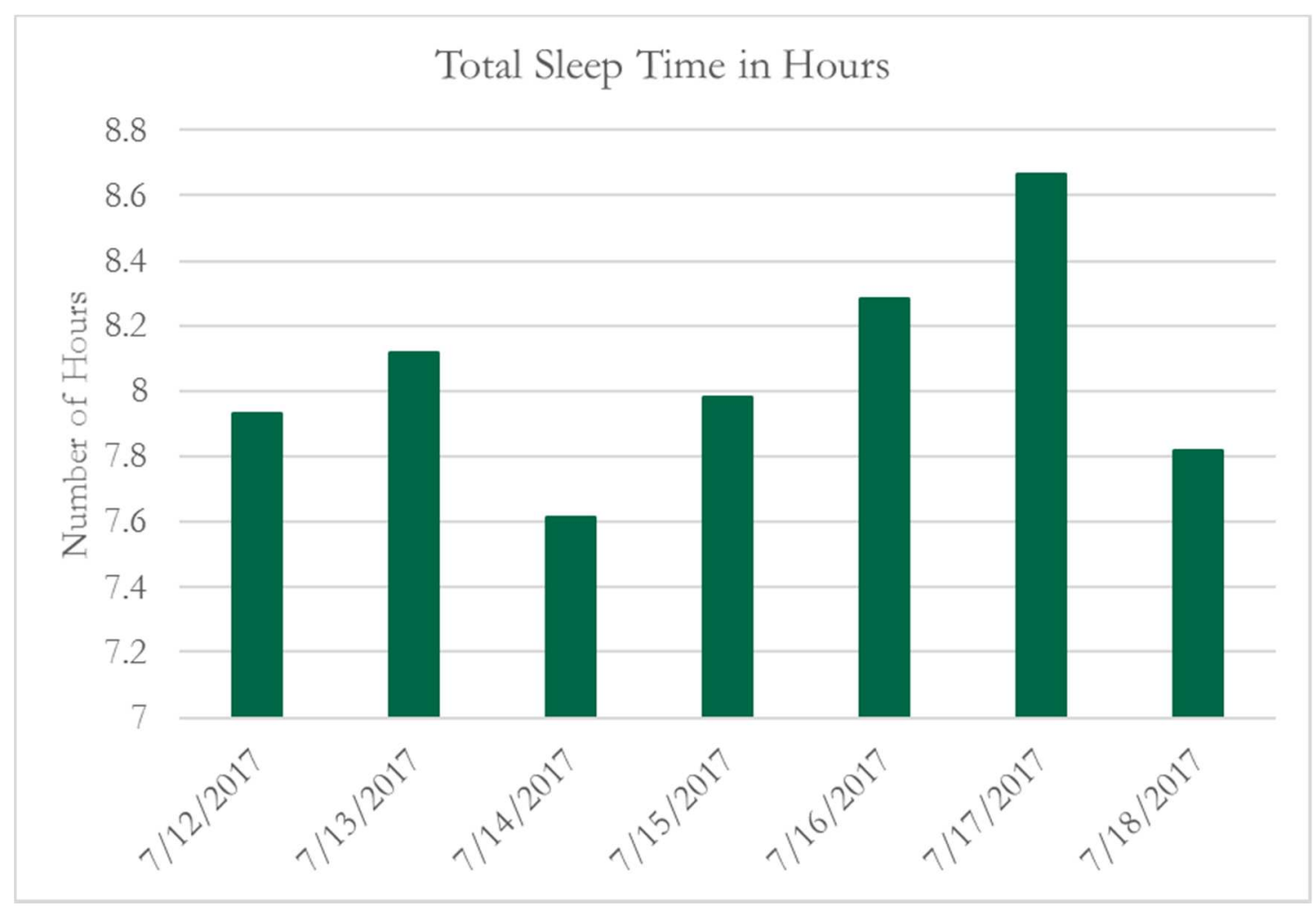

\section{Sleep Quality}

In addition to enough sleep hours, good quality sleep is important for a healthy lifestyle. Below, we've shown two measures of sleep quality taken from the data on your actigraphy watch. Sleep efficiency is the percentage of time you spent asleep during your bedtime hours. The more efficiency you have, the better your quality of sleep. We've also shown how much time you spent awake after initially falling asleep for the evening. Less time waking after sleep onset is an indicator of better quality sleep. 

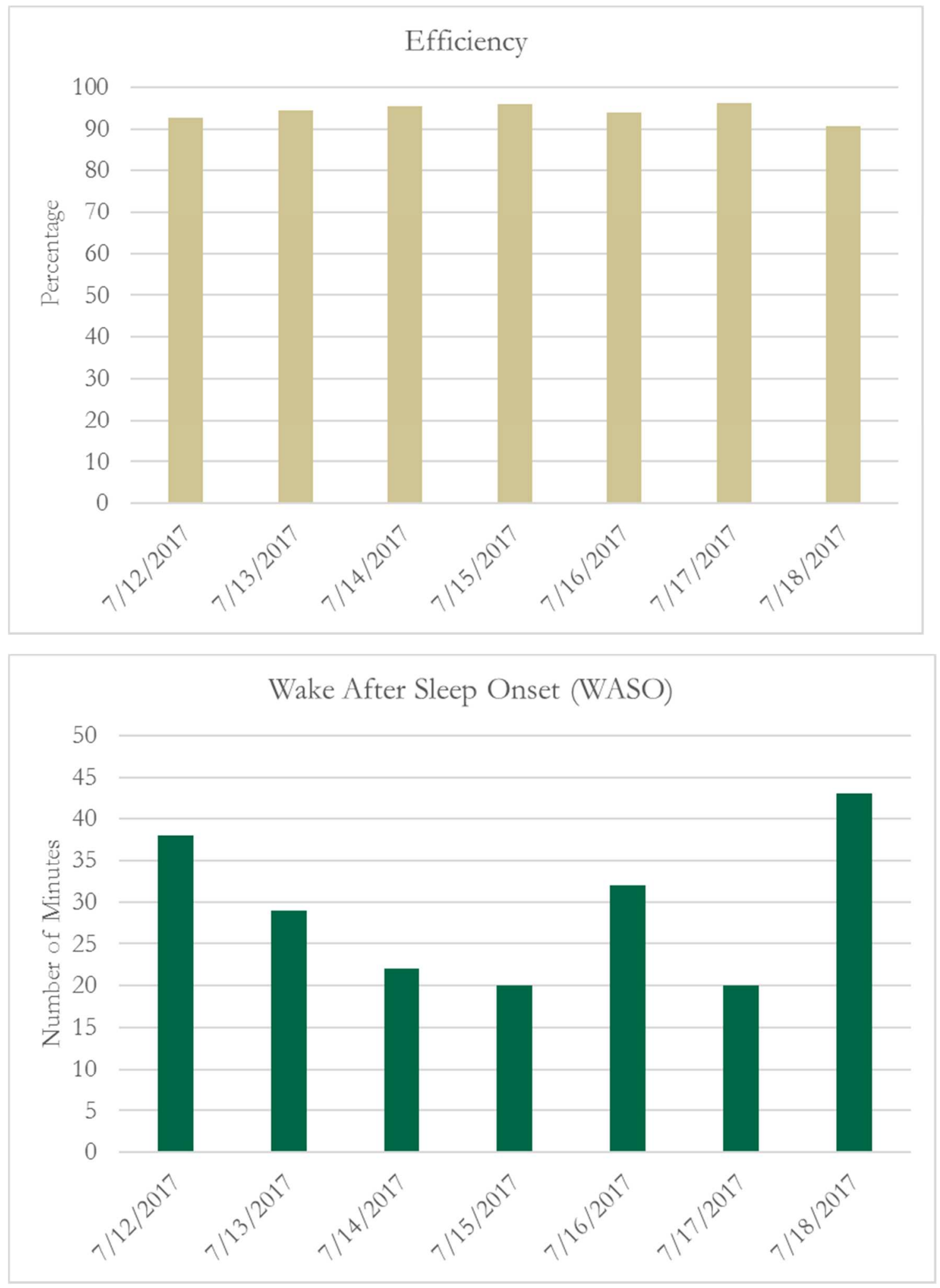


\section{RESOURCES}

American Heart Association Health Recommendations https://healthyforgood.heart.org/

Centers for Disease Control Health Recommendations https://www.cdc.gov/healthyliving/

National Sleep Foundation Sleep Recommendations https://sleepfoundation.org/how-sleep-

works/how-much-sleep-do-we-really-need

\section{U.S. Department of Agriculture Dietary Recommendations}

https://www.cnpp.usda.gov/dietary-guidelines

World Health Organization Health Recommendations http://www.euro.who.int/en/healthtopics/disease-prevention/nutrition/a-healthy-lifestyle 


\section{Appendix G: Baseline Measures.}

\section{A. ID Questions}

1. What are the first two letters of your middle name?

(Open response)

2. What are the first two letters of your mother's maiden name?

(Open response)

3. What is your birthday month and year? Please use four digits (e.g., 0429 for April $29^{\text {th }}$ ).

(Open response)

\section{B. Demographics}

Gender: What is your gender?

(Male/Female/Prefer not to answer)

Age: What is your age in years?

(Open response)

Ethnicity/Race: What is your ethnicity?

(Whitel American Indian or Alaska Native/ Hispanic or Latino/Black or African

American / Asian/ Native Hawaiian or Other Pacific Islander/Other (Please list))

Education Level: What is the highest level of education you have completed? (Some Pre-High School/ Some High School/High School/ Post-Secondary, Trade, or Vocational School/ Some College/ Bachelor's Degree/ Master's Degree/ Doctoral or Other Professional Degree)

Job Title: Being as specific as possible, what is your job title?

(Open response)

Industry: and in what industry do you work?

(Accommodation and food services/Administrative and support services/Agricultural, forestry, fishing, hunting/Arts, entertainment, and recreation/Construction/Educational services/Finance and insurance/ Government/ Healthcare and social assistance/ Information/Managing companies and enterprises/Mining, quarrying, and oil and gas extraction/Other services (except public administration)/ Professional, scientific, and technical services/ Retail trade/ Self-employed/Transportation and warehousing/ Warehousing/ Wholesale trades)

Job Tenure: How long have you been in your current job in years?

(Open response)

Work Hours: On average, how many hours do you work for pay each week?

(Open response)

Household Income: What is your yearly household income? (Open response)

Work Schedule: Please indicate the hours you are scheduled to work for pay over a full week, starting on this coming Monday.

(Open response for each day, participants indicate start/end times of the scheduled work day)

Marital Status: What is your marital status? 
(Single/Married/Committed Relationship/ Domestic Partnership/Separated/ Divorced/ Widow/Widower)

Parental Status: How many children do you have?

(Open response)

Child Ages: Please indicate how old each child is, from youngest to oldest.

(Open response)

Dependent Status: How many children under the age of 18 live with you?

(Open response)

Family Schedule: Please indicate the hours you are scheduled for family obligations over a full week, starting on this coming Monday.

(Open response for each day, participants indicate start/end times for scheduled family activities)

\section{Cardiovascular Screening Items}

1. Has a medical professional ever diagnosed you with a cardiovascular disease, or cardiovascular problems (e.g., arrhythmia, congenital heart defect, blocked arteries, heart attack)?

(No, Yes)

2. Are you currently taking prescription medication that you know to have an affect on your cardiovascular system (such as raising/lowering your blood pressure or heart rate?

(No, Yes)

3. Have you been diagnosed with high blood pressure (i.e., hypertension)?

(No, Yes)

4. Are you pregnant?

(No, Yes) 


\section{Appendix H. Daily Measures for Monday-Wednesday}

\section{A. ID Questions}

\section{Items:}

1. What are the first two letters of your middle name?

(Open response)

2. What are the first two letters of your mother's maiden name?

(Open response)

3. What is your birthday month and year? Please use four digits (e.g., 0429 for April $29^{\text {th }}$ ).

(Open response)

\section{Recodes and Computes: None.}

\section{B. Heart Rate and Blood Pressure}

Instructions: Please enter the readings from the blood pressure/heart rate monitor taken just before you logged onto this survey. If you have not taken your reading, please do so now.

\section{Items:}

1. Please enter your current heart rate. This is the number on the lower left corner of the monitor screen.

(Open response)

2. Please enter your current systolic blood pressure. This is the larger number on the upper right side of the monitor screen.

(Open response)

3. Please enter your current diastolic blood pressure. This is the smaller number on the lower right side of the screen.

(Open response)

\section{Recodes and Computes: None.}

\section{Role Transitions}

\section{Items:}

1. Within the last two hours, have you switched from a work activity to a family activity? (No/Yes)

2. Within the last two hours, have you switched from a work activity to a family activity?

$$
\text { (No/Yes) }
$$

3. Within the last two hours, have you moved from a work location/space to a family location/space?

$$
\text { (No/Yes) }
$$

4. Within the last two hours, have you moved from a family location/space to a work location/space?

(No/Yes) 
Recodes and Computes: Each item is a single indicator of one of four types of role transitions: work-to-family temporal transition, family-to-work temporal transition, work-to-family spatial transition, family-to-work spatial transition. In addition, a temporal transition occurrence variable will be computed, such that a "yes" on either items 1 or 2 will be computed as a "1," meaning a transition occurred. A "no" on both items will be computed as a "0," meaning no transition occurred. A spatial transition occurrence variable will be computed similarly using responses from items 3 and 4.

\section{State Negative Affect}

Instructions: Please rate the extent to which you currently feel each of the following:

\section{Items:}

1. Distressed

2. Guilty

3. Irritable

4. Nervous

5. Afraid

Scale: $0=$ very slightly or not at all, $1=$ a little, $2=$ moderately, $3=$ quite a bit, $4=$ extremely

Recodes and Computes: Average items 1-5 for an index of state negative affect.

\section{E. Fatigue}

Instructions: Please rate the extent to which you currently feel each of the following:

\section{Items:}

1. Exhausted

2. Fatigued

Scale: $0=$ very slightly or not at all, $1=$ a little, $2=$ moderately, $3=$ quite a bit, $4=$ extremely

Recodes and Computes: Average items 1-4 for an index of fatigue.

\section{F. Unhealthy Eating}

Have you eaten within the last two hours?

$$
\text { (No/Yes) }
$$

If yes...

Instructions: Please indicate which of the following categories of food or beverages you consumed.

If a food/beverage falls into more than one category, please only list it once. 


\section{Items:}

1. Sugary beverage (e.g., non-diet soda, energy drink, juice)

2. Sugary food (e.g., chocolate, syrup, pastries, cake)

3. Fried food (e.g., french fries, fried vegetables, fried chicken)

4. Chips or bagged snacks, (e.g., Doritos, Lays, Combos)

5. Full-fat dairy products (e.g., alfredo sauce, cheese, butter, ice cream)

6. Red meat (e.g., steak, sausage, bacon, hamburger)

Scale: Participants select all types of items that were consumed.

Recodes and Computes: Number of foods are summed over a given period (e.g., two hours, one day, one week) for an index of total unhealthy eating.

\section{G. Episodic Work-Family Conflict}

Instructions: The following are a list of possible conflicts in which work made it difficult to meet the demands of family. Please check each of the following that occurred today. You may select more than one option if you've experienced more than one conflict. Please choose the one option that you feel most accurately describes each conflict you experienced.

\section{Items:}

1. You missed all or part of a family activity (for example, leave early or arrive late) due to your job.

2. You had to delay a family activity due to your job.

3. You had to take care of something for your family while at work.

4. You were mentally preoccupied or distracted by a work issue while you were trying to engage in a family activity.

5. You did job-related work while you were engaged in a family activity.

6. You were interrupted by something work-related while you were engaged in a family activity.

7. You were in a bad mood about your job while you were engaged in a family activity.

8. Your job left you tired or out of energy, which limited your engagement in a family activity.

9. Other (please describe)

(Open Response)

Instructions: The following are a list of possible conflicts in which family made it difficult to meet the demands of work. Please check each of the following that occurred today. You may select more than one option if you've experienced more than one conflict. Please choose the one option that you feel most accurately describes each conflict you experienced.

10. You missed all or part of a work responsibility (for example, leave early or arrive late) due to your family.

11. You had to delay working on a job task due to your family.

12. You had to take care of something for your work while at home.

13. You were mentally preoccupied or distracted by a family issue while you were trying to perform one of your work tasks.

14. You did family-related work while you were performing one of your work tasks. 
15. You were interrupted by something family-related while you were performing a work task. 16. You were in a bad mood about your family while you were performing a work task.

17. Your family left you tired or out of energy, which limited your engagement in a job task.

18. Other (please describe)

(Open Response)

For each endorsed conflict, participants will respond to the following two questions:

1. When did this occur?

(Time options, rounded to the nearest 15 minutes)

Recodes and Computes: EWIF/EFIW occurrence will be dichotomously scored for each time point $(0=$ no conflict, $1=$ at least one conflict occurred. EWIF/EFIW-response lag will be computed by two independent coders by subtracting the time at which the conflict occurred from the survey response time (recorded by Qualtrics). Time lag between conflict and response will be coded in minutes. For example, if a conflict occurred at 1:30, and the participant responded at 1:55, the time would be recorded as "25." Number of EWIF/EFIWs will be computed by summing the checklist.

\section{H. Cardiovascular Controls}

Instructions: While taking your blood pressure/heart rate reading...

Items:

1. Describe your posture.

(On your feet/Sitting/Lying Down)

2. Were you talking during cuff inflation?

(No/Yes)

3. Describe your physical activity within the last 30 minutes.

(Inactive/Some movement/Moderate/ Strenuous)

Instructions: In the last thirty minutes have you...

Items:

4. Consumed caffeine?

(No/Yes)

5. Consumed a meal?

(No/Yes)

Recodes and Computes: All responses recoded to dichotomous indicators, with 0 indicating compliant and 1 indicating non-compliant. For items 2 and 4-5, no is a compliant response (coded as 0 ), and yes is non-compliant (coded as 1). For item 1, sitting is a compliant response (coded as 0 ), and on your feet/lying down are both non-compliant responses (coded as 1). For item 3, inactive is a compliant response (coded as 0 ), and the alternative options all noncompliant responses (coded as 1). All items are used a single covariates; no composites are created. 


\section{Appendix I. Daily Measures for Thursday-Sunday}

\section{A. ID Questions}

\section{Items:}

1. What are the first two letters of your middle name?

(Open response)

2. What are the first two letters of your mother's maiden name?

(Open response)

3. What is your birthday month and year? Please use four digits (e.g., 0429 for April $29^{\text {th }}$ ).

(Open response)

\section{Recodes and Computes: None.}

\section{B. Heart Rate and Blood Pressure}

Instructions: Please enter the readings from the blood pressure/heart rate monitor taken just before you logged onto this survey. If you have not taken your reading, please do so now.

\section{Items:}

1. Please enter your current heart rate. This is the number on the lower left corner of the monitor screen.

(Open response)

2. Please enter your current systolic blood pressure. This is the larger number on the upper right side of the monitor screen.

(Open response)

3. Please enter your current diastolic blood pressure. This is the smaller number on the lower right side of the screen.

(Open response)

\section{Recodes and Computes: None.}

\section{Role Transitions}

Instructions:

Today, have you...

\section{Items:}

1. Switched from a work activity to a family activity?

2. Switched from a work activity to a family activity?

3. Moved from a work location/space to a family location/space?

4. Moved from a family location/space to a work location/space?

Recodes and Computes: Each item is a single indicator of one of four types of role transitions: work-to-family temporal transition, family-to-work temporal transition, work-to-family spatial transition, family-to-work spatial transition. In addition, a temporal transition variable will be 
computed, such that a "yes" on either items 1 or 2 will be computed as a "1," meaning a transition occurred. A "no" on both items will be computed as a "0," meaning no transition occurred. A spatial transition variable will be computed similarly using responses from items 3 and 4 .

\section{State Negative Affect}

Instructions: Please rate the extent to which you currently feel each of the following:

\section{Items:}

1. Distressed

2. Guilty

3. Irritable

4. Nervous

5. Afraid

Scale: 0 = very slightly or not at all, $1=$ a little, $2=$ moderately, $3=$ quite a bit, $4=$ extremely

Recodes and Computes: Average items 1-5 for an index of state negative affect.

\section{E. Fatigue}

Instructions: Please rate the extent to which you currently feel each of the following:

\section{Items:}

1. Exhausted

2. Fatigued

Scale: 0 = very slightly or not at all, $1=$ a little, $2=$ moderately, $3=$ quite a bit, $4=$ extremely

Recodes and Computes: Average items 1-2 for an index of fatigue.

\section{F. Unhealthy Eating}

Please indicate the times when you ate today:

(Before 8 AM, 8 AM-9:59 AM, 10 AM-11:59AM, 12 PM-1:59 PM, 2 PM-3:59 PM, 4 PM- 5:59 PM, 6 PM-7:59 PM, 8 PM-9:59 PM, After 10 PM)

For each selected time window:

Instructions: Please indicate which of the following foods or beverages you consumed before $\mathrm{XX}-\mathrm{XX}$.

*Note. $X X-X X$ will be completed based on the time window selected by the participant.

If a food/beverage falls into more than one category, please only list it once.

\section{Items:}

1. Sugary beverage (e.g., non-diet soda, energy drink, juice) 
2. Sugary food (e.g., chocolate, syrup, pastries, cake)

3. Fried food (e.g., french fries, fried vegetables, fried chicken)

4. Chips or bagged snacks, (e.g., Doritos, Lays, Combos)

5. Full-fat dairy products (e.g., alfredo sauce, cheese, butter, ice cream)

6. Red meat (e.g., steak, sausage, bacon, hamburger)

Scale: Participants select all types of items that were consumed.

Recodes and Computes: Number of foods are summed over a given period (e.g., two hours, one day, one week) for an index of total unhealthy eating.

\section{G. Episodic Work-Family Conflict}

Instructions: The following are a list of possible conflicts in which work made it difficult to meet the demands of family. Please check each of the following that occurred today. You may select more than one option if you've experienced more than one conflict. Please choose the one option that you feel most accurately describes each conflict you experienced.

\section{Items:}

1. You missed all or part of a family activity (for example, leave early or arrive late) due to your job.

2. You had to delay a family activity due to your job.

3. You had to take care of something for your family while at work.

4. You were mentally preoccupied or distracted by a work issue while you were trying to engage in a family activity.

5. You did job-related work while you were engaged in a family activity.

6. You were interrupted by something work-related while you were engaged in a family activity.

7. You were in a bad mood about your job while you were engaged in a family activity.

8. Your job left you tired or out of energy, which limited your engagement in a family activity.

9. Other (please describe)

(Open Response)

Instructions: The following are a list of possible conflicts in which family made it difficult to meet the demands of work. Please check each of the following that occurred today. You may select more than one option if you've experienced more than one conflict. Please choose the one option that you feel most accurately describes each conflict you experienced.

10. You missed all or part of a work responsibility (for example, leave early or arrive late) due to your family.

11. You had to delay working on a job task due to your family.

12. You had to take care of something for your work while at home.

13. You were mentally preoccupied or distracted by a family issue while you were trying to perform one of your work tasks.

14. You did family-related work while you were performing one of your work tasks.

15. You were interrupted by something family-related while you were performing a work task.

16. You were in a bad mood about your family while you were performing a work task. 
17. Your family left you tired or out of energy, which limited your engagement in a job task. 18. Other (please describe)

(Open Response)

For each endorsed conflict, participants will respond to the following two questions: 1. When did this occur?

(Time options, rounded to the nearest 15 minutes)

Recodes and Computes: EWIF/EFIW occurrence will be dichotomously scored for each time point $(0=$ no conflict, $1=$ at least one conflict occurred. EWIF/EFIW-response lag will be computed by two independent coders by subtracting the time at which the conflict occurred from the survey response time (recorded by Qualtrics). Time lag between conflict and response will be coded in minutes. For example, if a conflict occurred at 1:30, and the participant responded at 1:55, the time would be recorded as "25." Number of EWIF/EFIWs will be computed by summing the checklist. For Thursday-Sunday EWIF/EFIW response, time of EWIF/EFIW will be recoded into a categorical variable, indicating during which time window the conflict occurred: before $8 \mathrm{AM}$, 8 AM-9:59 AM, 10 AM-11:59 AM, 12 PM - 1:59 PM, 2 PM - 3:59 PM, 4 PM - 5:59 PM, 6 PM - 7:59 PM, 8 PM - 9:59 PM, 10 PM or later

\section{H. Cardiovascular Controls}

Instructions: While taking your blood pressure/heart rate reading...

\section{Items:}

1. Describe your posture.

(On your feet/ Sitting/ Lying Down)

2. Were you talking during cuff inflation? (No/Yes)

3. Describe your physical activity within the last 30 minutes. (Inactive/Some movement/Moderate/Strenuous)

Instructions: In the last thirty minutes have you...

\section{Items:}

4. Consumed caffeine?

(No/Yes)

5. Consumed a meal?

(No/Yes)

Recodes and Computes: All responses recoded to dichotomous indicators, with 0 indicating compliant and 1 indicating non-compliant. For items 2 and 4-5, no is a compliant response (coded as 0 ), and yes is non-compliant (coded as 1). For item 1, sitting is a compliant response (coded as 0 ), and on your feet/lying down are both non-compliant responses (coded as 1). For item 3 , inactive is a compliant response (coded as 0 ), and the alternative options all noncompliant responses (coded as 1). All items are used a single covariates; no composites are created. 


\section{Appendix J. IRB Approval Letter}

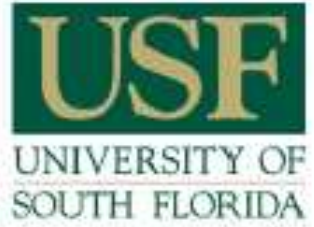

RESEARCH INIEGRITY AND COMPLIANCE

Institutional Review Boards, FWA No. 00001669

12901 Bruce B. Downs Blud,, MDC035 - Tampa, FL 33612-4799

(813) 974.5638 - FAX(813)974.7091

March 21, 2017

KimberlyFrench, MS

Psychology

Tampa, FL 33647

RE: $\quad$ Exped ited App roval for Initial Review

IRB\#: $\quad$ Pro00028866

Title: Work, $\mathrm{F}$ amily, and Health

Study Approval Period: $3 / 21 / 2017$ to $3 / 21 / 2018$

Dear Ms. French:

On 3/21/2017, the Institutional Review Board (IRB) reviewed and APPROVED the above application and all documents contained within, including those outlined below.

App roved Item(s):

Pro tocol Document(s):

Dissertation IRB Protocol V1 3.16.17.docx

Consent/Assent Document(s)*:

Informed Consent W1 3.17.17. docx.pdf

*Please use only the official IRB stamped inform ed consent/assent document's) found under the "Attachments" tab. Please note, these consent/assent docum ents are valid until the consent. document is amended and approved.

It was the determination of the IRB that your study qualified for ex pedited review which includes activities that (1) present no more than m inimal risk to human subjects, and (2) involve only procedures listed in one or more of the categories outlined below. The IRB may review resear ch through the ex pedited review procedure authorized by 45CFR46.110. The research proposed in this study is categorized under the following ex pedited review category. 
(4) Collection of data through norinvasive procedures (not involving general anesthesia or sedation) routinely employed in clinical practice, ex cluding procechures involving $x$-rays or microw aves. Where medical devices are employed they must be cleared/approved for marketing.

(6) Collection of data from voice, video, digital, or image recor dings made for research purposes.

(7) Research on individual or group characteristics or behavior (including but not limited to, resear ch on perception, cogrition, m otivation, identity, language, comm unication, cultural beliefs or practices, and social behaviot) or research employing survey, interview, oral history, focus group, program evaluation, hum an factors evaluation, or quality assurance methodologies.

As the principal investigator of this study, it is your responsibility to conduct this study in accordance with IRB policies and procedures and as approved by the IRB. Any changes to the approved research must be submitted to the IRB for review and approval via an am endment. Additionally, all unanticipated problems must be reported to the USF IRB within five (5) calendar days.

We appreciate your dedication to the ethical conduct of human subject research at the University of South Florida and your contimued comm itm ent to hum an research protections. If you have any questions regarding this m atter, please call 813-974-5638.

Sincerely,

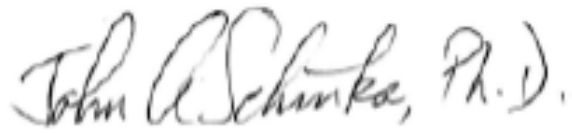

J ohn Schinka, Ph.D., Chairperson

USF Institutional Review Board 